\title{
Pedagogical Realities of Implementing Task-Based Language Teaching
}

\section{Rosemary Erlam \\ Constanza Tolosa}
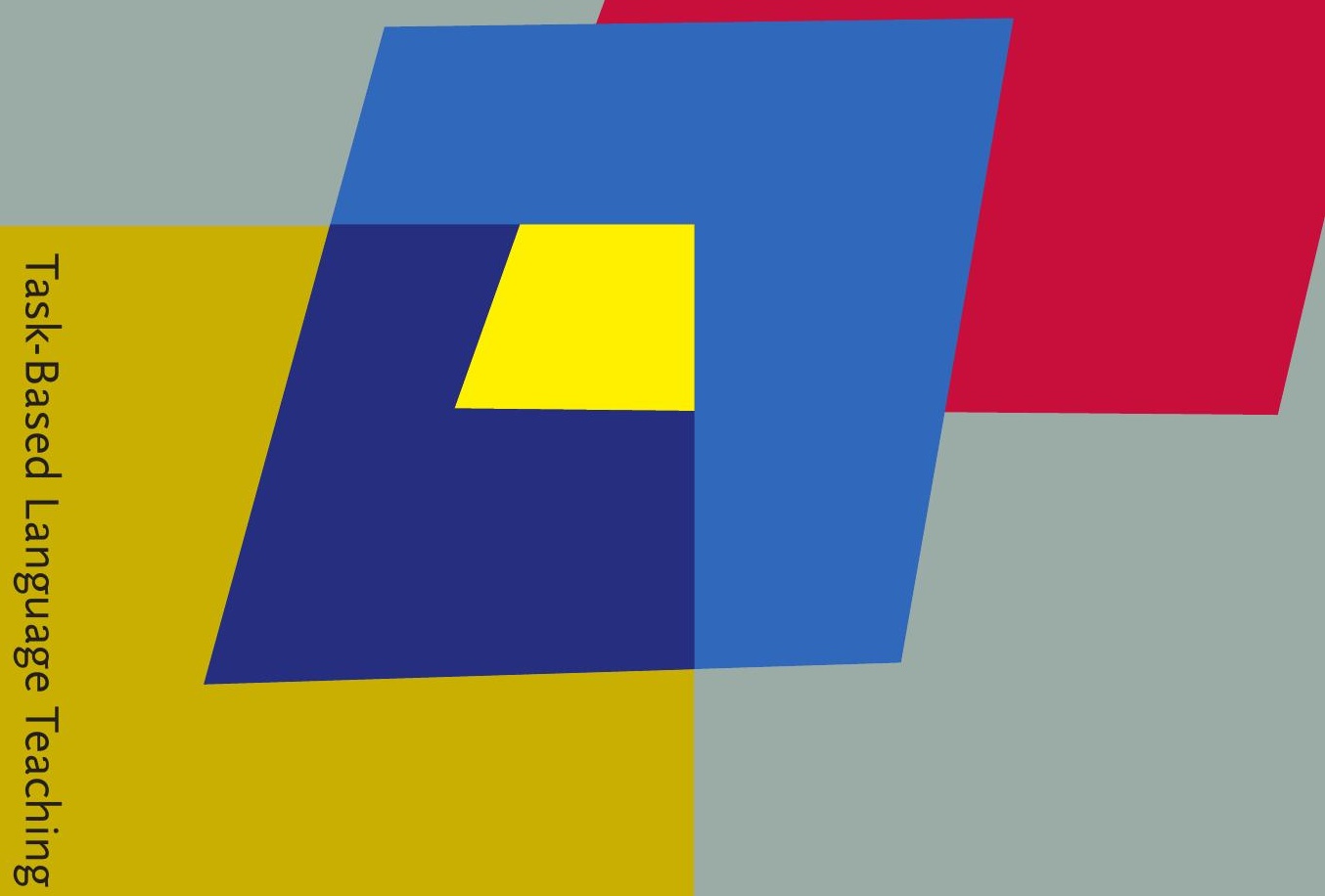

离.

14

John Benjamins Publishing Company 
Pedagogical Realities of Implementing Task-Based

Language Teaching 


\section{Task-Based Language Teaching: Issues, Research and Practice (TBLT)}

ISSN 1877-346x

Task-Based Language Teaching (TBLT) is an educational framework for the theory and practice of teaching second or foreign languages. The TBLT book series is devoted to the dissemination of TBLT issues and practices, and to fostering improved understanding and communication across the various clines of TBLT work.

For an overview of all books published in this series, please see benjamins.com/catalog/tblt

\section{Editors}

Marta González-Lloret

University of Hawai'i at Manoa
John M. Norris

Educational Testing Service
Kris Van den Branden

KU Leuven

\section{Volume 14}

Pedagogical Realities of Implementing Task-Based Language Teaching by Rosemary Erlam and Constanza Tolosa 


\section{Pedagogical Realities of Implementing Task-Based Language Teaching}

Rosemary Erlam

Constanza Tolosa

University of Auckland

John Benjamins Publishing Company

Amsterdam/Philadelphia 
The paper used in this publication meets the minimum requirements of the American National Standard for Information Sciences - Permanence of Paper for Printed Library Materials, ANSI z39.48-1984.

DOI $10.1075 /$ tblt.14

Cataloging-in-Publication Data available from Library of Congress: LCCN 2021049525 (PRINT)

ISBN 9789027210784 (HB)

ISBN 9789027210791 (РB)

ISBN 9789027258168 (Е-BOOK)

(C) 2022 - John Benjamins B.V.

This e-book is Open Access under a CC BY-NC-ND 4.o license. https://creativecommons.org/ licenses/by-nc-nd/4.0

This license permits reuse, distribution and reproduction in any medium for non-commercial purposes, provided that the original author(s) and source are credited. Derivative works may not be distributed without prior permission.

This work may contain content reproduced under license from third parties. Permission to reproduce this third-party content must be obtained from these third parties directly.

Permission for any reuse beyond the scope of this license must be obtained from John Benjamins Publishing Company, rights@benjamins.nl

John Benjamins Publishing Company · https://benjamins.com 
To the TPDL team, in particular to Wendy, Nathalie, Janelle and Sheena. And to the teachers who generously agreed to participate in this research study. 



\section{Table of contents}

CHAPTER 1

Researching the implementation of TBLT in the classroom

Introduction 1

Why TBLT? 4

The theoretical rationale for TBLT 5

The pedagogical rationale for tasks 7

The options for TBLT in the pedagogical context $\mathbf{8}$

Issues to consider in the implementation of TBLT $\mathbf{1 1}$

The New Zealand context $\mathbf{1 3}$

The curriculum 14

The learning languages area in the New Zealand Curriculum $\quad 14$

The assessment of learning 15

Support for language teaching with the implementation

of the new curriculum 16

An initiative to equip teachers to teach languages

in New Zealand schools - TPDL $\quad \mathbf{1 8}$

The current research and its relationship to the TPDL programme $\quad \mathbf{2 6}$

Summary of factors relevant to implementation of TBLT/tasks

in the New Zealand context $\mathbf{2 7}$

Outline of the book 30

Introduction to Part 1

CHAPTER 2

Teachers learning about TBLT and tasks

Introduction 39

Reflection 39

The reading log assignment 40

Teachers' understandings of the rationale and theory behind TBLT 42

Relevance that teachers ascribe to TBLT in their current teaching contexts $\quad 48$

Differences teachers notice between TBLT and their current

pedagogical approach 49

Conclusion 56 


\section{CHAPTER 3}

Teacher learning through inquiry into TBLT

Introduction 59

Inquiry 60

The learning inquiry assignment $\quad \mathbf{6 1}$

Context of teaching $\mathbf{6 3}$

Focus of learning inquiry $\quad 64$

Task design and planning 65

Task evaluation 74

Task revision 77

Teachers' conclusions of their inquiries $\quad 78$

Limitations 78

Conclusion 81

CHAPTER 4

From learning about TBLT to implementing TBLT

Section I: Bringing TBLT to practice $\mathbf{8 6}$

Impact of the TPDL professional learning programme $\mathbf{8 6}$

Changes to practice $\mathbf{8 8}$

TBLT and language teaching $\mathbf{8 9}$

Implementing TBLT 91

Enablers and constraints for implementing TBLT 92

Section II: TBLT in the classroom $\mathbf{9 6}$

Teachers' practices $\mathbf{9 7}$

TBLT as seen in teacher practices $\mathbf{1 1 4}$

Conclusion $\mathbf{1 1 6}$

Introduction to Part 2

CHAPTER 5

Voices from the classroom

Data sets 131

The 10 tasks $\mathbf{1 3 6}$

Conclusion 175

CHAPTER 6

An evaluation of the use of tasks in the classroom

Data sets $\mathbf{1 8 0}$

Evidence of teacher fulfilment of task criteria $\mathbf{1 8 0}$

Target tasks and pedagogic tasks $\quad \mathbf{1 8 3}$

Task goals $\mathbf{1 8 5}$ 
Communicative goals $\quad \mathbf{1 8 7}$

The task cycle $\mathbf{1 8 9}$

Task type 190

Implementation of principles of TBLT 192

Conclusion 198

CHAPTER 7

The teachers' perspectives

Teacher orientation to tasks and TBLT $\quad 204$

Learning about and reaction to TBLT during professional development $\quad \mathbf{2 0 6}$

Prior knowledge of TBLT 206

Teachers' understanding and implementation of TBLT $\quad 208$

The benefits of and role for tasks $\mathbf{2 1 7}$

Factors motivating or constraining implementation of TBLT and use of tasks 219

Embracing TBLT and tasks in the classroom: Accounting for change in teacher practice $\mathbf{2 2 3}$

Conclusion 225

CHAPTER 8

Conclusion

Introduction 229

Learning about tasks $\mathbf{2 3 0}$

Implementing tasks in the classroom 234

Tasks opening up "pedagogical spaces" for language learning 235

The context behind the use of tasks and TBLT $\quad 239$

The beginner language learner 239

Blurring the dichotomies 241

The challenge for TBLT 243

The TB syllabus - realistic or not? 243

Equipping teachers to implement TBLT and use tasks

in their instructional contexts $\mathbf{2 4 6}$

Limitations 251

In summary 252

References

Appendices

Name index 



\section{Researching the implementation of TBLT in the classroom}

\section{Introduction}

Over the past 20 years, Task-based language teaching (TBLT) has attracted much attention (e.g., Cook, 2010; East, 2012; Van den Branden, 2006). There is now an impressive literature dealing with a range of TBLT issues and numerous studies investigating the impact of TBLT, uptake of TBLT, and learner response to TBLT, among others (e.g., Bygate, 2015; Ellis et al., 2020; Samuda et al., 2018; Van den Branden et al., 2009). At the same time, there is a documented imbalance in the TBLT literature. Much of what is written about TBLT is informed by the world of research rather than by the real world of practice (Bygate, 2020; Van den Branden et al., 2009). There is a need for TBLT to deal with the issues and concerns that are relevant to stakeholders (e.g., teacher educators, curriculum designers, teachers, learners) if this disconnect between theory and practice is to be bridged. This book explores how tasks and TBLT are understood, and used as pedagogical tools, in classrooms by New Zealand teachers. We claim that the New Zealand context is one which is typical of other teaching and learning contexts where TBLT may be introduced. As we explore how TBLT has been implemented in our specific context, we focus on two main questions.

We first ask how teachers learn about and understand tasks and TBLT after completing an in-service education programme where they are introduced to second language acquisition (SLA) theory and TBLT. This programme, Teacher Professional Development Languages (TPDL), provides the context for the research informing this book. In Part 1, the main focus is on how a group of teachers, participating in TPDL, learn about, understand, and position tasks and TBLT as relevant and of value to their specific teaching contexts. This section also presents data on whether a small subset of this group of teachers use tasks in their practice the year following participation in TPDL, and, if so, how they use them. Our analysis of data from Part 1 introduces some of the pedagogical realities of implementing an innovation like TBLT in school contexts.

The second main research focus of the book is whether and how teachers implement TBLT and use tasks as pedagogical tools within their teaching contexts. Part 2 
of the study investigates the extent to which another group of teachers is able to implement TBLT after some time (on average 4 years) has elapsed following on from their learning about tasks and TBLT in the TPDL programme. In Part 2, we first look at whether these teachers use tasks and embody TBLT in their practice and, if so, how they create opportunities for learning. Part 2 extends on the investigation conducted in Part 1 by exploring the pedagogical realities that teachers, who use tasks in their practice, face. It also investigates teachers' understanding of tasks and TBLT and the benefits they see for incorporating them into their practice. The fact that this part of the research focuses on a participant group who are at some distance from their professional learning allows for some investigation of the sustainability of tasks and TBLT, and of those factors which facilitate or constrain the implementation of this pedagogical approach.

Samuda et al. (2018) conclude, from their experience in working with, and observing, teachers who use tasks, that the challenges involved in putting TBLT principles into practice in the classroom are greater than the literature tends to acknowledge. They call for bottom-up approaches to research where the pedagogical realities of implementing TBLT are worthy of investigation. This book aims to address this gap. We write from the premise that any innovation is likely to require adaptation and that it is important that TBLT research engages with the real world and with the practices, demands, and perspectives of teachers as they implement and/or adapt TBLT to meet the characteristics and needs of students in their different instructional contexts (Ellis et al., 2020).

\section{An under-researched context}

As mentioned, TBLT literature is heavily weighted by the world of research. However, this research tends to be informed, as Bygate (2020) claims, by the priorities of the academy, rather than by the needs of language teachers and learners. Evidence of this is the fact that many studies have been conducted in laboratory, rather than classroom, contexts. Furthermore, a significant proportion of classroom-based research has involved experimental manipulation. Many of the studies in the recent special issues of Language Teaching Research (2016) and TESOL Quarterly (2017), which are designated especially as contributions to TBLT research, fit within this category. In the current book, there is no attempt on the part of the researchers to manipulate the settings in which data are collected. The aim is to investigate how tasks and TBLT are used naturally, that is, in intact, regular classes (Bygate, 2020).

It is important to acknowledge, nonetheless, that there is a TBLT literature that is informed by the classroom context and that investigates how tasks are used naturally. However, this literature has tended to be representative of a narrow range 
of instructional contexts. It has tended to focus on the teaching and learning of English rather than of other modern languages (Klapper, 2003). It has mostly involved the adult language learner rather than the younger learner (Carless, 2012), and most often represented the tertiary context. It has also tended to focus on the post-beginner, rather than the beginner language learner (Bygate, 2020).

This project aims to present pedagogically informed and relevant research from contexts which we outline below, some of which, we have claimed, are underrepresented in literature to date.

- the foreign language learning context

In the foreign language learning context, learners typically have no, or limited exposure to, or contact with, the target language outside of the classroom. This means, of course, that their language learning is largely limited to, and constrained by, the opportunities that are provided for them in the classroom. This learning context has been described as one that is acquisition-poor (Long, 1983). In the New Zealand foreign language classroom, exposure to the target language is even further restricted by the time allocated in the school timetable to language classes, which is typically more limited than that in other language learning contexts. Classes may be scheduled to allow from between 1 to 4 hours of instruction per week. More information about the New Zealand language learning context will be presented in a later section of this chapter.

While there is an emphasis in TBLT literature on the foreign language learning context (e.g. see Bryfonski \& McKay, 2019), the contexts listed below feature less commonly.

- the teaching and learning of languages other than English In this study the focus is on the teaching of foreign languages other than English and te reo Māori (the indigenous language of New Zealand). The most commonly taught foreign languages in New Zealand schools, and the ones that feature prominently in our study, are: Chinese, French, Japanese, and Spanish. Also taught are German, Samoan, Tongan, Cook Islands Māori and Tokelauan.

- school-aged learners in a range of New Zealand educational contexts The learners in this project were younger language learners than those that tend to be the focus of much TBLT research. They represented both primary (Years 1 to 8 , approximate ages 5 to 12 ) and secondary (Years 9 to 13, approximate ages 13 to 17) levels. The schools that they attended represented a range of educational contexts (e.g., single sex or co-educational, significant proportion of students from other cultural and language backgrounds) and a varied socioeconomic demographic. Most schools were state-funded, though a minority were private or of special character (i.e., implementing a programme reflecting a specific faith or educational philosophy). 
- the beginner language learner

Another important characteristic of this study, which differentiates it from much of the existing TBLT literature, is that the learners were mostly beginner learners with limited proficiency in the language they were learning. This was because most of them had been learning the language for between only 1 and 3 years in, as described above, an acquisition-poor context where the number of language lessons they received on a weekly basis was limited.

The teachers who taught in these contexts were from widely different backgrounds. Some had extensive experience teaching languages, others had very little, or, at the time of their participation in the TPDL programme, none. The level of proficiency that they had in the language that they were teaching also varied significantly. Some were L1 speakers, that is, spoke the language as their first language; others were beginner language learners. Lastly, teachers varied considerably in the knowledge that they had about TBLT prior to their enrolment in the TPDL programme. Some had never heard of it, others had attended TBLT workshops or, even, in one case, a TBLT conference.

While the pedagogical contexts that we describe above are less typical of much of the published TBLT research, they are not, we claim, uncommon. For many language learners, their first experience of language learning is at school, in a context where the target language is not the standard medium of communication and where the main, or only, exposure to it is within the classroom. In this book we are interested in investigating to what extent these contextual factors might facilitate or constrain teachers in implementing TBLT. We hope to thus contribute to a greater understanding of TBLT, and of the task as a pedagogical tool, and so to highlight convergences and divergences between theory and practice.

\section{Why TBLT?}

Strong arguments have been made for including tasks and TBLT (e.g., Long, 2015) as central to any language programme. It is not the purview of this book to present a detailed justification for TBLT; however, a summary of key theoretical and pedagogical reasons for TBLT will be presented. 


\section{The theoretical rationale for TBLT}

TBLT accords well with theories of SLA and with what is known about the processes of language learning. Furthermore, the major theoretical traditions which seek to explain second language acquisition, the cognitive-interactionist and sociocultural, are each able to find a rationale to support the implementation of TBLT. Arguments that support TBLT in relation to these theoretical traditions are summarised below.

\section{From a cognitive-interactionist perspective}

Cognitive theories of learning emphasise mental processes and focus less on the social aspects of L2 learning. They propose that language learning relies on general learning skills and are concerned with how second language (L2) knowledge is stored and processed in the brain. Information processing is a cognitive theory that argues that learning takes place as learners are exposed to language input. Learners need the chance to receive lots of input that contains positive evidence, that is, examples of what is possible in a language. Tasks, which require learners to process language for meaning, can be designed to help with this process and so to promote language learning (Robinson, 2001). The noticing hypothesis (Schmidt, 1995) proposes that learners must attend to language forms (i.e., notice specific linguistic items) in language input that they are exposed to in order for these forms to potentially become intake, that is, processed in some way so that they can eventually be incorporated into the learner's developing language system. Tasks can be designed to enhance the possibility that learners will notice target language forms. Furthermore, learners' attention can be directed to a particular language form at any stage during the cycle of a task (Ellis, 2003). What is important is that this attention to language form occurs in a context where the primary focus is on meaning. The output hypothesis (Swain, 2005) argues that opportunities for learners to produce language output support the acquisition of language. In working at output tasks, learners may have opportunities to notice gaps between what they want to say and can say, to reflect on their output (Robinson, 2011), and to receive feedback about their performance, which may include the correction of errors and/or information about what is not possible in the target language (i.e., negative evidence). These opportunities can promote awareness of, and reflection on, grammar. They can help learners notice aspects of language form and so promote learning.

The interaction hypothesis (Long, 1983, 1996), which also views the processes involved in language acquisition from a cognitive perspective, marries together some of these theoretical positions, specifying a role for both input and output in language learning. This theoretical perspective is, according to Pica et al. (1993), the one that 
best supports the use of communication tasks. As learners, or a learner interacting with a more proficient speaker, work to understand each other, they negotiate meaning to increase comprehension, they receive feedback about their use or understanding of the language, and they modify output, or their use of language, in response to this feedback. All these processes drive L2 acquisition. In other words, the input and information that the learner receives interacts with the learners' internal cognitive processes, such as noticing and hypothesis testing, to promote language acquisition (Keck \& Kim, 2014). A common feature of all these cognitive perspectives on language learning is that learning is incidental rather than intentional. Incidental learning results in implicit language knowledge, the type of knowledge that learners have of their first language so that they are able to use the language fluently and spontaneously without having to think consciously about how they use it (Ellis et al., 2009).

Since Long's interaction hypothesis there has been considerable research examining the effects of task-based interaction. For example, two meta-analyses (Keck et al., 2006; Mackey \& Goo, 2007), conclude that learners who take part in task-based interaction make greater language learning gains than learners who receive a different type of instruction.

\section{From a sociocultural perspective}

In this theoretical viewpoint, second language learning is seen as taking place in, and through, participation in social interaction (Newman \& Holzman, 1997; Vygotsky, 1978), rather than as a result of social interaction. According to sociocultural theory, learning is facilitated as learners build meaning together and scaffold or support one another to use language for their own purposes. It is important, for learning and language development, that students receive assistance in their Zone of Proximal Development (ZPD). The ZPD refers to the difference between what a learner can do on his or her own and what they can do with assistance. Gradually a learner will be able to use independently language forms that they have previously needed assistance with. When this happens, learning is said to have taken place. The co-construction and scaffolding that is central to this perspective is very similar to the type of interaction that researchers holding to a cognitive-interactive perspective also find facilitative of acquisition. In both theoretical traditions, learning is facilitated as a learner interacts with a more proficient speaker and receives support. In sociocultural theory, tasks can assist language learning because they can create conditions for learners to receive scaffolded help and engage in collaborative dialogue. These opportunities are not, however, created by the tasks themselves, but rather by the way in which they are performed by participants (Ellis, 2003). Sociocultural theory, drawing on activity theory (Lantolf, 2000), claims that the same task will be approached in different ways by different learners and so may result in very different kinds of activity, or be performed in different ways (Ellis, 2003). 


\section{The pedagogical rationale for tasks}

There are a number of pedagogical reasons why teachers might use tasks in their language classroom.

\section{Authentic and meaningful use of language}

In a foreign language learning context, the language learner may not have many opportunities to use the language to communicate meaningfully, to function as a language user. In a second language learning context, in contrast, the learner will often have the opportunity to use the language outside of the classroom (both to process language input and to produce output). TBLT, with its emphasis on what learners are able to do with the language (Norris, 2009), gives learners the opportunity to communicate meaningfully and to use language in authentic and meaningful ways that are similar to how it is used in the real world (Ellis, 2009). For example, Ellis and Shintani (2014) argue that, in many classrooms, there are few opportunities for pushed or modified output. In pushed output, the learner is challenged to produce language at the "cutting edge" of their linguistic competence, that is, at the limit of their ability and thus requiring effort on their part. In modified output, the learner modifies language production, usually as a result of feedback they have received.

Tasks which provide opportunities for the productive use of language may require learners to push or modify output and also to improvise, paraphrase, repair and reorganise what they say. These skills all reflect natural language use and can promote language acquisition (Brumfit, 1979; Ellis, 1994; Skehan, 1996).

\section{The development of language fluency}

Nation and Macalister (2010) point out that one of the biggest obstacles to fluency development in the classroom is lack of opportunity to use the target language to communicate outside of the classroom. They stress the need for fluency activities that make use of items learners have encountered several days or weeks before, arguing that these should constitute approximately one quarter of the time spent in the classroom. In working at the development of fluency, learners have the opportunity to automatise the language they know and potentially call on and develop implicit language knowledge. This notion of using tasks to prioritise the development of fluency fits well with Brumfit's (1985, p. 12) idea of a "syllabus with holes in it." These holes are times when no new material is presented and students complete fluency directed activities. This model of task use, which, in the way it is described, tends to suggest the periodic use of tasks, aligns with a task-supported approach to language teaching, which will be described more fully later. The idea that learners 
have the opportunity to use language they know, fits well with one of the criteria for a task (see Chapter 2), that is, that learners need to rely on their own language resources (linguistic or nonlinguistic) to complete the task (Ellis \& Shintani, 2014). This allows them to choose for themselves the language they use and, at the same time, to produce language that is not always predictable.

\section{Motivating learners}

Perhaps one of the most convincing reasons for using tasks in the language classroom is that they are motivating for learners (East, 2012; Erlam, 2015a). In Erlam's study (2015a), teachers talked about how learners were motivated to use language in the ways that it is used outside of the classroom. TBLT was seen as being more fun in that it led to more oral language use in the classroom and provided opportunities for learners to interact with their peers, an aspect that the learners who participated in the research project informing this book often reported as contributing significantly to their enjoyment of lessons (see Chapters 4 and 5).

\section{The options for TBLT in the pedagogical context}

The literature claims that there are a number of ways in which TBLT and tasks may be used in the classroom.

\section{Task-based learning and teaching approach}

In the first of these, the Task-based learning and teaching approach, tasks define both the curriculum and the syllabus and determine how learners will be assessed (Long, 1985). The tasks, and the language that is activated by these tasks, are determined according to the needs of the students (Samuda \& Bygate, 2008). A task-based approach to curriculum, syllabus, and assessment design is seen to accord with what is known about how learners acquire a second language. Proponents (e.g., Long, 2015) argue that the adoption of a syllabus which specifies a predetermined sequence of language structures that are to be taught is inappropriate. This is because it cannot be assumed that the same language or syllabus will be appropriate for all learners, nor that learners will be developmentally ready to incorporate this language into their L2 repertoire. Acquisition, as it is used here, refers to the ability to use language spontaneously, similar to how a native speaker might. In other words, it refers to the development of implicit, rather than explicit language knowledge. 
The rejection of a structural syllabus, outlining the language forms to be taught, in favour of the adoption of a task-based syllabus and curriculum has consequences for form-focused instruction. Ellis (2001, p. 1-2) defines form-focused instruction as 'any planned or incidental instructional activity that is intended to induce language learners to pay attention to language form'. In task-based language teaching this focus of attention on language form is incidental, rather than planned. It arises from an instructional context which is not oriented to the teaching of specific forms and where the student is focused on communicating meaning. It is typically referred to as focus on form (Long, 1988). On the other hand, however, in a structural syllabus, attention to language form tends to be planned. Discrete linguistic targets will be selected and taught in an attempt to influence the interlanguage development of learners. Lessons thus usually involve an explicit focus on the pre-selected linguistic target and students are aware of what this linguistic target is. This approach is referred to as focus on forms (Long, 1988).

While, as we have seen above, in a strong version of the Task-based learning and teaching approach, there is an emphasis on a focus on form approach and on attention to language form arising incidentally during task performance, more nuanced versions of this approach also exist. These more nuanced versions do not preclude other options for focusing on language form. For example, there is a place for the use of focused tasks which may be designed to orientate learners to the use of a particular linguistic feature (Ellis, 2003; Long, 1988).

Despite the fact that there is considerable emphasis in much of the TBLT literature on the importance of curricula and syllabi being defined by tasks, there is evidence to suggest that, while the use of tasks is widespread, the implementation of task-based syllabi remains the exception rather than the rule (Liu et al., 2018; Nation \& Macalister, 2010; Shintani, 2016).

\section{Task-referenced teaching and learning approach}

In the second approach, tasks are used to set achievement targets (e.g., can participate in casual conversation) and for assessment. Learners are assessed on "competencies" or "attainment targets" (Samuda \& Bygate, 2008, p. 59). Their progress through the syllabus is evaluated according to these achievement tasks. There is no assumption about the extent to which tasks may be used in teaching; it is quite possible that a range of teaching approaches may be used to prepare students to reach these targets. 


\section{Task-supported language teaching (TSLT) approach}

In a TSLT approach, tasks are incorporated into the learning cycle as key elements. They are seen as tools that may enrich the syllabus. While they can be exploited by teachers in order to promote language learning, the key feature of a TSLT approach is that they are not used to define the curriculum and syllabus. For example, one way a task may be used in a task-supported approach is at the final stage in a Present, Practice, Produce (PPP) sequence. In PPP, learners are, first given explicit information about a target structure, or a particular aspect of language (present stage), then work at controlled practice exercises, and finally, are given opportunities for free production of the target structure. It is at this produce stage of the lesson or unit that learners are often given the opportunity to work at a task (Nation \& Macalister, 2010). In a task-supported approach, there is a greater focus on intentional learning (Ellis et al., 2009). Learners' attention is specifically directed to predetermined language forms, whereas in a TBLT approach, attention to form arises out of the task, and is therefore more likely to be incidental than intentional. Skill acquisition theory supports the concept of intentional learning, arguing that explicit knowledge, that is, conscious knowledge about language (e.g., knowledge of language rules), can help learners learn language that, with practice, they will be able to use in spontaneous communication (DeKeyser, 1998).

Task-supported language teaching has been described as a weak form of TBLT (Ellis, 2003). We argue, as do Samuda and Bygate (2008), that this view is unfortunate and that it obscures the task as a pedagogic construct in its own right. Rather than seeing TSLT as a weak form of TBLT, it is interesting to investigate the many ways that tasks are used to support learning outcomes for students (Samuda \& Bygate, 2008).

There are encouraging examples in the literature of the implementation of TBLT within language programmes (e.g., Gatbonton, 2015; Müller-Hartmann \& Schockervon Ditfurth, 2011; Van den Branden, 2006). However, it is also clear that TBLT is not easy to implement (Ellis \& Shintani, 2014). We will explore, in the next section, some of the issues that might need to be considered in embedding TBLT within a language programme. 


\section{Issues to consider in the implementation of TBLT}

\section{The syllabus}

Many teachers are required to work with a structural syllabus, that is, one that specifies a list of linguistic items that are to be taught in a prescribed order. Hu and McKay (2012) document, for example, that the use of structural syllabi for language teaching is widespread in schools in Asia. A syllabus will, furthermore, often be accompanied by a textbook specifying more precisely what is to be taught. $\mathrm{Hu}$ (2013) describes how teachers in her study in China taught to the textbook in the belief that if they had done this, they had met the requirements of their job. Approaching language teaching with a focus on a series of linguistic items, as prescribed by a syllabus, textbook, or both, is difficult to reconcile with TBLT where the content is specified in terms of tasks determined according to the communicative needs of learners.

One possible solution to this problem, for teachers who are required to teach to a structural syllabus, is to use focused tasks (Ellis, 2003). Focused tasks can be designed to draw learners' attention to specific language forms. However, this approach does not solve the issue that learners do not acquire grammar as a series of predetermined and separate linguistic entities. Another solution, according to Ellis (2019), is to employ a modular syllabus where a linguistic and a task-based syllabus are used in parallel. The two syllabi would be quite separate and there would be no attempt to link them. Such an approach might not be practical in all instructional contexts, however.

\section{The assessment-driven curriculum}

A structural syllabus tends to be associated with an examination system that requires learners to demonstrate knowledge of particular language forms. Such an assessment system does not align well with a TBLT syllabus specified by tasks that are determined in relation to learner needs. Traditional examination systems can present problems, not just for TBLT, but for any approach to language teaching that emphasises communicative competence (e.g., Carless, 2007; Hu, 2002). With respect to TBLT, there is considerable documentation of teacher concern that a task-based approach may not adequately prepare students to pass national exams (Dao, 2016; Hu, 2013; Yim, 2009; Zheng \& Borg, 2014). In a study based in the New Zealand context, the same context which informs the research in this book, East (2014a) reported, from a study of preservice teachers, that some expressed concern about how TBLT might be integrated with high-stakes assessment. This would not seem to be a problem if the achievement and assessment targets are themselves tasks, as is the case in a task-referenced approach to language teaching. 


\section{The beginner language learner}

Critics of TBLT have suggested that it is not an appropriate approach for beginner learners who lack oral proficiency in the language that they are learning (Carless, 2007; Swan, 2005). Teachers have also referred to lack of proficiency on the part of the learner as a constraint to the implementation of TBLT (Erlam, 2015a; Pham \& Nguyen, 2018; Yim, 2009). Key to this problem is a tendency for teachers to see tasks as requiring learners to produce language (Erlam, 2016a). This objection would seem less pertinent if the importance of tasks that are designed to provide the learner with language input, and the role that these can have for the beginner learner could be acknowledged. There are now encouraging examples in the literature of complete beginners successfully learning from input-based tasks (Erlam \& Ellis, 2018; Shintani, 2016).

\section{The foreign-language proficiency of the teacher}

Some teachers may feel that they lack the proficiency in the language they are teaching to be able to implement TBLT, or even use tasks in the classroom in a task-supported approach (Carless, 2004; McDonough \& Chaikitmongkol, 2007; Yim, 2009). The reality for many teachers teaching in a foreign language learning context is that they themselves speak the language they are teaching as a second or foreign language. In a study of three primary school teachers in Hong Kong, Carless (2004) found that teachers questioned whether they had the language proficiency necessary to implement TBLT. Shintani (2016) documented widespread anxiety amongst elementary school teachers in Japan about their perceived level of proficiency in English. However, she concluded that this is not the main problem working against the implementation of TBLT in Asia. She claimed that, if teachers do use tasks in their classrooms, it may help them to improve their language proficiency and suggested that, for those teachers who struggle to have the language they need for a given task, the use of scripts may help.

\section{Lack of resources and time}

Teachers consistently mention lack of resources and lack of time to plan tasks as a constraint to the use of tasks in the language classroom; this has been documented as the most commonly mentioned difficulty in implementing TBLT (Erlam, 2015a; Pham \& Nguyen, 2018; Zheng \& Borg, 2014). In her study of teachers in the New Zealand school system, Erlam (2015a) found that $25 \%$ of her 48 respondents referred to a lack of time to design or make tasks. Time is also mentioned in the literature, in 
relation both to the time needed for teachers to adapt their practice to TBLT (Van Avermaet et al., cited in Van den Branden et al., 2009) and for students to adjust to a new way of being taught (McDonough \& Chaikitmongkol, 2007).

\section{Teachers' understanding of the construct of task}

Another issue is teachers' understanding of TBLT and of the construct of task (e.g., Andon \& Eckerth, 2009; East, 2014a). In her article entitled, “'I'm Still Not Sure What a Task Is': Teachers Designing Language Tasks,” Erlam (2016a) documented difficulty with understanding the concept of task as a factor that might impact on teachers' ability to use tasks in their practice. In this study, a number of teachers had problems understanding the criteria that were used to differentiate a task from an activity or exercise.

\section{Maintaining control and orienting learners to tasks and TBLT}

For some teachers there is a fear that there will be a loss of control with the use of tasks in the language classroom (Carless, 2004; Erlam, 2015a; Jeon \& Hahn, 2006; Linsen, 1994). There have also been concerns reported that students find the open-ended nature of tasks too difficult, even that they might be inclined to panic at the demands that tasks make on them. This would seem to be less of an issue if students could be oriented to TBLT, taught how to use tasks and, of course, supported in their use of them.

\section{The New Zealand context}

Given that this book documents a study conducted with teachers in New Zealand schools, it is important that the reader understand the foreign language learning context which is typical of New Zealand. We provide background information in this next section. We argue that the context we describe is typical of many acquisitionpoor language-learning contexts and that, therefore, the research we present here has relevance to contexts beyond our own.

School in New Zealand is compulsory from ages 6 to 17. The languages of instruction are English and Māori (the indigenous language of the country); although Māori is mostly used as the language of instruction in kura kaupapa Māori, or, Māori immersion schools. Some other schools have bilingual language units where students may receive instruction in one of the community languages that form part of New Zealand's linguistic landscape, for example, Samoan. 
During the last 3 years of their schooling, students' achievement in the different learning areas of the curriculum is assessed against National Standards through the National Certificate of Educational Achievement (NCEA) (see below for further information).

\section{The curriculum}

The current national curriculum was introduced in 2007 (Ministry of Education [MOE], 2007b). At the time it was seen as an innovation, representing a shift from a prescriptive specification of knowledge to a stronger emphasis on competencies and generic skills. Learning is represented as being experiential and learner-centred with teachers acting as facilitators of learning. Learners and teachers are to co-construct knowledge that is individualised, situated, and contextualised. This curriculum is standards-based and promotes the development of competencies in eight learning areas. While the curriculum is provided at a national level, it allows for considerable flexibility in its implementation. Individual schools and teachers can define the educational priorities for their communities and make decisions as to how the curriculum is to be applied.

\section{The learning languages area in the New Zealand Curriculum}

The 2007 national curriculum was innovative in that it established a new learning area, the Learning Languages area. This new curriculum area gave a greater priority to the learning of languages and necessitated the provision of a framework for the development, in schools, of programmes in foreign languages. For the first time there was an expectation that students would be entitled to have the opportunity to learn a language at school between Years 7 and 10 (students aged approximately 11 to 14 years). It is important to point out, however, that the opportunity to learn a language does not mean that it is a requirement for students in these year groups.

The goal of the Foreign Language (FL) curriculum is the development of intercultural communicative competence. The Learning Languages area is comprised of three strands:

1. The core communication strand

2. The supporting language knowledge strand

3. The supporting cultural knowledge strand 
Defining communication as the core strand "puts students' ability to communicate at the centre" (MOE, 2007b, p. 24) with formal knowledge of language and culture as having an important supportive role to play.

The new learning area was accompanied by a review of proficiency statements. As East (2012) describes, these were first aligned to proficiency levels in the Common European Framework of Reference for Languages (CEFR), and then aligned to the New Zealand context. The fact that the levels of proficiency were somewhat arbitrary was acknowledged (Council of Europe, 2001), as was the fact that these statements did not specify topics, language, functions, and structures. The MOE (2017) made these significant changes clear to teachers in a summary entitled, "what's new or different." The two changes most relevant, for the purposes of our study, were, firstly, that there were no longer language-specific guidelines with specific achievement objectives. Since 2010, achievement objectives which are generic across languages are used as the basis of language programmes. Furthermore, there were no longer prescribed lists of topics with associated vocabulary and grammar structures for each language at each curriculum level. Since 2010, vocabulary and structures have not been prescribed in the curriculum (see below, however).

\section{The assessment of learning}

The introduction of the new curriculum necessitated a review of the New Zealand high-stakes assessment system. NCEA is a criterion-based assessment system which aims to cater for both summative (assessment of learning) and formative (assessment for learning) approaches to assessment. It operates at three levels, Years 11, 12, and 13. Students complete both internal assessments, which are teacher constructed and teacher assessed, and external assessments, which are set and marked by external examiners.

NCEA for Languages was designed to align with the communicative emphasis of the Learning Languages area of the new curriculum. For example, one new assessment, an internal assessment, known as the "Interact Standard" requires students to "Interact using spoken [language] to communicate personal information, ideas and opinions in different situations" (www.nzqa.govt.nz). Information about the standard says that "reward is given for contributing to and maintaining the interaction" and "some level of spontaneity will be required. This is not a standard which should reward students writing, then learning, pre-scripted role plays" (www. nzqa.govt.nz/qualifications-standards). Such an assessment aims for interactional authenticity, one way in which Ellis et al. (2020) suggest that task-based assessment 
can be implemented when the purpose is to assess the general communicative abilities of learners in a context where there is no defined target domain. It was seen as having the potential to create positive "wash-back," that is, to have a beneficial effect on teaching practice in New Zealand foreign language classrooms (Erlam, 2015b).

At the same time, however, that it seemed that the curriculum and assessment system was taking the initiative of resisting any prescription of, or constraint around, the language and structures that students should be taught or know, an important decision was taken that weakened this innovation. The decision was made to retain the vocabulary and structure lists which set boundaries for external examiners when writing examination questions. This issue was debated considerably. Teachers argued that it would not be fair for test takers if there were no limits in terms of the language that could be used in assessments (East, 2012). These lists were maintained therefore, although modified, and are published by the New Zealand Qualifications Authority (NZQA). They specify the vocabulary and structures that examiners can draw on for the external assessments at each NCEA level.

\section{Support for language teaching with the implementation of the new curriculum}

Teachers needed to be supported in understanding and in implementing the new 2007 languages curriculum with its strong focus on communication. Although foreign language programmes had had a long tradition in New Zealand secondary schools (Waite, 1992), there was, historically, a strong emphasis in classroom practice on the development of language knowledge. The MOE produced a number of resources to support the new focus on communication and to provide the assistance that teachers might need (see East, 2012, for a detailed account). One of these resources, A Generic Framework for Teaching Languages (MOE, 2007a) synthesised key aspects of language pedagogy. These included:

- the view of learners as language users;

- the promotion of social interactions where learners make meaning in authentic language use contexts;

- the development of language proficiency in increasingly complex communicative situations; and

- the integration of language and culture throughout the language programme.

Central to this framework were a series of research-based principles that were to provide guidance for how languages could be taught effectively in instructed contexts and serve as a basis against which teachers could evaluate their own teaching practice. 
These principles were the synthesis of a literature review that the MOE commissioned from Professor Rod Ellis. In drawing up this list of principles, Ellis describes how he focused on key theoretical claims and seminal studies. The resulting document, Instructed Second Language Acquisition: A Literature Review (Ellis, 2005), presented 10 principles of effective instructed language learning, as listed in Table 1. It is important to point out that these principles were offered "as 'provisional specifications' (in line with Stenhouse's (1975) arguments) that [were] best discussed, interpreted, and then tried out by teachers in their own contexts" (Erlam \& Sakui, 2006, p. 2).

Table 1. Principles of instructed second language acquisition (Ellis, 2005)

\footnotetext{
1. Instruction needs to ensure that learners develop both a rich repertoire of formulaic expressions and a rule-based competence

2. Instruction needs to ensure that learners focus predominantly on meaning

3. Instruction needs to ensure that learners also focus on form

4. Instruction needs to be predominantly directed at developing implicit knowledge of the L2 while not neglecting explicit knowledge

5. Instruction needs to take into account learners' 'built-in syllabus'

6. Successful instructed language learning requires extensive L2 input

7. Successful instructed language learning also requires opportunities for output

8. The opportunity to interact in the L2 is central to developing L2 proficiency

9. Instruction needs to take account of individual differences in learners

10. In assessing learners' L2 proficiency it is important to examine free as well as controlled production
}

Another document, produced by the MOE in support of the Learning Languages area, was informed by a study in which Erlam and Sakui looked for evidence of Ellis's (2005) 10 principles in New Zealand FL classrooms. They first established classroom practices that might constitute evidence of each principle and then collected evidence for the principles in French and Japanese classrooms. The resulting document presented a series of case studies as an evidence base that could inform "teacher professional learning and practice" and that could serve as the "development of exemplars of effective practice" (Erlam \& Sakui, 2006, p. 2).

Erlam (2008) describes in detail how the Principles document (Ellis, 2005) and the Case Studies (Erlam \& Sakui, 2006) were made widely available to the language teaching community with copies being sent to all schools and presentations and workshops held across the country. As Erlam (2008) concludes, key to the success of ensuring that this SLA research reached its intended audience was the fact that, firstly, "technical knowledge [was made] accessible to practitioners" and, secondly, that they were encouraged "to use it as a tool to reflect on their own teaching practice" (p. 265). In that sense, the commissioned project that resulted in the principles 
of instructed SLA (Ellis, 2005) attempted to bridge the gap between research and practice. The efforts made to ensure that teachers engaged in dialogue and reflection about their practice when discussing the outcomes of the project not only validated their teaching experience, but also resulted in research becoming dynamic and available for appropriation (Erlam \& Sakui, 2006).

The changes in language teaching pedagogy outlined earlier that were necessitated by the new curriculum focus on communication, along with the expectation that language programmes now accommodate primary students, posed considerable challenges for schools and language teachers. An immediate concern was the need for a sufficient number of qualified teachers to cope with the requirement that all students from Years 7 to 10 have the opportunity to learn a language. Other challenges were also identified in a critical evaluation of the teaching of foreign languages in New Zealand schools at Years 7 and 8 (Gibbs \& Holt, 2003). This evaluation recommended that the MOE provide "additional support to develop further both the teacher's own IL [international language] proficiency and their understanding of IL-appropriate methodologies" (Gibbs \& Holt, 2003, p. 71). The Ministry responded to this recommendation swiftly by launching, in 2005, a national programme for teachers of languages, the Teacher Professional Development Languages (TPDL) programme. The programme (described in the next section) intended "to develop teacher language proficiency and second language teaching capabilities in order to improve student language learning outcomes" (Insley \& Thomson, 2008, p. 21). A detailed description of this programme is crucial, because it underpins the research context in which the investigation that informs this book took place.

\section{An initiative to equip teachers to teach languages in New Zealand schools - TPDL}

From its inception in 2005, the TPDL programme defined two goals:

- develop teachers' language proficiency in the language they are teaching; and

- equip or upskill them to teach this or another language effectively with an ultimate emphasis on effecting improvement in student learning outcomes.

The year-long programme was made available throughout New Zealand to teachers of international languages (Chinese, French, German, Japanese, and Spanish) and community languages (mainly languages from the neighbouring Pacific islands). Priority was initially given to teachers of students in Years 7 to 10, but the programme increasingly became available to teachers at all curriculum levels. Enrolments were capped at around 80 per year. Participants in the TPDL programme typically worked in schools 
that advocated the inclusion of languages in their curriculum and supported their teachers in developing their pedagogical skills to teach language. Teachers were free to choose to participate, although in some cases may have been encouraged to do so by colleagues or senior staff.

The theoretical basis which underpinned the programme drew extensively from Ellis's 10 principles. These were also used to establish the criteria against which teacher practice would be evaluated during the course of the year over which the programme extended, and the Case Studies (Erlam \& Sakui, 2006) informed the type of information that could be collected as evidence for implementation of the principles in classroom practice.

Teachers participating in TPDL completed three interrelated components of the programme (see Figure 1): language study, SLA pedagogy, and in-school support. The overlapping of the circles was significant in that all three were seen to be essential components of the central aim of the programme, that was, the effective teaching of languages. Each of these programme components will be described in more detail below (see Erlam, 2016b; Insley \& Thomson, 2008; and Appendix 1 for additional information), but first the authors' relationships with this programme will be outlined.

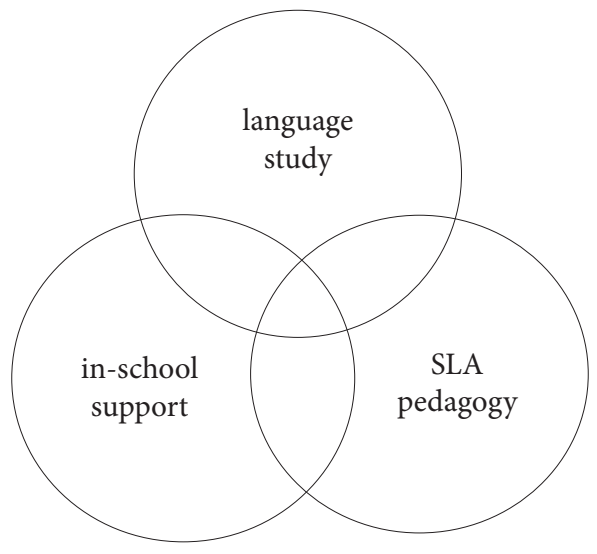

Figure 1. Main components of TPDL programme

Structure and personnel

TPDL was funded by the MOE, but located physically at the University of Auckland. The MOE contracted with the university for the delivery of the SLA pedagogy course. This led to the authors' initial involvement with the programme. At the time of this study, Constanza Tolosa was the coordinator of the SLA pedagogy course and the principal lecturer, responsible also for the marking of all assessments. Rosemary 
Erlam contributed to some of the teaching of this course. The TPDL director, with responsibility for all aspects of the running of the programme, contracted the involvement of Rosemary Erlam, in the role of Academic Advisor. This was mainly a consultative role and involved Rosemary in overseeing the academic quality of the programme and in advising with regard to academic matters.

The TPDL director provided overall oversight of the programme in response to MOE requirements, feedback from teachers, and advice from the Academic Director. The content of the pedagogy course was shaped by decisions made at this level. The TPDL director worked with a team comprising an administrator and a group of facilitators who were proficient in the languages that the programme catered for. These facilitators carried out, over the course of the year, four visits to observe programme participants teaching in their specific contexts. This formed the in-school support component of the programme.

The main components of the programme are described in greater detail below.

\section{Language study}

The language study component of the programme aimed to allow TPDL participants to improve their proficiency in the language they were teaching. Participants were given information about appropriate language courses available in their local areas and enrolment fees were met by the programme. Those who were already proficient in the language they were teaching were encouraged to study another language during the TPDL year. The reason for this was two-fold: teachers would have greater potential to contribute in their contexts of employment if they could offer to teach an additional language, and they would also have the valuable recent experience of being a language learner.

\section{SLA pedagogy}

The SLA pedagogy component of the programme was delivered over a total of 8 days, spread over the year, in four 2-day blocks. Because TPDL was available to teachers throughout New Zealand, the pedagogy component was delivered in at least two (but sometimes three, depending on number of enrolments and geographical location of teachers) cities. Some teachers, that is, those in more rural locations, would travel considerable distances to attend the pedagogy days at the times it was delivered in the centre closest to them. For the sake of consistency, the same content was delivered in each location. 


\section{The introduction days}

The 2 introduction days were run by the TPDL team, however, Rosemary Erlam was asked to contribute some content. The main aims were that teachers would meet each other and understand the purpose and requirements of the TPDL programme. The teachers were also given initial practical and pedagogical tools that they needed to implement the Ellis principles in their language classrooms. There was a particular emphasis on equipping teachers to help learners build up a repertoire of formulaic expressions (Principle 1) so that they would be able to use the target language meaningfully (Principles 2,7). At the same time, the teachers were prepared for understanding the concept of a task and the TBLT approach. Over these 2 days, the teachers experienced a variety of language learning and teaching activities and tasks, and they had the opportunity to discuss how effective practice might be supported by the use of each activity and task.

During these 2 introductory days, teachers were not explicitly taught about tasks, although as will be explained below, they had the opportunity to engage in experiential learning about tasks. The TPDL director had requested that there be an emphasis on the Ellis (2005) principles at this stage of the programme, and that tasks and TBLT be introduced subsequently in the following pedagogy days. This was for two main reasons. The first was that the TPDL team felt that some teachers had become too narrowly focused on whether they were teaching a task, rather than on thinking more widely about their classroom practice in terms of implementing the principles of effective instructed learning. A second reason for delaying an explicit focus on tasks and TBLT was that, in a previous year, there had been criticism (from programme evaluation feedback) that TBLT had been mandated as the only methodological approach that had any merit. It was for this reason also, as will be discussed further below, that teachers were introduced to TSLT rather than to TBLT.

However, while there was no explicit information given about tasks during these 2 days, teachers were prepared for a subsequent focus on tasks and TBLT.

1. They were given the TPDL programme booklet which contained information about tasks and TSLT. It briefly outlined a rationale for TSLT, listed the task criteria (Ellis \& Shintani, 2014) outlined below (Figure 2) and described the stages of a task cycle.

2. Teachers had the opportunity to learn experientially about tasks through completing a number of these. For example, the "Find Out Who" game required them to mix and interact in order to find, in the group, the person who fulfilled a specific criterion that each had been given (e.g., the person who has been to the most unusual place). During a lecture on assessment, they completed three 
input-based tasks (one taken from Erlam \& Ellis, 2018). Later in the programme, when TBLT was introduced, references were made back to the tasks that they had experienced on Day 2 and these were evaluated against task criteria as a way of informing and helping teachers learn about the construct of task.

3. Many of the resources, which the teachers were given during the language workshop component of the introduction days (in particular, to help learners build up a repertoire of formulaic expressions), constituted tasks. For example, teachers were given a song along with a set of pictures which students would be asked to put in correct order as they listened to the song. As the teachers were given these resources, they were reminded that they might need to adapt them to their own specific teaching contexts. Teachers were also reminded that they should look for evidence of student learning as they used these tasks and activities.

\section{The course content of pedagogy Days 3 to 8}

During the remaining 6 days of the SLA pedagogy component, the teachers completed a 36-hour language teaching course delivered exclusively for the TPDL programme. The course aimed to support teachers' understanding of SLA and language teaching theories, broaden their curriculum knowledge and enhance their classroom pedagogy. Ellis's principles underpinned most of the content of this course. TBLT and tasks were presented as ways in which the Ellis principles could be operationalised or implemented into their teaching practice. The construct of task that was used with the teachers was taken from Ellis and Shintani (2014) (See Figure 2). Complementing the Ellis principles was the framework for Intercultural Communicative Language Teaching (Newton et al., 2010), focusing on the development of intercultural competence through language learning.

Figure 2. Task criteria

Task criteria (Ellis \& Shintani, 2014, p. 135)

1. The primary focus should be on "meaning"

2. There should be some kind of "gap"

3. Learners should largely rely on their own resources (linguistic and nonlinguistic)

4. There is a clearly defined outcome other than the use of language.

Pedagogically, the course modelled effective practice by engaging the teachers in active and experiential learning of content. It included systematic reflection on the links between theory and research, and gave participants the opportunity to reflect on, and talk about, their own experiences as language learners and language teachers. In order to support the teachers' application of Ellis's principles, the course used 
concepts, readings, and resources derived from TBLT (e.g., East, 2012; Ellis, 2009; Erlam, 2016a; Nunan, 2004; Willis, 2004).

An outline of the content of Days 3 to 8 of the pedagogy course, as presented to programme participants in the pedagogy course-book, is given in Table 2.

Table 2. Pedagogy Days 3 to 8 course schedule

\begin{tabular}{|c|c|}
\hline Day & Indicative content and readings \\
\hline Day 3 & $\begin{array}{l}\text { Learning Languages and the New Zealand Curriculum } \\
\text { Principles of Instructed Second Language Acquisition } \\
\text { Pedagogy for learning languages } \\
\text { Information about the Reading Logs }\end{array}$ \\
\hline Day 4 & $\begin{array}{l}\text { Focus on meaning in the language classroom } \\
\text { Focus on form in the language classroom } \\
\text { Introduction to Task-supported language teaching } \\
\text { Information about the test (Day 5) }\end{array}$ \\
\hline Day 5 & $\begin{array}{l}\text { Test } \\
\text { Intercultural communicative language teaching } \\
\text { Teaching diverse learners } \\
\text { Task-supported language teaching }\end{array}$ \\
\hline Day 6 & $\begin{array}{l}\text { Planning with tasks } \\
\text { Tasks in the language classroom } \\
\text { Preparing for the Learning Inquiry assessment }\end{array}$ \\
\hline Day 7 & $\begin{array}{l}\text { Revisiting the Principles of Instructed Language Acquisition (and a new principle) } \\
\text { Assessing language tasks }\end{array}$ \\
\hline Day 8 & Learning Inquiry presentations \\
\hline
\end{tabular}

More specific information about the ways in which teachers were introduced to and learnt about tasks and TBLT over these 6 days is given below.

\section{Days 3 and 4}

The initial focus was on introducing the teachers to the requirements and expectations of the New Zealand curriculum for languages. The content, therefore included a focus on Ellis's principles and a description of the pedagogical features expected in the teaching of languages in New Zealand. This was followed by an introduction to the distinction between focus on form and focus on meaning, used as a way of making explicit differences in approaching language teaching. In our experience teaching the course, we knew that most teachers had been taught languages following a grammarbased approach. Therefore, we considered it important that the teachers were aware of how the focus on the development of communicative competence (emphasised in the New Zealand Curriculum) required a different approach to language teaching. This comparison served as a preamble to the introduction of TSLT that closed these 2 days. 
As explained before, the TPDL programme introduced tasks as a way in which Ellis's principles could be operationalised. The session on TSLT started by clarifying that the New Zealand Curriculum promoted TBLT as one of a range of "activity-based approaches" (MOE, 2012). Teachers were then introduced to a comparison of different definitions of tasks, an analysis of Ellis's and Shintani's definition of task, and a comparison of two types of lesson structures: a PPP structure and a TBLT cycle (following Willis, 1996). Teachers were invited to share recent lessons they had taught and identify the structure they were following. The day finished with the teachers working in groups to revisit Days 1 and 2 of TPDL, analysing whether the activities they had engaged in were tasks or not, using the task criteria.

During these initial 2 days, the content was delivered using a task-based approach where, for example, teachers would work in groups to organise paragraphs provided to recompose a text, or they would work in language groups to complete an information-gap task focusing on the Ellis's principles. After each of these short tasks, teachers were encouraged to reflect on the pedagogical characteristics of the tasks (for example, the need for interaction or having a clear outcome). This experiential approach of engaging teachers with the content was consistent with the pedagogy underpinning TBLT.

\section{Days 5 and 6}

The initial focus on these 2 days was introducing the Principles of Intercultural Communicative Language Teaching (Newton et al. 2010), the second set of principles underpinning the New Zealand curriculum for languages. This introduction was illustrated by intercultural tasks that the teachers engaged with. The rest of the time was dedicated to revisiting the TSLT session from Day 4, analysing the concept of task and task criteria, planning with tasks, and discussing some of the realities of working with tasks that the teachers were already experiencing. The work completed during these 2 days included an overview of the readings on TBLT that teachers had done for their first reading log and in preparation for these sessions; and an identification and evaluation of tasks that the teachers had already experienced during the programme. As previously, during Days 5 and 6 teachers were engaged in working with tasks. The teachers completed a number of language tasks for beginners in their language groups. After each task, the group analysed and discussed how it corresponded to task criteria.

On Day 6, time was spent in groups to plan lessons using tasks and to prepare the teachers for the Learning Inquiry assignment. This preparation included a description of the requirements of the assignment, a review of the concept of inquiry (following the $\mathrm{MOE}$ description of teaching inquiries), and time for brainstorming possible inquiry topics. 


\section{Day 7}

There were two components to the session "assessing language tasks," hinging on two ways in which the word assessment could be used. In the first of these, teachers assessed a series of tasks to establish to what extent they fulfilled task criteria (Ellis \& Shintani, 2014). In this part of the session the focus was therefore on task design and the tasks that the teachers worked with were taken from the Erlam (2016a) paper "'I'm Still Not Sure What a Task Is": Teachers Designing Language Tasks." The content of this session component drew heavily on this article. In the second part, the focus was a return to the principles of valid assessment, and on how learners may be assessed following the completion of tasks and on how tasks may be used to assess learning.

\section{Day 8}

Each TPDL participant presented his/her Learning Inquiry to the whole group. This involved a description of the task that they designed and taught, and an evaluation of its effectiveness. In describing and evaluating their tasks, many of the teachers used the Ellis and Shintani (2014) criteria.

\section{Course assessment}

The teachers completed three assignments in which they were expected to explicitly demonstrate connections between research and theory and their own practices. The second and third assignments required teachers to engage with TBLT literature and demonstrate understanding of TBLT and tasks.

1. In-class test

Teachers had to explain one of the Ellis (2005) principles, say why it was important for language learning and discuss how it could be applied in their teaching context.

2. Reading $\log (20 \%)$

There were two reading logs. In the first, teachers had to choose one of three readings on TBLT and answer questions related to it (see Chapter 2 for further information). The second reading log required choice of a reading related to Intercultural Communicative Language Teaching.

3. Learning inquiry $(50 \%)$

Teachers were asked to design, teach and evaluate a language task (see Chapter 3 for further information). 


\section{In-school support component}

The in-school support component provided for each TPDL participant to be visited four times over the course of the year by a TPDL facilitator (experienced language teachers trained to provide pedagogical support and collect learning evidence in classrooms). On each occasion the facilitator observed the participating teacher as $\mathrm{s} /$ he taught a lesson with her/his language class. During the observation, the facilitator took detailed notes of the lesson, manually transcribing as much as possible of the teacher and students' discourse. These notes formed the basis of a learning discussion that took place after the lesson, prompting the teacher to reflect on and evaluate their own practice (Dangel et al., 2004; Scarino, 2014). This discussion did not specifically address the use of tasks or implementation of TBLT, however, there was a focus on practice that is consistent with TBLT principles. For example, teachers were asked to think about whether they created opportunities for students to use the target language "as a tool for communication."

So that the data collected from these observations would be as reliable as possible, all TPDL facilitators used a template that identified the areas to be observed (e.g., use of the target language, opportunities for interaction) and guided them in their note-taking. This template was used to document practice over the course of the year and thus provided evidence of any changes in practice.

The authors of this manuscript had no jurisdiction over, or involvement in, this aspect of the programme, although, as Academic Advisor, Rosemary Erlam was, at times, asked for advice. More information about this component of the TPDL programme, including data collected, as part of a research project (Erlam, 2016b) over the course of a year from one teacher participant, is available in Appendix 1.

\section{The current research and its relationship to the TPDL programme}

While the TPDL team collected a lot of data from the TPDL teacher participants during their year of involvement in the programme, not all of this was available to the authors for the purposes of this study. For example, no data from the in-school support component was incorporated in the research informing this manuscript. The research project informing the writing of the current manuscript stood outside the TPDL programme, conducted by the authors only, although with the knowledge and consent of the TPDL team and director. It involved Ethics consent from all participants; a key consideration was to keep demands on participants to a minimum so as to encourage involvement. A summary of data collected in relation to each of the two main parts of the project (explained in greater detail in subsequent chapters) is outlined in Table 3. 
Table 3. Scheduling of data collected in relation to TPDL programme

\begin{tabular}{lll}
\hline $\begin{array}{l}\text { Study/ } \\
\text { book stage }\end{array}$ & Data collected & $\begin{array}{l}\text { Time period of data collection in relation } \\
\text { to teacher participation in TPDL }\end{array}$ \\
\hline Part 1 & $\begin{array}{l}\text { Reading logs } \\
\text { Learning inquiry projects } \\
\text { Interviews }\end{array}$ & $\begin{array}{l}\text { During the year teachers participated in } \\
\text { TPDL } \\
\text { Classroom observations }\end{array}$ \\
& $\begin{array}{l}\text { Year immediately following TPDL } \\
\text { Student questionnaires } \\
\text { Classroom observations } 2\end{array}$ & \\
& $\begin{array}{l}\text { Student questionnaires } \\
\text { Interviews }\end{array}$ & $\begin{array}{l}\text { A longer time period subsequent to } \\
\text { completion of TPDL, on average } 4 \text { years } \\
\text { later }\end{array}$ \\
\hline
\end{tabular}

\section{Summary of factors relevant to implementation of TBLT/tasks in the New Zealand context}

This chapter has endeavoured to present a general overview of aspects of the New Zealand context which are relevant to this study. In this next section we present a summary of factors which are relevant more specifically to the implementation of TBLT in this context and to teachers' uptake and use of tasks in their language classrooms.

Learning a language is not a requirement

Reference has been made in an earlier section of this chapter to the fact that learning a foreign or second language at school in New Zealand is not a requirement. The current curriculum (MOE, 2007b) required students from Years 7 to 10 to have the opportunity to learn a language; however, this stipulation aimed only to provide students with the option of learning a language.

Perhaps not surprisingly, given the fact that language learning is not mandated for all students in the New Zealand educational context, language classes tend to be poorly subscribed. Part of this can be attributed to rhetoric at government level which puts heavy emphasis on the STEM subjects (science, technology, engineering, and maths). The fact that New Zealand has had a strong monolingual tradition, with English as the first and only language of the majority of New Zealanders, is also a contributing factor (although Māori was given legal status as an official language in 1987, only $4 \%$ of the population speaks the language). The consequences, for the classroom language teacher, are the ongoing difficulties of encouraging students to choose to learn a language, but, more importantly, of retaining students 
in language classrooms in the senior years of study (Years 11 to 13). It is against this backdrop, where teachers are seeking to motivate students to continue language study, that the implementation of TBLT and the use of tasks has taken place in the New Zealand context.

\section{The acquisition-poor context}

Earlier in this chapter, the New Zealand FL learning context has been described as one which is acquisition-poor. For those students who do choose to learn a language at school, classes may be scheduled for as little as 1 hour per week (especially for younger learners). In many schools, younger language learners (Years 7 to 9) are offered "taster" language classes throughout a school year. This means that, for the duration of the year, they are given the chance to experience learning a number of different languages, each for a limited number of hours during the period of a set number of weeks or for a semester, subsequent to which they are to select one of these with which to continue the following year. The maximum number of hours offered to language students, in the research project informing this book, was no more than 4 hours a week. The fact that there is usually no exposure to the target language outside of the language classroom, and that many students do not begin consistent language study until Years 9 or 10, has implications for the level of proficiency which students attain in the target language. This has a potential impact on the implementation of TBLT and tasks in the New Zealand classroom.

\section{The curriculum}

The 2007 New Zealand Curriculum was innovative and a departure from earlier curriculum documents in that it created a distinct Learning Languages area. Arguably, however, the greatest shift was from a curriculum that specified the vocabulary, topics, and grammatical structures that were to be taught, along with the stages at which they should be taught, to one that did not attempt to define or prescribe any of these. Such a curriculum could be seen to align well with the implementation of TBLT. It is important to point out, however, that the curriculum did not mandate that teachers adopt a TBLT approach to language teaching. Rather, as East (2012) points out, at best, it implicitly endorsed such an approach. 


\section{NCEA - the assessment system}

While NCEA attempted to align assessment with the new curriculum emphasis on communication and adopt a policy of not constraining the language to which students would be exposed in the language classroom, this was difficult to implement in practice. Teachers were reluctant to see that this would constitute fair and transparent assessment practice for their students. Therefore, NZQA continued to publish lists of vocabulary and structures which would constrain the use of language in assessments for students at Years 11 to 13.

\section{The post-method phase in language teaching}

The teachers whose journey and practice we describe in this book were mainly introduced to TBLT and to the construct of task in the TPDL programme which is outlined above. It is important to point out that, in this programme, there was an emphasis on principles of effective instructed language learning (Ellis, 2005) rather than on the notion of a best method for language teaching. This has been referred to as a post-method perspective (Kumaravadivelu, 2001). Consistent with the approach described in Erlam (2008) and in Erlam and Sakui (2006), TBLT was not described to teachers as the method that they must (or needed to) adopt in their classroom practice. This was particularly the case during the pedagogical component of the course, but it was also characteristic of the way that the facilitators worked with the teacher participants. Rather, TBLT and tasks were presented as ways in which the SLA principles could be embodied in classroom practice. The principles themselves were presented to participants as provisional specifications (Ellis, 2003; Stenhouse, 1975). At all times, the expertise and experience of these teachers was acknowledged, and they were credited as being the ones who could best decide what was appropriate for their instructional contexts. They were encouraged to try out new ideas and to evaluate for themselves the evidence for effective student learning. This approach was not unique to our context; it was consistent with that adopted by Van den Branden (2006), for example, where teachers were encouraged to gradually take ownership of tasks and to be active in implementing change in their contexts. At the same time, detaching the task from the idea of a best method of language teaching, allowed for a greater focus, in the programme, on the task as a pedagogic tool and on the different ways that tasks can be used in language teaching (Samuda \& Bygate, 2008). 


\section{Outline of the book}

In this book, we investigate how teachers learn about tasks and TBLT and how they understand this new approach to language teaching. We document whether they implement tasks and TBLT in their classroom practice, in both the short and longer term, and in what way. We focus on a group of teachers who all completed the TPDL programme, where they were introduced to (some for the first time) and taught about TBLT and tasks. As we explain in the Introduction, our approach is bottom-up. In this way we seek to engage with the "practices, demands, pressures and perspectives of stakeholders in real world classrooms" (Bygate, 2020, p. 275). We investigate the pedagogical realities that teachers face as they implement tasks and TBLT and, from this bottom-up approach, draw conclusions, both for teacher professional development and for our current understanding and framing of tasks and TBLT.

The book is divided into two parts, each one in relation to a different participant group. The first part, written mainly by Constanza Tolosa, presents data that will be used to investigate how a group of 14 teachers go through the process of learning about and implementing tasks. Data collected from coursework documents the learning of these teachers while, as a group, they complete the year-long TPDL in-service programme. During this year, they attempt to make sense of the concepts crucial to tasks and TBLT and gradually internalise these. They are given opportunities to design tasks and implement them in their instructional contexts. The study follows up on these teachers in the year subsequent to the programme, investigating to what extent they indicate that they use tasks in their classroom contexts and how they use them.

The second part of the book, written mainly by Rosemary Erlam, focuses on a group of teachers who are removed, in terms of time, from their initial opportunity to learn about and first use tasks and TBLT. It presents data from eight teachers who had all previously completed TPDL some years (on average four) prior to taking part in this research project. The aim of this section is to investigate firstly, whether these teachers were, of their own volition, implementing tasks and TBLT in their ongoing programmes, and for those teachers who were using tasks, to explore how they were using them, and with what potential benefit for language learning. It also presents data documenting students' response to lessons where they worked at tasks. It explores the understanding that the eight teachers had of tasks and TBLT, the priority that they afforded them in their teaching contexts, and those factors that enabled or constrained their implementation of TBLT. In this second part of the book, the emphasis is very much on the task as a pedagogic tool and on the different ways in which tasks may be used to create opportunities for language learning (Samuda \& Bygate, 2008). 
In examining how TBLT is both understood and implemented, we are able, in our conclusion, to make practical implications for teacher development courses which introduce teachers to this methodology. At the same time, we demonstrate that analysis of our data may suggest how some of the theoretical framing of tasks and TBLT could be reconsidered. These two main aims underpin this manuscript, and are themes throughout; however, it is in the conclusion, Chapter 8, that they are addressed more completely. 



\title{
Introduction to Part 1
}

\author{
Learning about TBLT and tasks
}

\section{Introduction}

The study reported in this book explored how tasks and TBLT were understood and used in intact school classrooms by two groups of teachers who had participated in a year-long, in-service education programme, known as TPDL and described in Chapter 1. Part 1 of the book focuses on teachers learning about tasks and TBLT during the programme and immediately following it, while Part 2 focuses on how teachers implemented TBLT in their classrooms some time after completing the programme.

Part 1 addresses the first of two broad research questions: (1) how teachers learn about and understand tasks and TBLT during the in-service programme, and (2) how those understandings are evident in their practice in the year following the completion of the programme. A focus on teacher learning is fundamental to the growth of TBLT as a researched pedagogy (Samuda et al., 2018). In fact, Van den Branden (2016) concludes that "the role of the teacher in TBLT is crucial. Teachers bring TBLT to life" (p. 179). The better we understand how teachers learn about tasks and incorporate them into their language teaching, the better we, as teacher educators, will be able to support them in this process and contribute to "a clearer operational framework for task-based language teaching in real world classrooms which is both research- and theory-informed and emerging from actual practice" (East, 2018, p. 47). As teacher educators and TBLT researchers, we join fellow academics who have investigated different dimensions of TBLT practice. These include an interest in teachers' cognitions about TBLT in different contexts (East, 2012; Van den Branden, 2009); evidence of the challenges teachers have encountered when implementing TBLT (Andon \& Eckerth, 2009; Carless, 2007; Erlam, 2016a; Zheng $\&$ Borg, 2014); and an examination of TBLT and teacher education programmes (Brandl, 2017; East, 2014a, 2014b; Van den Branden, 2006). Extending this work, we investigated FL teachers learning about, and implementing TBLT in schools, thus moving from task-in-theory to task-in-action (East, 2018).

The overall aim of this phase of the study (Part 1 of the book) was to investigate how teachers learned about tasks during a professional development programme 
and then took this learning to their classrooms. Chapters 2 and 3 document how teachers engaged with the content of the language teaching course, the pedagogical component of the TPDL programme described in Chapter 1. In Chapter 4 we follow the teachers into their classrooms in the year following TPDL and examine how they are implementing the innovation of working with tasks in their practice. We now provide a brief overview of the theoretical framing that guided the analysis presented in these three chapters and then describe the participants and the methodology we used.

\section{Language teacher learning}

Language teacher education has the dual goal of developing teachers' understandings of language learning and teaching as well as developing self-awareness about how their practices can engender students' language learning (Scarino, 2014). Like all learners, teachers interpret new content based on their existing understandings, prior learning, and experiences (Feiman-Nemser, 2008). The extensive literature on teacher cognitions has noted a range of diverse, and often conflicting, influences that result in teachers' unique ways of integrating new learning and translating it into their practices (see Borg (2006) for a comprehensive review).

Instrumental to these interpretive processes is (1) positioning teachers as knowers and thinkers who can translate new ideas into their own systems of practice (Cochran-Smith \& Lytle, 1999); (2) a recognition of teachers as reflective professionals who can enact a thoughtful interplay of theory and practice (Schön, 1983); and (3) the importance of integrating disciplinary inquiry into instruction (Shulman, 1986). Drawing on sociocultural perspectives, Johnson and Golombeck (2018) additionally argue that teacher education should be grounded in the activity of language teaching and learning as it is situated in the teachers' own contexts. Situating teachers' learning in their immediate contexts should result in privileging practices that impact positively on student learning (Kubanyiova \& Feryok, 2015). All these features of teacher learning are included in a recent report synthesising the characteristics of effective teacher professional learning (Darling-Hammond et al., 2017). The report found that, in effective professional learning programmes, (1) learning is active, contentfocused and reflective; (2) programmes are supportive of collaboration; (3) they are sustained over a period of time; (4) they model effective practice; and (5) they constantly provide feedback and expert support to the teachers involved.

In practical terms, building new professional knowledge requires that teachers recognise what is the same and what is different in what is presented to them. This process may require assistance to avoid misinterpretations and potentially superficial or ineffective changes to practice (Hammerness et al., 2005). Kubanyiova 
(2012) posits that, when teachers embark on such processes of conceptual change, the integration of the new learning into their existing cognitions is dynamic - often resulting in cyclical reassessment of their understandings at different stages in their practice. In TBLT research, Van den Branden (2009) found that teachers gradually developed skill in their use of tasks. When working with practising teachers, learning often requires not merely adopting a new idea that will result in new practices, but also abandoning previous ideas. Kennedy (1999) warns of the possibility of teachers embracing new learning theoretically, yet continuing to enact their previous understandings without noticing the contradiction.

Given what we now know of the possible challenges and limitations of teacher learning, we were interested in investigating teachers' learning and understanding of TBLT, particularly in terms of its theoretical and pedagogical benefits. Such an investigation would help us understand how professional development initiatives might better equip teachers to adopt innovations such as TBLT. In the next paragraph, we will describe the data and the participants of this part of the study.

\section{The data we collected}

Data presented in Part 1 of the book were collected from teachers of languages in schools throughout New Zealand who had participated in a recent cohort of the yearlong TPDL programme presented in the previous chapter. As part of TPDL, teachers completed a university credit-bearing course delivered over the year in four 2-day blocks of 12 hours each, for a total of 48 hours (see Chapter 1 for a detailed description). The course aimed to support teachers' understanding of SLA and language teaching theories, broaden their curriculum knowledge, and enhance their classroom pedagogy. Pedagogically, the course modelled effective practices by engaging the teachers in active and experiential learning of content including systematic reflection on the links between theory and research, and their own experiences as language learners and language teachers. The teachers submitted three types of written assignments as part of the coursework requirements, requiring them to explicitly demonstrate connections between research and theory and their own practices.

Following the university's ethics protocols and, given that the researchers were also the course lecturer (Constanza) and the TPDL Academic Director (Rosemary), we minimised any potential for coercion by communicating with the teachers about the research project via a research assistant. Furthermore, we accessed all data only at the end of the course when final grades had already been released and the TPDL programme had finished for the year.

All teachers enrolled in TPDL were invited to participate. Participation in the initial part of the study (reported in Chapters 2 and 3) consisted of giving permission 
for the researchers to analyse completed course assignments to ascertain the extent to which the teachers were engaging with new learning and exploring how they would implement it in their classroom. We thus addressed the first overarching research question of the study "how teachers learn about and understand tasks and TBLT." In particular, we analysed two course assignments: a reading log completed after the first 4 days of the course, and a learning inquiry (i.e., the final course assignment).

Data presented in Chapter 4 was collected in the year following these teachers' participation in TPDL. We first conducted interviews with the teachers and then observed the practices of a small subset who agreed to participate in this stage of the study.

\section{The participants}

From the 43 teachers enrolled in the course during the year of our study, 14 agreed to participate in the first part (reported in Chapters 2 and 3) and to allow their coursework to be used for research purposes. Table 4 provides demographic information about these 14 teachers. As agreed with the teachers, pseudonyms are used throughout the book.

Table 4. Demographic information of teacher participants

\begin{tabular}{|c|c|c|c|c|c|}
\hline Name & L1 & $\begin{array}{l}\text { Other languages spoken by the } \\
\text { teacher (in descending order of } \\
\text { self-reported proficiency) }\end{array}$ & $\begin{array}{l}\text { Language } \\
\text { used as } \\
\text { the focus } \\
\text { of TPDL }\end{array}$ & $\begin{array}{c}\text { Years of } \\
\text { teaching } \\
\text { experience }\end{array}$ & $\begin{array}{l}\text { Teaching } \\
\text { level }\end{array}$ \\
\hline Amanda & Spanish & English, French & Spanish & 16 & Secondary \\
\hline Ane & Tongan & English & Tongan & 30 & Secondary \\
\hline Ashley & English & Spanish, French, Chinese & Chinese & 9 & Secondary \\
\hline Danielle & English & French, German & French & 5 & Secondary \\
\hline David & $\begin{array}{l}\text { Spanish / } \\
\text { French }\end{array}$ & English, German, Sign Language & Spanish & 19 & Secondary \\
\hline Elizabeth & English & Māori, Chinese & Chinese & 5 & Primary \\
\hline Eric & English & Japanese & Japanese & 7 & Secondary \\
\hline Heather & English & Chinese, Spanish, German & Chinese & 4 & Secondary \\
\hline Laura & English & French, Spanish, German, Latin & Spanish & 38 & Secondary \\
\hline Lauren & English & Japanese, French, Chinese & Chinese & 15 & Primary \\
\hline Melissa & English & Chinese, Māori & Chinese & 21 & Primary \\
\hline Michelle & English & French, German, Spanish & French & 7 & Secondary \\
\hline Samuel & Spanish & English, French & Spanish & 4 & Secondary \\
\hline Sara & English & Spanish & Spanish & 7 & Primary \\
\hline
\end{tabular}


As can be seen in Table 4, these teachers had a range of experience and language backgrounds, and they worked in different types of schools. Of the 14 teachers, three were male and 11 were female. Teaching experience averaged 13.3 years and ranged between 4 and 38 years. Four teachers had teaching experience of fewer than 5 years, four had between 5 and 10 years of experience, and six had more than 15 years. Most worked in the secondary school sector, while four were teaching in primary schools. Four of the 14 teachers spoke languages other than English as their first language and 11 spoke, or had studied, two languages or more before entering the programme. The demographic characteristics of this volunteer group of participant teachers seemed to reflect our experience with FL teachers in New Zealand schools where the majority are women who, on average, have 8 years of teaching experience and work predominantly in secondary schools.

\section{Outline of Part 1 of the book}

This section of the book examines how the 14 participant teachers, described in Table 4, learned about tasks and TBLT through an analysis of two assignments submitted for the course as part of the TPDL programme. Chapter 2 presents data from the reading log assignment completed at the beginning of the course. In Chapter 3 we analyse the final assignment that consisted of a report written by the teachers of a learning inquiry into their own language teaching. Chapter 4 presents self-report and observation data about whether and how the teachers were implementing what they had learned in the course about tasks and TBLT in the year following TPDL. From the 14 teachers whose data is presented in Chapters 2 and 3, nine teachers volunteered for follow-up interviews and three agreed to classrooms observations. Chapter 4, then, allowed us to describe the extent to which this small group of teachers reported that they were incorporating, or were, indeed, incorporating what they learned in the course, in their specific teaching contexts. 



\title{
Teachers learning about TBLT and tasks
}

\begin{abstract}
This article allowed me to reflect deeply about the way that I implement language teaching in my classroom and the value of TBLT has been made clear. I can see that traditional approaches of learning vocabulary lists and grammatical rules will not be enough for meaningful language learning. The cognitive processes students use to acquire language and complete tasks will provide greater opportunities to learn. I feel strongly that language should be understood as a tool for communication rather than a set of rules to be memorised. (Excerpt from Melissa's reading log)
\end{abstract}

\section{Introduction}

We start our examination of teachers' learning about TBLT by documenting how the participant teachers (presented in the introduction) engaged with the pedagogical content of the language teaching course they completed as part of the TPDL programme (see Chapter 1). In order to answer the broad research question for Part 1 of the book (i.e., how teachers learn about TBLT), this chapter presents our analysis of an assignment submitted by the teachers towards the beginning of the course. The reading log assignment required teachers to select a reading and answer guiding questions to demonstrate their understanding of key course concepts. The aim was to support the teachers' reflection on matters relevant to second language teaching and learning. Before presenting the analysis of the teachers' reading logs, we provide the theoretical framing used here.

\section{Reflection}

The value of reflection has been widely advocated in the literature on teacher learning (Korthagen, 2017; Loughran, 2010). Reflection has become an integral part of teacher education, helping teachers to understand both the process of teaching and learning how to teach. Reflection is also considered a standard professional disposition (Schön, 1987) that supports an understanding of the theoretical background necessary for teaching, and also of the practical approaches teachers might take to classroom action. Reflection helps both new and practising teachers make sense 
of the complexities of teaching, usually through connecting theory and practice (Loughran, 2010). Through reflection, teachers "make the unconscious conscious and analyse the reasons for their behaviour" (Korthagen, 2011, p. 78). This theoryinformed disposition supports teachers to engage in carefully considered, informed, and effective practices that are necessary to meet their intended outcome - their students' learning. However, since reflection develops over time as a habit of mind (Costa \& Kallick, 2009), it cannot be established by a few isolated exercises. In order for intentional conceptual change to occur, it is necessary for teachers to engage meaningfully with new concepts (Kubanyiova, 2012). Therefore, when presenting teachers with new learning or fresh understandings, teacher educators need to design learning activities, including assessment tasks, through which to promote reflection (East, 2014a). To support teachers in these processes, Farrell (2016) advocates for teachers to be given opportunities to reflect individually and collectively on their experiences as learners and as teachers of a particular curriculum area. In short, teacher education should create the conditions to provide teachers with new understandings, diverse viewpoints, and useful ideas that both acknowledge their experiences and expertise and challenge their own approaches to practice. In turn, it is expected that teachers should view these reflective practices as instrumental to their professional commitment to improved practice.

\section{The reading log assignment}

The reading log assignment was designed to support the teachers' understanding of key course concepts and to demonstrate critical reading and reflection in matters relevant to second language teaching and learning. It aimed to increase the teachers' opportunities to engage meaningfully with relevant readings (Bartolomeo-Maida, 2016) and support the development of their pedagogical content knowledge (Shulman, 1986). In the logs the teachers were expected to engage with and relate theory to their language teaching practice, articulating thinking which might otherwise be implicit. In this way, the logs promoted professional reflection (Loughran, 2010). Reflective writing has been considered useful as a means of articulating connections and organising representations of thought, which Bruner (1973) considered a purposeful heuristic.

The reading log was due at the end of the first semester of the TPDL programme. At that point, the teachers had attended Introductory Days 1 and 2 where tasks were introduced experientially in a way which established their importance for beginner learners of languages. Each teacher also received a copy of the "Principles of Instructed Second Language Acquisition" (Ellis, 2005), which they were encouraged to read as a key document (see East, 2012; Erlam, 2008, for accounts of the 
importance of Ellis's principles in New Zealand). Days 3 and 4 of the course provided an overview of the New Zealand Curriculum Learning Languages learning area, including the theoretical underpinnings of the Ellis principles (2005) and an introduction to TBLT.

After Days 3 and 4, the teachers submitted their first reading log focused on their understanding of TBLT. The instructions to the reading log assignment are presented in Box 1.

Box 1. Description of the reading log assignment

\section{Reading log assignment}

Description: The reading log assignment is designed to help you to demonstrate critical reading and reflection in matters relevant to second language teaching and learning, with special focus on the New Zealand context.

Choose ONE of these three readings on Task-based language teaching:

Ellis, R. (2009). Task-based language teaching: Sorting out the misunderstandings. International Journal of Applied Linguistics, 19(3), 221-246.

Nunan, D. (2004). Task-based language teaching. Cambridge, England: Cambridge University Press. [Chapter 1: What is Task-based language teaching? pp. 1-16]

Willis, J. (2004). Perspectives on task-based instruction. In B. L. Leaver \& J. Willis, Task-based instruction in foreign language education: Practices and programs (pp. 3-44). Washington, DC: Georgetown University Press.

Four generic guiding questions were developed to guide the teachers' professional reflection and to support them in completing the reading log (see Box 2). The first two aimed to check for comprehension of the reading. The third asked them to articulate their reaction to the reading (critical engagement with theory), and the fourth related the content of the reading (theory) to their language teaching practices (situated practice).

Box 2. Guiding questions for the reading logs

Write answers to the following questions in the template provided.

1. According to the author, what is a task-based approach to language teaching?

2. In what ways does the author claim that task-based language teaching is superior to more traditional ways of language learning? What are the benefits of this approach to language teaching for language learning?

3. Write a personal response to the author's claims where you give your reaction to the ideas presented.

4. Suggest ways in which the content of what you have read could be applied in your language classroom. 
For research purposes, each reading log was read at least twice for initial familiarisation with what the teachers had written. This stage of data analysis focused on the nature of the participants' reflective thinking, identifying the content of the log and evidence of their learning through their writing. The aim was to establish:

- the extent of the participant teachers' understanding of the rationales and theory underpinning TBLT;

- the relevance that the teachers ascribed to TBLT in their current teaching contexts;

- the differences teachers noticed between TBLT and their current pedagogical approach.

Table 5 specifies which aspects in the logs we took into consideration in the analysis of each aim.

Table 5. Aims and aspects analysed in the reading logs

\begin{tabular}{ll}
\hline Aim & Aspects considered in the logs \\
\hline $\begin{array}{l}\text { Extent of the participant } \\
\text { teachers' understanding of }\end{array}$ & - description of prior experience with tasks or TBLT \\
the rationale and theory & - understanding of the content of the selected reading \\
underpinning TBLT & - description of a task \\
Relevance that the teachers & - alignment between theoretical underpinnings of TBLT \\
ascribe to TBLT in their current & and features of the New Zealand Curriculum \\
teaching contexts & \\
$\begin{array}{l}\text { Differences teachers notice } \\
\text { between TBLT and their current } \\
\text { pedagogical approach }\end{array}$ & - evidence of reflection on own language learning \\
& - practices \\
& - pedagogical insights that arise as a result of the readings \\
& practice as a result of the ideas from the reading and their \\
& participation (so far) in the course and the programme \\
\hline
\end{tabular}

\section{Teachers' understandings of the rationale and theory behind TBLT}

To address the first research aim posed for this part of the study, we examined the reading logs according to the first four types of evidence listed in Table 5 (used as headings in the following sections). This evidence was mostly found in the teachers' answers to the reading $\log$ Questions 1 and 2 where they were synthesising the reading they had selected and demonstrating their overall comprehension of the reading. 


\section{Teachers' prior experience with tasks or TBLT}

In order to establish the starting point of the teachers' learning about tasks, we looked for comments made by the teachers in their logs that indicated familiarity with TBLT and tasks. While we had not specifically asked for this information, we considered prior learning about, or experience with, tasks an important initial step in establishing the teachers' learning journeys. Of the 13 teachers, six stated that tasks and TBLT were completely new concepts; five described previous knowledge and use of tasks in their practices; one teacher's log implied previous knowledge of tasks but no detail; and one teacher gave no information.

Of the five teachers who knew about TBLT, Heather mentioned that the prior experience of learning about tasks in her preservice programme had been unhelpful for her and had failed to engage her. In her words, her introduction to TBLT during her initial teacher education "seemed inflexible" in that "it felt like there was a golden standard of TBLT... and anything else was less than perfect." For Heather, this meant that she overtly rejected it in her practice. Heather makes mention of the reasonable expectation that an experiential approach to teaching like TBLT requires first-hand experience in those promoting it. Furthermore, her allusion to TBLT being "the golden standard" seems to indicate that she perceived the way TBLT had been introduced as the approach to teaching languages with no room for considering other alternatives. While this teacher established that her introduction to TBLT had been less than ideal, she conceded that she was planning to incorporate it into her practice: "At least once in each unit I will incorporate a bigger project which is a task and have students producing language creatively."

In contrast, both Danielle and Ane described positive experiences in how they already engaged their classes in tasks. Danielle described how she used tasks with her beginner students of French who found them motivating. Ane provided a lengthy account of a task where her heritage students of Tongan organised a trip to visit New Zealand's parliament and the national museum. Samuel positively described his engagement with TBLT in his teaching of Spanish: "Most of my lessons revolve around solving a question or problem [...]. This question or problem has a clear interactive and real-life goal and the way we achieve it is most of the time using task-based lessons." David was more critical of his prior use of tasks stating, "my previous attempts were in fact failures because I did not meet the fundamental criteria for a task." This response indicates that he was already able to self-assess his practice against the criteria for tasks put forward in the course. Samuel's and David's knowledge and understanding of TBLT at the start of the course are perhaps attributable to the focus on TBLT that they had received during their initial teacher education, which seemed to have been positive in shaping their openness to the approach. 
In establishing a baseline of their prior knowledge of, and experiences with, tasks, we concluded that almost half of the group was completely new to tasks, while the other half had already engaged with the concepts and practice of TBLT in their teaching practice with different degrees of success (as self-reported). Raising awareness of prior learning experiences is important in framing teachers' new learning and shaping their willingness to engage in different conceptualisations of language learning and teaching (Borg, 2006; Feiman-Nemser, 2008). In particular, we were keen to examine how the "provisional specifications" provided by theory (Ellis, 2009) might inform these teachers' practices.

\section{Understanding of the content of the selected reading}

As teacher educators, we were interested in analysing the participants' answers to the first two main questions in the log that aimed to assess their comprehension of the reading:

- According to the author of the reading, what is a task-based approach to language teaching?

- In what ways does the author claim that task-based language teaching is superior to more traditional ways of language learning? What are the benefits of this approach to language teaching for language learning?

A robust answer to these questions should accurately synthesise the content of the reading and be written in the teacher's own words. We found that one teacher's answer indicated that she either did not understand the expectation of synthesis or had a superficial understanding of the reading as her answers consisted of sections taken verbatim from the original text without elaboration. Five teachers accurately summarised the reading, identifying key ideas in bullet point lists (which were allowed in the instructions to the reading log assignment). For example, one of the teachers included the following key points drawn from the reading:

- Teaching can be "task-based" or "task-supported."

- A task-based lesson can have three phrases: pre-task, task, post-task.

- In a task, meaning is primary; there is a goal; activity is outcome-evaluated; and there is real-world relationship.

Three teachers provided thorough syntheses of the reading in their own words and the other four teachers' answers were also thorough, with further evidence of their understanding and engagement with the reading included in Questions 3 and 4 of the reading log. The following summary illustrates one of those thorough answers: 
An overriding feature of a task-based approach is that learners should use the target language to communicate during the lessons through performing tasks. A key component of a task is that they have a clearly defined outcome, goal or objective that is understood by the learner. Tasks are focused on meaning as opposed to merely a display of knowledge of linguistic items.

Overall, analysis of the logs indicated that the majority of the 13 teachers demonstrated reasonably thorough comprehension of the readings as judged by the marking criteria set for the assignments. This early engagement with course content and theory (Kubanyiova, 2012) - as evidenced by these answers to the first reading $\log$ - constituted a first step towards building a disciplinary base (Shulman, 1986), where the teachers' emerging knowledge could then be translated into their practices (Borg, 2006).

\section{Use of SLA and TBLT terminology}

A second indicator of the teachers' understanding of key concepts of tasks and TBLT was their use of SLA terminology in their logs. Being able to draw on disciplinary knowledge is key to the teachers' knowledge base (Kubanyiova, 2012). We considered evidence of learning, the fact that teachers accurately and appropriately incorporated, in their logs, terminology derived from their participation in the course and/or their engagement with assigned readings. In other words, we could establish when a teacher was applying knowledge to a new context and not merely inserting terms arbitrarily. At this early stage of the course, it was not surprising that four teachers felt confident to use only one term in their log, even if these were fairly sophisticated (e.g., consciousness-raising; linguistic resources). Of the other nine teachers, three used between three and five terms, four used more than five terms (e.g., input/output; accuracy/fluency); and two teachers used SLA terms extensively and accurately in their logs. The latter demonstrated full understanding of the concepts and included terms throughout their logs to describe their own language learning experiences and their practice. For example, Lauren describes her experience learning Chinese in China:

I was forced to use my limited language to communicate in authentic daily tasks, including shopping, using public transport and asking for information. Specifically, the drive to communicate motivated me to take risks and experiment with language [...]. I also found myself noticing language forms in these interactions that helped me to acquire new learning. Now, in my language learning I recognise the need to participate in tasks to help transform what I know into implicit knowledge. 
Lauren's use of SLA terminology (italicised in the quote above) demonstrates that she was able to incorporate theoretical knowledge to portray her own language learning experiences. Even more remarkable, Lauren was a teacher who had not had any previous experience with tasks before entering the programme.

Although the use of SLA and TBLT terminology ranged considerably, it was an indicator that the teachers were increasing their content knowledge (Shulman, 1986) about language learning and language teaching through their reading logs.

\section{Inclusion of a description of a task}

Our analysis of the teachers' answers to the first part of the reading log involved an examination of any description of tasks that the teachers included in their log. Although at this point, the teachers had only been introduced to TBLT (see description of the contents of the course in Chapter 1), we considered that any mention or description of task was worth analysing as this would denote the teachers' understandings and would be evidence of their growing content knowledge. Of the 13 teachers, four did not mention tasks in their present or future practice and one teacher said he used tasks but did not provide an example. Five teachers did not provide illustrations of tasks, yet they mentioned principles of TBLT, features of tasks or ideas for future use of tasks. For example, Laura described her interest in features of tasks such as solving a problem and use of genuine interactions. Sara provided possible scenarios that might become tasks in her teaching of young students (5and 6-year-olds) with a clear interest in involving her learners in expressing their needs so that she could make decisions about what to teach:

I could ask them what they would like to learn. The provocation could be "If you were a child in Spain, what language would you need to know?" Some options I imagine would be: playground language, birthday parties, shopping, and classroom language.

Two teachers were more explicit about their future use of tasks. Ane, the teacher of Tongan, planned to revise a project that her class had been involved in the previous year to include a number of language-learning tasks. Her school had been invited to be part of a mentoring scheme by the national museum in the country's capital for a second year. Since this entailed a trip for her students, she planned to give her students the responsibility of planning all aspects of the trip and report on each task in the language class. She even planned to use the authenticity of the planning and organisation of the trip as assessment tasks. Eric described in detail a task he was planning for his Japanese class, yet it is evident that he had misunderstandings of some task features, most evident in his use of built-in syllabus and the focus on form to start the lesson: 
I have a new idea for a Year 9 Self-Introduction lesson. This would consist of a pre-task phase of showing spoken and written forms via video/powerpoint of "Guess Who?" characters introducing themselves. The names and people would vary, as would the pronoun for "I" depending on gender. The implied goal of the students would be to use their "built-in-syllabus" to identify which elements of the structure [change], and to infer what this could mean. The task phase would then consist of students playing the board game "Guess Who" with the slight modification that they assume the role of the person shown on their card. They would use their existing linguistic resources to find / elicit key vocabulary that would assist them in this task. The post-task phase would involve a traditional clarification of the structures and vocabulary used in the form of traditional exercises but which contain references to the "Guess Who?" task they were previously engaged in. Learners who are more deeply engaged in the main task however, would still have the option of continuing the activity, and I would continue to keep them in proximity so that I could engage in "focus-on-form" interactions as needed.

Despite a few inaccuracies, Eric's description indicates an emerging sense of the task stages, the use of a game to promote interaction, and a focus on form in the post-task.

\section{Summary}

To sum up, the above section aimed to establish the extent of the participant teachers' initial understanding of the rationales and theories underpinning TBLT. We looked at four aspects that we believed would provide evidence of the teachers' new learning and current understandings. Initially, we were interested in establishing the teachers' prior learning and starting point in learning about TBLT as we were mindful of how teachers' interpretations of new content would be based on their existing understandings (Feiman-Nemser, 2008). As teacher educators, we were also interested in establishing the teachers' comprehension of the selected reading. Mindful that language teacher education is instrumental in facilitating the process by which teachers incorporate technical knowledge of SLA to their own practical knowledge of language teaching (Cochran-Smith \& Lytle, 1999; Ellis, 2010), we also examined how the teachers used SLA terminology in the logs. Finally, we analysed any mention or description of tasks in the logs because we wanted to establish how the teachers' descriptions demonstrated emerging understanding of the concept of task.

Analysis of the answers to Questions 1 and 2 of the logs established that the majority of the teachers were able to identify the key points of the readings which constituted a strong base for understanding the theories behind TBLT. The 13 teachers exhibited a range of comfort in using SLA terminology: from four teachers using only one term to two teachers' use of several terms drawn from the readings and the 
coursework. Only two teachers actually described tasks, with another five teachers mentioning aspects of tasks, possible tasks, or contexts to use tasks. In general, then, the analysis of the extent of the participant teachers' understandings of TBLT (Questions 1 and 2 as presented in Box 2) indicates the teachers' engagement with new learning (Kubanyiova, 2012), the incorporation of this new knowledge into their previous learning, and the connections made between theory and practice (Loughran, 2010). For the moment, this learning is, as expected, at a theoretical level, that is, they were at the task-in-theory stage. The next two dimensions of analysis will examine how this content knowledge continued turning into pedagogical content knowledge.

\section{Relevance that teachers ascribe to TBLT in their current teaching contexts}

In this second section, we are mindful that a crucial motivator for change in practice is the degree of congruence that teachers observe between the innovative proposal (TBLT, in this case) and their teaching contexts (Andon \& Eckerth, 2009). Therefore, we examined the reading logs for evidence of teachers' identification of correspondence between TBLT and features of the New Zealand Curriculum and more widely of practices valued in the New Zealand educational context. As described in Chapter 1, the pedagogy course grounded the introduction of task and TBLT in the expectations and requirements of the New Zealand curriculum for languages. TBLT aligned pedagogically with the national curriculum favouring learner-centred experiential pedagogies.

Four teachers made explicit mention of how TBLT was consistent with different aspects of the New Zealand Curriculum. Two identified alignment between TBLT and the focus on learning by doing and developing, in teachers and students, attitudes of inquiry in their learning processes. For Lauren, "task-based instruction fits neatly alongside inquiry, which is seen as an integral part of education today." Sara agreed: "Task-based language learning sits well with the pedagogy of inquiry and experiential learning [in New Zealand]."

Both Danielle and Laura mentioned alignment with the country's curriculum and assessment. For Laura:

TBLT is best suited to an educational system that uses performance-based testing, rather than assessment of knowledge accumulation. This means it is ideal for the New Zealand context, where the national curriculum calls for a focus on skills, and where the NCEA assessment is standards-based.

and Danielle stated: 
The most exciting aspect of TBLT is the fact that Ellis suggests it is best applied in schools and alongside curricula that value acquisition of skills over knowledge. While he admits that this is rare in a global context, we are fortunate enough in New Zealand that our national qualification focuses on just that - skills-based learning.

Eric seemed to hold an erroneous understanding of how TBLT had influenced the development of the Languages curriculum: "the theoretical underpinnings of Task Based Language Teaching were highly influential when the New Zealand Languages Curriculum was updated post 2007" (see East, 2012, for a discussion of the influence of these ideas in shaping the New Zealand Curriculum).

Although brief, these mentions made by some of the teachers in their reading logs indicated their identification of elements of TBLT that might align conceptually with the expectations and guidelines of the New Zealand Curriculum, a conceptual alignment considered important for teacher learning in professional development initiatives that are embedded and responsive to the particular circumstances of the learning and teaching contexts (Darling-Hammond et al., 2017).

\section{Differences teachers notice between TBLT and their current pedagogical approach}

As established in previous research (e.g., Van den Branden, 2006), in order for teachers to be open to any innovation or change in practice, they first need awareness of their own teaching approach and recognition of what is similar to, and different from, their practices (Hammerness et al., 2005). In the case of language teachers, practice is informed by a range of influences including their language learning experiences, their teacher education, and their teaching experiences (Borg, 2006; Tolosa, 2007). Therefore, in this section we will present the last four types of evidence listed in Table 5 and corresponding to the headings of the next four sections.

\section{Evidence of reflection on own language learning}

Given the pervasive influence of teachers' language learning experiences on their teaching practices (Borg, 2006; Coffey, 2015), we looked for descriptions of previous language learning in teachers' logs. While eight teachers did not mention prior language learning, five explicitly detailed and reflected on their previous experiences, particularly those that they perceived as being different to TBLT. Laura identified her past experience as having "learned languages by the grammar-translation method." Michelle also described learning with an exclusive focus on accuracy: "[As a learner,] I want to know which form is correct, rather than on just trying different 
forms to figure out which works best." Elizabeth's comments referred to her emotions: "Reflecting back on my own language learning from secondary school, I can see how learning a language would have been more enjoyable, motivating and meaningful if my teachers had used a task-based approach to language teaching."

As seen previously, Lauren ably articulated how she learned Chinese as an adult in an immersion experience; she contrasted that experience with learning a different language in school:

Specifically, the drive to communicate [in Chinese] motivated me to take risks and experiment with language, something my personality had made me more reluctant to do when I learned French in a more traditional language classroom at secondary school in the 1980s.

Finally, Sara not only described her learning of Spanish but also explicitly acknowledged its influence on her teaching:

There is some discomfort in acknowledging that I have learnt a language through more traditional methods of a gradual accumulation of parts, following a sequence of a prescribed syllabus. This in turn, has formed the basis for where I began, naïvely, commencing to teach Spanish last year.

These responses indicated that, for these teachers, engagement with the reading had motivated a reflection on the contrast between the way they learned languages and TBLT. The reading log assignment had provided them both with the opportunity to reflect on their own experiences as language learners (Coffey, 2015; Farrell \& Ives, 2015) and to engage with new theories and research which they were able to compare to their previous understandings (Cochran-Smith \& Lytle, 1999). These comparisons may establish a foundation for changes in their practices.

\section{Evidence of reflection on current language teaching practices}

Our analysis of the reading logs also included the teachers' reflections on their current language teaching practices. Of the 13 teachers, only one did not provide any reference to her own teaching of languages. Engaging with the readings provided language for the others to describe their current practices and a catalyst for them to explore how their current teaching differed from the descriptions of TBLT provided in the readings.

For example, Michelle reflected that she "always spend[s] too much energy up at the front, modelling language (especially with the PPP model)." Laura also described her teaching as PPP (Presentation, Practice and Production) and demonstrated clarity on the sharp contrast between her current teaching and TBLT. She 
admitted that she "depended heavily on a textbook," and that this "dictated what I have taught and when." She continued her analysis of her teaching approach and its effect on her students' learning:

This has meant that I have used a structural-oral-situational approach. This has led me to the impression that students have learned the structure, whereas in reality they have later shown that it has not been internalised and retained.

Another teacher who mentioned her preference for a focus on formS was Ashley, who described herself as "a firm believer in teaching grammar and making grammar rules explicit to learners." Sara seemed to regret her tendency to have her young learners "regurgitate the second language," alluding to a focus on memorisation of isolated vocabulary words. The comments from these teachers indicate not only their level of reflection, but also their appropriation of specialised jargon to describe their practices. This could be seen as evidence of their deep engagement with the readings and the course.

In contrast, four teachers realised that their current language teaching practices already demonstrated partial alignment with TBLT. David, for example, described how his teaching had an exclusive focus on meaning where his learners "were only exposed to a vast range of communicative activities" with "no focus on form at all." However, in his opinion, neglecting a focus on form resulted in poor results because "When it came to perform [in] examinations, students did not perform well as they had nothing to relate their learning to." David realised that his understanding of TBLT was incomplete and was critical of how he had interpreted TBLT as purely focused on fluency and neglecting accuracy. Danielle only briefly mentioned that she "already attempted some tasks." Heather and Samuel provided more detail of how their teaching included tasks. For Heather, it was clear that she combined approaches:

I tend to introduce vocabulary and grammar in a traditional way and use practice activities that are a mix of traditional activities and tasks. At least once in each unit I will incorporate a bigger project which is a task and has students producing language creatively.

In conclusion, the majority of teachers described their language teaching as focusing mostly on linguistic form and following a teaching pattern of PPP. Four of the 13 teachers recognised some alignment of their current practices with TBLT. The teachers' descriptions of their language teaching practices constitute a valuable first level of reflection necessary for changing practices (Korthagen, 2011). Our analysis indicated that they were developing an awareness and were starting to compare the new learnings to their current practices (Farrell, 2016), based on what they were learning 
about TBLT in the course and through the first reading log. So far, the evidence of their reflections indicates that the teachers were critically examining their beliefs (Feiman-Nemser, 2008; Korthagen, 2011) and recognising how their practices were (in most cases) different to what the readings offered. In other words, the teachers seemed to be starting to ask questions about their own language teaching practices and beginning to see possibilities for developing and extending their usual practices in ways that might include TBLT.

\section{Pedagogical insights}

The second aim of the analysis of this section of the log was to identify explicit pedagogical insights motivated by the readings. All the teachers revealed insights into language learning and teaching processes, resulting from the selected reading and more widely from the course and programme, and some of them explicitly described realisations and takeaways.

In our analysis, we established three types of pedagogical insight. Firstly, for two of the teachers, the reading motivated a renewed perception of the role of the teacher in TBLT. For Danielle, the language teacher's role expanded from "merely monitoring and perhaps giving feedback" to engaging in modelling and even, depending on the task, to "a teacher-centred focus at some stage, thus enabling a more effective opportunity for language acquisition to take place." Michelle "took away the myriad of roles I can have in the classroom. [...] I do want to move into more of a "skilled communicator" - that can flow from teaching at the front, to facilitating students to communicate together."

A second type of insight had to do with the alignment between TBLT and student-centred pedagogies. Both Ane and Sara explicitly mentioned the importance of planning with the learners' interests in mind. Samuel specifically described this as "giving voice" to his learners, and Melissa as "catering for all learners," including the L1 (Chinese) speakers in her class. For David, engaging with tasks had made him more aware of the importance of sharing lesson goals with his students as he wanted them to look forward to task outcomes. Along the same lines, Lauren considered that having nonlinguistic outcomes as a goal suited her more "competitive" students. She further elaborated: "[tasks] inherently make language learning more interesting and motivating for all learners." Elizabeth summed up the impact of the reading by stating that TBLT "engages students in the learning process by "learning by doing" instead of being passive learners."

A third type of insight indicated the teachers' growing awareness of various aspects of the language learning process. In particular, the reading had supported their identification of the distinction between learning language for communication 
and as an object of study, which we considered a fundamental outcome from the course. For example, Elizabeth realised that language is "a tool for communication and should be taught through communicating." Melissa pondered:

This article allowed me to reflect deeply about the way that I implement language
teaching in my classroom and the value of TBLT has been made clear. I can see that
traditional approaches of learning vocabulary lists and grammatical rules will not
be enough for meaningful language learning. The cognitive processes students use
to acquire language and complete tasks will provide greater opportunities to learn.
I feel strongly that language should be understood as a tool for communication
rather than a set of rules to be memorised.

Both David and Melissa provided illustrations from their language lessons where they could see their learners' SLA processes arising naturally from a more meaningfocused approach to teaching, acknowledging, in particular, the benefit of extensive use of formulaic expressions. David was pleasantly surprised to see that his beginner learners of Spanish had started to notice language patterns from his efforts to provide them with more input. Similarly, Melissa described how in her Chinese lesson to Year 2 students (7+ years of age), "a student witnessed me answer bu ke chi [you are welcome] to a native speaker after they said xie xie [thank you]. Later in the lesson she [the learner] used the phrase independently and appropriately." As the most experienced of the 13 teachers, Laura's account of the insights from the reading summarised how learning about TBLT had resulted in a completely different way of teaching where she:

Must think very carefully about the stages of a task, as the principal aim - that students achieve meaningful communication - will fail if I do not provide adequate input in the pre-task phase. Failure may also result if I do not make the task interesting for the students and at the appropriate developmental level for them.

Alongside these pedagogical insights, some of the teachers admitted to misconceptions about tasks and TBLT that had been clarified by the reading. Laura, for example, had the erroneous belief that TBLT was only for oral language work. Danielle said that "until reading the article, I was of the opinion that a task was mainly an opportunity to put into practice language that has already been acquired." David admitted that, before, he "was a firm believer that TBLT was just another communicative approach with more work for the teacher and providing same results." $\mathrm{He}$ further reflected that the tasks that he was designing did not meet the criteria for a task and concluded "my previous attempts were, in fact, failures." Some of these comments were made by the teachers who had selected Ellis's article (2009) which accounts for typical misunderstandings about TBLT. 
Other realisations reported by the teachers were potentially more problematic in terms of encouraging them to be open to implementing TBLT. For example, Heather, Eric and Michelle expressed "relief" after reading Ellis "not say[ing] that there was only one way to do things" (Heather), and an acknowledgement of "the premise that more traditional approaches still have a role in the classroom" (Eric). Although, on the one hand, TBLT was not presented in the course as an "orthodoxy" (Littlewood, 2014), we were advocating for a change in teachers' practices.

This section synthesised a number of pedagogical reflections prompted by the reading log assignment and described as takeaways by some teachers. At this initial point in the programme, it seemed that the teachers were open to engaging with tasks as a complement to their current teaching practices. This may be evidence of an initial stage of conceptual change (Kubanyiova, 2012) and a connection of theory to practice (Korthagen, 2011). These diverse understandings constitute valuable insights into what the teachers were learning from the readings and how they were contextualising these insights in their own practice. The teachers' own assessment of their understandings (Kubaniyova, 2012) was a fundamental step in their critical examination of the nature of language learning theories (Scarino, 2014).

\section{Planned changes to practices}

One of the indicators of teachers' learning is the role that they see for newly acquired knowledge in their practices. Therefore, we examined the reading logs for mentions of the teachers' plans to incorporate ideas motivated by the TBLT readings in response to the fourth question in the log (i.e., "Suggest ways in which the content of what you have read could be applied to your language classroom").

Some of the teachers referred to specific actions related to language acquisition processes. For example, Laura planned to have a "stronger focus on meaning." She also, along with Ashley and Heather, intended to provide learners with more exposure to target language input. Michelle had a more generic plan to "adhere to the SLA principles." Samuel and Sara wanted to create opportunities for their Spanish learners to interact in the target language. With such different aims and without further explanations of the ways these teachers planned to implement these ideas, we took these comments as signs of a change in orientation towards their teaching of languages and an indication that the new content offered in the course and the readings resonated with the teachers.

Other teachers detailed intentions and plans which revealed different stages in their use of tasks, a common occurrence in teachers' journey towards implementing tasks (Van den Branden, 2009). Two of the teachers mentioned the task design stage. Ashley and Danielle discussed plans to design tasks, Danielle, not only for 
her junior students as she had been doing, but also for her advanced students. Four teachers' accounts implied the inclusion of a wider variety of tasks and each mentioned specific aspects or types of tasks. Hence, Heather and Michelle planned to use more "input-based" tasks, Eric's goal was to start using "focused" tasks, while Laura wanted to include more "genuine" tasks. Two teachers (Laura and Lauren) had managerial concerns about working with tasks, specifically to ensure their planning allowed time for the post-task phase of the task cycles they designed for their learners. Finally, both Ane and Michelle intended to review and critique tasks that they had already trialled in their classes before implementing new tasks.

Analysis of these answers indicates a range of plans that the participating teachers had after engaging with the reading log assignments. This diversity highlights the personal nature of each teacher's learning journey. The engagement with theory and research through the readings allowed the teachers to see possibilities in their practices that may not have been so evident without the demands that the assignment made on them. As with all teacher education, we were hoping to support the teachers in developing theory-informed reflection. These early answers indicate that this process was already in motion.

Overall, our analysis of the answers to this fourth question of the reading logs portrayed a positive reaction to TBLT from these 13 teachers. It also showed enthusiasm towards the changes in their practices as a result of their involvement in the TPDL programme. However, some of the teachers also voiced reservations and limitations in using TBLT. For instance, Ashley expressed her hesitation to change: "I remain to be convinced about how TBLT would be better than my tried and tested PPP approach." Elizabeth expressed her challenge to "ensure curriculum content is covered," a common concern of teachers approaching TBLT. Laura's enthusiasm for allowing her learners to make mistakes was followed by "I do worry, however, that students may internalise incorrect ways of expressing information." Both Eric and Michelle were concerned about the fact that there was no unified definition of a task and that there were multiple approaches to TBLT. In Michelle's words, "I feel overwhelmed by the myriad of different ways in which TBLT can be run." She concluded, trying to weigh on both sides: "I know TBLT is good, but it also feels like a behemoth task to try and ensure that there is a task each lesson that is at the appropriate level of language, where there is an information gap, and that there is a clearly defined outcome." These reflections from the teachers indicated that they recognised the complexities of teaching (Loughran, 2010) and, in particular, the fact that implementing TBLT is not easy (Ellis \& Shintani, 2014).

This last section has included the analysis of explicit mentions that the teachers provided as to how they planned to use features of TBLT in their teaching. One of the purposes of the reading logs was to support teachers making explicit connections 
between the ideas of the readings and situating these within their current practices. The literature on effective teacher learning has insisted on the importance of situating learning (Darling-Hammond et al., 2017) and connecting it to everyday practice (Zheng \& Borg, 2014). It is only through the teachers' articulation of their knowledge of practice (Schön, 1983) that they can more effectively translate ideas presented in the readings to their own systems of practice. Although most of the teachers seemed to be open and willing to start incorporating tasks and TBLT into their practices, it is also evident that some of them expressed some reservations. Interestingly, some of those reservations (e.g., curriculum coverage, lack of a unified definition of tasks) have been documented in academic discussions (Ellis, 2009; Samuda et al., 2018).

\section{Conclusion}

This chapter has started to address the first overarching research question of the study focusing on examining how teachers learn about and understand tasks and TBLT. It has presented evidence of different aspects of the participant teachers' learning by drawing on data from reading logs submitted towards the beginning of an academic course taken as part of a professional learning programme. We were interested in examining how - through this assignment - the teachers started to articulate their emerging understandings about TBLT and reflected on their own learning and their teaching in response to the readings. The logs' predetermined questions required focused thinking in light of theory and research that prompted the teachers' analysis and discussion of their own practices. The process of reflection supported the teachers' in examining their implicit, and perhaps unexamined, understandings about language learning and teaching as a prelude to acquiring new content knowledge that they might use for pedagogical purposes (Borg, 2006; East, 2014a; Loughran, 2010).

The starting places for this group of teachers turned out to be diverse, with six of the 13 being new to TBLT. Despite this heterogeneity, the teachers' responses demonstrated, at this early stage of the course, good to excellent understanding of the key concepts presented in the readings. Furthermore, some indicated a level of ease in using specialised terminology to express their ideas about SLA and aspects of TBLT. We also found that the teachers' responses provided evidence that, through the process of writing about their reading, they seemed to have been able to make explicit their developing understandings, appropriate a language to describe their practices and connect new knowledge to their existing knowledge. At this stage, it would seem that the teachers were still at the task-in-theory stage in their learning about tasks. 
Next, we aimed to establish the relevance that the teachers ascribed to TBLT for their current teaching practice. Literature would indicate that establishing the relevance of any innovation is vital for its adoption (Andon \& Eckerth, 2009) and that any change in cognitions and practices needs to align with other elements of the teaching context (Borg, 2006). The teachers' logs offered some evidence of recognition of pedagogical alignment between TBLT and their teaching contexts, with particular mention of the value of experiential learning and inquiry for both TBLT and the New Zealand educational context. Although identifying pedagogical alignment did not, in itself, guarantee the teachers' uptake of tasks, it seemed to indicate that the teachers would be positively inclined to consider incorporating TBLT in their practice.

Analysis of five teachers' descriptions of their language learning experiences indicates that they were reflecting on the differences between TBLT and the way they had learned languages, a process recognised as strongly influencing any teacher's practice (Borg, 2006). Even more crucial to any professional learning is the recognition of how current practices compare to an innovation. Our examination of the teachers' comments about the differences between their practices and TBLT indicated their openness to discuss their practices and their willingness to consider other practices.

The teachers' pedagogical insights, resulting from their assignment demands, were considered essential to any new professional learning where new understandings influence subsequent practices (Loughran, 2010). Analysis yielded four main insights, namely: new considerations of the roles of both teachers and learners, and renewed appreciation for language learning processes. We concluded that the range of teachers' reflections about their practices and their assessment of their understandings provided evidence of professional learning which went beyond a comprehension of the theoretical content of the selected reading. Finally, we documented teachers' stated intentions to implement TBLT. Although most teachers expressed willingness to incorporate tasks in their language teaching practices, a few expressed reservations towards TBLT.

Teacher education literature stresses the importance of both enriching and challenging teachers' knowledge of language teaching and their own practices. The willingness of teachers to talk about their own understandings in relation to their practice and in relation to new content on TBLT, is evidence that our participants may have been prepared to do this. Analysis of the reading log assignment highlighted processes whereby these teachers incorporated their emerging understandings of theory and research to their existing knowledge. Such understandings can potentially support theory-informed changes to practices (Korthagen, 2011). As reflective practitioners, these teachers developed awareness of their own, often tacit, theories about language 
learning and language teaching while they were interpreting new content presented in the readings. Importantly, especially at this initial stage of the course, analysis indicated that they were reflecting on their own practices in a way that indicated they were willing to extend their professional knowledge and consider the implications raised for their own teaching.

This chapter has presented evidence of teacher learning towards the beginning of the course that was part of the TPDL programme. The following chapter will continue the examination of these teachers' learning through their engagement with inquiries into their teaching practices, the last of their course assignments. 


\section{CHAPTER 3}

\section{Teacher learning through inquiry into TBLT}

I remain challenged to design meaningful tasks based on the four criteria of a task. (Excerpt from Sara's learning inquiry report)

\section{Introduction}

The previous chapter presented evidence of teacher learning by analysing reading logs completed by teachers towards the beginning of the pedagogy component of the TPDL programme. We documented how the teachers articulated their emerging understandings about TBLT and started to reflect on their own learning and teaching practices. This chapter continues our examination of teacher learning about tasks and TBLT by investigating how the same group designed, implemented and evaluated tasks through a process of inquiry into their own teaching. In particular, we will look at the tasks the teachers designed for their specific language classrooms as a requirement for their Learning Inquiry, the last assignment of the course.

As described in Chapter 1, the pedagogy course was an opportunity for practising language teachers to upskill in their understanding of SLA, extend their pedagogical content knowledge, and enhance their classroom pedagogy. Consistent with professional experiential and situated learning, the inquiry assignment expected them to connect theory they had engaged with in the course with their classroom practices. Using the lens of teacher inquiry, this chapter will focus on the "task-asworkplan," an underrepresented area of study (Samuda \& Bygate, 2008). As in the previous chapter, the teachers' reflections on their learning processes will provide evidence of their emerging understanding of tasks as well as their initial appraisal of potential opportunities and limitations resulting from implementation of TBLT in their teaching contexts.

This chapter starts with a brief description of the theoretical underpinnings of professional inquiry. The following section describes the source of the evidence for the chapter: the learning inquiry assignment. We next introduce the inquiries that the 14 participant teachers carried out. These are then analysed according to the stages that the teachers followed: identification of a focus for the inquiry, 
planning, implementing, evaluating and revising. Finally, we present conclusions, those drawn by the teachers themselves, from their inquiries, and our own as to how the teachers' inquiries provide evidence of their development and learning about TBLT and tasks.

\section{Inquiry}

Dewey $(1933)$ and Schön $(1983,1987)$ have been instrumental in advancing our conceptualisation of reflection as a specialised form of thinking revolving around a particular problem of practice, something which may now be placed under the umbrella of "inquiry practices" (for an overview, see Burns, 2019). In particular, Schön's (1983) distinction between reflection in and on action highlighted teachers' reflection both during and after action to improve practice. This distinction was further extended to the concept of reflection for action (Killion \& Todnem, 1991), connecting reflection to future action. In the New Zealand context, East (2014a) has illustrated how reflection in-on-for action have been crucial elements in helping preservice teachers of languages embrace task-based ideas in their practices. When teachers adopt a stance of inquiry, they see themselves, not only as teachers but also as agents of their own learning - rejecting roles as receivers, transmitters, or implementers of other people's knowledge (Cochran-Smith \& Lytle, 1999). Through processes of intentional inquiry, teachers construct knowledge and make decisions that take their contexts into consideration, with the potential for improving practice (Burns, 2019; McNiff, 2016). Teacher inquiry usually involves first gaining understanding of the problem at hand, and eventually taking action to improve student outcomes. Through inquiry teachers learn to frame and reframe problems of practice, examine alternatives, and modify their practice (Loughran, 2002). The inquiry process motivates teachers to be strategic about changes that they consider appropriate and to be metacognitive about their practice (Baumfield et al, 2013).

In the New Zealand educational context, inquiry is a fundamental concept to the extent that Teaching as Inquiry is considered a characteristic of effective pedagogy (MOE, 2007b). Teaching as inquiry is generally described as a pedagogical mindset where students' needs are central and refinements to teaching are part of everyday practice. This process engages teachers in asking how to improve student learning, what teaching strategies can be used to attain learning goals, and in evaluating the effectiveness of these strategies. For inquiry to be effective, teachers need to be "accessing different kinds of knowledge that will push their thinking and challenge their practice" (Timperley, 2011, p. 10). When implemented as part of teaching, inquiry involves teachers reflecting critically on the impact of their 
decisions on student learning. Admittedly, these reflections might not necessarily imply changing practices, a reality for all professional learning.

Different scholars have developed frameworks for teachers' inquiries. In the New Zealand context, the process described in the curriculum resources (MOE, 2020) consists of three main components, usually implemented recursively. First, teachers identify a focus for their inquiry directly related to improvement of their learners' outcomes. The next component is the inquiry itself, where the teachers identify specific changes they need to make in their practices that they consider will improve these outcomes. This process of identification might involve engagement with academic literature either independently or in a formal context of professional learning guided by experts that will help to focus the inquiry. Then, teachers might work individually or collaboratively to select and implement teaching strategies to effect the desired change to their practices. The third component consists of collecting evidence to monitor the success of the inquiry. Typically, this will involve evaluating students' progress towards identified outcomes.

The cyclical process of inquiry entails professional reflection as teachers are constantly examining their own practices with the aim of improving their learners' outcomes. This process supports teachers' knowledge-building. At its core is the notion of teachers as adaptive experts, willing to consider change to their practice to benefit their learners and open to engaging in understanding best practice and to developing action plans to address their needs (Muijs et al., 2014). In the New Zealand context, East (2019) provided examples of how the teaching as inquiry process informed two teachers' inquiries into the implementation of TBLT within their practice. This chapter will provide further evidence from the cohort of teachers who embarked on the TPDL programme.

\section{The learning inquiry assignment}

The data examined in this chapter were collected as part of the coursework the participant teachers submitted towards the end of the year of the TPDL programme. In this inquiry assignment, as described below, the teachers had to design and teach a task. At this stage of the programme (see Chapter 1), the teachers had had 8 days dedicated to language teaching pedagogy where they had explored tasks, evaluated existing tasks, and planned how they might integrate tasks in their teaching.

The aim of the learning inquiry assignment was to give the teachers the experience of teaching a task and evaluating its effectiveness as part of their normal teaching of a foreign language. We anticipated that some teachers might be familiar with inquiring into their teaching, but we did not assume a particular level of 
expertise or experience in working with inquiry. Even for those who had experience with learning inquiry, we considered the assignment would be important in further developing expertise in independently investigating the impact of their teaching on student learning. As a course assignment, we concurred with Freese (2006) that carefully designed assessment tasks support teachers' pedagogical reasoning enabling them to learn from reflection on their practice.

Box 3. Description of the learning inquiry

You will teach a language task, collect evidence of its effectiveness and then evaluate it to determine how effective it was. This evidence will be available to you as part of your normal teaching practice. You should collect two types of evidence to evaluate your task. As a basis of this evaluation you will think about how you might revise your task were you to teach it again.

In order to support the evaluation of the task that they had designed and taught, the teachers were introduced to three approaches to the microevaluation of tasks proposed by Ellis (2011). These approaches were presented to the teachers using Table 6 during Day 6 of the course.

Table 6. Three approaches to microevaluation of tasks (Ellis, 2011)

\begin{tabular}{|c|c|c|}
\hline Approach & Criterion for evaluating the Task & Data collection \\
\hline $\begin{array}{l}\text { Student-based: looking } \\
\text { at student feedback }\end{array}$ & $\begin{array}{l}\text { Motivation: Were students } \\
\text { motivated to perform the task? } \\
\text { Did they enjoy it? }\end{array}$ & $\begin{array}{l}\text { Self-report: rating slips, } \\
\text { questionnaire, interviews, } \\
\text { post-task written feedback }\end{array}$ \\
\hline $\begin{array}{l}\text { Response-based: } \\
\text { looking at how } \\
\text { students responded to } \\
\text { and performed the task }\end{array}$ & $\begin{array}{l}\text { Performance: Did the students } \\
\text { perform the task as intended? } \\
\text { Did they achieve the outcome? }\end{array}$ & $\begin{array}{l}\text { Information about how students } \\
\text { perform the task: completed } \\
\text { tasks, information on student } \\
\text { performance, observation data }\end{array}$ \\
\hline $\begin{array}{l}\text { Learning-based: } \\
\text { investigating what } \\
\text { students learnt }\end{array}$ & $\begin{array}{l}\text { Learning: what evidence is there } \\
\text { of what the students learnt in } \\
\text { terms of language? }\end{array}$ & $\begin{array}{l}\text { Tests, language learning charts, } \\
\text { other evidence of what students } \\
\text { learnt }\end{array}$ \\
\hline
\end{tabular}

When these approaches were introduced, it was explained that they were, ideally, complementary. However, given the teachers' lack of experience in using these, we told them that, for their inquiry assignment, they were to use only two approaches.

In common with the practice we followed for all assignments, we provided the teachers with a template for their written inquiry report as well as a detailed assessment rubric with the marking criteria we would use (see Appendix 2). We also provided the teachers with exemplars of previous inquiry assignments.

The learning inquiry assignment was due at the end of the course and was worth $50 \%$ of the course's grades. The written report comprised four main sections and 
the word limit was specified as 3,000 words. In the introductory section the teachers were to provide information about the context of the inquiry (e.g., language, grade level, number of students) as well as their rationale for the particular focus of the inquiry. In other words, although the inquiry was a course requirement, the teachers were encouraged to see it as a supported and situated professional learning opportunity responsive to their students' particular needs and characteristics. Therefore, they were to set specific aims for the inquiry that they perceived as most useful (details are provided in Tables 7 and 8). In the second section of the report, the teachers were to include relevant academic literature. We wanted them to demonstrate how the inquiry related to SLA and TBLT content as presented in the course. The third section was the core of the report. Here, teachers were asked to describe the task that they had chosen, describe how it was implemented, and then evaluate its effectiveness using two different approaches selected from those in Table 6. In the final section, the teachers were to reflect on how they would revise and improve the task, based on the data collected from their evaluation. They were also asked to include any limitations or factors that could have affected the implementation of the task, and an overall conclusion.

For research purposes, as with the reading log assignments presented in Chapter 2, the learning inquiries were analysed in order to establish the development of teachers' learning about tasks and TBLT as a result of their participation in the TPDL programme, and in the pedagogy course more particularly.

\section{Context of teaching}

We first present information about the inquiries set by the teachers (see Table 7). This contextual information provides background to the investigation into the learning inquiries. Demographic information about these teachers and their classes was provided in the Introduction to Part 1.

The 14 teachers who participated in this part of the study taught across five foreign languages: five taught Spanish and another five taught Chinese; three taught French, and there was one teacher each for Japanese and Tongan. In these classes, students were beginners, ranging from absolute beginners with less than 10 hours of language tuition to those in their second year of FL learning. One exception was the Tongan class, made up of mostly heritage speakers of higher proficiency. Melissa's and Lauren's classes also had some heritage Chinese speakers, but under $10 \%$. The number of students in each classroom ranged from 8 to 31, with most classes having more than 20 students. 
Table 7. Description of the inquiries

\begin{tabular}{|c|c|c|c|c|}
\hline Teacher & $\begin{array}{l}\text { Language } \\
\text { taught }\end{array}$ & Year level & $\begin{array}{l}\text { Number of } \\
\text { students }\end{array}$ & $\begin{array}{l}\text { Focus of the inquiry (i.e., the teachers' } \\
\text { description of the rationale for their inquiry) }\end{array}$ \\
\hline Amanda & Spanish & 9 & 22 & $\begin{array}{l}\text { Impact of increase of the amount of target } \\
\text { language used during lessons }\end{array}$ \\
\hline Ane & Tongan & 10 & 18 & No specific focus indicated \\
\hline Ashley & $\begin{array}{l}\text { French } \\
\text { and } \\
\text { Chinese }\end{array}$ & $\begin{array}{c}9 \text { (two } \\
\text { different } \\
\text { classes) }\end{array}$ & $\begin{array}{l}8 \mathrm{~F} \\
9 \mathrm{Ch}\end{array}$ & Compare lesson structures: TBLT and PPP \\
\hline Danielle & French & 10 & 31 & $\begin{array}{l}\text { Use of tasks in a predominantly } \\
\text { grammar-focused lesson }\end{array}$ \\
\hline David & Spanish & 9 & 27 & $\begin{array}{l}\text { Retention of vocabulary when working with } \\
\text { tasks }\end{array}$ \\
\hline Elizabeth & Chinese & $\begin{array}{l}5 \& 6 \\
\text { (combined } \\
\text { class) }\end{array}$ & 24 & Students' motivation as a result of using tasks \\
\hline Eric & Japanese & 10 & 15 & Use of tasks within a PPP sequence \\
\hline Heather & Chinese & 10 & 26 & $\begin{array}{l}\text { Use of tasks to review and assess course } \\
\text { content }\end{array}$ \\
\hline Laura & Spanish & 9 & 28 & Students' motivation as a result of using tasks \\
\hline Lauren & Chinese & 7 & 21 & $\begin{array}{l}\text { Engage students in cultural knowledge } \\
\text { through tasks }\end{array}$ \\
\hline Melissa & Chinese & 2 & 24 & $\begin{array}{l}\text { Impact of increase of the amount of target } \\
\text { language used during lessons }\end{array}$ \\
\hline Michelle & French & $\begin{array}{l}9 \text { (two } \\
\text { different } \\
\text { classes) }\end{array}$ & $24+26$ & Compare lesson structures: TBLT and PPP \\
\hline Samuel & Spanish & 9 & 17 & $\begin{array}{l}\text { Increase male students' engagement through } \\
\text { the use of tasks }\end{array}$ \\
\hline Sara & Spanish & 1 & 18 & Use of input-based tasks \\
\hline
\end{tabular}

\section{Focus of learning inquiry}

The starting point of the assignment was for teachers to identify an aspect of their practice where they considered that the inclusion of tasks may make a difference and thus was worth inquiring about. Within this overarching inquiry focus, they were to implement a task or tasks that would be evaluated using Ellis's framework. As can be seen in Table 7, four teachers decided to focus on their students' motivation and engagement as a result of including a task in their FL teaching. Another four decided to focus their inquiry on exploring aspects of TBLT as a language teaching approach; from these, two explicitly focused on comparing TBLT and PPP lesson structures, while the other two teachers were interested in tasks as a complement to their FL 
teaching. Three teachers focused their inquiries on examining their students' language development (increase/improvement in the amount of target language use, vocabulary acquisition). Finally, two teachers decided to examine the role and use of particular types of tasks. Although in the explanation about the assignment the teachers were advised to keep the focus of the inquiry manageable in scope, it was evident that some of them had set ambitious goals for their inquiries.

The wide variety of interests is a characteristic of teachers' inquiries when they investigate their own classes, as they are able to contextualise their interests and collect evidence from their learners. Despite the diversity of interests, all teachers were to evaluate the innovation that TBLT represented to them. Towards the end of this chapter, we will return to the expressed focus of interest from the teachers when we examine the outcomes of the inquiries as reported by the teachers.

\section{Task design and planning}

In this section, we focus our analysis on what the teachers reported regarding the processes they followed to individually implement tasks in their classrooms. These processes accompanied what was, for most of them, their initial attempt at using a task in their classroom. In our focus on the "task-as-workplan," we first look at the overall planning decisions teachers made in their inquiries. In particular, we look at what informed task design, describe how the tasks corresponded to the teachers' ongoing unit workplan, outline what pedagogic roles these tasks played within a sequence of instruction, and articulate how the teachers conceived of, and planned, different task stages. The next section investigates to what extent these teachers were able to incorporate specific task criteria, taught during the programme, into their task design, that is, a focus on meaning, some kind of gap, learner reliance on their own resources, and a clearly defined outcome (Ellis \& Shintani, 2014; Erlam, 2016a).

\section{What informed task design}

Aligned with what researchers deem effective, the teachers in this study were expected to frame their inquiries within the literature on TBLT, which, for most of them, was new, and therefore challenged their practice (Timperley, 2011). Therefore, we included, in our analysis, the literature that informed their task design.

All the teachers referenced key readings encountered in the course, including the Ellis (2005) Principles, as well as other references provided (e.g., Ellis, 2009; Nunan, 2004; Willis, 1996; Willis \& Willis, 2007). Six of the teachers identified other references they had not been introduced to, but which they deemed necessary given the focus of their inquiry. 
Our examination indicates that most teachers finished the course being able to use the literature and demonstrate their understanding of the key concepts that underpin TBLT, including "focus on meaning versus focus on formS," "importance of formulaic language," and "authentic contexts of language interaction." Most of the reports indicated that the teachers were comfortable paraphrasing and integrating the literature to advance their justification of the specific focus of their inquiry. For some teachers interested in comparing lesson structures used in TBLT and PPP or other language teaching approaches, the sequencing of tasks, the types of tasks, and the inclusion of grammar were key concepts in their inquiries. As stated before, since four of the teachers focused on students' reactions to TBLT, their inquiries were also informed by literature on student motivation and engagement while learning a foreign language. Some teachers used specific literature, focusing on, for example, the integration of culture into TBLT, assessing vocabulary, or integration of games for interaction.

\section{Selection and/or design of tasks}

This section describes how the teachers went about deciding on the task/s they would use. Table 8 includes information on the types of tasks chosen by each teacher, the language skills, the goals or objectives they had set for the tasks, and how the task corresponded to their unit workplan.

The teachers' tasks were mostly adapted from those they had encountered in the course readings or resources or had experienced during the course. Half were oral information-gap tasks, including four surveys and three tasks where students were giving directions. Three combined language skills. In Danielle's task, for example, her learners of French had to read postcards of holiday descriptions and then work in pairs to rank the holidays according to how attractive they thought each was. Two teachers' tasks were creative projects where the learners had the opportunity to review, through an extended task, all the content learned in the academic term. Heather, for instance, had her students of Chinese create a mystery to be solved by their peers. The creation of the mystery involved the use of the four language skills. This task was also used as an assessment of the learners' achievement during the school term. Similarly, Laura set up a task where her learners of Spanish used the language they had learned over one academic term to create a product for a child. This resulted in multimedia products (e.g., book, PowerPoint, poster) that required language and technological skills.

Our analysis revealed that the majority of the teachers developed a task that was clearly embedded in a language unit they had been working on (see the third column in Table 8). Most were focused and had specific goals and objectives set by the teachers. For example, Elizabeth's task had her learners direct each other 
Table 8. Description of the tasks

\begin{tabular}{|c|c|c|c|c|}
\hline Teacher & Type of task & Topic/Unit & Language skill & Task goals or objectives \\
\hline Amanda & $\begin{array}{l}\text { Matching } \\
\text { picture to } \\
\text { description }\end{array}$ & $\begin{array}{l}\text { Physical } \\
\text { descriptions/ } \\
\text { Family and friends }\end{array}$ & Reading/ writing & $\begin{array}{l}\text { Reinforce vocabulary } \\
\text { Provide opportunities for output } \\
\text { Gender agreement }\end{array}$ \\
\hline Ane & Report & $\begin{array}{l}\text { School attendance/ } \\
\text { Home and school }\end{array}$ & Writing & $\begin{array}{l}\text { Write a report based on data of their } \\
\text { school attendance; provide opinions } \\
\text { and reasons for their attendance }\end{array}$ \\
\hline Ashley & $\begin{array}{l}\text { No specific } \\
\text { tasks were } \\
\text { described }\end{array}$ & & & \\
\hline Danielle & $\begin{array}{l}\text { Ranking and } \\
\text { comparing }\end{array}$ & $\begin{array}{l}\text { Paris/ Description } \\
\text { of holidays }\end{array}$ & $\begin{array}{l}\text { Reading and } \\
\text { speaking }\end{array}$ & $\begin{array}{l}\text { Rank holidays described in } \\
\text { postcards } \\
\text { Compare the ranking with other } \\
\text { groups } \\
\text { Introduce the past tense }\end{array}$ \\
\hline David & $\begin{array}{l}\text { Information } \\
\text { gap }\end{array}$ & $\begin{array}{l}\text { Directions/ } \\
\text { Directions and } \\
\text { places in a town }\end{array}$ & $\begin{array}{l}\text { Listening and } \\
\text { speaking }\end{array}$ & $\begin{array}{l}\text { Give directions to locate and arrive } \\
\text { at different places in a map }\end{array}$ \\
\hline Elizabeth & $\begin{array}{l}\text { Information } \\
\text { gap }\end{array}$ & $\begin{array}{l}\text { Directions/ } \\
\text { Directions and } \\
\text { transport }\end{array}$ & $\begin{array}{l}\text { Listening and } \\
\text { speaking }\end{array}$ & Direct learners through a maze \\
\hline Eric & $\begin{array}{l}\text { Information } \\
\text { gap/survey }\end{array}$ & $\begin{array}{l}\text { Describing abilities } \\
\text { in sports and } \\
\text { hobbies }\end{array}$ & $\begin{array}{l}\text { Listening and } \\
\text { speaking }\end{array}$ & $\begin{array}{l}\text { Inquire about abilities of peers in } \\
\text { relation to sports and hobbies } \\
\text { Identify peers once the survey } \\
\text { information is collated } \\
\text { Use of can do/cannot do }\end{array}$ \\
\hline Heather & $\begin{array}{l}\text { Create a } \\
\text { crime for } \\
\text { classmates to } \\
\text { solve }\end{array}$ & $\begin{array}{l}\text { Revision of all } \\
\text { language learned }\end{array}$ & All skills & $\begin{array}{l}\text { Review and assess different language } \\
\text { items and topics covered in the } \\
\text { previous units }\end{array}$ \\
\hline Laura & $\begin{array}{l}\text { Create a } \\
\text { product in } \\
\text { groups }\end{array}$ & $\begin{array}{l}\text { Review of all } \\
\text { content/My home }\end{array}$ & Multimedia & $\begin{array}{l}\text { Review all unit content s through the } \\
\text { creation of a product (book, poster, } \\
\text { PowerPoint) that can be given to a } \\
\text { child learning the language }\end{array}$ \\
\hline Lauren & $\begin{array}{l}\text { Information } \\
\text { gap/survey }\end{array}$ & Birthdays/ Numbers & $\begin{array}{l}\text { Listening and } \\
\text { speaking }\end{array}$ & Find out classmates' birthdays \\
\hline Melissa & $\begin{array}{l}\text { Information } \\
\text { gap/survey }\end{array}$ & Family & $\begin{array}{l}\text { Listening and } \\
\text { speaking }\end{array}$ & $\begin{array}{l}\text { Describe their family when asked in } \\
\text { a class survey }\end{array}$ \\
\hline Michelle & $\begin{array}{l}\text { Information } \\
\text { gap/survey } \\
\text { and ranking }\end{array}$ & Food & $\begin{array}{l}\text { Listening and } \\
\text { writing }\end{array}$ & $\begin{array}{l}\text { Collate information about food } \\
\text { preferences to create a shopping list } \\
\text { for peers }\end{array}$ \\
\hline Samuel & $\begin{array}{l}\text { Information } \\
\text { gap }\end{array}$ & $\begin{array}{l}\text { Directions/ } \\
\text { Directions }\end{array}$ & $\begin{array}{l}\text { Listening and } \\
\text { speaking }\end{array}$ & $\begin{array}{l}\text { Give directions to blindfolded } \\
\text { students who move through a } \\
\text { pretend town }\end{array}$ \\
\hline Sara & $\begin{array}{l}\text { Information } \\
\text { gap/draw } \\
\text { based on cues }\end{array}$ & Birthdays & $\begin{array}{l}\text { Listening and } \\
\text { speaking }\end{array}$ & $\begin{array}{l}\text { Practice vocabulary related to } \\
\text { birthdays: draw on a cake template, } \\
\text { say how old you are based on dice, } \\
\text { draw and ask }\end{array}$ \\
\hline
\end{tabular}


through a simple maze; other extended tasks, such as Laura's and Heather's, had multiple steps and diverse outcomes produced over several lessons. As can be seen in the last column of Table 8, most teachers defined specific linguistic and communicative goals for their tasks. The exceptions were Heather and Laura who had the broader goal of reviewing (and assessing) all content from a unit of learning.

Consistent with the level of language of most of these classes, the tasks developed were suited to beginner learners (the exceptions were Laura and Ane who worked with more advanced students). According to the Willis (1996) taxonomy, most of these tasks had learners asking and answering questions in predictable contexts such as surveys or in following directions, as would be appropriate in the initial stages of language production. The topics that most classes were working on suited beginner learners: family, food, directions, and birthdays. Sara's class, with the youngest learners, used three different, short input-based tasks which included identification of items in pictures and drawing pictures based on oral cues. In contrast, the most advanced class was Ane's Tongan class with heritage speakers who had the language ability to analyse data on their attendance at school, and then write a report and provide opinions and reasons for their attendance. In short, this sample set of tasks includes a range of types, designed mostly for beginner learners with varying levels of complexity and different language modes.

\section{Evaluation of task design against task criteria}

As part of the data analysis informing this research, we examined the tasks that the 14 participating teachers designed in order to establish their "task-likeness," that is, to establish to what extent they fulfilled criteria. This would enable an investigation of the teachers' understanding of the construct of task and task criteria. This analysis was done subsequent to participants' completion of the TPDL programme meaning that they were not individually checked prior to the teachers' using them.

Ellis (2012) proposes a set of definitional criteria as a way of "assessing with some rigour to what extent an activity is a task" (Ellis, 2003, p. 35). He further elaborates on, and explains, these four key criteria in Ellis and Shintani (2014, p. 135):

1. The primary focus should be on "meaning" (i.e., learners should be mainly concerned with encoding and decoding messages, not with focusing on linguistic form).

2. There should be some kind of "gap" (i.e., a need to convey information, to express an opinion or to infer meaning).

3. Learners should largely rely on their own resources (linguistic and non-linguistic) in order to complete the activity. That is, learners are not "taught" the language they will need to perform the task, although they may be able to "borrow" from the input the task provides to help them perform it. 
4. There is a clearly defined outcome other than the use of language (i.e., the language serves as the means for achieving the outcome, not as an end in its own right). Thus, when performing a task, learners are not primarily concerned with using language correctly but rather with achieving the goal stipulated by the task.

These are not the only criteria that can be used to define tasks. Other researchers have given definitions against which we could have evaluated the teachers' tasks (e.g., Nunan, 1989; Skehan, 1998; Willis, 1996). However, the Ellis and Shintani (2014) criteria were the ones which were consistently presented to teachers during TPDL. Furthermore, during the pedagogical component of the programme, these were the criteria which the lecturer used with the teachers to establish to what extent a specific activity could be considered a task. It seemed logical that we would use the same criteria that we had encouraged the teachers to use themselves.

For research purposes, all tasks were rated by both researchers independently and then agreement was established through discussion. The focus, during rating, was on the task-as-workplan, that is, on the teachers' written descriptions of their tasks as they intended to teach them. However, for Criterion 3 (see Table 9), we also relied on a description of how the task was implemented. This was because it was necessary to know what language support students had during task completion, information which teachers did not always cover in their workplan description. In order to decide whether a task met the four criteria outlined above, the researchers asked a series of questions, as in Erlam (2016a, p. 288). There were two questions for each criterion. These, along with the answers that were expected for each criterion, are listed in Table 9.

Table 9. Questions relating to coding of criteria

1 The primary focus should be on meaning

Does the learner function as a language user and not a language learner?

Is the learner primarily concerned with encoding and decoding Required answer messages, not with focusing on linguistic form?

2 There should be some kind of gap

Is this gap closed as a result of the communication that takes place?

As a result of the communication does the learner find out something Yes they didn't know?

Yes

Yes

3 Learners should have to rely on their own resources (linguistic and nonlinguistic)

So that they can do the task, are the learners taught the language they will No need?

Does the task allow learners to automatise/use language they have Yes already been taught on a previous occasion?

4 There is a clearly defined outcome other than the use of language Does the language serve as a means for achieving the outcome rather than as an in its own right?

Does achieving the outcome determine when the task is completed? 
For Criterion 3, it was decided teachers needed to have clearer guidance about the level of linguistic input appropriate for learners to have prior to a task and the level of linguistic support appropriate as they completed tasks. This responded to earlier research showing how difficult this criterion was for teachers (Erlam, 2016a). The guidance given informed both the pedagogy component of TPDL and the TPDL team in their work with participants. Teachers were therefore told that they should not teach students new language structures and expect them to immediately use these communicatively in a task. They were taught to differentiate between item-based learning and rule-based learning (Loewen \& Reinders, 2011). Item-based learning involves the learning of linguistic features that are unique in their features, for example, a formulaic phrase or vocabulary item (Skehan, 1998). Some new language that constituted item-based learning was considered appropriate to incorporate into task design; this would allow for students to be given and/or ask for words and/or phrases that might help them complete the task. On the other hand, rule-based learning, which refers to learning of grammatical structures and systems, was not considered appropriate as new learning for a task-based lesson. The reason was that students would be unlikely to be able to use new language structures successfully while their attention was focused on communicating meaning.

Another aspect of this criterion was the need for teachers to provide the right amount of scaffolding to encourage automatisation. Students could have language support available but be encouraged to rely as much as possible on their memory for language they had been taught. This would allow students to use creatively any language they might know, help them notice any gaps in their ability to use language communicatively, and motivate them to ask for language they needed.

By way of illustration, for each of the above criteria, two tasks from our data set are presented in Table 10. In each case, one of the tasks fulfilled the task criterion, and one did not. Our comments as to why each task did or did not meet the specified criterion are in italics below each description.

We evaluated 13 potential tasks against these criteria. One Learning Inquiry project was excluded because the task in this project was not described in sufficient detail for decisions about each criterion to be made.

We made a series of decisions as we coded the tasks described in the Learning Inquiry projects. On a number of occasions, decisions were not straightforward because not enough information was given in the inquiry project description. In particular, decisions about the third criterion, "rely on their own resources," were sometimes difficult. In one example, a pre-task was described but, because it was not clear that it took place in a previous lesson, it was not clear whether learners were required to use new language in the task or rely on language they already knew. In cases where there was some doubt, the criterion was graded as not fulfilled. In another lesson description it was difficult to decide whether the second criterion, 
Table 10. Tasks that did and did not meet criteria

\section{Fulfilled}

Focus on meaning

Year 10 students of Tongan (mainly heritage speakers) had to analyse information about their school attendance over a 3-month period, give reasons for nonattendance and evaluate this record of their school attendance.

Students were using language to communicate their own meaning/encoding and decoding messages, rather than just functioning as language learners.

\section{Some kind of gap}

Beginner learners of Chinese (Years 5/6) were each given a grid of squares. A partner, who had a maze, had to give instructions, according to a route traced on this maze, to help them find their way across the grid. Students could not see the route and had to listen for directions. In listening they found the right route across the grid.

\section{Rely on own resources}

Learners of French (Year 10) had to read postcards which described holidays and rank them in order of most to least interesting. They had a vocabulary bank of words to refer to if they needed to.

The vocabulary bank contained words they already knew, rather than new language that they needed to complete the task.

\section{Clearly defined outcome}

Beginner learners of Spanish (Year 9) had to create something for a young child. This could be a small book/story, a poster with pictures and text, a PowerPoint or a comic strip.

The completed product was distinct from the use of language and determined when the task was completed.

\section{Not fulfilled}

Elementary learners of Spanish (Year 1) threw a dice. According to the number displayed on the dice, they said in Spanish what their age was and put the corresponding number of candles on to a birthday cake.

The learners were not functioning as language users to communicate information that was personally true for them. The only part of this statement that they had to encode/decode in order to succeed was the number in Spanish.

Year 9 beginner learners of Spanish moved chairs and tables to create a Spanish city in their classroom. One student was a blindfolded tourist and the other a local. The local gave directions as to how to get to a certain place in the city and the tourist followed these.

This could have involved a gap but the tourist and local walked the route together first with no blindfold. This means that the tourist did not need to rely on the instructions, nor did s/he walk a route that s/he did not know.

The teacher first taught language needed to express varying levels of ability. Year 10 learners of Japanese then had to ask each other how well they could do certain activities and record answers on a survey sheet. Students were taught the language they needed immediately prior to completing the task.

Beginner learners of Chinese (Year 7) were given a survey sheet and had to complete it by collecting information from six classmates about their birthdays.

The use of language was not distinct from achieving the outcome; there was no stated purpose for collecting the information nor was it used or consulted for any reason. 
"there should be some kind of gap," was met. Once again, because this was not clear, it was coded as not fulfilled. This conservative approach to rating could mean that more tasks fulfilled task criterion than appeared to be the case.

The percentage of agreement after the first rating was $87 \%$. According to Miles and Huberman (1994), who say that coders should reach an agreement for a minimum of $80 \%$ of the time, this demonstrates adequate reliability. After discussion and negotiation, the percentage agreement reached $98 \%$.

In Table 11 we present data to show to what extent teachers in this study were able to incorporate all four of the key components of a task into their task design.

Table 11. Number of tasks that fulfilled different criteria

\begin{tabular}{lcccc}
\hline No of criteria & All 4 criteria & 3 criteria & 2 criteria & 1 criterion \\
\hline No of tasks & 3 & 4 & 5 & 1 \\
Percentage & $23 \%$ & $31 \%$ & $38 \%$ & $8 \%$ \\
& \multicolumn{2}{c}{$\begin{array}{c}\text { designated as tasks } \\
\text { total }=7\end{array}$} & \multicolumn{2}{c}{ designated as activities } \\
& total $=6$ & \\
\hline
\end{tabular}

At this stage, we had to decide whether in the lessons teachers described, they had, indeed taught tasks, according to the Ellis and Shintani (2014) criteria. We considered that being able to fulfil three or more components of task design would constitute evidence of a task, whereas fulfilling two criteria or less would mean that what was described was better considered an activity, because it was not sufficiently tasklike. We therefore concluded (see Table 11) that 7/13 or 54\% of lessons contained tasks, and the rest contained activities.

Results, which show how many of the tasks that teachers described in their Learning Inquiry projects fulfilled each of the four task criteria, are presented in Table 12.

Table 12. Results for evaluation of task descriptions against task criteria

Criteria

The primary focus should be on meaning

There should be some kind of gap

Learners should rely on their own resources

There is a clearly defined outcome
No and percentage fulfilled

$n=13$

$\begin{array}{rr}12 & 92 \% \\ 9 & 69 \% \\ 5 & 39 \% \\ 9 & 69 \%\end{array}$

The criterion that was most difficult for teachers to fulfil was the one requiring learners to rely on their own resources (linguistic and nonlinguistic) as they completed tasks. This replicates earlier research (Erlam, 2016a) conducted in the same context, but, with a different group of TPDL programme participants in a different 
year. The reasons identified to explain this result (Erlam, 2016a) could also apply to the present study:

- Teachers designed tasks that required learners to produce output rather than process input. One reason for this, perhaps, is that the in-school support component of TPDL required teachers to teach lessons where students produced language output. Teachers struggled to design production tasks which were suitable, in terms of language demands, for learners who were, predominantly, at elementary or beginner level in terms of their language proficiency.

- Teachers did not always design tasks that integrated well with previous lessons. A number of teachers, in writing their inquiry projects, made no reference to previous work covered in class nor explained how the task they described was designed to complement this work.

- Many of the teachers in this programme were familiar with a PPP lesson format, which does start with a presentation of grammar (Richards \& Rodgers, 2014). Breaking this cycle and implementing a new approach was difficult for them, requiring a completely new way of thinking about language form, as previously documented (e.g., Zheng \& Borg, 2014).

The criterion, "there needs to be some sort of gap," was difficult for some $(n=4)$ to incorporate into task design, as in Erlam (2016a). One teacher whose task required learners to create something for a young child, did not specify an audience of readers or recipient for the creation, nor any purpose for such an audience to read what the students had created (Klapper, 2003). She recognised this in her own task evaluation and suggested that, were she to use this task again, she could include a communication gap. Her suggestions for task revision implied that the audience would be the students' classmates and reasons for them to engage with the created product could either be that they would have to write the end of a story (deliberately left incomplete) or decide which ending they liked best.

Equally challenging for some teachers $(n=4)$ was the requirement that a task should have an outcome other than the use of language. Interestingly, in Erlam (2016a), this is the criterion that teachers found easiest to satisfy. One possible reason for the difference in findings is that the proportion of teachers of primary students in the present study was much lower, less than a third of the data set, whereas in the earlier study more than half of the teachers had students at this level. Erlam (2016a) pointed out that teachers of younger students may be more aware that students would need a goal other than the use of the language itself in order to be motivated to complete a task.

As in Erlam (2016a), the criterion "there should be a primary focus on meaning" was easier to satisfy. It is perhaps encouraging that this is the criterion that was most fulfilled in task design in the current study. Van den Branden (2006) pointed out that, 
in understanding the construct of task, the key concepts are the importance of meaning and the learner functioning as language user and not just as language learner.

To summarise, we were interested in establishing how the teachers used the task criteria for their task design. As seen in the analysis presented in this section, we conclude that teachers required more guidance and more experience with tasks. Perhaps we could have incorporated a step in the inquiries where the teachers consulted with each other or with us to establish how they were applying the task criteria.

\section{Task evaluation}

This section examines the way the teachers evaluated the tasks described in the previous sections. Although not all tasks met the criteria for tasks (as seen in the previous section), we still considered it important to continue our examination of the teachers' development as they engaged with the other steps in their inquiries. As explained at the beginning of the chapter, the teachers were expected to select two of three approaches (student-based, response-based and/or learning-based) to the microevaluation of tasks (Ellis, 2011) to evaluate their tasks (see Table 6 for details). Table 13 summarises the two types of evaluation selected by each of the teachers.

Table 13. Approaches used to evaluate the tasks

\begin{tabular}{|c|c|c|c|}
\hline Teacher & Student-based & Response-based & Learning-based \\
\hline Amanda & Survey & & Test \\
\hline Ashley & Survey & Teacher tallying utterances & \\
\hline Heather & Survey & & Test \\
\hline Elizabeth & Survey & Completed mazes & \\
\hline David & Survey & Labelled maps & \\
\hline Samuel & Survey & & Teacher observation \\
\hline Lauren & Survey & $\begin{array}{l}\text { Task sheets + language data } \\
\text { collected by facilitator }\end{array}$ & \\
\hline Laura & $\begin{array}{l}\text { Survey + self-report } \\
\text { ("I know how to...”) }\end{array}$ & & Grammar sheet \\
\hline Melissa & Survey & Teacher participation & \\
\hline Ane & Feedback & & Teacher observation \\
\hline Danielle & Survey & & $\begin{array}{l}\text { Teacher observation }+ \\
\text { grammar sheet }\end{array}$ \\
\hline Eric & Survey & $\begin{array}{l}\text { Teacher observation + language } \\
\text { data collected by facilitator }\end{array}$ & \\
\hline Michelle & Survey & & Test \\
\hline Sara & Survey & Task sheets & \\
\hline
\end{tabular}


The overwhelming majority of teachers (13 out of 14 ) surveyed the students to ascertain their opinion of the task. This decision is consistent with our experience teaching this course and reading teachers' inquiries over the years. Faced with an innovation and inquiring into their teaching, the teachers consider their students' opinions to be valuable. However, this appreciation for student voice sat alongside the teachers' awareness of the possible limitations of asking for students' views on teaching and learning processes.

Because of possible differences in reliability and validity of the data collected by the teachers and the incomparability of the diverse data presented in the reports, in what follows, we comment only on overall results reported by the teachers in their inquiries.

The surveys were all anonymous (i.e., students were not asked to include their names), as the teachers seemed to be interested in collecting honest opinions. Each teacher decided on a survey mode (online or on paper) with different questions and types of scales. Sara asked only three questions using a simple three-point scale to have her Year 1 (approx. age 5 years) students indicate their degree of satisfaction by circling face icons (happy face for like, serious face for neutral, sad face for dislike). On the other extreme, Elizabeth surveyed her Year 5/6 class asking 10 questions using a 5-point Likert scale. Some teachers collected students' opinions on a variety of issues such as enjoyment, degree of difficulty, support for learning, ability to complete the task, and willingness to engage with tasks in the future. Despite differences, across the 13 classes surveyed, the learners reported enjoyment of the tasks (ranging from $60 \%$ to $90 \%$ enjoyment or satisfaction). It seemed that, for the majority of the classes, the tasks had been an opportunity to use the language to interact with peers and to share personal information, often for the first time. Therefore, it is not surprising that most of the students reported a positive response to those activities when compared, for example, with form-focused work or working from textbooks and completing worksheets. This largely positive outcome is consistent with research done on TBLT where high learner motivation is consistently reported.

Some teachers also collected information about the language used during the tasks. For example, both Melissa and Lauren asked their primary-aged learners how much Chinese they thought they had used in the task and how much of the time they had only spoken in Chinese. In both classes, the students reported greater use of the target language during the tasks. On the other hand, Eric's Year 10 learners reported that they had to switch from Japanese to English to complete their interactive task. Whether the students would use the target language or fall back on use of the L1 was a common concern for the teachers.

Seven teachers evaluated the effectiveness of the task by collecting evidence of student learning. The evidence available for analysis using this approach varied extensively, as can be seen in Table 13. Some of the teachers used vocabulary and 
grammar tests to check how much language their students had learned through completing the task. This seemed to be particularly important for those teachers who were comparing language learning approaches. For example, the results of Michelle's vocabulary test in her two classes, one using a PPP and the other a TBLT structure, indicated that the students in the PPP class retained more vocabulary words than in the TBLT class. Given the manageable size of her language classes ( 8 and 9 learners respectively), Ashley was able to count the number of target language words used by her learners. The result was an average of 6.5 words in the PPP class compared to 30.6 words in the TBLT class. This result in Ashley's classes needs to be taken with caution as she was tallying responses on the whiteboard while her students were providing answers to decontextualised vocabulary questions.

Seven teachers decided to evaluate the effectiveness of the tasks using a responsebased approach that aims to establish whether the students performed the task as the teacher had planned it. For example, Eric and Melissa walked around their classes to hear their students speaking in the target language and collected evidence of their students' utterances by keeping a tally. In Eric's case, the evidence was collected by one of the TPDL facilitators who was conducting a scheduled visit to his classroom as an observer. Both Elizabeth and David collected completed student work resulting from tasks that involved following instructions to complete a maze (Elizabeth) and a tourist map (David). These two teachers evaluated the success of the instructions provided by peers during the task against the students' completed work. In Elizabeth's class, 10 out of 12 students completed the mazes and David reported that the majority of his class (no exact number provided) had accurately completed the names of places in a town's map.

Given the short timeframe of these inquiries, embedded in the teachers' normal language teaching, most teachers collected evidence of the effectiveness of their tasks at only one point of their teaching, mainly during one lesson. The exception to this were the two teachers who used extended tasks to review content over a whole unit of instruction. In Heather's class, the review and assessment crime task was done over five lessons, while for Laura, it was over three lessons.

The only teacher who completed a full cycle of design (implementation - evaluation - reteaching) and, therefore, was able to evaluate and modify her tasks as part of the inquiry was Sara whose Year 1 (5/6-year-olds) students completed three tasks related to birthdays. Sara designed and refined aged-appropriate information-gap activities until she was satisfied that all her students participated and completed successfully based on her monitoring of individual learning.

In conclusion, the teachers selected different approaches to evaluate the tasks they had taught. The 13 teachers who surveyed their students reported high levels of student satisfaction and engagement with the tasks. Seven teachers evaluated mostly positive language learning outcomes on their students using tests or tallying language used during tasks. Other seven teachers used observational techniques to 
establish that their students performed the tasks as intended. Only three teachers collected evidence of the effectiveness of their tasks beyond a single point. Two of these teachers reported successful extended tasks over three to five lessons while one teacher evaluated and refined a full cycle of three short tasks until she felt the outcomes were what she had intended. Two further sections of the teachers' inquiry reports may shed some light on the teachers' conclusions. One section asked the teachers to use the evidence collected in their evaluation to determine how they would revise the task if they were to use it again with these or other learners. Inherent to the reflection on revision was the teachers' professional view on the pedagogical success of the task and possible reasons for the outcome of the task. Finally, the teachers were expected to draw conclusions on their own learning based on the inquiry process.

\section{Task revision}

Most teachers concluded in their inquiries that the tasks they had designed and implemented had met their preestablished aims. Despite these positive conclusions, all teachers included specific revisions for their tasks, as required. In our analysis of these revisions, it seemed that the teachers focused their attention on the implementation of the task (i.e., task-as-process) rather than on task design. Only Michelle seemed to focus her revision on the actual design of the task, as she mentioned that, on future occasions, her starting step would be ensuring that she had designed a task that fulfilled criteria.

The revisions suggested by the teachers can be broadly classified as logistic and pedagogic. In terms of logistics, some of the teachers mentioned aspects such as allowing more time for implementing the task, ensuring they had adequate teaching spaces, trying out the technology, or dividing the learners in groups with clear criteria. Pedagogically, they mentioned many revisions. One mentioned by eight of the 14 teachers, was to ensure their learners were well prepared in terms of the language required to engage with the task. In other words, they focused on the Ellis criterion of "learners relying on their own resources" which, as mentioned in our analysis of the tasks, was the criterion that most teachers found the most challenging. Consequently, the teachers indicated that they would either modify the pre-task or embed the task at a later time in the sequence of instruction to allow, for example, vocabulary to be accessible to the learners. Similarly, three teachers felt that their learners needed more time learning formulaic expressions before these could be used in tasks.

Although initially the teachers declared that their task had been successful, in the revisions listed, six teachers included modifications that they would make to the implementation of the task. Elizabeth, for example, planned to change her maze to a map as she considered maps more concrete for her young learners. Danielle 
wanted to keep the postcards task but, in the future, would use authentic postcards written by young French speakers. Both Heather and David would change the roles assigned to learners in the tasks they set. Lauren considered that her task had been too complex for her beginner learners and suggested ways of simplifying it and supporting the learners.

A revision suggested by five teachers was to ensure that the tasks they designed supported their diverse learners by integrating strategies for differentiation. This seems to indicate that the teachers saw a role for tasks in catering to different learners' needs. Heather and Samuel suggested offering extensions for their more proficient learners and Elizabeth suggested having different support strategies embedded in the task, mindful that some of her learners struggled to read Chinese characters.

Overall, the section on task revisions indicated the teachers' learning from the process of monitoring their own implementation of tasks. Each teacher seemed to have focused attention on aspects they considered relevant after their experience of teaching the task. This process supports a goal of inquiry, where teachers examine their own decisions and modify their practices to benefit their learners.

\section{Teachers' conclusions of their inquiries}

\section{Limitations}

Although the inquiry assignment specifically asked the teachers to include a limitations section, four did not do so. Of those who did, three mentioned contextual limitations such as the large number of students, the teaching space, or the time of day they taught the task. Seven comments can be classified as relating to planning: three teachers mentioned that planning for the tasks was very time consuming, questioning how realistic selecting and including tasks in lesson plans would be for their normal busy teaching lives; four teachers mentioned other planning-related issues such as familiarity and experience with teaching tasks. One teacher wondered whether her learners' readiness was a factor that would need addressing in future tasks. Most of these limitations indicate the teachers' growing awareness of pedagogical issues that they would need to address when designing and implementing tasks.

Teachers' conclusions about the focus of the inquiry

As mentioned before, we now present a comparison (see Table 14) of the aim or focus of the inquiry given by each of the teachers with conclusions drawn at the end of the report. 
Table 14. Teacher conclusions in relation to the aim of the inquiry

\section{Teacher Focus of the inquiry (i.e., the Teacher conclusion at the end of the inquiry teachers' description of the rationale for their inquiry)}

Amanda Impact of increase of the amount of target language used during lessons

Ane No inquiry focus indicated

Ashley Compare lesson structures: TBLT and PPP

Danielle Use of tasks in a predominantly grammar-focused lesson

David Retention of vocabulary when working with tasks

Elizabeth Students' motivation as a result of using tasks

Eric Use of tasks within a PPP lesson sequence

Heather Use of tasks to review and assess course content

Laura Students' motivation as a result of using tasks

Lauren Engage students in cultural knowledge through tasks

Melissa Impact of increase of the amount of target language used during lessons

Michelle Compare lesson structures: TBLT and PPP

Samuel Increase male students' engagement through the use of tasks

Sara Use of input-based tasks
Increase in use of the target language; task promoted authentic language use; students developed an awareness of grammar; students reported having fun and a positive experience with the task No information provided Greater use of the target language with a TBLT structure; the TBLT structure perceived by the teacher as "a better way" to teach language Anecdotally, compared to previous classes, the students used the past tense with more ease and confidence

The majority of the students labelled the map correctly but there was no quantification of increase in vocabulary

Students were not as motivated as expected because the instructions provided by the teacher were not clear (as reported by the teacher)

Many instances of students resorting to English; one of the tasks was more effective than the other in promoting the use of target language

Task was a good way to assess speaking ability; students paid more attention to form

Student motivation was reported as higher than other language lessons; the teacher perceived the task as promoting a positive cognitive challenge for her learners

Effective learning opportunity but no time for the cultural reflection

Amount of Chinese use increased with the task

Students and teacher more familiar with PPP and out of their comfort zones with the integration of what the teacher considered a task

Male Māori and Pasifika students seemed more relaxed and comfortable communicating; task-supported, authentic use of the target language, students noticed some form, task covered all of Ellis's principles

One of the input-based tasks was successful after several revisions 
As can be seen, most of the teachers revisited their initial intent in their conclusions with only a couple of exceptions. Evidence thus suggests that the inquiries had supported the teachers in investigating their own practices when using tasks. Since the initial aims set by the teachers were so varied, the conclusions drawn are limited. For those teachers who wanted to compare a TBLT lesson structure to other approaches to language teaching, the results were mixed. For Danielle and Michelle, the results of their inquiry were not decisive, hence both concluded that there were benefits in both lesson structures. Ashley was more positive about TBLT, declaring it "the best method." Eric did not include a conclusion. We take these teachers' comments being mindful that they were drawing conclusions based on limited data and we communicated this to them in our feedback on their inquiry reports. We did not want to create the false impression that collecting evidence from one task is enough to conclude that one teaching approach is better than another.

As to teacher learning, the process of going through an inquiry cycle to collect evidence on the impact of the inclusion of a task (or what the teacher considered a task) in their language teaching allowed the teachers to experience first-hand the connection between theory and practice as well as their role as inquiring professionals. This is a positive outcome of all inquiry, yet one that seems unrealistic for teachers in their normal teaching practice when there are different issues competing for their attention.

\section{Teachers' final reflections}

The teachers finished their learning inquiry reports with reflection on the experience of implementing the task. Most of them found the experience positive with Lauren and Laura almost using the same words to describe it as valuable, worthwhile and constructive for themselves and their students. A couple of the teachers' conclusions focused on the process of learning about tasks. For example, Eric described the evolving nature of learning and indicated that the implementation of "this type of [task-based] lesson has continued to evolve throughout the year." Danielle also alluded to the process of learning about tasks when she concluded: "This is definitely a work in progress, however I do think that this task was a good start point." Also referring to their learning processes, three teachers specifically mentioned meeting task criteria. David expressed his realistic view that "there is no such thing as the perfect task," and concluded that the "key to a successful approach to TBLT is about having a clear understanding of the four principles of a task and making sure they are fulfilled whenever possible." Similarly, Michelle declared that "the more the activity is examined, the clearer is the myriad of ways it can be improved for use next year to ensure it is a task." Sara admitted to "remain[ing] challenged to design meaningful 
tasks based on Ellis's four criteria of a task," yet she also had a clear aspiration: "Tasks that will inspire learners to become language users." Sara's reflections consistently made references to her learners.

Similar to Sara, other teachers were seeing the experience from the point of view of the learners, so their conclusions demonstrated their interest in TBLT as a way of increasing learners' motivation and engagement. Elizabeth, for instance, was hoping to motivate her students of Chinese with the task she designed, so she expressed her disappointment in her conclusion: "I believe the idea behind the task was effective, however the implementation was not. Due to this, my students' perspectives on TBLT [were] affected and viewed negatively." She then detailed her plan for improvement and concluded "as my ability to teach using TBLT improves, I believe so too will my students' perspectives and enjoyment of TBLT." Also looking at the variety of responses from her learners, Heather concluded: "Not everyone will enjoy every activity every time, but by varying tasks and trying new things I hope to cater to all learning styles, personalities and preferences." Although she admitted that student motivation and enjoyment when learning were important, Melissa went further to declare that "this was not enough for me." She insisted in using the opportunity of the inquiry to collect evidence of increased amount of use of the target language through the task which she described as "rich, real and relevant."

The participating teachers demonstrated in their own conclusions their capacity for reflection on their own practices. It seemed evident that the inquiry assignment had provided them with the opportunity to examine these through the lens of implementing tasks in their language teaching.

\section{Conclusion}

This chapter has drawn on teachers' written reports of learning inquiries into their own teaching. Although we are cautious in our conclusions and thus resist any generalisation on the outcomes of the inquiries, we still consider the many lessons learned by the teachers, from the exercise of guided inquiry as professional learning, valuable.

The learning inquiry assignment gave the teachers the experience of teaching a task and evaluating its effectiveness. As part of professional learning, we expected that the teachers would be willing to examine and change their teaching as they reflected on the impact of their decisions on student learning. The assignment used the cycle of reflection (MOE, 2020) where the teachers decided on a focus for their inquiry, designed and implemented a task, then collected evidence to evaluate the task effectiveness, and finally identified aspects that could be revised in the process. As seen at the beginning of this chapter, teachers made their decisions based on the characteristics of their students and school contexts as well as on their own interest and knowledge 
of tasks (mainly acquired during the course). Common to this structured approach to reflection was the teachers' interest in examining how their students learned languages using tasks as a lens although, as seen in our analysis, many of the tasks did not meet task criteria. The teachers collected evidence that indicated that their attempts to include tasks seemed to have increased the level of engagement of their learners. Their final reflections and the revisions that they included in their inquiry reports indicate that they reached a level of self-reflection, an important outcome in terms of teacher learning, and a basis for professional change.

The teachers' efforts to identify aspects of their teaching that could be improved by including tasks and modifying how they delivered their language lessons were initial steps in the process of learning from practice and being open to being challenged (Timperley, 2011). The actual design of the task sequence and implementation indicated that, at this stage, the teachers were still developing their emerging understandings about tasks given that in our analysis, many of the tasks did not meet the task criteria. This is consistent with Van den Branden's (2009) conclusion that change in teachers' practices "entails gradual development of skill" (p. 665). Our analysis of the teachers' own evaluation of their tasks indicated their interest in examining how students responded to and engaged with tasks. This seemed particularly important as most of these students were beginner learners of the language, needing strong motivation to continue learning. Reports of higher student motivation and engagement seemed to have resulted from tasks where the students had opportunities to use the language to interact with peers and to share personal information, often for the first time. In analysing the teachers' revisions and final reflections, the inquiries provided an opportunity for the teachers to develop insights into the potential for tasks in their language teaching practices as well as a better understanding of the process of implementing tasks so as to make a difference to their students' learning.

In terms of professional learning, the process of going through an inquiry cycle allowed the teachers to experience first-hand the connection between theory and practice as well as their role as inquiring professionals. Most of the inquiry report conclusions indicated that the teachers had finished the course with a positive view of the potential of implementing tasks and TBLT to their language teaching practices. Although, as explained in Chapter 1, TPDL and the pedagogical course did not present TBLT as the approach that the teachers had (or needed) to adopt in their classroom practice, this interest in incorporating tasks indicated that the teachers were taking ownership of tasks and planning how to implement change in their contexts (Van den Branden, 2006).

The analysis of the participant teachers' inquiries for the purposes of this study motivated our own reflections as teacher educators. In working with the teachers during the course, we had allowed them to set the focus and direction of what they wanted to inquire about and how to proceed with implementation and evaluation 
of their inquiries. If time and resources had allowed, we would have liked to have provided more guidance to ensure that the scope and aims of their inquiries were feasible given the limited time for the assignment. It would also have been beneficial for them to have received more support in task design and in incorporating task criteria into their task planning. For example, we could have promoted more input-based tasks knowing that most of the learners were beginners. We could also have supported better understanding of the concept of task. These findings have, of course, implications for professional development programmes that introduce teachers to TBLT (see Chapter 8 for more detail).

We will follow some of these teachers in the next chapter where we report on their practices after the TPDL programme had finished and they returned to their classrooms. 



\section{From learning about TBLT to implementing TBLT}

[A task is] something that they've got the vocabulary for, that they've developed, or have access to... That they could have an exchange of language, and I know that that can be either talking and listening or, you know, a reading and writing thing. And then actually completing something. (Excerpt from interview with Sara)

The previous two chapters examined how teachers learned about tasks and TBLT through their participation in a professional development programme (TPDL) and, specifically, through the pedagogy course they took as part of this programme. In Chapters 2 and 3 we presented a close analysis of two assignments completed by 14 teachers and identified aspects of learning that resulted from their engagement with the course. We concluded that, at the end of the course and the 1-year TPDL programme, the teachers had a foundational understanding of TBLT and seemed interested in incorporating tasks into their regular language teaching programme.

This chapter will extend that investigation by examining the impact of the TPDL programme on these teachers' language teaching practices immediately after finishing the programme - effectively moving from "task-in-theory" to task in the classroom. Following TPDL, we set out to examine to what extent they were incorporating their learning about TBLT in their specific teaching contexts. Our investigation was guided by a broad question: Are the teachers implementing TBLT in their classrooms and, if so, how? We were interested in establishing (1) how the teachers described their professional learning as a result of the TPDL programme; (2) the roles that tasks and TBLT had in these teachers' language teaching practices; (3) the enablers and constraints for implementing TBLT; and (4) students' perspectives. By collecting this information, we aimed to understand the needs and conditions of language teachers and their learners to contribute to our understandings of TBLT in the real world of practice.

We contacted the 14 teachers whose data we analysed in the previous two chapters to invite them to participate in this follow-up study the year after their participation in TPDL. Our analysis draws first on self-reported data collected from interviews with nine of these teachers, and then on data collected from three of those teachers whose practice we observed. This includes lesson observations, post-observation 
interviews and student questionnaires. We wanted to be able to include more teachers in this stage but, as explained later, a number of reasons precluded this. We report on the initial interviews in the first section of this chapter. We will report on the three volunteer teachers' implementation of TBLT in the second section of this chapter.

\section{Section I: Bringing TBLT to practice}

In order to establish how the teachers' practices were influenced by what they had learned about TBLT, we interviewed them in the year following the TPDL programme. We were interested in finding out what they had learned from the programme, how they were incorporating this learning into their practices, and the factors which enabled and constrained the implementation of TBLT. Given the challenges of TBLT as an innovation (East, 2014a; Erlam, 2016a; Shintani, 2016), we wanted to understand the conditions that might hinder or enhance its implementation in school classrooms.

Nine teachers responded positively to our invitation, two teachers were not teaching languages that year, and three did not respond to our communications. We still felt that interviews with almost $65 \%$ of the original group would provide insights into the implementation of TBLT after the year of TPDL. Those who agreed, participated in short interviews within 6 months of the end of the programme. According to teacher preference, seven of these interviews were conducted by phone and two by email. The interview questions were divided into three sections (see Appendix 3). In the first, we aimed to establish the impact that the TPDL programme had on the teachers. The second section focused on the teachers' views of TBLT and its status in their current practice. If the teachers reported that they were using TBLT, they answered questions from a third section, describing how they were using tasks in their classrooms. A synthesis of results is presented in the following sections.

\section{Impact of the TPDL professional learning programme}

As teacher educators and researchers, we wanted to know how the TPDL programme had influenced the teachers' practices. Although an evaluation of the elements of the programme is beyond the scope of this book (see Chapter 1 for programme details), we wanted to establish the teachers' overall reflections on changes to their practices resulting from their participation in TPDL. 
The follow-up interview started with an open question about what learning had been most significant for the teachers. In other words, we did not ask specifically about TBLT but purposefully decided to include such an open question to ascertain the teachers' candid views on the impact of the TPDL programme. Most of the replies (seven out of nine teachers) to this open question alluded to learning about tasks as being most significant. Some of these answers indicated the positive impact of this innovation, with Danielle considering learning about TBLT as "an eye opener." Other answers pointed specifically at the teachers' perception of increased understanding of what a task is, knowledge of a task sequence, the effectiveness of tasks, and the benefits of learning about a variety of tasks. We will return to these replies in another section where we focus on TBLT.

The teachers also mentioned broader aspects of second language acquisition and language teaching as significant learning. Two teachers mentioned that learning about Ellis's Principles of Instructed Second Language Acquisition had been most useful. Another two teachers mentioned learning about the importance of input and of consistent use of the target language for students' language acquisition. Even more broadly, two teachers mentioned that shifting their view to see the importance of an emphasis on communication in language learning was the most significant learning. Two conflicting answers alluded to the importance of learning about language learning theory: whereas David found the connection between theory and practice a valuable aspect of the programme, Amanda would have wanted less emphasis on the theory (which she said she already knew) and more time devoted in the course to practical aspects of task implementation. In short, teachers' answers to the initial open question indicate that their engagement with research during the course they took as part of TPDL had introduced them to new concepts pertinent to language teaching. The answers also indicated that this new learning may have resulted in some emerging conceptual changes (Kubanyiova, 2012) about their practice, similar to those which we documented in the previous two chapters.

Other elements of the TPDL programme mentioned in the interview included the professional support provided, the collaborative space to network with colleagues, and the opportunity to reflect and inquire into their own practices. Overall, the participants conveyed a positive disposition towards their professional growth (Ogilvie \& Dunn, 2010) in a programme which had been conducted in a supportive and sustained manner. 


\section{Changes to practice}

Although there are glimpses of conceptual change in the answers provided earlier, the expected outcome of any professional learning programme is the identification of changes in practices. We considered TBLT an innovation in the sense that it "attempt[ed] to bring about educational improvement by doing something... new or different" (Carless, 2013, p. 1). Therefore, in the interviews we specifically asked the teachers how their language teaching practices had changed after their participation in the TPDL programme.

All teachers claimed that their practices had changed and they mentioned a number of areas where they felt these were visible. Both Ashley and David explicitly talked about how their practices had moved away from what they described as more traditional language teaching, which characterised the settings where they had been previously teaching, to viewing their language teaching in terms of communicative practices. However, they also admitted that they were finding the change to TBLT difficult (as will be documented later in the chapter). Ashley regretted not being $100 \%$ consistent with the changes she had planned to make when she had finished TPDL. Another two teachers described a broad shift in their approach to language teaching towards being more learner-centred and more focused on communication. Melissa's reply illustrates this shift when she said, "learning the language is not only about the language but instead with enriching their [the students'] lives with communication."

Some teachers described changes, resulting from their learning about TBLT, in their use of the target language. Four referred to increases in the amount of target language being used in their classrooms, by them, but, more importantly, by their students. Sara, for example, stated that "it's clear to me that they [the students] have to be doing the talking, not me. And if I have to be talking, I have to be talking in Spanish." Also in relation to greater use of the target language, two teachers made particular mention of wider use of formulaic expressions as the main change in their teaching.

In short, evidence from interview data shows that an outcome of these teachers' participation in TPDL was that their reported practices were aligned with placing communication at the core of language teaching, an expectation of the New Zealand Curriculum for languages. The teachers had started to realise that "a language is best learned through the effort to use it communicatively" (Ellis et al., 2020, p. 23). Comments about the role of tasks were further examined in the second part of the interview reported next. 


\section{TBLT and language teaching}

In this section, we will look at responses from the participant teachers regarding TBLT. We first wanted to establish the teachers' opinions of the alignment of TBLT with the New Zealand educational context. Next, we sought the teachers' views on TBLT as a language teaching methodology. Most of their responses in the interviews confirm what we have found in our analysis of the assignments reported in the previous two chapters. It seemed that after some time to reflect on their learning during TPDL, these teachers had been able to reframe aspects of their teaching.

\section{Alignment of TBLT with the New Zealand Curriculum}

We first wanted to establish how the teachers perceived an innovation such as TBLT within their own professional context and, more broadly within the New Zealand educational context. Consistent with what we reported in the two previous chapters, the nine teachers agreed that TBLT aligned well with some of the characteristics of the New Zealand Curriculum. A few teachers elaborated. Two mentioned how TBLT was a good fit to the open, flexible and student-centred national curriculum. Amanda specifically mentioned how TBLT matches the key competencies defined in the curriculum, encouraging students to be autonomous and use their own resources (in key competencies terms, the students "manage themselves"). These answers indicate these teachers' identification of philosophical alignment between TBLT and holistic, experience-driven pedagogies (Samuda \& Bygate, 2008).

In terms of alignment for language teaching, both Elizabeth and David mentioned how, by using TBLT, they were meeting the expectation of the New Zealand Curriculum for languages to position communication at the core of language learning. Finally, Danielle identified how TBLT suited national assessment that privileged assessment of skills rather than knowledge. These responses are positive in the sense that they indicate an acknowledgement by the teachers of a crucial aspect of an educational innovation, a good fit with existing curricular expectations and a recognition of common goals and features (Carless, 2013). 


\section{TBLT as a language teaching methodology}

We asked these nine teachers their opinions of TBLT as a language teaching methodology. After analysing the teachers' descriptions and establishing their sentiment towards TBLT, we have located some of the key words they used in the following continuum where we provide the qualifiers that the teachers used to describe TBLT. Their descriptions ranged from highly enthusiastic expressions such as "a revelation" or "great" to expressions of how useful TBLT was perceived (Figure 3).

\section{A revelation Great Effective Relevant Interesting Useful Applicable Workable}

Figure 3. Continuum of teachers' descriptions of TBLT

Some of the answers to this question included lengthy descriptions from three of the teachers of their TBLT journey. Ashley, for instance, described how her teaching of languages had been "totally traditional" in the UK where she had taught for 9 years before coming to New Zealand. The opportunity to participate in the TPDL programme had been a welcome introduction to the expectations of the New Zealand Curriculum with its emphasis on communication. She had been completely unaware of TBLT and considered it "a revelation." She went on to detail how the course readings and sessions opened "a new world of possibilities for teaching languages." David explained how he had learned about TBLT in his initial teacher education programme in New Zealand. He admits having been initially "cynical about TBLT." He tried implementing his learning yet abandoned it quickly. He acknowledged that TPDL gave him the right amount of support "on the ground" to "give it [TBLT] a second chance." In particular, he discovered the importance of pre-tasks as a way of scaffolding the students to embark on the tasks "naturally." David concluded that he now considered TBLT as an effective methodology. Like David and Ashley, Melissa conceded that the course made her understand "what students bring to language learning" and described how she changed her approach to "focus on them [the students] using the language." These teachers' reflections indicated that they benefitted from the opportunity to learn about TBLT as an innovation.

Despite the enthusiastic responses, seven of the teachers qualified their answers, adding "but it has to be combined with something else" (Amanda), or "it's not the only valid approach" (Danielle), or "but you won't be able to do it [incorporating a task] all the time" (Melissa). Michelle alluded to TBLT having "constraints." Finally, for Eric, the difficulty for using TBLT in New Zealand was "the New Zealand assessment structure" which did not support TBLT, an answer which contrasted with Danielle who saw full alignment between TBLT and the goals of the current assessment regime. We will explore these reservations in the section on constraints. 
What was evident at this point in the follow-up interview was that the teachers had developed a critical view of TBLT whereby they could identify both opportunities and limitations in what TBLT offered them as a language teaching methodology. The responses to the initial part of the interview were brief and seemed to indicate an acknowledgement from the nine teachers of the potential of TBLT, yet an ambivalence about embracing it in their practices.

\section{Implementing TBLT}

The last part of the interview focused on asking the teachers about their experiences implementing TBLT in their classrooms after finishing TPDL. Eight teachers reported using tasks in their language teaching. Ashley was the only one who admitted being "disappointed for not implementing TBLT this year at all." She attributed this to lack of time as she worked only part-time and her busy teaching load "leaves no time to think about tasks." Despite this, she claimed that her teaching included more interaction than before. She described how, as a result of her participation in TPDL, she tried to establish if the activities she planned met the criteria for task saying: "I've gotten to the habit of [thinking] task/no task."

The eight teachers who mentioned using tasks reported differences in the frequency and way they were implementing these. Amanda, Melissa and Sara reported using tasks every lesson; David and Elizabeth reported using tasks regularly but not every lesson; and Michelle, Danielle and Eric reported using tasks only sporadically.

\section{The roles of tasks}

Teachers' replies to the question about how they were implementing tasks indicated wide variation in the roles they were ascribing to tasks in their teaching. Two described specific roles for their use of tasks, with Amanda mentioning using tasks only to teach vocabulary and Sara describing how she had turned all the games she used into tasks as opportunities for interaction (we will see illustrations of Sara's games in the second section of this chapter). The responses provided by David and Elizabeth indicated that they were regularly planning their lessons with tasks. In other words, tasks had a stronger pedagogical presence for them. In the responses to the interview sent by email, Elizabeth described that "in planning, I often start from 'my task' and work backwards." It seemed that, for her, tasks were central to her planning and lesson structure.

For David, tasks had a key role in planning. He reported that he decided to start implementing TBLT with his beginner students only, providing an explanation of the sequence that he follows, that is, building the students' fluency and confidence 
in using the language first with extensive use of formulaic expressions, games and simple tasks. He considered this method of planning his courses around tasks "an absolute success... they [the students] don't realise that with every game and every little task they are using a lot of language that then can be used more formally and extensively for other purposes."

For Melissa also, tasks provided her teaching programme with an organisational structure. In the interview she described how she had rewritten all her lessons to include at least one task in each. She went on to explain how her classes were more motivating as a result of having more tasks. She described her learners as being more engaged and enjoying learning Chinese because "the tasks make it [learning] more challenging and enjoyable at the same time." The interview data demonstrated that the teachers in this study assigned different roles to the tasks they were using. These ranged from specific uses of tasks within lessons (for example in the games used by Sara) to tasks becoming central to planning lessons and the entire programme (as reported by Melissa, for example). Overall, given the autonomy they can exercise in their curriculum, the teachers seemed to be selective with elements of TBLT, combining these with other pedagogical elements in their lessons.

In conclusion, our analysis of the teachers' self-report information of their practices indicated wide variation in their implementation of tasks. For some of them, tasks were being used at the level of activity, which Long (2015) considers "pedagogic tasks." In other words, these teachers included tasks in their lessons (with different frequency, ranging from sporadically to every lesson), yet the task was one of a number of activities and not necessarily the defining feature of the lesson. Even Melissa and David who seemed to be including tasks more intentionally in their planning were not describing their teaching as TBLT. Overall, we conclude that the key role that tasks had for these teachers was as "pedagogical tools" (Samuda \& Bygate, 2008). The next section will provide more information on the reasons for these variations.

\section{Enablers and constraints for implementing TBLT}

We now turn to examine the data to understand the factors that, according to these teachers, promoted or hindered their use of tasks in their classrooms. To do this, we analysed answers to the interview questions and identified teachers' responses that referred to factors influencing their implementation of TBLT. We then classified these as either "enablers" or "constraints" for implementing TBLT. While similar typologies have focused mostly on barriers, we found these terms useful to determine our own categories. For example, Adams and Newton (2009) proposed a typology classifying the barriers to adopting TBLT, specifying factors related to institutional culture, classroom teaching and teacher development. In synthesising research examining 
barriers to the implementation of TBLT and Communicative Language Teaching, Butler (2011) identified factors at conceptual, classroom and societal/institutional levels. When discussing barriers to innovation, Carless (2013) identified factors related to the teacher, the system and to the school (including learners). Our analysis of interview data resulted in our classifying the factors mentioned by the teachers according to three categories: factors at system, at teacher and at student levels (see Tables 15 and 16).

Table 15. Enablers to implementing TBLT

\begin{tabular}{|c|c|c|}
\hline System level & Teacher level & Student level \\
\hline $\begin{array}{l}\text { Alignment with the New } \\
\text { Zealand Curriculum }\end{array}$ & $\begin{array}{l}\text { Having learnt about a different } \\
\text { way to teach languages }\end{array}$ & $\begin{array}{l}\text { Increase motivation and } \\
\text { engagement }\end{array}$ \\
\hline $\begin{array}{l}\text { Alignment with aspirations of } \\
\text { the FL curriculum }\end{array}$ & $\begin{array}{l}\text { Provide structure and } \\
\text { organisation for teaching }\end{array}$ & Develop fluency \\
\hline \multirow[t]{2}{*}{$\begin{array}{l}\text { Alignment with assessment } \\
\text { requirements }\end{array}$} & Support to reflect on practice & $\begin{array}{l}\text { Use the language for } \\
\text { communication }\end{array}$ \\
\hline & & Differentiate learning \\
\hline
\end{tabular}

\section{Enablers to implementing TBLT}

Consistent with what we reported in the section on TBLT and language teaching, the teachers identified clear benefits to implementing TBLT at system level. In particular, there was agreement about the strong alignment between TBLT and the curriculum with its emphasis on flexibility and student-centred learning, as well as on developing competencies such as autonomy and resourcefulness. Similarly, alignment was mentioned with the FL curriculum expectation of a focus on communication. A couple of mentions were made about how TBLT supports the skill-based focus of the national assessment system.

At teacher level, interview responses indicated that the teachers had identified different benefits from incorporating TBLT into their practices. For some, TBLT was a new approach which fitted with their pedagogical views. A couple mentioned TBLT supporting them at managerial and pedagogical level. Melissa, who had made tasks the core of her programme, stated that TBLT had "helped me organise my teaching." Individual mentions were made of how the teachers' involvement in learning about TBLT encouraged reflection on their practices.

The factor most mentioned by teachers was the increase in engagement and motivation they had seen in their learners when using tasks. Several teachers described their students finding TBLT motivating, engaging and enjoyable. Other benefits for learners were that TBLT promoted confidence, encouraging some students to be 
more creative, take initiative and risks while engaging with tasks. In terms of language learning, the teachers also mentioned TBLT supporting the development of oral fluency in the target language ("more use of the target language"; "getting the students to speak") as well as use of the language for communicative purposes ("making their own meaning"; "overall more competent in communication"). An interesting benefit that three of the teachers mentioned was that TBLT supported differentiation in learning, as the same task could be set for different types of learners.

\section{Constraints to implementing TBLT}

Two interview questions gave teachers opportunities to describe limitations to implementing TBLT in their contexts. Question 6 asked the teachers to identify any disadvantages of TBLT, while Question 10 asked whether there was anything that made implementing TBLT difficult in the classroom.

Table 16. Constraints to implementing TBLT

\begin{tabular}{lll}
\hline System level & Teacher level & Student level \\
\hline Time & Time & Preference for teacher-led activities \\
Busy teaching load & Access to resources & Limited language at beginner level \\
Support for innovation & Understanding and designing & $\begin{array}{l}\text { Conflict with preferred learning } \\
\text { styles }\end{array}$ \\
& $\begin{array}{l}\text { tasks } \\
\text { Predicting language needed } \\
\end{array}$ & \\
& by students & \\
\hline
\end{tabular}

Responses overwhelmingly indicated time as the major disadvantage and the main factor for not implementing TBLT. In examining responses, we considered time both at system and teacher level. At system level (i.e., factors beyond the teachers' control), six teachers mentioned needing more time in the school timetable to teach languages with TBLT, which "requires carefully sequenced and scaffolded instructional sequences" (Michelle). Three specifically mentioned their busy teaching load as a barrier. On the other hand, David identified lack of institutional support as he described his language department was "traditional on their views of language and therefore did not support innovations such as TBLT."

At teacher level, time was again the major barrier to implementing TBLT. Most teachers concluded that it was the lack of available time to plan for tasks that was the greatest limitation to using TBLT. They described having to design their own tasks as too time consuming. A contributing factor was the mention of the unavailability of resources for TBLT classes with Amanda saying "it would be totally different if we had access to ready-made tasks." Four teachers said that, although all language teaching required time to plan and create resources, they found teaching with tasks 
meant that they had to "invest extra time creating resources for each task that seems to require unique resources" (Sara).

Other teacher-related limitations referred to the process of designing tasks. Michelle, for instance, considered following the criteria for tasks a limitation, particularly the "need to be able to predict in advance any language students may need, and pre-teach it in order for them [the tasks] to truly satisfy the criteria of using their [the students'] own linguistic resources." Both Elizabeth and David mentioned that designing tasks to cater for the level and diversity of their students was a barrier in the sense that the teacher had to take into account so many variables in their lesson design that it became "overwhelming to check so many things" (Elizabeth).

Only a few answers mentioned constraints referring to students. A couple of mentions were made of TBLT not being suitable for students who preferred more traditional, teacher-led activities. For example, Amanda seemed to allude to the students' lack of familiarity with tasks when she mentioned that some of her students did not engage with tasks because they found them overwhelming and preferred teacher-led activities. Two teachers referred to how beginner learners did not have enough language to participate in oral tasks. We interpreted that Sara's mention of her beginner students' "lack of access to the language" was attributed to their low proficiency. Similarly, Elizabeth observed that she was limited in the oral tasks she could use with her beginner learners of Chinese. In contrast to limitations ascribed to low proficiency, both Danielle and Eric, who taught senior students, commented on the students' preferred learning styles as a limitation since, in their experience, more advanced students prefer to learn the language more deductively. Some of the teachers' comments in this section reflected, in our view, incomplete understanding of TBLT. Teachers did not seem to realise that with beginner learners, input-based tasks might be used where oral output tasks might not, nor did they seem to realise that TBLT does not preclude a deductive approach to language learning.

On the whole, our analysis of the enablers and constraints to implementing TBLT confirm those identified in the literature (e.g., Erlam, 2015a; Müller-Hartmann \& Schocker-von Ditfurth, 2018; Van den Branden, 2016).

As reflective practitioners, teachers approached their new learning about TBLT with positive dispositions (Ogilvie \& Dunn, 2010), yet with discernment which resulted in eclectic practices (Van den Branden, 2009). As widely documented in the TBLT literature, the "realities of using tasks in the classroom are not always straightforward" (Calvert \& Sheen, 2015, p. 227). The implementation of any innovation is a complex endeavour that involves a gradual process of learning where teachers "mould" (Carless, 2004) the novel content to their own contexts and their own practices. The second section of this chapter will document the participating teachers' practices thus allowing for a more direct examination of how they were starting to implement TBLT. 


\section{Section II: TBLT in the classroom}

This second section will analyse data from teachers' practices. We are, therefore, moving into classrooms to examine how teachers implement TBLT in the real world of practice after having participated in a programme of professional learning. By following the teachers into their classrooms, we will better understand how they have been influenced by what they have learned and how their initial theoretical engagement with ideas from TBLT is enacted. As mentioned before, this chapter documents our follow-up of nine teachers who had volunteered to let us examine their implementation of TBLT in their normal language teaching. Five of these initially volunteered to be observed, but we were only able to conduct observations as planned with three teachers. From these, two taught in primary and one in secondary schools. The low number of participants in this section limited the conclusions that we were able to draw, yet we still found value in reporting on these teachers who were part of the initial dataset. Their experiences add insights to our understanding of the realities of implementing TBLT.

Besides collecting data on implementation, the observations of practice provided evidence of opportunities for student learning. The data included lesson observations, post-observation interviews with the teachers, and short written questionnaires that collected views from students. The lesson observations (conducted by one of us as researchers) were scheduled according to the availability of the teachers. We had aimed to observe two lessons from each teacher so that we could see different aspects of the implementation of tasks, yet this was only possible with David. We collected evidence during the observed lesson from classroom materials, researchers' notes and transcriptions of teacher discourse as well as transcriptions of student discourse and questionnaires completed by students after the observed lesson. These questionnaires aimed to collect students' responses to what they had learned in the lesson, their views on their level of enjoyment of the lesson, their self-perception of difficulty in learning the language, and what they had liked or not liked about the lesson (see Appendix 4). After the lesson, we interviewed the teacher to provide context to what was observed, collect their reflections on the lesson and the task/s observed, and to discuss their decisions. These post-observation interviews complemented information gathered about each of these teachers in the initial interviews reported in Section I of this chapter.

Data from each teacher will be presented separately and then any commonalities and differences across the teachers will be examined. For each teacher, we will provide a brief contextualisation of the setting where they were teaching and information about their language learning and teaching histories. We then present the description of the lesson/s observed, focusing on the task nominated by the teacher. In order to ensure consistency in the way that all tasks presented in the book are 
described, we include the analysis of the task in a table, thus corresponding to how tasks are presented in Part 2 (see Chapter 5). Here we identify aspects such as goals, language skills involved, relationship of the task to previous work and so on. In the following section we present our evaluation of the task using the Ellis and Shintani criteria. Part of the data collection included voice recordings of the learners' and teachers' discourse. For each teacher, we selected a representative excerpt of the interactions motivated by the task being analysed. These included teacher-student discourse and student-student discourse. We looked for illustrations where engagement in the task prompted use of the TL.

\section{Teachers' practices}

Sara - teaching Spanish to Year 1 students

Sara spoke English as an L1 and had learned Spanish in South America where she worked as a teacher assistant for 5 years. On her return to New Zealand, she became a primary teacher and had been working in the school where we observed her teaching for over 3 years. She was the classroom teacher for Year 1 (5- and 6-year-old students) and also taught Spanish to Years 7 and 8. To complement her generalist teaching qualification with education on how to teach foreign languages, she had participated in the TPDL programme. After TPDL and on her own initiative, Sara started offering Spanish lessons before school once a week for 30 minutes to volunteer students from her Year 1 class. When we contacted Sara, she wanted us to observe her teaching Spanish in the extracurricular format where she said that she was implementing some of the tasks that she had taught her primary-aged children. Although the conditions of this class were different to regular timetabled school teaching, it is not uncommon for languages to be taught in these informal formats in New Zealand primary schools. We decided to include Sara in the study as, being part of our initial data set, we wanted to see how she might be implementing learning about tasks and TBLT in her instructional context.

At the time of our observation of one of these extracurricular lessons, there were 10 students who attended regularly before school, some of them with their parents and other siblings. Some had been in Sara's regular class in the previous year where she had incorporated Spanish once a week. The interest of these learners (a couple with Spanish heritage) and of some of her current students motivated Sara to continue with these extracurricular lessons. 


\section{Observed lesson}

On the day of the observation, seven students participated in a lesson focused on food that included three short tasks. During the observed 30-minute lesson, Sara and her students were engaged in three types of interactions: (1) an initial task where students were setting the table on laminated placemats while engaged in dialogues; (2) a task to describe like and/or dislike of food items (with actual food provided by Sara); (3) a vocabulary game with dominoes.

\section{Main task}

Setting the Table describes what we consider the main task in Sara's observed lesson and analyses the extent to which it fulfilled the task criteria (presented in Table 17).

Sara's task: Setting the table

\section{Task objectives/goals}

Brief interactions to inquire about food-related items to complete placemats (e.g., "tienes un plato?"/do you have a dish?) (see Photo 1)

Talking about food

\section{Learning intentions}

Using "do you have? I have/don't have"

\section{Skills involved}

Spoken production

Listening comprehension

\section{Relationship to previous work}

This was the fourth lesson on the topic of food. The class had already worked with some vocabulary for food items including items to set a table. They had also been introduced to like/dislike.

\section{Pre-task}

Brief review of food items. Teacher modelled the dialogue with one student.

\section{Task input / resources}

- laminated place mats with drawings of typical items (e.g., cutlery, cups)

- bags containing items required to set the table (see picture).

\section{Task instructions (given mostly in Spanish)}

Students told to interact with peers to set the table, using the laminated placemats, with items placed inside bags.

\section{Task implementation}

Pair work task that required the students to identify the items that were missing in their placemats and see if their partner had the missing items in their bags. The students interacted with each other and the teacher to ask for the items using the question and answer "Tienes X?" (Do you have?), "Si tengo" (Yes, I have) or "No tengo" (I don't have). 


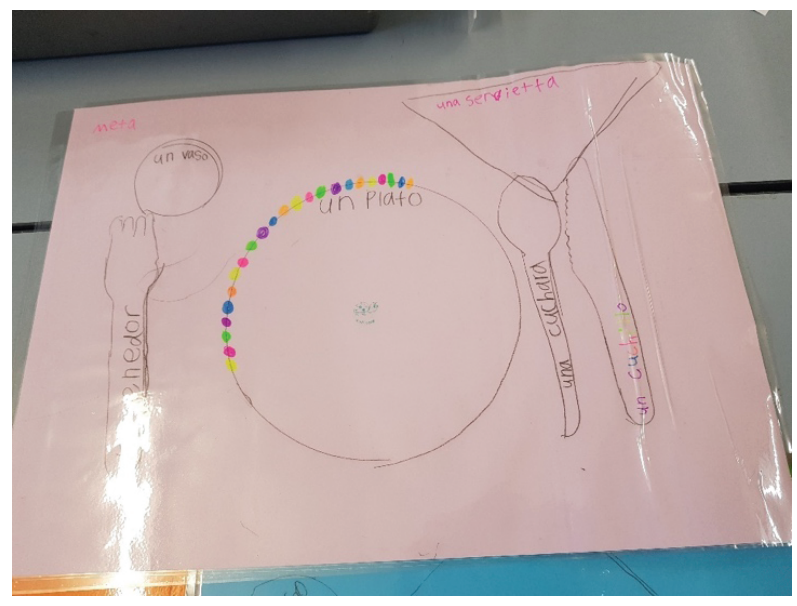

Photo 1. Picture of the placemat

Our analysis of the placemat task indicates that it fulfilled the four criteria for tasks.

Table 17. Evaluation of task against task criteria

\begin{tabular}{|c|c|c|}
\hline Criterion & Fulfilled? & Comment \\
\hline Focus on meaning & yes & $\begin{array}{l}\text { Students had to communicate meaning to complete their } \\
\text { placemats. }\end{array}$ \\
\hline Some kind of gap & yes & Students did not know if their peers had what they needed. \\
\hline $\begin{array}{l}\text { Rely on own } \\
\text { resources }\end{array}$ & yes & $\begin{array}{l}\text { Students were using language already learned previously, with } \\
\text { the teacher modelling the dialogue immediately before the task. }\end{array}$ \\
\hline Outcome & yes & The completed placemat. \\
\hline
\end{tabular}

Example of interaction (teacher and student discourse)

The excerpt in Example (1) illustrates the type of language use and interactions, which often demonstrated use of both English and Spanish, Sara had with her students. A girl had arrived after the instructions had been given, so Sara, in this excerpt, was demonstrating the purpose of the game.

Although the dialogue asking for "having or not having food-related items" was the focus of this interaction, it is evident that Sara used more language than just this question-and-answer pattern. In this way she was able to extend the language input given to students by including other language forms and authentic language about what was happening around them. The small size of the group allowed Sara to constantly interact with the seven learners and ensure they were engaged in the class activities. 
Example 1. Excerpt from interaction in Sara's lesson

\begin{tabular}{|c|c|c|c|c|}
\hline Turn & Interlocutor & & Translation & Researcher comment \\
\hline 1 & Teacher & $\begin{array}{l}\text { Esta es de Emma, pero } \\
\text { vamos a usarla. Esta es } \\
\text { la tuya. ¿Tienes un plato? } \\
\text { ¿Tienes un plato? Sí tengo } \\
\text { o no tengo. ¿Vale? Yo } \\
\text { quiero por favor. Yeah? } \\
\text { Vale. ¿Tienes un vaso? } \\
\text { ¿Un vaso? }\end{array}$ & $\begin{array}{l}\text { This is Emma's, but we're } \\
\text { going to use it. This one } \\
\text { is yours. Do you have } \\
\text { a plate? Do you have a } \\
\text { plate? Yes, I do have one } \\
\text { or no I don't have one. } \\
\text { Okay? I want it, please. } \\
\text { Yeah? Okay. Do you have } \\
\text { a cup? A cup? }\end{array}$ & $\begin{array}{l}\text { The teacher interacts with } \\
\text { the student who has just } \\
\text { arrived by modelling the } \\
\text { vocabulary and question / } \\
\text { answer focus of the } \\
\text { interaction. }\end{array}$ \\
\hline 2 & Student & No & & \\
\hline 3 & Teacher & $\begin{array}{l}\text { No tengo, ¡ahh qué pena! } \\
\text { ¿Tienes un tenedor? } \\
\text { ¿Tienes un tenedor? } \\
\text { Ahhh. }\end{array}$ & $\begin{array}{l}\text { I don't have one. What } \\
\text { a shame! Do you have } \\
\text { a fork? Do you have a } \\
\text { fork? }\end{array}$ & $\begin{array}{l}\text { The teacher uses } \\
\text { repetition and elaborated } \\
\text { input, modelling the use } \\
\text { of a formulaic expression } \\
\text { (What a shame) to extend } \\
\text { the reply. }\end{array}$ \\
\hline 4 & Student & Sí tengo & Yes, I have one & $\begin{array}{l}\text { The student answers } \\
\text { correctly using the short } \\
\text { (more natural) form. }\end{array}$ \\
\hline 5 & Teacher & ¿Un ...? & A ...? & $\begin{array}{l}\text { The teacher elicits a full } \\
\text { response. }\end{array}$ \\
\hline 6 & Student & Tenedor & Fork & $\begin{array}{l}\text { The student provides the } \\
\text { response. }\end{array}$ \\
\hline 7 & Teacher & $\begin{array}{l}\text { Tenedor. ¡Muy bien, } \\
\text { Sally! ¿Tienes un cuchillo? } \\
\text { Mira Sally, un cuchillo. } \\
\text { ¿Tienes un cuchillo en la } \\
\text { bolsa? } \\
\text { ¿Qué pasa? ¿Qué } \\
\text { necesitas Andrew? }\end{array}$ & $\begin{array}{l}\text { Fork. Very good Sally! } \\
\text { Do you have a knife? } \\
\text { Look Sally, a knife. Do } \\
\text { you have a knife in the } \\
\text { bag? } \\
\text { What happens? What do } \\
\text { you need, Andrew? }\end{array}$ & $\begin{array}{l}\text { The teacher praises the } \\
\text { use of the correct word. } \\
\text { The interaction is } \\
\text { interrupted because } \\
\text { the teacher turned her } \\
\text { attention to another } \\
\text { student. }\end{array}$ \\
\hline
\end{tabular}

\section{Student voice}

Given the young age of Sara's learners, the questionnaires used a child-friendly format with face expressions to represent the scale of satisfaction corresponding to a Likert scale (e.g., happy face for "I liked" and sad face for "I did not like"). Some of the children wrote their own answers to the open-ended questions (e.g., What did you learn today in the Spanish lesson?) and others dictated their answers to Sara. The questionnaires were completed by six of the seven students present. All agreed that they had enjoyed the lesson and in particular they liked the food provided. 
Their responses to the question "What did you learn in the lesson?" indicated that they all had clarity of the focus on food items and all, except for one, demonstrated that they remembered these by listing them.

\section{Teacher reflections}

In the post-lesson interview, Sara self-rated her lesson as successful because it was implemented as she had planned it. She commented “... successful when I look back here in terms of, well you'll read they enjoyed the food factor. So that was engaging for them. Yes, and I could hear them talking... in Spanish." For Sara, success with this volunteer group of 5- and 6-year-olds had to do with their motivation and with the extent of their target language use. From our observation, it was evident that the students were motivated enough to arrive early to school to learn Spanish. They participated enthusiastically in interactions and used the target language they knew authentically.

Later in the interview Sara identified how understanding about tasks had influenced her teaching and her learners' motivation and learning: "It's meant more engagement from the children." She then reflected that tasks had "impacted on me by always having to think... about how much talking I'm doing and giving more power to the children to use the language." She further elaborated when she provided her definition of tasks:

something that they've got the vocabulary for, that they've developed, or have access to.... That they could have an exchange of language, and I know that that can be either talking and listening or, you know, a reading and writing thing. And then actually completing something.

She illustrated this further referring to the observed lesson: “... the game or the task was to complete their... placemat with objects and that someone had to listen to what they wanted and then they had to confirm that they actually got the right thing." Sara's explanation indicates her awareness of the different criteria of task: having an outcome (completion), using own resources (they've got the vocabulary), focus on meaning (have an exchange of language), and a gap (confirm they actually got the right thing). For Sara, learning about tasks had shifted her to be more learner-centred in her teaching and more focused on using the language for communication, as in this lesson.

Reflecting on the impact of learning about TBLT on her teaching, Sara acknowledged that her journey to become a teacher of languages involved what she called "unlearning." That meant not approaching language learning as she had: "writing 
out... conjugations [laughs] and I realise in reflection I was very much a paper, pen and textbook learner." Sara reflected that after TPDL, she had realised "to learn colours is not just to learn the colours, it has to be some kind of meaningful exchange." She was illustrating that the big shift for her was that communication became the core of language learning and teaching. She continued, "I try to make every lesson at least an exchange of conversations," and she concluded, "All I keep in my mind to be honest is communication, communication."

\section{Conclusion - Sara}

In our analysis we conclude that Sara seemed highly motivated to use tasks in her teaching. The fact that her students volunteered to come to school early one morning a week to learn Spanish confirms their motivation and engagement. We collected evidence of her interest in creating opportunities for interaction and in making language learning an enjoyable experience. More importantly, as evident in her lesson, Sara had redefined her own views, moving from an emphasis on the learning of isolated vocabulary items to the use of the $\mathrm{L} 2$ for communication.

\section{Melissa - teaching Chinese to Year 2 students}

Melissa speaks English as L1 and, at the time of the study, had been learning Chinese for 2 years. She taught in a primary school that offers Chinese to all students from Years 2 to 6 . Melissa was in charge of developing the programme and designing the lessons for all school levels. Most of the classes were delivered by native Chinese tutors. Melissa said that she always included a task in her lessons. The lesson we observed was one of the Year 2 (6-year-old pupils) classes that Melissa taught on Fridays for 45 minutes. At the time of the observation, this beginners' class was finishing their first year of Chinese. There were normally 30 students in the class, although only 23 were present on the day of the observation; of these, six were heritage speakers of Chinese who Melissa called “the experts." Melissa's task: Describing the Colour of Hair and Eyes describes the main features of the task-based lesson on the topic of Physical Descriptions. The lesson started with different Chinese language routines that included, introducing the researcher, greeting classmates in circles and a Guess Who game. It was evident, from the beginning, that the students were confident in using Chinese to communicate and enjoyed the class and that Melissa provided extensive input. The main task of the lesson was focused on physical description, in particular describing hair and eye colour. 
Melissa's task: Describing the colour of hair and eyes

\section{Task objectives/goals}

Brief oral interactions where students establish the hair and eye colour of stick figures

\section{Learning intentions}

Describe hair and eye colour

\section{Skills involved}

Spoken production

Listening comprehension through correctly colouring the stick figure

\section{Relationship to previous work}

Class had been working on a unit on "Describing ourselves" and had already covered the language of basic physical descriptions, and the language for family and colours.

\section{Pre-tasks}

A Guess Who game where Melissa pretended to be a well-known person describing himself with wrong information (e.g., an adult pretending to be an 8-year-old) which the students clearly recognised as wrong.

Melissa introduced the topic of the day and described her own hair and eye colour with erroneous information which was also recognised by the students. She used the structure required for the interaction and drew the students' attention to it.

\section{Task input / resources}

- a sheet of paper with a number of stick figures that have different hair and eye colour (one per student)

- coloured pencils

- the structures required for the description were written on the whiteboard.

\section{Task instructions (given mostly in English)}

Melissa introduced the task: "Today you are going to get a sheet like this with a picture of a boy/girl. We have special little people [stick figures]." Students were to pick a stick figure already coloured and write their name under it. They could select a figure whose colours did not necessarily match their real appearance. They had to describe their selected figure to their partner without showing the picture. The partner had to draw the right colour of hair and eyes in their sheet. Each pupil had to go around the room and ask as many classmates as possible. Melissa encouraged them to complete both sides of the sheet (about 24 figures).

After giving general instructions, Melissa demonstrates the dialogue with a heritage speaker.

我有棕色的眼睛和棕色的头发。 [I have brown eyes and brown hair]

As she interacts with the heritage speaker, she draws the students' attention to the sentences and the instructions.

\section{Task implementation}

Students moved around the room working in pairs, each student had their own stick figure and, as they interacted, completed their worksheet colouring other stick figures. 
Table 18. Evaluation of task against task criteria

\begin{tabular}{lll}
\hline Criterion & Fulfilled? & Comment \\
\hline Focus on meaning & yes & $\begin{array}{l}\text { Students had to correctly colour a stick figure in } \\
\text { response to a partner's description of their selected } \\
\text { stick figure. }\end{array}$ \\
Some kind of gap & yes & $\begin{array}{l}\text { Students did not know what eye and hair colour their } \\
\text { partner had drawn. }\end{array}$ \\
Rely on own resources & yes & $\begin{array}{l}\text { Melissa described herself to remind them of the } \\
\text { language they already knew and drew their attention } \\
\text { to the structure used in a previous lesson and written } \\
\text { on the board. } \\
\text { Completed sheet with the stick figures coloured. }\end{array}$ \\
& & yes
\end{tabular}

The task planned by Melissa was focused on oral interaction. The students used Chinese for all their interactions and participated willingly in the brief conversations. Given their age and grade level, colouring the stick figures made the task engaging and varied. More importantly, the colouring of the figure provided them with concrete evidence of their listening, and their partner with immediate feedback about their spoken production. Melissa also participated in the task by selecting a stick figure and going around the room interacting with most students, especially those she knew may find the dialogues difficult. The transcript of the recording of teacher discourse during the task included interactions such as those in Example (2).

Example 2. Excerpt from interaction in Melissa's lesson

\begin{tabular}{|c|c|c|c|c|}
\hline Turn & Interlocutor & & Translation & Researcher comment \\
\hline 1 & Teacher & $\begin{array}{l}\text { 我有棕色眼睛。 } \\
\text { 我有棕色的眼睛。 } \\
\text { 和金色的短头发。 } \\
\text { 短, 短。 } \\
\text { 非常好。非常好。 }\end{array}$ & $\begin{array}{l}\text { I have brown eyes. } \\
\text { I have brown eyes } \\
\text { And short blond } \\
\text { hair. Short, short. } \\
\text { Very good. Very } \\
\text { good. }\end{array}$ & $\begin{array}{l}\text { The teacher describes her } \\
\text { stick figure using gestures and } \\
\text { repeating the initial sentence } \\
\text { slowly. } \\
\text { The student colours the stick } \\
\text { figure. } \\
\text { The teacher praises the student. }\end{array}$ \\
\hline 2 & Student & $\begin{array}{l}\text { 我有黑色的眼睛 } \\
\text { 和黑色的短头发。 }\end{array}$ & $\begin{array}{l}\text { I have black eyes } \\
\text { and short black } \\
\text { hair. }\end{array}$ & $\begin{array}{l}\text { The student describes his stick } \\
\text { figure. }\end{array}$ \\
\hline 3 & Teacher & 非常好。 & Very good. & $\begin{array}{l}\text { The teacher draws a stick figure } \\
\text { based on the student's description } \\
\text { and shows the drawing to the } \\
\text { student as she praises him. }\end{array}$ \\
\hline
\end{tabular}


The task went on until the end of the lesson where Melissa asked the students to ensure their task sheets had their names on them and were placed on a pile for her to check later. As a post-task, Melissa asked the class, "Who can stand and tell us the colour of their eyes and their hair?" A couple of students volunteered answers describing themselves and their fellow classmates (and Melissa) decided if the description was accurate.

After the lesson, Melissa reported that she considered the task had been successful in that all the students were engaged and performed to the best of their capability. She explained that she had a number of students with special needs for whom just colouring the figure correctly (i.e., attending to and understanding the input) was a huge accomplishment. On the other hand, she also had some talented students whom she knew would excel and finish all their short dialogues. The discourse of one of those talented students (Sophie) was recorded. According to the transcription, in Sophie's initial three descriptions where she said 我有棕色的眼 睛和蓝色长的头发。(I have brown eyes and long blue hair), she mispronounced “and" (和 he) as hei (黑), which means black. However, in her fourth description Sophie had the interaction in Example (3) with a peer:

Example 3. Second excerpt from interaction in Melissa's lesson

\begin{tabular}{lllll}
\hline Turn & Interlocutor & & Translation & Researcher comment \\
\hline 1 & Sophie & $\begin{array}{l}\text { 我有蓝色的眼睛 } \\
\text { 黑.. 我有蓝色的 }\end{array}$ & $\begin{array}{l}\text { I have blue eyes } \\
\text { black... I have } \\
\end{array}$ & $\begin{array}{l}\text { Sophie mispronounced “and” } \\
\text { again. }\end{array}$ \\
& & 眼睛和棕色长的 \\
& 头发。 & $\begin{array}{l}\text { blue eyes and long } \\
\text { brown hair. }\end{array}$ & \\
& Sophie & 我有蓝色的眼睛和 & I have blue eyes & Sophie repeated her description \\
& 棕色长的头发。 & and long brown & after a long pause. She did not \\
& & hair. & mispronounce “and" this time. \\
\hline
\end{tabular}

It seems that Sophie had self-corrected her own description and when she repeated it, she produced the sentence correctly. From this point of the recording on, she used correct pronunciation. Unfortunately, since a number of children had recorders and several interactions were taking place simultaneously, we were unable to monitor all interactions, including Sophie's. In this case, we cannot establish what triggered Sophie's self-correction. It may have been feedback from her interlocutor, or her own awareness of her pronunciation while producing output. In any case, it is remarkable that, as a 6-year-old, and with exposure to Chinese once a week only for less than a year, the evidence in the recording suggests that she was able to selfcorrect during this task. The recordings from other students provided evidence of their interactions, albeit with errors in accuracy, that, as seen in Example (4), were often corrected by the "experts" (heritage speakers). 
Example 4. Third excerpt from interaction in Melissa's lesson

\begin{tabular}{|c|c|c|c|c|}
\hline Turn & Interlocutor & & Translation & Researcher comment \\
\hline 1 & Moira & $\begin{array}{l}\text { 我有绿色的眼 } \\
\text { 睛॰我有绿色的 } \\
\text { 眼睛和黄色的长 } \\
\text { 头发。 } \\
\text { 我有黄色的长 } \\
\text { 头发。 }\end{array}$ & $\begin{array}{l}\text { I have green eyes. } \\
\text { I have green eyes } \\
\text { and long yellow } \\
\text { hair. } \\
\text { I have long yellow } \\
\text { hair. }\end{array}$ & $\begin{array}{l}\text { Moira seems to be using "yellow" } \\
\text { to mean "blond." } \\
\text { She repeats the description of } \\
\text { the hair probably because of } \\
\text { interlocutor's nonverbal feedback. }\end{array}$ \\
\hline 2 & $\begin{array}{l}\text { Harry } \\
\text { (heritage } \\
\text { speaker) }\end{array}$ & 金色。 & Blond. & $\begin{array}{l}\text { The heritage speaker provides the } \\
\text { word for "blond." } \\
\text { [Recording stops here] }\end{array}$ \\
\hline
\end{tabular}

From the researcher's observations, after the initial interactions where each student was describing their stick figure for the first time, the students carried on more confidently with no use of English. Some of the students were observed looking at the structure that was written as language support on the whiteboard.

\section{Student voice}

In the next opportunity that Melissa had with this class, she gave the students the questionnaire that we had provided, asking for their feedback on the observed lesson. From the 14 questionnaires returned, all the students stated that they had learned hair and eye colours. Eleven students marked in the Likert-scale items that they had found the lesson enjoyable $(n=4)$ or very enjoyable $(n=7)$, with one student not finding it enjoyable and two being neutral. Melissa collected the answers to the last two questions of the questionnaire (requiring them to say what they liked and did not like about the lesson) orally from the whole class. The students reported that they had liked talking to a variety of peers about their stick figures' hair and eye colour. They also liked using the cards with their own little person and having support on the board. Only two comments alluded to what they did not like about the lesson with one student reporting that the task "was hard" and another one reporting not finishing the sheet. To sum up, the questionnaires in Melissa's task-based lesson seem to indicate overall pupil satisfaction. 


\section{Teacher reflections}

In the post-lesson interview, the researcher asked Melissa about her perception of the success of the task as she had intended it (i.e., task-as-a-workplan). She commented that she had tried different types of tasks and her students "love surveys" because "children love talking about themselves." So, she knew that they would engage with the task and with the opportunity to use Chinese in an "age-appropriate" activity, pretending to be someone else and colouring. She also considered that, since the task required students to repeat their description with different partners, it allowed for practice of the target structures, so consolidating learning for this part of the unit. Melissa was taking advantage of the benefits of task familiarity with her frequent use of surveys and task repetition to provide her students with the opportunity to recycle the same language.

When asked about how she assessed her students' progress, Melissa explained that this class was not formally assessed in any way. For her, the assessment was "probably mentally... the fact that $90 \%$ were keen to stand up in front of their peers and try, it is a tick." Melissa appeared to be assessing task effectiveness in terms of her learners' willingness to participate and make efforts to use the language. Since Melissa worked with native Chinese tutors, she had also collected anecdotal information from them. For example, the tutor who was currently teaching Melissa's students from the previous year (when Melissa participated in TPDL and started using tasks) had reported that those students had retained much more of the language than previous years. Melissa saw this as validation, not only of the use of tasks, but also of her own efforts to teach a language she was learning herself. She realised that in her own learning she was modelling taking risks for her students: "it's also powerful that I'm not an expert because I get stuff wrong all the time." We were mindful that Melissa's own level of proficiency in Chinese may be limiting her students' learning, yet she seemed to offset any potential limitation with her use of heritage speakers and the support she received from Chinese tutors.

Melissa reflected how, for her, the decision to offer Chinese was more than just offering a language as "first and foremost I'm about breaking down stereotypes in culture as our school is $30 \%$ Chinese so if the children can appreciate that [the language spoken by the Chinese peers], then they can appreciate Indian children and everyone." She expanded on other gains: "for me the enthusiasm and the desire and the positive nature. I want it to be a positive experience." She considered TBLT to align with features of the New Zealand Curriculum that emphasise "creativity and group work, thinking outside the box, coming up with solutions, it's about challenging yourself, and yeah I think it's a useful way of doing things." When probed as to what she meant by "useful," Melissa said "I think [with TBLT] you have a good blend, like you have input lessons and then you have output lessons. There was a lot of output 
today." Melissa also mentioned that, while she was trying to incorporate one task in every lesson, the limitation was "creating and thinking up tasks." She balanced this limitation with what she considered the greatest benefit of tasks: "it's one of the easiest ways to cope with differentiation." She described how a simple dialogue, like the one in the observed lesson, allowed the heritage speakers to extend the conversations to other topics (as they did in the lesson observed), and those with verbal limitations to only do the colouring (also evident during the observation). She concluded the interview by restating that her goal "is for the children to enjoy the lesson and take part," something which she was clearly achieving.

\section{Conclusion - Melissa}

In contrast to Sara, Melissa was teaching Chinese in a structured programme that she had developed. As she had described in the interview before our observation (see the first section of this chapter), Melissa was using her learning in TPDL to incorporate tasks in her weekly lessons. In particular, she was applying her learning about task criteria to design her own tasks. In other words, her participation in the TPDL programme had had an immediate influence on how she structured the Chinese programme in her school. For her, tasks were central to her lessons and she listed a number of benefits including seeing her students use the language with a communicative purpose, an increased level of motivation and engagement, and the opportunity to use tasks that were age-appropriate (e.g., colouring in) and to embed differentiation within the task. From our observation, Melissa was also targeting language at the right level for her students, scaffolding them to use language independently. Besides these benefits, she also appreciated the alignment of TBLT with the development of other skills such as creativity, resilience, risk-taking, and cultural awareness.

\section{David - teaching Spanish to Year 9 students}

David grew up as a bilingual (Spanish and French) speaker who, at the time of the study, had over 10 years of language teaching experience, six of those in New Zealand. At the school where he was observed, he was teaching Spanish from Years 7 to 11 . We observed two consecutive lessons in a Year 9 class (approximate age 13 years) that met six times on a 7-day cycle and had 23 students. David explained that the class was moving from the topic of school to food by using "telling time" as the connection between the two topics. In both lessons, David had planned information-gap tasks. He said he included tasks in his teaching of Spanish at least twice a week. 
David's task: Completing a school timetable

\section{Task objectives/goals}

Brief interactions with classmates to complete a timetable

Completing a school timetable

\section{Learning intentions}

Using known vocabulary of days of the week, times and school subjects

\section{Skills involved}

Spoken production

Listening comprehension

Writing in a timetable provided

\section{Relationship to previous work}

This was the last lesson on the topic of timetables. Students already knew language for telling time and school subjects.

\section{Pre-task}

Review of telling time and school subjects. As he introduces the task, David builds the language the students will require to ask and answer questions.

\section{Task input / resources}

Copies of different versions of incomplete timetables.

\section{Task instructions}

David provides the scenario "Today you start a new day in a school in Mexico." Then he explains that they will need to find out about the subjects and dates and times by asking their classmates. He models the exact question and answer they had to use with their peers and writes the scripted dialogue on the whiteboard.

\section{Task implementation}

Students go around the room asking and answering questions of their peers. They write down answers in the timetable provided (see Photo 2)

The students were observed interacting with their classmates using the question and answer provided. They seemed comfortable using a range of formulaic expressions. When they needed language support, they would look at posters placed on the classroom walls and boards. The task took approximately 12 minutes, after which David projected the completed timetables and the students used these to check their answers. When evaluating against the task criteria (Table 19) we can see that the timetable task met two of the criteria: a focus on meaning during the interactions and the existence of a gap. On the other hand, David had provided the question and answer before the task and the scenario of starting in a new school was not revisited at the end of the task. Instead, David asked the students to check their answers with those projected on the board. We considered David's timetable task an illustration of a weak version of a task in that it only fulfilled two criteria and partially fulfilled another two criteria (in brackets in Table 19). 


\begin{tabular}{|c|c|c|c|c|c|}
\hline $\begin{array}{l}\text { 11. Institu } \\
\text { Juár } \\
\text { Secunda }\end{array}$ & & \multicolumn{2}{|c|}{$\begin{array}{c}\text { HORARIODE CLASES } \\
\text { GRUP0 } 702\end{array}$} & \multicolumn{2}{|c|}{$\begin{array}{c}\text { CICLO ESCOLAR } \\
2016-2017\end{array}$} \\
\hline HORA & LUNES & MARTES & MIÉRCOLES & JUEVES & VIERNES \\
\hline $7: 00-7: 50$ & GEOGRAFIA & Musica & $\begin{array}{l}\text { HABILIDAD } \\
\text { MATEMÁTICA }\end{array}$ & $\begin{array}{l}\text { ASIGNATURA } \\
\text { ESTATAL }\end{array}$ & tenologia \\
\hline $7: 50-8: 40$ & BIOLOGIA & $\begin{array}{l}\text { LABORATORIO DE } \\
\text { BIOLOGÍA }\end{array}$ & $\begin{array}{l}\text { EDUCACIÓN } \\
\text { FISICA }\end{array}$ & TECNOLOGIAA & TECNOLOGIA \\
\hline $8: 40-9: 30$ & $\begin{array}{l}\text { DESARROLLO } \\
\text { HUMANO }\end{array}$ & MATEMÁTICAS & GEOGRAFIA & BIOLOGIA & GEOGRAFIA \\
\hline $9: 30-9: 50$ & \multicolumn{5}{|c|}{ DESCANSO } \\
\hline $9: 50-10: 40$ & INGLÉS & MÚSICA & INGLÉS & INGLÉS & MATEMÁTICAS \\
\hline $10: 40-11: 30$ & Espanol & GEOGRAFIA & ESPAÑOL & MATEMÁTICAS & INGLÉS \\
\hline $11: 30-12: 20$ & MATEMÁTICAS & INGLÉS & BIOLOGÍA & Cieografia & ESPAÑOL \\
\hline $12: 20-12: 30$ & \multicolumn{5}{|c|}{ DESCANSO } \\
\hline $12: 30-13: 20$ & $\begin{array}{l}\text { EDUCACIÓN } \\
\text { FÍSICA }\end{array}$ & $\begin{array}{l}\text { ASIGNATURA } \\
\text { ESTATAL }\end{array}$ & BIOLOGIA & ESPAÑOL & CERTIFICACIÓN \\
\hline $13: 20-14: 10$ & ESPAÑOL & $\begin{array}{l}\text { LABORATORIO DE } \\
\text { MATEMÁTICAS }\end{array}$ & matematicas & TUTORIA & $\begin{array}{l}\text { ASIGNATURA } \\
\text { ESTATAL }\end{array}$ \\
\hline $14: 10-15: 00$ & INGLÉS & Espanol & ECOLOGÍA & CERTIFICACIÓN & BIOLOGIA \\
\hline
\end{tabular}

Photo 2. Picture of one of the students' completed timetables

Table 19. Evaluation of task against task criteria

\begin{tabular}{|c|c|c|}
\hline Criterion & Fulfilled? & Comment \\
\hline Focus on meaning & yes & $\begin{array}{l}\text { Students had to communicate meaning to complete } \\
\text { their timetables. }\end{array}$ \\
\hline Some kind of gap & yes & $\begin{array}{l}\text { Students did not know what their partner had in their } \\
\text { timetable. }\end{array}$ \\
\hline Rely on own resources & [yes] & $\begin{array}{l}\text { The question and answer were co-constructed between } \\
\text { the teacher and students based on similar structures } \\
\text { they already knew. However, during the task, the } \\
\text { students were relying on the dialogue written on the } \\
\text { board. }\end{array}$ \\
\hline Outcome & [yes] & $\begin{array}{l}\text { Students completed timetables but nothing was done } \\
\text { with the information collected. }\end{array}$ \\
\hline
\end{tabular}

Note:

The use of [yes] indicates that there is partial fulfilment of the criterion 
In the remaining time of the first observed lesson, David connected time with food by asking students what time they ate. David's task: Breakfast Food Preferences provides a description of the second task observed the following day.

David's task: Breakfast food preferences

\section{Task objectives/goals}

Surveying peers to talk about their food preferences at breakfast

\section{Learning intentions}

To identify the most popular breakfast food

To establish who has breakfast the earliest in the class

Spoken production

\section{Skills involved}

Listening comprehension (tallying answers)

\section{Relationship to previous work}

The class already knew time. Talking about times when people eat had been introduced the day before.

\section{Pre-task}

Review of telling time and of verbs used for the different meals.

Introduction of breakfast food vocabulary using pictures David drew on the whiteboard.

Using formulaic language the students already knew, David elicited the possible questions and answers to be used in the survey.

Modelling the survey interaction.

\section{Task input / resources}

The students take notes in their notebooks.

\section{Task instructions}

David sets the scene by telling the class that he is very curious and wants to know what the most popular breakfast foods are, and who in the class has breakfast at an earlier time than the others. He insists that only Spanish should be spoken and that the survey should include him and the researcher.

\section{Task implementation}

Students going around the room asking their peers about the food they preferred for breakfast and the time they had breakfast to establish who had the earliest breakfast. Each student tallied the answers in their books.

The survey took about 20 minutes and, at the end, before dismissing the class, David asked the students what the most popular breakfast food was and who ate the earliest. We next evaluate the survey task. 
Table 20. Evaluation of task against task criteria

\begin{tabular}{lll}
\hline Criterion & Fulfilled? & Comment \\
\hline $\begin{array}{ll}\text { Focus on meaning } \\
\text { Some kind of gap }\end{array}$ & yes & $\begin{array}{l}\text { Students talking about their breakfast-eating habits. } \\
\text { Students did not know about each other's }\end{array}$ \\
Rely on own resources & [yes] & $\begin{array}{l}\text { Steakfast-eating habits. } \\
\text { The students knew some of the language required for the } \\
\text { question and answer, however, vocabulary for breakfast } \\
\text { food had been introduced immediately before the task. } \\
\text { In addition, students mostly read from the board as they } \\
\text { interacted with each other. } \\
\text { The class established the most popular breakfast food } \\
\text { and the person who ate the earliest. }\end{array}$ \\
& yes &
\end{tabular}

The students in David's class engaged in the tasks with some initial degree of reluctance, yet eventually went around the room interacting with each other to complete these. Their level of confidence in using Spanish seemed rather low and, except for the formulaic questions and answers, they mostly relied on using English for understanding. Some of the interactions were more accurate, yet the students did not seem to interact naturally or be genuinely interested in engaging in conversation beyond the structures provided. Most of the recorded interactions were brief and read from the example provided on the board. An example of an interaction with some spontaneity is provided in Example (5).

Example 5. Excerpt from interaction in David's lesson

\begin{tabular}{|c|c|c|c|c|}
\hline Turn & Interlocutor & & Translation & Researcher comment \\
\hline 1 & James & $\begin{array}{l}{ }^{*} \text { ¿A qué hora como } \\
\text { regularmente? }\end{array}$ & $\begin{array}{l}\text { What time do I } \\
\text { regularly eat? }\end{array}$ & $\begin{array}{l}\text { The student uses the incorrect } \\
\text { verb form. }\end{array}$ \\
\hline 2 & Linda & Comes & You eat & $\begin{array}{l}\text { Linda recasts the correct verb } \\
\text { form. }\end{array}$ \\
\hline 3 & James & $\begin{array}{l}\text { ¿A qué hora comes } \\
\text { regularmente? }\end{array}$ & $\begin{array}{l}\text { What time do you } \\
\text { regularly eat? }\end{array}$ & James uptakes the correct form. \\
\hline 4 & Linda & $\begin{array}{l}{ }^{*} \text { Las doce cuaranta } \\
\text { cinco }\end{array}$ & $12: 45$ & $\begin{array}{l}\text { Linda provides the answer with } \\
\text { some inaccuracies (missing "at" } \\
\text { and mispronouncing "forty"). }\end{array}$ \\
\hline 5 & Linda & $\begin{array}{l}\text { ¿Qué desayunas } \\
\text { usualmente? }\end{array}$ & $\begin{array}{l}\text { What do you } \\
\text { usually have for } \\
\text { breakfast? }\end{array}$ & $\begin{array}{l}\text { Linda moves to the next } \\
\text { question. }\end{array}$ \\
\hline 6 & James & $\begin{array}{l}\text { Normalmente } \\
\text { desayuno a las } \\
\text { [inaudible]. }\end{array}$ & $\begin{array}{l}\text { Normally I have } \\
\text { breakfast at }\end{array}$ & $\begin{array}{l}\text { James provides an answer which } \\
\text { is inappropriate for the question. } \\
\text { Both students move to work } \\
\text { with another pair. }\end{array}$ \\
\hline
\end{tabular}

* Indicates an error was made by the speaker 


\section{Student voice}

The students' observed reluctance seemed consistent with their responses to the questionnaire completed after the second lesson. From 22 respondents, half considered speaking Spanish hard $(n=4)$ or very hard $(n=7)$. Only one considered it easy, four okay and six were neutral. Most of the explanations for this rating alluded to pronunciation being difficult for them. Despite this reported difficulty, 18 of the 22 students enjoyed the task and attributed this to the fact that they were interacting and moving around.

\section{Teacher reflections}

As with Melissa and Sara, David considered that the tasks had been successful because the students were engaged. During the post-lesson interview, he stated that he was pleased with the fact that students were taking risks in using the language even if it was inaccurate: "The kids are comfortable with the language. They're confident. They're not afraid to speak with mistakes." David's view seemed to conflict both with what the researcher observed and what the students reported in the questionnaires. Perhaps David's perception of these students being confident reflected the contrast he observed with his more senior students who had been taught with less focus on communication. He described the senior students as being typically reluctant to use any Spanish even when provided with scripted dialogues. David had, therefore, decided not to use tasks with these classes where the students were too focused on obtaining good results in high-stakes assessments and preferred to be taught the structures and vocabulary they thought they needed. David attributed this to the school being result-driven and "obsessed with the results in the end of year exams." He was not able to see how he could apply TBLT or make use of tasks in this context.

David described in the interview how, with his junior students, he was experimenting with oral interaction tasks, like the one we observed, to support fluency development. For him, lesson planning had turned into an "exercise of searching for the interactive moment." In other words, he was consciously identifying moments in his lessons where he could introduce authentic interactions where the students would communicate personal information, "even if highly scripted." As he had admitted in the initial interview, his participation in TPDL had provided a "much needed reminder" of language for communication and he acknowledged the support of the TPDL facilitators to "force me to use more Spanish and let the kids use the language." 


\section{Conclusion - David}

David demonstrated willingness to use tasks in his teaching, yet this was limited to beginner students and to only some times in a week. Throughout the study, we were able to see how David's journey implementing TBLT had been uneven. He had been introduced to TBLT in his preservice programme after which he seemed willing to try TBLT but admitted to having not understood the premises of the approach at the time. Consequently, he abandoned it and reinvigorated his interest with participation in TPDL. In particular, he felt that the support of the experienced TPDL facilitators who observed his lessons had motivated him to take a more reflective and critical approach to his teaching with tasks. After the programme, he had persevered to implement TBLT with his junior students whom he perceived as more willing to take risks and use the language communicatively.

However, as the data shows, he appeared to be experiencing difficulty in knowing how to design tasks that were at an appropriate level in terms of the language demands that they made of his students. This is something that the literature suggests can be a common difficulty for teachers, especially with beginner learners (Erlam, 2016a), and a finding that is replicated in Part 2 of this study. For David, difficulty designing a task for which his students had the level of language they needed to be able to complete it confidently, led to a lack of learner engagement.

\section{TBLT as seen in teacher practices}

The second section of this chapter presented data collected from teachers' practices including lesson observations, teacher interviews, transcripts of teacher and student discourse and responses to students' questionnaires.

The students' responses to the questionnaires indicate that the three groups of students reported enjoying different aspects of the observed lessons. A questionnaire item on which the students in the three classes concurred was the identification of the specific language structure targeted in the observed lessons. This seems to indicate that learning of the target structures in each of these lessons had been successful, at least in the short term. Learners were able to identify the specific language forms that the teacher targeted, a sign of development of language awareness.

Samples of students' discourse collected by audio recorders in the three classes presented similar results. The transcriptions indicated that the learners used the targeted structures in their interactions with their peers and their teacher with a certain degree of fluency, mainly in the primary classrooms. Admittedly, though, these were brief interactions that had been carefully scaffolded and modelled by the three teachers. In David's lessons, the language was pre-scripted and the students 
seemed to rely much more on English to complete the tasks. In the three classrooms observed, the tasks took place after the teachers overtly drew their students' attention to the dialogues that were to take place.

Besides collecting evidence of students' perceptions and opportunities for learning, the second aim of our analysis was to examine the way the teachers were implementing TBLT in their classrooms. Several commonalities can be drawn from the three observed classes. The tasks planned by these three teachers were oral informationgap tasks used as pedagogic tasks. The three teachers had clear target structures for the tasks that they had designed (i.e., "focused" tasks). For the most part, the tasks were successful in that the students engaged in the interactions and used the target structures, meeting their purpose as pedagogic tasks with a degree of interactional authenticity (Ellis, 2003). According to Sara and Melissa, the tasks-in-action that we observed corresponded for the most part to their tasks-as-workplan. In other words, task implementation corresponded with what the teachers had planned.

The three teachers considered that the lessons had been successful because of the level of learner engagement, a conclusion that mirrors their students' responses. Although these self-assessments were subjective, the teachers unanimously mentioned that using TBLT increased their students' motivation and enjoyment. Similarly, the three teachers were positively surprised to see their students using the target language (even if limited to the moment of the task). Also consistent with what has been reported in these three chapters, the teachers were most satisfied to see their students using the language to communicate contextualised meaning.

Finally, the teachers' reflections about their experience implementing tasks were mostly positive. A caveat here is that these teachers volunteered to this part of the study. Therefore, they most probably felt comfortable sharing their practices with us and already had a favourable attitude towards TBLT. All mentioned that teaching with tasks had made them put communication at the core of their teaching. The three also agreed that a major focus for them was using the target language much more as they had become aware of their role as input providers and "mediators of language learning" (Van den Branden, 2016, p. 167). This was certainly the case in the observed lessons in the primary classroom but not so much the case in David's lessons. The three teachers also saw a wider benefit to using TBLT in that they saw its alignment with wider curricular and educational aspirations of teaching. Even though these teachers' views seemed positive towards using tasks, none of them considered their teaching "fully TBLT." We saw evidence of the three teachers' tasks meeting most of the criteria for tasks (particularly in the primary classrooms), yet the tasks were not the exclusive focus of the lessons observed. 


\section{Conclusion}

The purpose of this chapter was to examine to what extent teachers who had participated in the TPDL programme were incorporating their learning about TBLT in their specific teaching contexts within 6 months of the end of the programme. We invited the teachers whose assignments had been examined in Chapters 2 and 3 to participate in a follow-up study. From the 14 teachers, nine participated in interviews which we reported in the first section of this chapter. We then asked these nine teachers if we could continue our examination of their implementation of TBLT by observing their practices. From the five teachers who agreed to being observed, we were able to collect complete data from three.

We acknowledge a number of limitations to this phase of the study. The first is the reduced number of volunteers we had, especially those whose practices we were able to observe. We attribute these low numbers to the busy lives of teachers. Most of these teachers work full time and any involvement in organising permissions from the schools, parents and students to allow researchers in their classrooms take time. Another possible explanation for this attrition may be that the teachers were not using TBLT or were not comfortable with their previous lecturers scrutinising their practices. In our experience as researchers in schools, we considered the first explanation (lack of teachers' time) as the most plausible, and one that we cannot control or remedy. Another limitation is that the teachers were volunteers and, therefore, may have an overly positive view of TBLT that may skew our conclusions. However, as documented, the nine teachers who volunteered had a range of experiences in their implementation of TBLT. In fact, we had some volunteers who had reservations about TBLT and many who were vocal about the constraints that they had to use tasks in their classrooms. Some teachers, like Eric, frankly admitted to being resistant to change. Our detailed analysis of enablers and constraints presented at the end of the first section of this chapter allowed us to record what the teachers actually face when learning about an innovation such as TBLT. This was, indeed, one of our objectives for this book project: to document the realities of implementing TBLT in school contexts where teachers' autonomy in embarking on an innovation is severely limited by factors beyond their control. As seen again and again, the teachers declared lack of time as the most influential factor limiting their implementation of TBLT. On the other hand, the volunteer teachers who participated in all aspects of the study, were generous and open in allowing us to document what they were doing and provided insights into their professional learning and their students' outcomes.

Despite the limitations listed, we would like to echo the conclusions drawn by Van den Branden (2016) in his positioning of the teacher as crucial for bringing TBLT to life. We documented in this chapter how the teachers who had been 
involved as action researchers through the TPDL programme continued as reflective practitioners making decisions as to how to best implement TBLT within the realities of their classroom lives. We saw in the first part of this chapter how the nine teachers described their decisions about planning with tasks and the diverse roles that tasks played in their teaching. For the overwhelming majority, tasks were seen as pedagogical tools that had interactional authenticity (Ellis et al., 2020) in the realities of the classroom. The teachers used tasks because they had already seen how their students engaged enthusiastically when participating in tasks. And evidence from the voices of these learners endorsed the teachers' views.

From the data presented in this chapter, the volunteer teacher participants demonstrated a shift to seeing language learning as focused on communication with the students' use of the language as paramount. In that sense, providing input and planning tasks where students use the language for communication became priorities in their teaching of languages. Our analysis of the tasks we observed confirmed that teachers were designing tasks that mostly met criteria, in particular the three criteria of being focused on meaning, having a gap and having an outcome. The teachers designed focused tasks which enabled learners to use communicatively language to which they had previously been introduced in class. The tasks they designed allowed for the repetition and recycling of language. Sara also created opportunities for learners to be exposed to extensive language input, and examples from Melissa's classroom showed that learners had opportunity to receive feedback as to their use of language. As we will conclude more clearly in the second part of the book, there was some evidence of difficulty designing tasks that were at an appropriate level in terms of the language demands they made of students. One teacher, in particular, seemed to be implementing interactive tasks that were too difficult for beginner learners who were unable to produce language fluently. One solution would have been for this, and other teachers, facing this problem, to use more input-based tasks. Admittedly, the teachers found creating tasks time consuming and this barrier may be significant in schools where time for learning languages is so limited.

Part 1 of the book used the lens of professional learning to describe how volunteer participants, drawn from a cohort of school teachers who participated in an in-service education programme, learned about and understood TBLT and tasks. Chapters 2 and 3 presented data collected from assignments submitted as part of a course the teachers took during the year-long programme. Analysis of the written assignments of 14 teacher participants provided evidence of the process of learning about tasks through engagement with the content of this pedagogy course. In Chapter 4 we first interviewed nine of those teachers and then followed three of these teachers into their classrooms in the year after they participated in TPDL to examine how their understandings about tasks and TBLT were evident in their practices. 
We contend that investigating the processes of learning about, and implementation of TBLT by teachers in FL programmes in schools contributes to evidence of seeing the transition from task-in-theory to task-in-action (East, 2018). Most of the data presented in Part 1 focused on the teachers' coursework and self-reported reflections and practices as a way of understanding their perspectives on their own learning. If we agree that a focus on teacher learning is fundamental to the growth of TBLT as a researched pedagogy (Samuda et al., 2018), then we need to explore how real teachers go through these processes of learning. In the latter part of this chapter, we presented some data showing how learning from the TPDL programme was evident in the emerging practice of a small number of the participating teachers. Part 2 of the book draws on data collected from a different set of teachers who had also taken the TPDL in-service programme on average 4 years before being part of our study. Here, we present our investigation of the extent to which these teachers implemented TBLT and used tasks as pedagogical tools within their teaching contexts. 


\title{
Introduction to Part 2
}

\author{
Tasks in the classroom
}

\section{Introduction}

Part 2 complements Part 1 of the book in that it continues to follow participants in the TPDL programme and their experience with tasks and TBLT. It explores to what extent teachers were implementing TBLT and using tasks as pedagogical tools in their classroom practice several years after completing TPDL, and, how they were doing this.

In Part 2, we present classroom observation and interview data from eight teacher participants who are not part of the data set that has informed the previous three chapters. These eight teachers had all completed TPDL previously and had essentially had similar experiences in learning about and working with tasks as they completed the TPDL programme. The focus is now on the "task-as-process" (Breen, 1987; Ellis, 2003), that is, on the task as it was implemented in the classroom.

\section{The participants}

At the time that the eight teacher participants in this part of the study were observed and interviewed, the average time that had elapsed since they had completed TPDL was 4 years, and ranged from 2 to 6 years. Table 21 presents background information about these teachers, including information about their teaching context, the language they taught in the lessons we observed, Year level and numbers of students in these classes. Pseudonyms are used.

Table 21 demonstrates that this group of teachers varied considerably in language teaching experience. While the average length of experience was 17 years, the range was from 4 to 37 years.

Six of the schools were in larger cities in New Zealand and two were in smaller towns; none were in rural locations. Six schools were co-educational, while one catered for boys and one for girls exclusively. One was a private boarding school (Years 7 to 13) with a small roll of under 300 pupils, explaining the disproportionally low number of pupils $(n=5)$ in the class observed. 
Table 21. Background information about teachers and teaching contexts

\begin{tabular}{lllcccc}
\hline Name & $\begin{array}{l}\text { Target } \\
\text { language } \\
\text { taught }\end{array}$ & L1 & $\begin{array}{c}\text { Years of } \\
\text { experience } \\
\text { in language } \\
\text { teaching }\end{array}$ & $\begin{array}{c}\text { Observed } \\
\text { teaching } \\
\text { year level }\end{array}$ & $\begin{array}{c}\text { No of } \\
\text { pupils } \\
\text { in class } \\
\text { observed }\end{array}$ & $\begin{array}{c}\text { Approximate hours of } \\
\text { instruction allocated } \\
\text { per week to language } \\
\text { taught }\end{array}$ \\
\hline Tania & Japanese & English & 26 & 10 & 22 & 4 \\
Margaret & French & English & 15 & 11 & 11 & 4 \\
Linda & Spanish & English & 37 & 11 & 5 & 4 \\
Annabel & Chinese & English & 6 & 10 & 14 & 3 \\
Emily & Chinese & Chinese & 8 & 10 & 24 & 3 \\
Sonia & Japanese & Dutch & 27 & 10 & 22 & no information available \\
Shona & Japanese & English & 17 & 11 & 13 & 4 \\
Toby & Spanish & English & 4 & 10 & 24 & 4 \\
\hline
\end{tabular}

* Some schools operate a 6-day timetable, so the hours of instruction per week may vary according to the timetable cycle.

Table 21 highlights differences in class size between Years 10 and 11. There were an average of 21 students in Year 10 and 9 in Year 11. This reflects an unfortunate trend of attrition as students advance through year levels.

Students in Year 10 (aged approximately 14 years) were normally in their second year of study of the target language. Most would have begun studying the language in Year 9, their first year at secondary school. However, this first year may not have included a full year of language learning. For example, Tania's students had studied Japanese for only 6 months in Year 9. Furthermore, because they were observed half-way through Year 10, they really had had, as Tania pointed out, only one full year of Japanese. Students in Year 11 were normally in their third year of study of the target language; however, once again, Year 9 may not have comprised a full year of instruction. It is important to remember, with respect to understanding any conclusions drawn from this study, that, firstly, students were learning in an acquisitionpoor environment where they had limited weekly exposure to the target language, and, secondly, that they had not had time to develop beyond a very basic proficiency (see Chapter 1).

\section{Rationale for the choice of teachers}

The eight teachers were selected and invited to participate in our research project for one, or two, main reasons. Firstly, they were known to embody excellent practice. Two had, for example, after completing TPDL, been employed as TPDL facilitators, an indication that the TPDL team considered them outstanding practitioners. A third teacher was employed, after her participation in this research, in 
another MOE initiative aiming to support language teachers. Another two teachers were remembered for their participation in TPDL and were reported (by the team) as embodying good practice. A second reason for inviting teachers was that they already had a positive relationship with one of the researchers and the degree of trust necessary to motivate participation in the study. Three participants, for example, had collaborated with one of the researchers in publishing in the journal, the New Zealand Language Teacher.

Two teachers who were invited to participate did not respond, another three teachers declined involvement, two due to personal circumstances. In the experience of the researchers, it is difficult to get teachers to participate in research, especially when classroom observation is involved. One reason is that the New Zealand Human Ethics committee requires written consent, not only from the teacher and school principals, but also from the parents of all students under the age of 16 years as well as assent from the students themselves. The burden for this, of course, rests primarily with the teacher. In this study, only teachers of Years 10 and 11 classes took part; this means that our data set represents a narrower sample of learners than we would have preferred. One reason for this may be that, in Years 12 and 13, both students and teachers are under greater pressure with external assessment requirements. A reason for the lack of Year 9 students may be that at this level students are $a b$ initio beginners and that they may not begin studying the target language until after the first half of the school year. This is because it is common to give Year 9 students "taster" courses where they have several weeks of exposure to a variety of languages during the first half of Year 9, after which they make a decision as to which language they would like to continue studying.

In conclusion, the sampling strategy used in this project was opportunistic and based on convenience (Richards, 2003), because of difficulty finding teachers prepared to give us access to their classrooms. The disadvantage is that we cannot claim that our teacher participants are in any way representative of the wider population of New Zealand language teachers; this remains a limitation which we further acknowledge in Chapter 8. In this study, we present, therefore, a view of what is possible in the language classroom; we are unable to claim that it is representative.

\section{The initial approach to participants}

The initial approach to teachers was quite different to that in Part 1. In Part 1, classroom observation was at the end of the data-collection process, after teachers had already taken part in an interview in which they had been asked questions about their views and implementation of TBLT (see Appendix 3). In this interview they were asked: "Would it be possible for me/us to come and observe you teaching a 
Task-based lesson?" These teachers, in Part 1, therefore, were aware that TBLT was a focus of the research and had the expectation that, in coming to observe their practice, we were expecting to see a task-based lesson.

In this second part of the study, classroom observations took place before the interview in we asked teachers specific questions about tasks and TBLT. We carefully considered, therefore, how we approached the teachers and the information that we gave them, deciding that we would not signal the specific focus of our study so that we could have information that was as neutral as possible in terms of teachers' use of, and orientation to, tasks and TBLT. Our initial approach to teachers was an invitation to be involved in a research project involving classroom observation followed by an interview. Once teachers expressed an openness to being involved in the project, they were sent written information about it, which included the title: Communication tasks for effective learning in the foreign language classroom.

This information included a rationale for why the teacher had been invited to participate, as follows:

We would like to ask you to consider being involved in a research project. We are extending this invitation to you because you are known to create opportunities for students to interact and use language meaningfully in your language classes.

Information, which the teachers were given about the lessons we wanted to observe, included: "We would like there to be an emphasis on the use of communication tasks in the classroom during these lessons." We therefore avoided any direct reference to TBLT. However, it is possible that potential participants interpreted task in the phrase "communication tasks" as the type of task associated with TBLT. Furthermore, as all these teachers had completed TPDL where they had been exposed to TBLT, it is quite likely that they did interpret the reference to the word task in this way. No teacher queried more specific information about what we wanted to see or what we meant by the word task.

The decision to observe two lessons was made purely because we were keen to minimise demands we made of teachers in terms of time. We were able to observe one teacher once only, due to semester and timetabling constraints. The lessons observed were sequential (with one exception), the second lesson either took place the following day, the next time the class was timetabled for this subject, or, was part of a two-lesson sequence on the same day. This meant that the researchers could see to what extent there was continuity in the way that any tasks were implemented. 


\section{The data we collected}

In order to have as complete a picture as possible of the classrooms and the practice and perspectives of the eight teachers we observed, we collected a range of data, outlined below.

\section{Recording of teacher discourse}

In each lesson the teacher was given a digital recorder which s/he wore on a lanyard around his/her neck. This meant that all teacher discourse could be recorded; this included discourse which the teacher addressed to the whole class as well as interactions that $\mathrm{s} / \mathrm{he}$ had with small groups or individual students.

\section{Recording of student discourse}

Students who had signed consent to participate in the research were also given recorders with built-in microphones. However, in most cases, there were not enough recorders for all students to have one each, so they were given to pairs, or small groups of students, and placed on desks.

\section{Observation data}

The researcher who had taken responsibility for collecting the data, that is, either one of the authors, sat in the classroom and observed during the lesson, taking notes. These notes tended to include information that would not be captured by the recordings, for example, information about which students were working together, to what extent students appeared engaged and focused, and any language that the teacher may have written on the board. At times the researcher was also able to take photos of information that the students were given.

\section{Documents}

The researcher kept any documents relating to the lesson that the teacher was prepared to make available. These mostly included handouts or worksheets given to the students. It also included, in some cases, examples of student work. Lesson plans did not form part of the data we collected as we were keen to minimise the demands we made of teachers. This means that, in this section of the book, we have limited information available about the "task- as-workplan." 


\section{Questionnaires}

A questionnaire completed, at the end of the lessons, by those students who had elected to participate in the research, collected information about their learning and responses to the lesson. The questionnaire (see Appendix 4) included the following questions:

What did you learn today in your lesson? Please write as many things as you want Please indicate how much you enjoyed today's lesson (rating scale included)

Please explain why you did or did not enjoy the lesson

Please write one thing that you really liked about today's lesson

Unfortunately, in some lessons, there was not time to complete questionnaires or they were forgotten, and so were completed once only, rather than after each lesson.

\section{Interviews with teachers}

An audio-recorded interview with the teacher, aiming to elicit further information about their practice, along with their views of tasks and TBLT, took place at the end of the second lesson. The aim of scheduling it after our observations was to reduce the possibility that the teacher might modify their practice after finding out about the focus of the study (see Appendix 5 for interview questions).

\section{Handling the data}

The recordings of teacher discourse were transcribed and translated by a research assistant who was proficient in the language being taught. The teacher discourse of 14 of the 15 lessons was transcribed; for one lesson, the transcript was lost and so analysis relied mainly on research observation notes.

The recordings of student discourse were also transcribed and translated by research assistants proficient in the target language. Transcripts included student errors and the translations signalled these. Not all files were transcribed; for some it was not possible to hear what students said. This was because, in some lessons, recorders were placed on desks so did not always record individual voices clearly; secondly, when students moved from their seats to take part in pair or group work, they, at times, forgot to take their recorders with them and thirdly, there was often too much ambient classroom noise. Other files were not transcribed because there was little student use of the target language. 


\section{Identifying the tasks}

The first question that we identified in the Introduction to Part 2 was whether the teachers used tasks in the 15 lessons we observed. This was because we were keen to establish whether, firstly, after having learnt about tasks and TBLT, at some time (on average 4 years) in the past during participation in TPDL, they had sufficiently retained information to be able to design and implement tasks in their practice. Furthermore, evidence of the implementation of tasks in the classroom would be some indication of the value that teachers accorded to TBLT and would complement interview data.

We therefore first evaluated the 15 lessons to establish whether teachers taught, or included, a task. At this stage of analysis, we were looking for whether, in each lesson, we found an activity, that according to our criteria (Ellis \& Shintani, 2014), could meet the definition of a task. In the lessons we observed many activities, including classroom routines. The challenge for the researcher was to identify which lesson activity should be chosen to investigate for evidence of a task. The decision process that was used to determine which activity would be evaluated was as follows:

- For lessons where the teacher identified an activity as the task, this was chosen for task evaluation.

- For lessons where no obvious activity was identified as a task by the teacher, the activity that had taken the most time during the lesson was chosen, as indicative of the major focus and way in which students were employing their time and learning resources.

- Three lessons which teachers described as being examples of a flipped mastery approach were observed. These were classes where learners, before the lesson, independently accessed film clips which contained relevant explicit grammatical information. In class they worked at their own pace on different activities. In each case the researcher observing the lesson chose an activity that she observed a student working at and coded it against task criteria. However, because she had audio-recorded the teacher discourse only, she did not have data that indicated how long students spent working at these.

The resulting activities were coded against the criteria (Ellis \& Shintani, 2014, p. 135) included in Chapters 1 and 3. The questions asked, and answers required, for each criterion, are listed in Chapter 3 (see Table 9). It is important to point out that, as we coded activities to determine task-likeness, we were considering how the activity was implemented in the classroom, rather than what might have been planned. In other words, we were focused on the "task-in-process," rather than the "task as work-plan." The results for coding are given in Table 22. A coding of "yes" means that the task criterion was fulfilled, a coding of "X" means that it was not. See 
below for an explanation of coding as [yes]. The final column of Table 22 presents our conclusion as to whether the activity we evaluated could be considered a task, or, if it did not meet criteria, remained an activity. In Chapter 6 we argue that fulfilling three or more of the components of a task makes a given activity more tasklike than activity-like. Therefore, for an activity to be designated a task, it needed to satisfy three or more criteria in the way that it was implemented. For each of the 10 tasks listed in Table 22, we present, in Chapter 5, a detailed description and justification for our coding against task criteria. The overall conclusion was that 10 of the 15 lessons contained tasks that satisfied three or more task criteria and, that six of the eight teachers implemented at least one task.

Table 22. Coding against criteria (Ellis \& Shintani, 2014)

\begin{tabular}{|c|c|c|c|c|c|c|}
\hline $\begin{array}{l}\text { Teacher's } \\
\text { name }\end{array}$ & $\begin{array}{c}\text { Lesson [Approximate } \\
\text { duration of activity } \\
\text { or task] }\end{array}$ & $\begin{array}{c}\text { Criterion } 1 \\
\text { Focus on } \\
\text { meaning }\end{array}$ & $\begin{array}{l}\text { Criterion } 2 \\
\text { Some kind } \\
\text { of 'gap' }\end{array}$ & $\begin{array}{c}\text { Criterion } 3 \\
\text { Relying on } \\
\text { own 'resources' }\end{array}$ & $\begin{array}{c}\text { Criterion } 4 \\
\text { outcome }\end{array}$ & $\begin{array}{c}\text { Task or } \\
\text { activity? }\end{array}$ \\
\hline \multirow[t]{2}{*}{ Tania } & 1 [16 mins] & yes & yes & $\mathrm{X}$ & yes & Task 1 \\
\hline & 2 [24 mins] & yes & [yes] & yes & yes & Task 2 \\
\hline \multirow[t]{2}{*}{ Margaret } & 1 [33 mins] & yes & yes & yes & yes & Task 3 \\
\hline & $2[50 \mathrm{~min}]$ & yes & yes & yes & yes & Task 4 \\
\hline \multirow[t]{2}{*}{ Linda } & 1 [35 mins] & [yes] & [yes] & $\mathrm{X}$ & $\mathrm{X}$ & Activity 1 \\
\hline & $2[30 \mathrm{mins}]$ & yes & yes & yes & [yes] & Task 5 \\
\hline \multirow[t]{2}{*}{ Annabel } & 1 Flipped class & yes & $\mathrm{X}$ & [yes] & $\mathrm{X}$ & Activity 2 \\
\hline & 2 [20 mins] & yes & yes & [yes] & [yes] & Activity 3 \\
\hline \multirow[t]{2}{*}{ Emily } & 1 [38 mins] & yes & yes & yes & yes & Task 6 \\
\hline & 2 [43 mins] & yes & yes & [yes] & yes & Task 7 \\
\hline Sonia & 1 [30 mins] & $\mathrm{X}$ & $\mathrm{X}$ & $\mathrm{X}$ & $\mathrm{X}$ & Activity 4 \\
\hline \multirow[t]{2}{*}{ Shona } & 1 Flipped class & yes & yes & $\mathrm{X}$ & yes & Task 8 \\
\hline & 2 Flipped class & $\mathrm{X}$ & $\mathrm{X}$ & $\mathrm{X}$ & $\mathrm{X}$ & Activity 5 \\
\hline \multirow[t]{2}{*}{ Toby } & $1[22 \mathrm{~min}]$ & yes & yes & $\mathrm{X}$ & yes & Task 9 \\
\hline & $2[30 \mathrm{~min}]$ & yes & yes & yes & [yes] & Task 10 \\
\hline
\end{tabular}

A coding of [yes] meant one of three things with respect to the relevant task feature:

1. It was part of the task design but, due to time constraints, was not completed during the lesson.

An example was from Annabel's second lesson (Activity 3 in Table 22) where students had to listen to each other giving information about a series of four Chinese student timetables of different year levels. As they listened to this information, they completed one of four timetables on a worksheet. The task outcome was for them to analyse the timetables to establish what life is like for Chinese students; however, there was no time for this analysis in the observed lesson, so the outcome was coded [yes], as it was incomplete. 
2. It was not necessarily a task characteristic that applied to all students. An example was Task 2 where students had conversations to find out about their hobbies, their families, where they lived, etc. The teacher thought that some students might be learning things they did not know about their conversation partners, but could not be sure that this was the case for all. This task was therefore coded as [yes] for some kind of gap. Of course, the potential lack of a gap does not mean that students may not have been listening to, and understanding each other, but building in a gap in task design is more likely to motivate them to do this.

3. Only one of the two questions listed in Table 9 were answered according to specification.

An example was Task 7, "Which Maze?" which students completed in pairs. The students had to write directions in Chinese for one of four mazes depicted on a handout they were given, then read the directions to their partner who had to listen and decide which maze was being described. The language they needed was written on the sheet for them to refer to. This was coded as [yes] for "rely on own resources" because not both questions (listed below) referring to this criterion could be answered (Question 3 in Table 9).

a. so that they can do the task, are they taught the language they will need?

b. does the task allow learners to automatise and use language they have already been taught on a previous occasion?

Question 3a was answered as they had not been taught the language they needed prior to working at the task. However, the fact that the language was on the handout did not, in the researcher's opinion, fully allow for automatisation (Question 3b not fulfilled). In reaching this decision, the researcher took into consideration the fact that the students had had considerable prior opportunity to use this language orally at the same time as having it available in written form. Therefore, she was making a judgement that, given the extensive opportunities they had already had to use this language, having it immediately available on their worksheet alongside the task may not have encouraged them to use it independently.

An activity that fulfilled all task criteria

An example of a task that satisfied all four criteria was the "Treasure Hunt" (see Task 6 in Table 22). In this task, students were put into different groups to go on a treasure hunt around the school. The groups were given different QR codes to scan on their phones. Each QR code was hidden at various locations around the school (e.g., on a tree) and contained directions in Chinese (e.g., "in the middle of the science and social building") to the next QR code, along with a word clue. The word clues needed to be reassembled to form a sentence specifying where the treasure 
was. Students were allowed to use Google Translate or Pleco Chinese dictionary to work out the meaning of words they did not know. The outcome of the task was to find the treasure, hidden under the teacher's car in the school carpark, through correctly assembling the clue words to form a sentence in Chinese. This sentence was (translated for the reader): "the treasure is underneath a small purple Japanese car with the number 800 in the registration number."

An activity that did not meet task criteria

An example of an activity (Activity 4 in Table 22) that did not satisfy any of the criteria for a task was a Snakes and Ladders game which was played in groups of four. The students were given a sheet with sentences relevant to the topic of hobbies and, as they had their turn, they needed to use this language to talk about hobbies, saying, for example, how often they did them, when, who with, etc. When someone won the game, they were encouraged to play it again. This was considered an activity, rather than a task, because the sentences the students made up did not necessarily encode meaning personal to them; they were functioning as language learners rather than using language to communicate. All students had the same sheet so there was no communicative gap, nor were learners required to rely on their own resources. Finally, the language did not serve as a means for achieving the outcome of winning the game.

\section{Outline of this section of the book}

In this Introduction to Part 2 of the book, we described the eight teachers who are participants in this part of the study and outlined the methodological procedures we used. Our first aim was to identify to what extent these teachers, who had completed TPDL in the past, were using tasks in their classrooms. The fact that we observed 10 tasks in 15 lessons and that six of the eight teachers used tasks in one or more of their lessons, is evidence that these teachers were able to design and use tasks in their practice after having learnt about them. It presents some evidence for the sustainability of TBLT. We have pointed out though, that our teacher participant group was not necessarily representative of typical practice.

In Chapter 5 we present data from the classroom lessons we observed, drawing principally on the transcripts of the teacher and student discourse, to investigate how the six teachers who taught tasks used them to create opportunities for learning. We also present data from the questionnaires where the students report on their learning and their affective response to these lessons. Chapter 5 therefore addresses more particularly the following questions with respect to the 10 tasks we observed: 
- How were the teachers in this part of the study using tasks?

- To what extent is there evidence that the use of tasks opened up opportunities for language learning?

- What did students report learning as they completed tasks?

- How did students view lessons where they worked at tasks?

In Chapter 6, an overall analysis is presented of the types of tasks that the six teachers taught, and of evidence for whether were implementing Long's (2015) TBLT principles in their classrooms. The following questions are explored:

- What types of tasks were teachers using?

- To what extent is there evidence that their practice was consistent with Long's (2015) principles of TBLT?

Chapter 7 draws principally on interview data and explores teacher responses to TBLT, the role the teachers saw for tasks in their teaching practice and the extent to which they were able, or willing, to use and sustain the use of tasks in their practice. This chapter includes the perspective of all eight teachers, not just of those whom we saw using tasks in their practice. It addresses the following:

- What priority and importance did the teachers accord to learning about TBLT?

- How did the teachers understand tasks and TBLT?

- What role did they see for tasks and TBLT in their classroom practice?

- What were the factors they reported that either facilitated or constrained the use of tasks and implementation of TBLT in their classroom practice? 



\section{CHAPTER 5}

\section{Voices from the classroom}

Today in Japanese, I learnt how to carry on a fluent conversation in Japanese and then report back the information to the class. I also learnt how to say what sport you do as well as the place you do your sport in the same question.

(Year 10 student's questionnaire response, at end of lesson, Task 2)

In the Introduction to Part 2, we describe how we identified 10 tasks in the lessons we observed, taught by six teachers, on average 4 years after learning about tasks and TBLT, in the TPDL professional development programme. We now look at these tasks as they were implemented in the classroom, and ask the following questions:

- How were the teachers using tasks?

- To what extent is there evidence that the use of tasks opened up opportunities for language learning?

- What did students report learning as they completed tasks?

- How did students view lessons where they worked at tasks?

In this chapter, then, the main focus is on how the tasks we observed may have created learning opportunities. An important contribution are the voices of the students, both in terms of what they reported learning, and their affective responses. A positive response to tasks may indicate willingness and motivation to engage with them and this, albeit indirectly, could be facilitative of opportunities for learning.

In summary, our analysis will contribute to our ongoing understanding of the task as a pedagogic tool and of the different ways tasks may be used to promote learning.

\section{Data sets}

Four main sets of data inform this chapter. The first are the transcripts of teacher and student classroom discourse recorded during task completion. We also, drew at times, on documents (i.e., handouts/worksheets/books/PowerPoints) that the teacher made available to us during or after the lesson. The third main data set comprises our observation notes. We were able to document, for example, teacher use of the whiteboard, information about classroom organisation, grouping of students 
and student engagement. The last data set was the written responses to questionnaires that students completed at the end of lessons (described in the Introduction to Part 2) providing information from the students in terms of what they thought they learnt and their opinions of these lessons.

\section{Analysis of classroom transcript data}

In this section we describe how we analysed the transcripts of teacher and student discourse. Firstly, in examining the classroom transcripts, we selected the part of the lesson which was evaluated as the task (excluding any part of the lesson which was labelled as "pre-task"; an exception is Task 7). This was to enable us to focus on opportunities for learning which were facilitated by the task. As we worked through the transcripts we identified examples of opportunities for language learning. These included:

- student exposure to extensive language input (Ellis, 2005) and elaborated input (Oh, 2001);

- student pushed and/or scaffolded use of the target language (Lantolf \& Beckett, 2009; Loewen, 2005);

- student reuse and recycling of target language promoting fluency and automatisation (DeKeyser \& Robinson, 2001).

Within the analysis of each task that we present in this chapter, we discuss, and at times quantify, these opportunities for learning.

At the same time, we identified language-related episodes (LREs) (Swain \& Lapkin, 1998) in the transcripts of task discourse. This was for two main reasons. Firstly, they are known, from the literature, to be likely to provide opportunities for learning. They were also frequent in our data set, given that our transcripts of classroom discourse tended to provide examples of interaction, both teacher-student, and student-student.

We defined a LRE as: "any part of a dialogue where students talk about language they are producing, question their language use, or other or self-correct their language production" (Swain \& Lapkin, 1998, p. 326). These opportunities to attend to language form have also been referred to as "form-focused episodes" (FFEs) (Ellis et al., 2001). A FFE is any occasion where "participants attend to some aspect of linguistic form" while engaged in meaning-focused activities or tasks (Ellis, 2012, p. 205). Ellis (2012) explains that the term LRE tends to be used in contexts where learners are interacting in pair or group work and FFE tends to be used in more teacher-fronted lessons. For purposes of consistency, we will use the term LRE to refer to both types of opportunity to focus on language form, recognising that in this study the focus on form tended to occur in group or pair work. However, as we explain below, we only included in our data set those LREs where there was evidence of a gap in the learners' knowledge. 
These LREs are examples of, and a subset of Long's definition of opportunities to focus on form, defined: "Focus on form... overtly draws students' attention to linguistic elements that arise incidentally in lessons whose overriding focus is on meaning or communication" (Long, 1991, pp. 4-5).

We examined the transcripts of classroom discourse for all LREs, identifying those occasions where there was a move from attending to meaning to attending to form, and where this move was initiated by an apparent gap in student knowledge. This move to a focus on language form was most often triggered by an error or by a question about some aspect of language. The end of an LRE was marked by a return to a focus on meaning. See Example (6), from Task 4, as an example of a LRE.

Example 6. A reactive LRE

\begin{tabular}{lllll}
\hline Turn & Interlocutor & & Translation & Researcher comment \\
\hline 1 & Student & $\begin{array}{l}\text { Est-ce que tu } \\
\text { [unintelligible } \\
\text { language] }{ }^{*} \text { plus grand? }\end{array}$ & $\begin{array}{l}\text { Did you... } \\
\text { bigger? }\end{array}$ & $\begin{array}{l}\text { Part of utterance not intelligible but } \\
\text { error is use of incorrect comparative } \\
\text { to refer to age. }\end{array}$ \\
& & $\begin{array}{l}\text { Plus grand? Plus âgé } \\
\text { ou plus jeune? }\end{array}$ & $\begin{array}{l}\text { Bigger? Older } \\
\text { or younger? }\end{array}$ & $\begin{array}{l}\text { Teacher draws learner attention to } \\
\text { error and gives correct comparative } \\
\text { feacher }\end{array}$ \\
& & & forms that refer to age. \\
& & &
\end{tabular}

* signals an error

We would claim that, in this LRE in Example (6), there is opportunity for learning because the student makes an error, demonstrating a gap in their knowledge, and the teacher gives a form of explicit corrective feedback (Ellis et al., 2006) in drawing attention to the error and proposing alternative forms. This opportunity to attend to language occurs at the same time as s/he communicates meaning (Long, 2015). We therefore call this a reactive LRE, that is, a response or reaction to an utterance that was problematic or unclear (Ellis et al., 2001).

In our data set we also found examples of LREs initiated by students, in anticipation of language that they did not know but that they needed in order to be able to communicate successfully. We called these preemptive LREs. They also provided evidence of a gap in learner knowledge. In Example (7) (taken from Task 4), the student initiates the focus on form, asking how to say police officer in French. In this LRE, there is an opportunity for the student to focus on and potentially learn this vocabulary item.

Example 7. A preemptive LRE initiated by a student

\begin{tabular}{lllll}
\hline Turn & Interlocutor & & Translation & Researcher comment \\
\hline 1 & Student & Comment dit-on & How do you say & Student initiates request for \\
& & police officer? & police officer? & word \\
2 & Teacher & Un policier & A police officer & Teacher supplies word \\
\hline
\end{tabular}


As explained above, we excluded from our data set LREs that did not provide a definite evidence of a gap in learners' knowledge and that may not have provided an opportunity for students to learn language they did not know. An example is given below (Example (8)), also taken from Task 4 . The teacher, Margaret, preempts by asking students if they know a form that she considers necessary for the task. However, we cannot be sure that it was an opportunity for them to learn language they did not know; there was, as we see, at least one student who knew this language form. While LREs like Example (8) were excluded from the LRE data set, we acknowledge that they provided opportunities for focus on form as defined by Long (1991), in that learners' attention was directed to linguistic elements of language in contexts where there was a focus on meaning.

Example 8. A preemptive LRE initiated by the teacher, excluded from our data set

\begin{tabular}{|c|c|c|c|c|}
\hline Turn & Interlocutor & & Translation & Researcher comment \\
\hline 1 & Teacher & $\begin{array}{l}\text { How are you going } \\
\text { to say I didn't have? }\end{array}$ & & $\begin{array}{l}\text { Teacher initiates attention to } \\
\text { language form, not in response } \\
\text { to gap in learner knowledge or } \\
\text { error. }\end{array}$ \\
\hline 2 & Student & Je n'avais pas & I didn't have. & \\
\hline 3 & Teacher & Je n'avais pas. Oui. & I didn't have. Yes. & \\
\hline
\end{tabular}

Within the LREs that we identified, there were a number of ways in which learner attention to form could take place. These included, but were not limited to:

- negotiation of meaning - including clarification requests and confirmation requests; (see T.3 in Example (9))

- provision, by the teacher, of explicit metalinguistic information; (see T.2 in Example (10))

- $\quad$ student uptake of target language (Loewen, 2004); (see T.3 in Example (10))

In Example (9), taken from Task 1, we have a LRE within which there were several opportunities for the learner to focus on language form. This LRE is initiated by the student as they query the meaning of the word "aikido", indicating a gap in their knowledge. The teacher provides the word and at the same time gives elaborate and extended language input. Then the student initiates a confirmation request, at the same time using or "uptaking" the language input that the teacher has provided. In response to the request for confirmation the teacher provides more extensive and elaborate language input (T. 4). 
Example 9. Opportunities for language learning within a LRE

\begin{tabular}{|c|c|c|c|c|}
\hline Turn & Interlocutor & & Translation & Researcher comment \\
\hline 1 & Student & Miss, what's Aikido? & & $\begin{array}{l}\text { Student initiates with } \\
\text { request for information. }\end{array}$ \\
\hline 2 & Teacher & $\begin{array}{l}\text { Aikidou ne! Aikidou } \\
\text { wa Nihon no supootsu. } \\
\text { Nihon no supootsu desu }\end{array}$ & $\begin{array}{l}\text { Ah, aikido! Aikido is } \\
\text { a Japanese sport. A } \\
\text { Japanese sport. }\end{array}$ & $\begin{array}{l}\text { Teacher provides answer } \\
\text { giving elaborated input } \\
\text { in target language. }\end{array}$ \\
\hline 3 & Student & $\begin{array}{l}\text { Nihon no supootsu desu } \\
\text { ka? }\end{array}$ & A Japanese sport? & $\begin{array}{l}\text { Student uptakes \& } \\
\text { requests confirmation. }\end{array}$ \\
\hline 4 & Teacher & $\begin{array}{l}\text { Hai. Eeto, aikidou wa } \\
\text { ne, juudou to sukoshi } \\
\text { karate ga haitteiru } \\
\text { nihon no supootsu. } \\
\text { Aikidou wa tabun hitori } \\
\text { de shimasu. Hai. Hitori } \\
\text { de shimasu. }\end{array}$ & $\begin{array}{l}\text { Yeah. Um, aikido is } \\
\text { a Japanese sport like } \\
\text { judo with a little bit } \\
\text { of karate thrown in. } \\
\text { You'd probably do } \\
\text { aikido by yourself. Yes. } \\
\text { By yourself. }\end{array}$ & $\begin{array}{l}\text { Teacher provides } \\
\text { extensive \& elaborated } \\
\text { input in the target } \\
\text { language \& models } \\
\text { preselected task } \\
\text { language (categorisation } \\
\text { of sport). }\end{array}$ \\
\hline
\end{tabular}

In Example (10), also from Task 1, we have an example of the teacher, Tania, providing scaffolding to help the learner produce language related to task goals. The LRE is teacher initiated, but reactive and in response to a learner problem (T.1). The teacher provides explicit metalinguistic explanation (T.2) which leads to uptake (T.3). At this stage, that is, at T.3, we would consider that the LRE is complete, in that the problem is resolved and there is a return to a focus on meaning. However, the teacher goes on to continue the interaction, providing scaffolding (T.4), which leads to correct production (T.5).

Example 10. Opportunities for language learning within a LRE

\begin{tabular}{|c|c|c|c|c|}
\hline Turn & Interlocutor & & Translation & Researcher comments \\
\hline 1 & Student & Ku rike & & $\begin{array}{l}\text { Student is finding it difficult to } \\
\text { decipher katakana. }\end{array}$ \\
\hline 2 & Teacher & That's a little $t s u$ & & $\begin{array}{l}\text { Teacher responds by giving explicit } \\
\text { metalinguistic explanation to help } \\
\text { student read word. }\end{array}$ \\
\hline 3 & Student & Kuriketto & Cricket & $\begin{array}{l}\text { Student uptakes and is able to } \\
\text { correctly decipher and pronounce } \\
\text { word. }\end{array}$ \\
\hline 4 & Teacher & $\begin{array}{l}\text { Kuriketto. Sou desu. } \\
\text { Yoku dekimashita. } \\
\text { Kuriketto wa chiimu } \\
\text { no supootsu desu ka? }\end{array}$ & $\begin{array}{l}\text { Cricket. That's } \\
\text { right. Well done. } \\
\text { Is cricket a team } \\
\text { sport? }\end{array}$ & $\begin{array}{l}\text { Teacher asks question related } \\
\text { to task (categorisation) which } \\
\text { contains scaffold for answer. }\end{array}$ \\
\hline 5 & Student & $\begin{array}{l}\text { Chiimu supootsu } \\
\text { desu. }\end{array}$ & It's a team sport. & $\begin{array}{l}\text { Student uses question form to help } \\
\text { form correct response, producing } \\
\text { correct output. }\end{array}$ \\
\hline
\end{tabular}


In working through the transcripts we identified and quantified all the LREs. We discuss the incidence of these in the analysis of each of the ten tasks we present in this chapter. At the same time, as documented earlier, we also refer to other opportunities for learning that we noted in the transcripts.

\section{Analysis of questionnaire data}

We now explain how we dealt with our second data set, the student questionnaires. Students who had consented to participate in the study, were given a questionnaire (see Appendix 4) to complete at the end of the lesson. This data was analysed to establish answers to the following questions:

- What did students say that they learnt in the lesson?

- How did students rate their enjoyment of the lesson?

- What did they report liking and enjoying about the lesson?

For each of the tasks, we present the data we have that answers these questions within the discussion of the task. It is important to point out that, given that the questions asked about the lesson as a whole, we cannot always attribute information that students provided to the task. Students were also able to give more than one answer to questions asking about what they learnt and enjoyed, so the number of responses are not necessarily indicative of the number of respondents.

\section{The 10 tasks}

We now present each of the tasks, using a template which includes goals, relationship to previous work and resources. We evaluate the task against criteria (Ellis \& Shintani, 2014) to determine task-likeness (see Introduction to Part 2). In the Comments section, we briefly discuss the task, as a precursor to a more in-depth discussion in Chapter 6. We describe other phases of the lesson and then discuss the "task-as-process", identifying opportunities for language learning. Lastly, we analyse the student questionnaire answers. 


\section{Tania’s classroom: Task 1. Categorising sports}

\section{Task description}

A sorting task that required students to categorise sports and activities according to whether they are practised individually, in pairs or in teams

Year 10 (approx. age 14) class of 22 students of Japanese (14 students completed questionnaires)

\section{Task objectives/goals}

Produce language independently

\section{Learning intentions}

(as explained to students)

Talking about sport

Categorising sports as team/individual/pair

\section{Skills involved}

Spoken production (main focus)

Listening comprehension and reading comprehension (to be able to decipher questions, word cards).

\section{Relationship to previous work}

Previous lessons had focused on sports.

\section{Pre-task (5 mins)}

Charades: students are placed in groups. One student acts out a sport and the others guess what it is in Japanese. They can refer to vocabulary lists in katakana in their books.

\section{Task input/resources}

- cards with sports written in hiragana/katakana on one side and English on the other.

- handout of formulaic expressions written in katakana and English containing phrases such as "is this a team sport?" "(sport) is a team sport," "I think you're wrong" etc.

- large sheet of paper divided into four categories labelled team/pair/individual/other in katakana.

\section{Task implementation}

(16 mins., $30 \%$ of class time)

Students working in groups of approximately four, each group has a leader who records the category decisions.

Examples of sports are: chess, archery, ballet, surfing, cricket etc.

Examples of student utterances: [translations for the reader]:

Sukii wa hitori de shimasu ka? [Do you ski by yourself?]

Booringu wa hitori de shimasu. [I do bowling by myself]

Hine chan no ban. [It's Hine's turn]

At the end of the task the teacher asks the students to write a sentence to summarise a conclusion e.g., aerobikkusu was chiimu de shimasen. [Aerobics is not done in a team] 3 mins. 
Table 23. Evaluation against task criteria

\begin{tabular}{lll}
\hline Criterion & Fulfilled & Comment \\
\hline focus on meaning & yes & $\begin{array}{l}\text { Students functioning as language users communicating } \\
\text { opinions about how the different sports are played }\end{array}$ \\
$\begin{array}{lll}\text { some kind of gap } \\
\text { rely own resources }\end{array}$ & no & $\begin{array}{l}\text { A reasoning gap required agreement on classification of sports } \\
\text { Japanese words for team/pairs/individual taught in lesson. } \\
\text { Students are given language support (cards and handout) in }\end{array}$ \\
& & written katakana and English \\
outcome & yes & The classification of the sports into categories
\end{tabular}

\section{Comments}

In Chapter 6 this is described as a "focused" task in that the intended language use was highly preselected. However, at the same time there were opportunities for students to produce language independently and spontaneously.

This task was categorised as not fulfilling Criterion 3 (see Table 23) in that key phrases were taught prior to the lesson and students were given a handout of language they needed to complete the task. However, students needed to decipher the hiragana/katakana; they were not provided with any romaji (Japanese words written using the Roman alphabet).

\section{Other phases of this lesson}

In the first part of this lesson, the teacher had students review katakana symbols they knew and also taught them some new symbols. At the end of the lesson, after the task, they also reviewed katakana in pairs.

\section{The task-as-process}

A transcription of the teacher's discourse allowed for an analysis of the interactions she had with students. During the 16 minutes of the task, she interacted with at least 11 different students whose names were recorded in the lesson transcriptions. It is possible that this figure was much higher, because a large number of interactions involved unknown students. From this transcript of teacher discourse, four examples of LREs were identified, including Examples (9) and (10), discussed above. Recordings were also made of student interactions but unfortunately, there was so much classroom noise that the transcriber was unable to decipher these. 


\section{Student feedback}

The 14 students who completed the questionnaire reported learning aspects of vocabulary (e.g., names of sports) or language structures. Table 24 summarises these responses (some students reported learning more than one aspect of language).

Table 24. Student report of learning during Task 1

\begin{tabular}{lclc}
\hline Vocabulary/characters & $\begin{array}{c}\text { No of } \\
\text { students }\end{array}$ & Language structures & $\begin{array}{c}\text { No. of } \\
\text { students }\end{array}$ \\
\hline team/pair/individual & 6 & $\begin{array}{l}\text { expressions for categorising sports } \\
\text { as team etc. }\end{array}$ & 6 \\
names of some sports/activities & 5 & $\begin{array}{l}\text { questions for categorising sports } \\
\text { "Yes, I play X" or "I don't play X" }\end{array}$ & 5 \\
katakana & 10 & "Your turn" & 2 \\
\hline
\end{tabular}

Further evidence of student learning during this task came from an incident that the teacher recounted during the interview, where one student demonstrated that they were able to apply the language they had just been using in the lesson to their own context. She talked about how, at the end of the lesson, she observed one student talking to another classmate:

He was talking to one of the other boys and said "Oh what have we got next?" "I've got PE." "Oh, what are we doing?" "Oh yeah, we're doing these three sports." And I said to him "Oh you can say that in Japanese you know." And then he just said it in Japanese "Oh we're playing etc. etc., and we're going to play etc. etc., and that one's a team sport, and that one's a pair sport" and we'd just been using it, and he used it without looking at any of the notes or anything.

The 14 students reported enjoying the following aspects of this lesson that could, possibly, be related to the task (see Table 25).

Table 25. Student affective responses to Task 1

\begin{tabular}{lc}
\hline Students reported enjoying & No. of "likes" \\
\hline Conversations with friends & 3 \\
[Learning while] having fun & 5 \\
Categorising/learning about sports & 3 \\
Playing games & 2 \\
\hline
\end{tabular}

Five students reported that they enjoyed the part of the lesson where they learnt or reviewed katakana.

The overall satisfaction with this lesson, reported on a scale of 1 to 5 , with 1 being "really not enjoyable" and 5 being "very enjoyable," was 4.07 . 


\section{Tania’s classroom: Task 2. Conversation}

This was Tania's second lesson, taking place the next day after the previous lesson.

\section{Task description}

Students had a conversation in Japanese in pairs or small groups

Year 10 (approx. age 14) class of 22 students of Japanese (15 students completed questionnaires)

\section{task objectives/goals}

Free conversation/opportunity to talk in the third person

\section{learning intentions}

(as explained to students)

Extended conversation/ natural speaking conversation.

\section{skills involved}

Spoken production (main focus)

Listening comprehension (to be able to participate in conversation).

\section{relationship to previous work}

Previous lessons had focused on sports.

\section{pre-task (11 mins)}

Students play a game where they have to ask a question e.g., "otousan wa nan no supootsu wo shimasu ka?" [What sport does your Dad play?] and/or give an answer e.g., "sakkaa wo shimasu" [He plays soccer]. They are given cards with the question \& the word for the sport e.g., "sakkaa" [soccer]. The aim is to find someone with the same question \& answer.

\section{task input/resources}

- PowerPoint (see below)

Task instructions

(given in English)

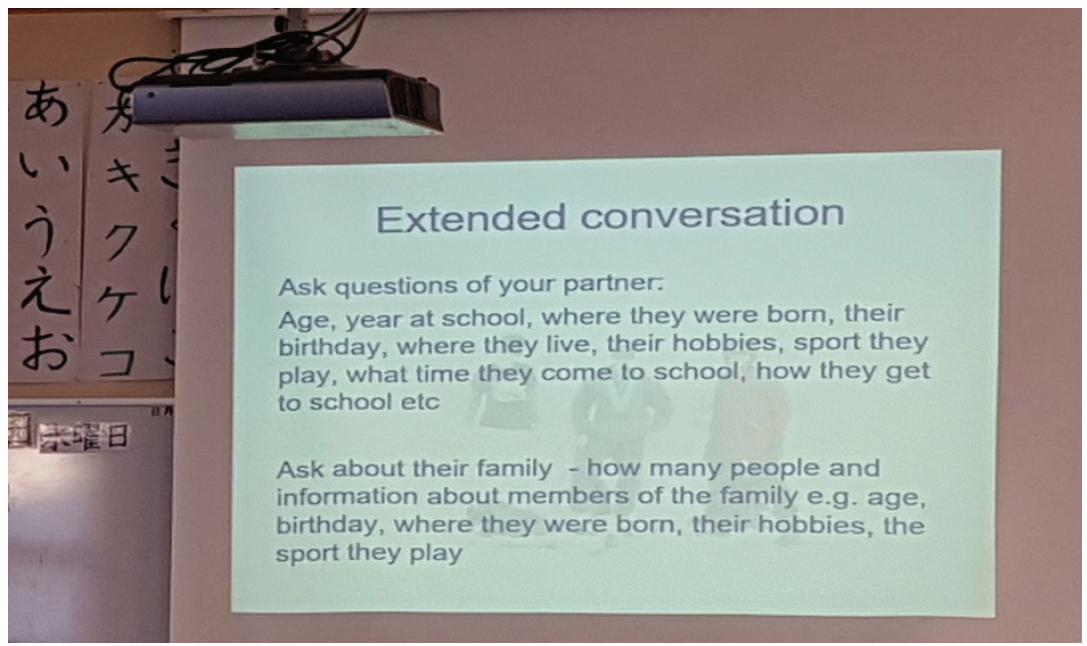


The teacher outlined possible topics and questions that could be asked. She also gave the following guidance.

The person who is talking to you... might correct you. And that's okay. They're not telling you you're wrong, they're just helping you get the right word... and if you make your own mistake... and partway through you realise... correct yourself.

Two minutes after the task had started, the teacher stopped the class and said: "at the end of this I am going to get you to give me some information about someone else that you talked to."

\section{Task implementation}

(24 mins., $44 \%$ of class time)

Students put into groups of four to have conversations

Examples of student language:

Chichi no namae wa nan desu ka? [What is your Dad's name?]

Gonin imasu. Haha to ane futari to imouto desu. [Five people. Mum and my two big sisters and my little sister].

Teacher stops the class (after 12 minutes) \& asks them to make notes of the information they have learnt so they can report back in Japanese. The students appear to make notes in English.

One student writes (in English):

$\mathrm{H}$. was born on the $23 \mathrm{rd}$ December, was born and raised in W. There are 4 people in her family, her Dad and Mum and younger brother. She has 2 dogs, Kate and Trixie. She plays soccer and does swimming. Her Dad was born and raised in W. She comes to school at $8: 30$.

Teacher calls on students to share what they have learnt about their classmates (in Japanese).

Examples of student language:

Otousan no namae wa X. Otousan no tanjoubi wa juugatsu desu. Otousan wa chokoreeto ga suki desu. [Her Dad's name is X. Her Dad's birthday is in October. Her Dad likes chocolate].

Otousan no namae wa W. W ni sunde imasu. Ragubii wo shimasu. [Their Dad's name is W. He lives in W. He plays rugby].

Table 26. Evaluation against task criteria

\begin{tabular}{|c|c|c|}
\hline Criterion & Fulfilled & Comment \\
\hline focus on meaning & yes & $\begin{array}{l}\text { Students functioning as language users communicating } \\
\text { about their lives. }\end{array}$ \\
\hline some kind of gap & [yes] & $\begin{array}{l}\text { Some students reported finding out things about their } \\
\text { classmates, but teacher confirmed this may not have been } \\
\text { the case for all. }\end{array}$ \\
\hline rely own resources & yes & $\begin{array}{l}\text { No language support provided; students could refer to their } \\
\text { class books if necessary. }\end{array}$ \\
\hline Outcome & yes & $\begin{array}{l}\text { Reporting to the class something they had learnt about a } \\
\text { classmate. }\end{array}$ \\
\hline
\end{tabular}




\section{Comments}

In Chapter 6, this is described as an "unfocused task" in that the intended language use was free and drew on all the language resources that the students had. In the interview, the teacher said, "we haven't had a conversation... we haven't done anything that free."

This task was categorised as only partially fulfilling Criterion 2 (see Table 26). We consider this notion of gap important because learners are likely to be more motivated to listen to a classmate giving information they might not already know. It is also worth noting that the outcome of reporting back something that they had learnt during the conversation (Criterion 4), was mentioned only after the task had begun.

\section{Other phases of this lesson}

After the task, students completed a reading comprehension activity. They were given a passage in hiragana and katakana and questions in English. They had to ask these questions of their partner in Japanese who looked for the answers in the text.

\section{The task-as-process}

As in Task 1, recordings of student interactions could not be used as there was too much classroom noise.

Seven examples of LREs were identified from the recording of the teacher discourse. Six were student-initiated and in five, information was given in the target language (see Example (11)). There were also examples of the teacher co-constructing dialogue with students and giving them interactional support.

Example 11. Student initiated LRE from Task 2

\begin{tabular}{|c|c|c|c|c|}
\hline Turn & Interlocutor & & Translation & Researcher comments \\
\hline 1 & Student & $\begin{array}{l}\text { Miss, how do you } \\
\text { reply like My Dad's } \\
\text { name's this? }\end{array}$ & & $\begin{array}{l}\text { Student initiates request for } \\
\text { language support. }\end{array}$ \\
\hline 2 & Teacher & $\begin{array}{l}\text { So you go chichi } \\
\text { no namae wa so if } \\
\text { someone goes outosan } \\
\text { no namae wa nana } \\
\text { desu ka? you say chichi } \\
\text { no namae wa }\end{array}$ & $\begin{array}{l}\text { So you go My } \\
\text { Dad's name is so } \\
\text { if someone goes } \\
\text { what is your Dad's } \\
\text { name? you say my } \\
\text { Dad's name is }\end{array}$ & $\begin{array}{l}\text { Teacher provides answer, } \\
\text { then models question and } \\
\text { answer. [Background noise } \\
\text { means we cannot know } \\
\text { whether there was any uptake } \\
\text { from this student]. }\end{array}$ \\
\hline
\end{tabular}


During the 24 minutes that this task lasted, the teacher interacted with at least seven different students, but it is possible that this figure was much higher. Classroom noise meant that sections of the teacher transcript were also unintelligible.

\section{Student feedback}

As shown in Table 27, students reported, most frequently, that they learnt how to use language to give or ask for specific information (here coded as language structures). The quotation given at the beginning of this chapter is an example of one learner's response. Four students reported learning something about (a) fellow classmate(s) that they didn't know, indicating that they were focused on meaning as a learning outcome.

Table 27. Student report of learning during Task 2

\begin{tabular}{cccccc}
\hline $\begin{array}{l}\text { Reported } \\
\text { learning }\end{array}$ & $\begin{array}{c}\text { About each } \\
\text { other }\end{array}$ & $\begin{array}{c}\text { How to have a } \\
\text { conversation in Japanese }\end{array}$ & Vocabulary & $\begin{array}{c}\text { Language } \\
\text { structures }\end{array}$ & Katakana \\
\hline 4 & 3 & 3 & 10 & 1 \\
\hline
\end{tabular}

Students reported enjoying the following aspects of this lesson (see Table 28) that could, possibly, be related to the task they completed:

Table 28. Student affective responses to Task 2

\begin{tabular}{lc}
\hline Students reported enjoying & No. of "likes" \\
\hline Having a conversation & 4 \\
Interacting/working with friends/classmates & 4 \\
\hline
\end{tabular}

The overall satisfaction with this lesson, reported on a scale of 1 to 5, was 3.9.

What we would conclude from Tania's two lessons containing Tasks 1 and 2

In these lessons, there was evidence of an approach typical of focus on formS in that much of the language use (especially in Task 1) was prescribed, preselected and even formulaic. At the same time, within this context where students were attending to and using particular language formS, they were also attending to meaning. This was particularly the case during the conversation (Task 2), where learners had the chance to encode and decode messages and opinions that were personal and true for them and their peers. However, this was also the case during Task 1, where even although the language that students used to classify sports could appear to be formulaic, the 
built-in cognitive challenge of reasoning and sorting these sports required a focus on meaning.

The information that students gave about their learning, furthermore, indicated attention to both language forms and meaning. Some students gave examples of language structures they had learnt, while others (e.g., in Task 2) reported "learning about each other," indicating that for some there were language, and for others, communicative outcomes. Interestingly, some students reported learning from, and enjoying, parts of the lessons that were not task-like and where there was a definite focus on language as an object, in particular, the memorisation of katakana characters.

These students had not been learning Japanese for a full year (the previous year they had had 6 months only), and they were timetabled for only 4 hours of classes a week. Taking account of these factors, it is, perhaps, difficult to imagine students working at tasks where the language use was significantly less prescribed and preselected than it was. However, even when the use of language tended to be formulaic, we found, as in Van den Branden (2009), the kind of interactions likely to promote language learning: negotiation of meaning, recasts, explicit metalinguistic information, clarification of meaning, pushed output and scaffolding. There were opportunities for learners to use language as a tool and construct form-meaning-function relationships. Furthermore, as already documented, we found these learning opportunities both in the context of more prescribed, and less predictable language use.

There was a high level of student engagement during both lessons. Evidence of this was the noise as students engaged in interaction. In both lessons, learners reported a high level of enjoyment. A number of students gave, as a reason for rating these lessons highly, the fact that they enjoyed working with each other and having conversations.

The teacher had a role as facilitator during both lessons, organising and motivating students to complete the task. However, arguably her role as conversational partner was the most important. She provided corrective feedback, extended and elaborated language input and met the language needs of different students in a variety of ways. She also prepared students to be effective conversational partners for their first conversation in Japanese, encouraging them to help and correct each other and trying to help them see that making errors was an expected part of the learning experience. Philp et al. (2014) emphasise the importance of teachers providing guidance in order to maximise the potential for interaction to be effective.

We conclude that even in completing a task where the language use was preselected, students had opportunities to use language communicatively and to engage in the types of interactions that are known to promote language learning.

We now turn to consider Tasks 3 and 4 from Margaret's classroom. 


\section{Margaret's classroom: Task 3. The teacher at age 6}

\section{Task description}

Students asked the teacher questions to find out about her life at age 6 years. They made notes of her answers and had 2 minutes to learn these. In groups they had to compete to see who could remember the most information about her.

Year 11 (approx. age 15) class of 11 students of French (questionnaire completed at end of following task)

\section{task objectives/goals}

Students learn imparfait (imperfect) in French and work towards NCEA assessment standard

\section{learning intentions}

(explained to students)

Preparation for NCEA writing assessment

Focus on imparfait

\section{skills involved}

Listening comprehension (main focus)

Spoken, written production and reading comprehension

\section{relationship to previous work}

No information available

\section{pre-task (9 mins)}

Students have brought baby photos; teacher puts these on board and numbers them. Students have to guess which photo belongs to whom.

\section{task input/resources}

- questions written in French on paper strips

- same questions on PowerPoint

\section{Task implementation}

\section{(33 mins., $55 \%$ of total lesson time)}

Each student is given a question e.g., Quel était ton livre péféré? [What was your favourite book?] on a strip of paper. They take turns to ask their question (displayed on a projector) of the teacher. Everyone listens and takes notes of the teacher's answers to all questions (18 minutes).

Students then have 2 minutes to memorise facts. In groups of between three and four students, they recall, in French, as many things as they can about their teacher (12 minutes). Two groups collaborate to share facts.

Group 2 wins with 25 facts, followed by Group 1 with 22 . 
Table 29. Evaluation against task criteria

\begin{tabular}{|c|c|c|}
\hline Criterion & Fulfilled & Comment \\
\hline focus on meaning & yes & $\begin{array}{l}\text { Students functioning as language users learning about their } \\
\text { teacher's childhood. }\end{array}$ \\
\hline some kind of gap & yes & $\begin{array}{l}\text { Students did not know the answers to questions that they } \\
\text { had to ask their teacher. }\end{array}$ \\
\hline rely own resources & yes & $\begin{array}{l}\text { Students not taught language they needed and had to recall } \\
\text { facts about teacher with no language support. }\end{array}$ \\
\hline outcome & yes & $\begin{array}{l}\text { To see which group could write down the most facts about } \\
\text { their teacher at the age of } 6 \text {. }\end{array}$ \\
\hline
\end{tabular}

\section{Comments}

This task was focused in that the teacher planned to create opportunities for students to use the imperfect tense. It was the only task in our data set that featured listening comprehension as the main language skill, and that had a post-task. This task was coded as fulfilling all criteria (see Table 29).

\section{Other phases of this lesson}

Following the task, the teacher read out a paragraph about herself as a 6-year-old which contained factual errors. The students were asked to identify these.

\section{The task-as-process}

As mentioned above, there was a post-task where Margaret asked the students if there was anything they had wanted to say but did not know how to. Two students asked questions, one asked how to conjugate the irregular verb vouloir (to want) in the imperfect. The teacher explained, and at the end of the lesson wrote the imperfect tense endings on the board. There were also instances of focus on language form at the beginning of the task, where learners asked about the questions that were displayed on the projector.

Because this task involved students having to listen to the teacher give information about herself, it was possible to have a record of all classroom discourse during a period of 18 minutes (excepting where students may have talked to each other rather than listen to the teacher). During these 18 minutes we identified at least 14 LREs. Five of these involved errors with correct production or pronunciation of the 
imperfect tense. In four of these, the teacher provided explicit negative feedback which was output-prompting, that is, it was designed to explicitly draw students' attention to the error and then required them to make a response. See Example (12).

Example 12. Reactive LRE from Task 3

\begin{tabular}{lllll}
\hline Turn & Interlocutor & & Translation & Researcher comments \\
\hline 1 & Student & $\begin{array}{l}{ }^{\star} \text { Est-ce que vous } \\
\text { entendez bien? } \\
\text { Entendez or } \\
\text { entendiez? }\end{array}$ & $\begin{array}{l}\text { Do you get on } \\
\text { well? }\end{array}$ & $\begin{array}{l}\text { Student uses present tense verb } \\
\text { when asking about the past. }\end{array}$ \\
& Teacher & & & Teacher draws attention to error \\
& & & $\begin{array}{l}\text { by repeating it and modelling } \\
\text { correct form using intonation to } \\
\text { get student to respond. }\end{array}$ \\
& Student & Entendiez & Got on & $\begin{array}{l}\text { Student uptakes to repeat correct } \\
\text { word after the teacher. }\end{array}$ \\
\hline
\end{tabular}

Three groups (a total of nine students) were also recorded interacting in small groups to recall, in French, facts about their teacher. An analysis of these transcripts shows that there were, during 6 minutes of recording, a total of nine student-student LREs (these did not include the teacher-student LREs mentioned earlier). There were also numerous examples of students scaffolding each other's production; see Example (13) which also contains a LRE in Turns 4 and 5.

Example 13. Students scaffolding each other's production in Task 3

\begin{tabular}{|c|c|c|c|c|}
\hline Turn & Interlocutor & & Translation & Researcher comments \\
\hline 1 & Student 1 & Elle a un frère & she has a brother & Together students scaffold each \\
\hline 2 & Student 2 & Oui & yes & other to produce information \\
\hline 3 & Student 1 & Il s'appelle $R$ & his name is $\mathrm{R}$ & about their teacher's childhood. \\
\hline 4 & Student 2 & ${ }^{\star}$ Ils battions & they used to fight & $\begin{array}{l}\text { Student } 2 \text { makes } 2 \text { mistakes - } \\
\text { omitting the reflexive form \& } \\
\text { using the incorrect imperfect verb } \\
\text { form. }\end{array}$ \\
\hline 5 & Student 1 & $\begin{array}{l}\text { Oui ouah }{ }^{*} \text { ils se } \\
\text { battions souvent }\end{array}$ & $\begin{array}{l}\text { yes yeah they } \\
\text { used to fight a lot }\end{array}$ & $\begin{array}{l}\text { Student } 1 \text { recasts the utterance, to } \\
\text { correctly model the reflexive form } \\
\text { but the verb is still incorrect. }\end{array}$ \\
\hline 6 & Student 2 & mais maintenant & but now & $\begin{array}{l}\text { Student } 2 \text { carries on but doesn't } \\
\text { uptake the correction. }\end{array}$ \\
\hline
\end{tabular}




\section{Margaret's classroom: Task 4. My childhood}

Margaret's second lesson, featuring Task 4, took place on the same day, after morning interval.

\section{Task description}

Students interviewed each other about their childhoods. Then they shared, with the class, interesting things they had learnt about each other.

Year 11 (approx. age 15) class of 11 students of French (nine students completed questionnaires).

\section{task objectives/goals}

Students learn imparfait (imperfect) in French \& work towards NCEA assessment standard

\section{learning intentions}

(same as for Task 3 and explained to students)

Preparation for NCEA writing assessment

\section{skills involved}

Spoken production (main focus)

Listening comprehension (to be able to answer questions)

\section{relationship to previous work}

Followed on from preceding lesson. Focus on having learners produce output after exposure to input in the previous lesson.

\section{pre-task (4 mins.)}

Teacher goes through the questions used in the task to make sure that all students understand them.

\section{task input/resources}

Two sheets of paper with the same questions on each e.g., Est-ce qu'il y avait des animaux chez toi? [Did you have any pets?] One set of questions was for them to answer in relation to themselves, the second set of questions was for them to pose to a classmate.

\section{Task implementation}

(50 mins., $80 \%$ of class time)

Teacher gives out a piece of paper with questions about students' childhood. Students have 5 minutes to write answers.

Example answers from one student:

Une petite maison à J. [A small house in J.]

Un chat qui s'appelait Sox [A cat called Sox]

J'allais au J School Primary [I went to J primary school]

*J'entendais bien avec mon frere [I got on well with my brother]

Students have 2 minutes (timed) to memorise their answers. They then move into new pairs and interview each other, asking and answering these same questions.

Teacher calls everyone to attention and asks students to share interesting things they learnt about their partner. 
Table 30. Evaluation against task criteria

\begin{tabular}{lll}
\hline Criterion & Fulfilled & Comment \\
\hline focus on meaning & yes & $\begin{array}{l}\text { Students functioning as language users communicating } \\
\text { about their childhoods. }\end{array}$ \\
some kind of gap & yes & $\begin{array}{l}\text { They did not know the answers to the questions they asked } \\
\text { their classmates. }\end{array}$ \\
$\begin{array}{l}\text { rely own resources } \\
\text { outcome }\end{array}$ & yes & $\begin{array}{l}\text { No language support provided. } \\
\text { The sharing of interesting facts about their classmates. }\end{array}$ \\
\hline
\end{tabular}

\section{Comments}

This was a focused task with the teacher's intention that students have opportunities to use the imperfect tense in French, after being exposed, during the previous lesson, to language using this structure, and language related to the topic of childhood. Once again, this task was coded as fulfilling all criteria (see Table 30).

\section{Other phases of the lesson}

There was no other clearly identified lesson phase.

\section{The task-as-process}

Unfortunately, approximately 10 minutes of discourse was not recorded due to recorder malfunction. At one stage, the teacher stopped students and reminded them that they would need to note answers that their classmates gave them in the third person form: "Think about the verb ending. The "il" and "elle" form."

In the 41 minutes that we have of Margaret's discourse as she moved around and interacted with students during the task, there were at least 46 LREs (unfortunately, there were many instances where the learner speech was unclear). This was over one form-focused episode per minute, a relatively high incidence of LREs (Erlam \& Pimentel-Hellier, 2017.) At least 22 of these were student-initiated queries where students were asking for language support to be able to say what they wanted to.

There were a variety of ways in which Margaret gave learners feedback about their language production and information about language in response to requests. In Example (14), she provided explicit metalinguistic information. 
Example 14. LRE from Task 4 incorporating explicit metalinguistic information

\begin{tabular}{ll}
\hline Teacher & Translation \\
\hline Je n'aimais pas - je n'aimais pas les broccolis. Do you remember & $\begin{array}{l}\text { I don't like - I don't like } \\
\text { broccoli... }\end{array}$ \\
\hline
\end{tabular}

It is highly likely that this information was given to the student who wrote on his questionnaire form (underlining as in the original): "I learned that when you don't like something you don't need to put an "un" in front of it, i.e., I put je n'aimais pas d'un broccoli, but you are meant to put... pas les broccoli."

Recordings were made of five pairs of students interviewing each other and an analysis of transcripts showed that, during a 16-minute period, there were a total of 30 LREs. This was almost two LREs per minute, a much higher rate than that reported in a review of task research conducted in EFL settings (McDonough, 2015). Once again, there were numerous examples of students scaffolding each other's production. Example (15) gives an example of a LRE which extended over several turns and involved a series of clarification requests (T. 3, $5 \& 7$ ) on the part of one of the students.

Example 15. Student scaffolded exchange from Task 4

\begin{tabular}{|c|c|c|c|c|}
\hline Turn & Interlocutor & & Translation & Researcher comments \\
\hline 1 & Student 1 & $\begin{array}{l}\text { Eh est-ce que tu } \\
\text { avais des animaux } \\
\text { chez toi? }\end{array}$ & $\begin{array}{l}\text { Did you have any } \\
\text { pets at your place? }\end{array}$ & \\
\hline 2 & Student 2 & $\begin{array}{l}\text { Oui javais des } \\
\text { poissons }\end{array}$ & Yes, I had some fish & \\
\hline 3 & Student 1 & Des poissons? & Some fish? & $\begin{array}{l}\text { Student } 1 \text { is querying what } S \text {. } \\
2 \text { has said. }\end{array}$ \\
\hline 4 & Student 2 & oui & yes & \\
\hline 5 & Student 1 & ${ }^{\star}$ Une poisson & one fish & $\begin{array}{l}\text { S. } 1 \text { checks whether S. } 2 \\
\text { intended to say one fish } \\
\text { (making a gender error with } \\
\text { the article). }\end{array}$ \\
\hline 6 & Student 2 & Des poissons & Some fish & S. 2 repeats original phrase. \\
\hline 7 & Student 1 & Des? & Some? & S. 1 queries meaning of des. \\
\hline 8 & Student 2 & Some & & S. 2 provides this in English. \\
\hline
\end{tabular}




\section{Student feedback}

The learning that nine students reported for two lessons (containing Tasks 3 and 4), is given in Table 31 .

Table 31. Student report of learning during Tasks 3 and 4

\begin{tabular}{cccc}
\hline $\begin{array}{l}\text { Reported } \\
\text { learning }\end{array}$ & Imperfect tense & $\begin{array}{c}\text { What a classmate/teacher } \\
\text { was like as a child }\end{array}$ & $\begin{array}{c}\text { A specific structure in } \\
\text { French }\end{array}$ \\
\hline 9 & 3 & 3 \\
\hline
\end{tabular}

Students reported enjoying the following aspects of both of Margaret's lessons (see Table 32).

Table 32. Student affective responses to Tasks 3 and 4

\begin{tabular}{lc}
\hline Students reported enjoying & No. of "likes" \\
\hline Learning about their teacher/classmates & 5 \\
Interacting/working with friends/classmates & 4 \\
Speaking in French & 2 \\
Using a variety of language skills & 2 \\
\hline
\end{tabular}

Students rated this lesson at 4, indicating that they found it enjoyable.

What we would conclude from Margaret's two lessons containing Tasks 3 and 4

Margaret was the teacher whose practice, was, according to our analysis, the most task-based, in that she was the only teacher who taught, in both lessons, a task that fulfilled all criteria. Ironically, however, she was the teacher who was most focused on the importance of language formS, in terms of her goals for the lesson (see Chapter 7). Her objectives, given to the students, were that they would focus on the imperfect and work towards an assessment task. Moreover, in her corrective feedback, she consistently oriented students to the imperfect, requiring them to choose between her repetition of their error and the correct form. The students were very aware of this language focus; all nine who completed the questionnaire reported that they had learnt the imperfect.

At the same time, Margaret's lessons provided lots of opportunity for learners to attend to meaning. Margaret's pre-task (Task 3) oriented students to the topic of the lesson rather than to language. In both lessons, students had opportunity to attend 
to language in the context of communicating meaning. The incidence of LREs, at a rate of 1.3 per minute in Task 3 and almost 2 (1.9) in Task 4, was the highest of all the tasks and lessons that we analysed as part of this research. These estimates are conservative because there were parts of the discourse that we could not decipher and, furthermore, we did not include teacher-initiated, preemptive focus on form as some studies do (because, as already explained, these did not necessarily indicate a gap in students' knowledge, although they may have represented opportunities for learners to focus on language form).

It is interesting to consider, in Task 4, whether the open-ended nature of this task may have accounted for the higher rate of LREs. According to Ellis (2003), the orientation of Task 4 is divergent, in that learners were unrestricted in the information they could provide whereas, in Task 3, it was convergent, in that learners were trying to recall a limited and determined set of facts (information about their teacher). While the quantity of LREs may have varied between the two lessons and tasks, the range, however, did not. In both, we found examples of negotiation of meaning, recasts, explicit metalinguistic information, pushed output and scaffolding. Relevant form-meaning-function relationships were being formed. Students' reports of what they learnt (facts about their teacher and each other) and of lesson enjoyment indicated engagement with content.

As in Tania's lesson, Margaret remained an active conversation partner, tailoring information and feedback to the needs of her students.

In summary, Margaret was a teacher who ascribed considerable importance to a focus on formS or to grammar (see Chapter 7). She carefully designed a lesson sequence, working from providing students with input, to scaffolding them to produce output. Students consistently encountered and practised the imparfait, which they knew was the target structure for the lesson. Yet, at the same time, students were focused on meaning and there were many opportunities for creative and unpredictable language use, promoting the types of interactions known to afford opportunities for learning. The incidence of LREs was high; this is also attributable to the higher language proficiency of these students who were in their third year of learning French. 


\section{Linda’s classroom: Task 5. Making predictions}

This lesson took place at a private school for girls. It was the second lesson observed in Linda's classroom. The first lesson did not contain a task (i.e., did not fulfil three of the four criteria).

\section{Task description}

Students were watching the film Viva Cuba. They had to predict what the main characters (two young children) would take with them as they ran away from home, and what problems they might encounter.

Year 11 (approx. age 15) three students (two absent) of Spanish (students did not fill out a questionnaire for this lesson).

\section{task objectives/goals}

Learn about life and culture in Cuba as they learn about language.

\section{learning intentions}

(explained to students)

To think about what to take when running away and to predict problems which would arise.

\section{skills involved}

Spoken production (main focus)

Listening comprehension as they watch film (however, they also have English subtitles).

\section{relationship to previous work}

Students were part way through a unit on Cuba and had already watched approx. 30 minutes of the film.

$$
\text { pre-task (20 mins. approx) }
$$

Discussion about topic and their own experiences of moving - orienting students to plot of the film where the main character does not want to leave Cuba.

\section{task input/resources}

- DVD - Viva Cuba

\section{Task implementation}

(30 mins., $50 \%$ of class time)

Students watch movie ( 8 mins) then stop to predict, in discussion with the teacher, what the characters will take with them (3 mins)

Examples of the things they suggest:

Un bolso con comida [a bag with food]

Pantalones cortos y una camiseta [shorts and a tee shirt]

Students watch (5 mins) and realise they haven't thought of items like una brújula [compass].

They then predict problems characters may face ( 5 mins), e.g.,

${ }^{*}$ Son demasiado joven [they are too young]

No lugar para dormir [nowhere to sleep]

Andar y tener hambre [walk and be hungry]

Students watch to see whether their predictions are true or not (9 mins). 
Table 33. Evaluation against task criteria

\begin{tabular}{|c|c|c|}
\hline Criterion & Fulfilled & Comment \\
\hline focus on meaning & yes & Students functioning as language users watching film. \\
\hline some kind of gap & yes & They do not know what happens in the film. \\
\hline rely own resources & yes & No language support provided \\
\hline outcome & [yes] & $\begin{array}{l}\text { To see whether or not they have made the correct } \\
\text { predictions, however there is no acknowledgement of } \\
\text { outcome completion (especially for } 2 \text { nd set of predictions) } \\
\text { in the lesson. }\end{array}$ \\
\hline
\end{tabular}

\section{Comments}

In the interview, Linda told the researcher that a goal for the unit she was working on was that the students would learn about Cuba as they also learnt Spanish. She believed that the unit would offer many opportunities for language learning.

This task was unfocused. It did not fulfil the last task criteria because there was no discussion as to how successful their predictions had or had not been (see Table 33).

\section{Other phases of the lesson}

The lesson started with one student giving a speech in Spanish that she had prepared as part of the requirement for her external assessment. The others listened.

\section{The task-as-process}

There were 20 LREs during the task; this also included time watching the film (approximately one every 1.5 minutes). Because the discussion was teacher-fronted, the students $(n=3)$, all had access to these LREs. Linda, tended to help students in two ways as they endeavoured to make predictions in Spanish. Firstly, she provided the words that the learners needed (see Example (16): Turns 1 \& 2). Secondly, Linda recast or reformulated errors (Ellis et al., 2001) that students made. In this way, she provided negative evidence, that is, information about language use that is not possible or correct in the target language (White, 1991) (see Example (16): Turns 3 \& 4). 
Example 16. LREs from Task 5

\begin{tabular}{|c|c|c|c|c|}
\hline Turn & Interlocutor & & Translation & Researcher comments \\
\hline 1 & Student & $\begin{array}{l}\text { They have a } \\
\text { compass }\end{array}$ & & $\begin{array}{l}\text { Student doesn't know how to say } \\
\text { the phrase in Spanish. }\end{array}$ \\
\hline 2 & Teacher & $\begin{array}{l}\text { Si, pero tienen una } \\
\text { brújula. }\end{array}$ & $\begin{array}{l}\text { Yes, but they have } \\
\text { a compass }\end{array}$ & $\begin{array}{l}\text { Teacher provides Spanish for this } \\
\text { phrase. }\end{array}$ \\
\hline 3 & Student & $\begin{array}{l}{ }^{*} \text { No pueden } \\
\text { duchar }\end{array}$ & They can't shower & $\begin{array}{l}\text { Student makes an error by not } \\
\text { using the verb "duchar" as a } \\
\text { reflexive verb. }\end{array}$ \\
\hline 4 & Teacher & $\begin{array}{l}\text { Ducharse, si, } \\
\text { exactamente }\end{array}$ & $\begin{array}{l}\text { Have a shower, } \\
\text { yes, exactly }\end{array}$ & $\begin{array}{l}\text { Teacher recasts error into correct } \\
\text { form. }\end{array}$ \\
\hline 5 & Student & ${ }^{*}$ No es bien & That's not well & $\begin{array}{l}\text { Student makes a mistake by using } \\
\text { the adjective instead of the adverb } \\
\text { to mean "That's not good" } \\
\text { Discussion continues. }\end{array}$ \\
\hline
\end{tabular}

Student feedback

Questionnaires were not completed for this lesson. However, it is interesting to note that all four of the five students who completed questionnaires in the previous lesson, reported that they had learnt more about Cuba.

What we would conclude from Linda's lesson containing Task 5

Of all the lessons we saw, this was the one that most embodied content and language integrated learning. The focus of the unit was that students would learn about Cuba, with the goal that, at the same time, they would have opportunities to make Spanish language gains. In the other lessons and units we observed, the topic/content provided the focus for the language used, but did not also provide a learning objective. The content-focused nature of Linda's lessons meant that the task was unfocused. These students, in Year 11, and in their third year of Spanish, had higher proficiency. The small class size $(n=5)$ and the fact that they students had access to a Spanish-speaking language assistant, could also have accounted for their level of language proficiency.

During the lesson there were opportunities for students to attend to language form in the context of communicating meaning. Over the whole lesson (which also included time watching the film) LREs were at a rate of almost 1 per minute.

In summary, Linda's task contrasts with the previous four that we have documented from Tania's and Margaret's lessons. We suggest that Linda's approach is more aligned with what some of the literature would predict would be typical of the 
TBLT classroom. There appears to be no predetermined set of structures underlying this lesson and unit but there were opportunities for learners to attend to language form that arose incidentally from the lesson.

In the next section we document two lessons from Emily's Chinese language classroom; these are Tasks 6 and 7 of our data set of 10 tasks

\section{Emily's classroom: Task 6. Treasure Hunt}

This and the following lesson took place in an all-boy's school.

\section{Task description}

Students completed a Treasure Hunt where they looked for QR codes hidden around the school. They scanned each QR code to obtain a word (in Chinese) relevant to where the treasure was hidden, and a clue for the next QR code. The words needed to be assembled so that the hiding place of the treasure could be revealed.

Year 10 (approx. age 15) 24 students of Chinese (15 students completed questionnaires).

\section{task objectives/goals}

Find directions, work independently in teams

\section{learning intentions}

\section{skills involved}

Reading comprehension (main focus)

Spoken production

\section{relationship to previous work}

Part of a unit on giving directions

\section{pre-task (5 mins)}

Students complete a vocabulary quiz on their phones of the words they will need in the task. They choose the correct character and pinyin corresponding to an English word or vice versa. The top five students get prizes.

- handout (see below)

task input/resources

- students' phones

Task implementation

(38 mins., $63 \%$ of class time)

Students are put in groups of approx. four. Each group looks for the same clues but works at finding \& solving these in a different order. Groups scan QR codes, obtain a word relevant to the location of the treasure and a clue to find the next QR code.

Some examples of the clues are:

在新体育馆和科技楼中间 [In the middle of the new gym and the science building] 在社会楼和艺术楼中间的椅子上。[It's on the chair in the middle of social and arts buildings]

Students complete the task outside in groups and the teacher, along with the Mandarin language assistant, are available for support. 
Table 34. Evaluation against task criteria

\begin{tabular}{|c|c|c|}
\hline Criterion & Fulfilled & Comment \\
\hline focus on meaning & yes & $\begin{array}{l}\text { Students functioning as language users and completing a } \\
\text { Treasure Hunt }\end{array}$ \\
\hline some kind of gap & yes & They did not know where the treasure was hidden \\
\hline rely own resources & yes & $\begin{array}{l}\text { Students using familiar language in a new context and } \\
\text { allowed to use online resources to work out the meaning of } \\
\text { words they did not know }\end{array}$ \\
\hline outcome & yes & To find out where the treasure was \\
\hline
\end{tabular}

\section{Comments}

This task was rated as one that was focused, requiring students to understand language for directions, school subjects and buildings, written in Chinese characters. It fulfilled all task criteria (see Table 34).

\section{Other phases of the lesson}

There was no other clearly identified lesson phase.

\section{The task-as-process}

The teacher was audio-recorded during this lesson, but the students were not, as they had not returned their signed ethics sheets in time.

There were seven examples of LREs in the teacher discourse transcript. We also found examples where the teacher provided language support or scaffolding for students as they completed the task, but where the focus on language, was, as far as could be ascertained from the recording, preemptive. This means that there was no clear evidence that her scaffolding met a gap in terms of learner knowledge (see Example (17)). However, it is hard to be sure of this as learners were working with written clues and may have been showing the teacher language they needed help with, rather than asking about it.

It is entirely probably that examples like Example (17) may have afforded opportunities for language learning in that students got repeated exposure to language they had already encountered in class. What is more, this focus on language was motivated by the task and students were encountering the language in a context in which they needed to engage with meaning. 
Example 17. Preemptive teacher-initiated focus on language

\begin{tabular}{|c|c|c|c|}
\hline Interlocutor & & Translation & Researcher comment \\
\hline Teacher & $\begin{array}{l}\text { 下面是什么? 下面 is the } \\
\text { clue }^{\circ}\end{array}$ & $\begin{array}{l}\text { What's "Xiamian"? "Xia } \\
\text { mian" is the clue. }\end{array}$ & $\begin{array}{l}\text { Xiamian means } \\
\text { "under." }\end{array}$ \\
\hline Student & 下面。 & Under & \\
\hline Teacher & $\begin{array}{l}\text { 写下面, 这里。在科学楼和 } \\
\text { 社会楼中间॰科学是什么? } \\
\text { 什么是科学?科学? }\end{array}$ & $\begin{array}{l}\text { Please write here. In the } \\
\text { middle of science and social } \\
\text { building. What's Kexue? }\end{array}$ & Kexue means "social." \\
\hline
\end{tabular}

At the same time as she provided language support for students, Emily also adopted a number of other roles demonstrating the importance of the teacher in task implementation. She continually monitored task conditions so as to help students achieve the task purpose. In each instance below, Emily used Chinese as she:

- organised students into groups

Samuel, 太多人了, 不可以五个人。

[Samuel, too many people. You can't have five people in one group]

- ensured students had the equipment they needed for the task

你应该有手机, 你的手机可以 scan QR code ○你们有手机吗? 把手机 拿出来。你有手机

[You should have a phone, your phone can scan QR code. Do you have your phones? Take out your phones. You have a phone]

- $\quad$ suggested access to support they might need for the task (Teacher Liu is the Mandarin language assistant).

你应该去看刘老师, 找刘老师。刘老师在橄榄球场。对, 好。

[You should go and see teacher Liu, find teacher Liu. Teacher Liu is in the rugby court. Yes, OK.]

你可以用 Google translate, 你可以用字典。

[You can use] Google translate. [You can use a dictionary.]

- monitored the pace as students completed the task

你们去数学楼。好, 快点。快快快○加油加油。

[You are going to the maths building. Ok, hurry up. Hurry, hurry. Good luck] 


\section{Student feedback}

Two students reported that they did not learn any new language but that they revised language. This emphasises the role of this lesson in enabling students to recycle language they already knew.

Table 35. Student report of learning during Task 6

\begin{tabular}{llccc}
\hline $\begin{array}{l}\text { Instructions/directions } \\
\text { in Chinese }\end{array}$ & \multicolumn{1}{c}{ Vocabulary } & $\begin{array}{c}\text { Working in } \\
\text { a team }\end{array}$ & $\begin{array}{c}\text { How to read } \\
\text { in Chinese }\end{array}$ \\
\hline 7 & $\begin{array}{l}\text { School subjects } \\
\text { School buildings }\end{array}$ & 2 & 2 & 2 \\
& Colours & 1 & & \\
\hline
\end{tabular}

Students reported enjoying the following aspects of this lesson (see Table 36).

Table 36. Student affective responses to Task 6

\begin{tabular}{lc}
\hline Students reported enjoying & No. of "likes" \\
\hline being outside the classroom/ & 9 \\
moving around & 4 \\
working in groups & 4 \\
a fun activity & 3 \\
getting prizes & \\
\hline
\end{tabular}

The students rated satisfaction with this lesson at 4.9, indicating that, for most, it was highly enjoyable.

\section{Emily's classroom: Task 7. Working with Mazes}

Emily's second lesson, featuring Task 7, took place on the following day. In this lesson, we describe three tasks, following on from what Emily described as the pre-task phase. While we incorporated the third task, as Task 7, in our data set of 10 tasks (see Introduction to Part 2) because it took the most time, we decided to include the two preceding tasks here in our lesson description because of the way in which they scaffolded students towards completing Task 7. 


\section{Task description}

Task 1: Students played a game Laoshi shuo (Teacher Says) based on Simon Says.

Task 2: Students took turns to give directions to another blindfolded student so that they could draw their way out of a maze projected onto the class whiteboard.

Task 3: (Task 7 in our overall data set): Students had a handout of four mazes. They first wrote and then read out instructions in Chinese for finding one's way out of one of these; their classmate had to decide which maze the instructions corresponded to.

Year 10 (approx. age 14) 24 students of Chinese (no questionnaires completed due to limited time).

$$
\text { task objectives/goals }
$$

Giving directions

\section{learning intentions}

\section{skills involved}

Spoken production (main focus)

Written production

\section{relationship to previous work}

Part of a unit on giving directions and following on from previous lesson, giving students opportunity to use language of directions in output.

\section{pre-task (8 mins. approx.)}

Students completed a "Finding Directions Sheet." They wrote translations in English next to a series of Chinese phrases and words.

\section{task input/resources}

- Task 1: the teacher projected on to the board, in English/characters and pinyin, direction phrases/words. She removed the English partway through the game.

- Task 2: students had access to pinyin and characters.

- Task 3: students were given a handout of task instructions, written in English. The language students needed was listed in pinyin and characters on this handout.

\section{Task implementation}

(Tasks 1-3, 24 mins. approx., 72\% of the total lesson time; Task 3, 19 mins., approx. 32\% of class time)

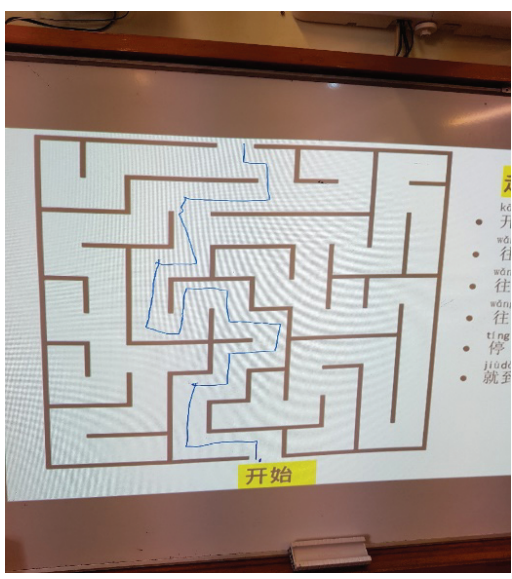


Task 1: Students play Laoshi shuo (Teacher says). The teacher calls out commands in Chinese ["teacher says back, teacher says front"] and the class follow when these are prefaced with "teacher says." Students who respond incorrectly are eliminated from the game. The teacher then gives individual students the chance to be the laoshi and call the commands [10 mins.]

Task 2: The teacher projects a picture of a maze on the board (see image above). She blindfolds one student and has another student give directions while the blindfolded student traces a line through the maze. The language needed for this task is to the right of the maze. Students take turns at giving the directions [14 mins.].

Task 3: (task 7 in our overall data set) In groups of two, students first write instructions in Chinese for one of four mazes on their handout. They then give their partner these directions. He has to establish which maze they have chosen [19 mins.].

Some examples of language students used:

往前走, 停, 往右拐॰停, 往前走。 [Go forward, stop. Turn right, stop. Go forward.] 往左拐, 往后走。[Turn left, go back.]

Table 37. Evaluation against task criteria for Tasks 1-3

\begin{tabular}{lll}
\hline Criterion & Fulfilled & Comment \\
\hline focus on meaning & yes & $\begin{array}{l}\text { Students functioning as language users and playing Laoshi } \\
\text { shuo [1] \& a puzzle game in Mandarin [2 \& 3] }\end{array}$ \\
some kind of gap & yes & $\begin{array}{l}\text { Following teachers' and classmates' instructions [1] } \\
\text { Understanding and communicating how to get through the } \\
\text { maze [2]. They did not know which maze their partner had } \\
\text { chosen [3] } \\
\text { They had not just been taught this language. However, most } \\
\text { of it was available for them on the blackboard [1 \& 2] or } \\
\text { handout [3], which may not have facilitated automatisation } \\
\text { outcome }\end{array}$ \\
& yes & $\begin{array}{l}\text { Not getting eliminated from the Laoshi shuo game [1], getting } \\
\text { out of the maze [2] and finding out which maze was the } \\
\text { correct one [3] }\end{array}$
\end{tabular}

\section{Comments}

We rated Task 3 (Task 7 in our data set of 10 tasks, as described above) as another focused task. However, in our opinion (as explained in our description in the Introduction to Part 2), it did not fulfill both questions for requiring learners to rely on their own linguistic resources (see Table 9). Students had not been taught the language they needed prior to working at the task (Question 3a answered), however, the fact that the language they needed to complete the task was on the worksheet handout did not, in the researcher's opinion, fully allow for automatisation (Question 3b not fulfilled). This judgement was made because students had 
had a lot of opportunity to hear and use this language as they played Laoshi shuo. Additionally, in Task 2, there was further opportunity to hear and use this language, which could have meant that less language support would have been necessary in Task 3. In other words, it was not unreasonable, in the researcher's view, to expect that students could have been required to rely more on the linguistic repertoire that they had built up of this language and having it available on their worksheet did not necessarily foster this independence.

An interesting feature was that a third student joined each pair to note the language used in the interaction with the aim of establishing which pair used the most target language. However, this information was not discussed with the students, perhaps because of time limitations, nor did students comment on it in the questionnaires.

\section{The task-as-process}

The teacher was recorded during this lesson but there was too much classroom noise for any recording of student interaction to be decipherable. Four LREs were identified in the transcript of teacher discourse.

This lesson built on the preceding where students had to read, decipher and follow directions in Chinese. Here the expectation was that they would have opportunities to produce directions in spoken Chinese. In Task 1, five students had the opportunity to give instructions, and in Task 2, six different students went to the front of the class and gave instructions to a blindfolded classmate. The whole class was focused, at times calling out instructions and commenting when an error was made. From the audio data we were able to document how many times the target formulaic phrases, for directions in Chinese, were produced by students. This output, of course, also constituted input for all learners. As we can see from Table 38, the instruction "forward" was spoken 10 times by students during Task 1, as was the phrase "go forward" (spoken a total of 34 times during Tasks 1 and 2). In Task 3, students had the opportunity individually, in pairs, to use these instructions.

Table 38. Student output of target formulaic phrases

\begin{tabular}{lccc}
\hline Direction in Chinese & Task 1 & Task 2 & Totals \\
\cline { 2 - 4 } & No of times directions spoken by students & \\
\hline go forward & 10 [forward 10] & 24 & $34[44]$ \\
turn right & $8[$ right 8] & 15 & $23[31]$ \\
turn left & 4 [left 9] & 13 & $17[26]$ \\
go back & $6[$ back 14] & 8 & $14[28]$ \\
stop & 2 & 31 & 33 \\
& $30[41]$ & 91 & $121[162]$ \\
\hline
\end{tabular}


What we would conclude from Emily's two lessons containing Tasks 6 and 7

The language of both these tasks, primarily, that of giving directions in Chinese, was predetermined, prescribed and formulaic. There was little opportunity for creative language use. The students were in their second year of learning Chinese, and were being encouraged to read characters rather than just rely on pinyin. These two lessons were carefully planned to move students from comprehending directions in Chinese, to also being able to produce them. In the second lesson, a series of tasks scaffolded students towards this goal.

In these lessons, students were exposed to and used the language of directions over, and over, again. In our conservative estimate (NOT including the 19 minutes where students interacted in pairs), students produced 162 direction phrases in Chinese during lesson 2, which also served as input for their fellow classmates. An interesting feature of both lessons is the relatively limited occurrence of LREs. This may be due to the fact that in the second lesson the use of language was related to a visual response, that is, tracing a route on the board or on a worksheet. At the same time, it is important to acknowledge that the occurrence of LRES is not, in itself, a guarantee of learning.

This was a class of noisy and boisterous young men, but they were all engaged in these lessons and loved calling out when their classmates made an error in tracing a route through the maze. The Treasure Hunt was highly rated; this class of 14-year-olds appreciated the chance to get outside the classroom and move around the school in teams. The teacher played the crucial role of task organiser, motivator, and support giver.

In summary, the students in these lessons were like those in Tania's (Tasks 1 \& 2) classroom in that they were beginners, and they were learning a new writing system at the same time as learning a new language. Emily planned lessons, as Margaret did, that exposed learners to extensive language input and then provided scaffolded opportunities for them to produce this same language. While the language was heavily preselected and predetermined, students had the opportunity to engage with it in the context of decoding and encoding meaning. The learning opportunities came not so much from opportunities to focus on language in LREs, but from opportunities to repeatedly hear and produce the same language, thus automatising these forms and developing language fluency. Researchers claim that language learning is gradual. Learners need to be exposed to massive amounts of input and have many opportunities to encounter the same meaning-form-function relationships (Dupuy, 1999; N. C. Ellis \& Wulff, 2015; Keenan \& MacWhinney, 1987; Lightbown, 2014). They also need the chance to recycle, by engaging in meaningful practice, the language they have started to acquire (DeKeyser, 2007; Ortega, 2007).

We now turn to another Japanese classroom and a very different approach to the use of tasks. 


\section{Shona’s classroom: Task 8. Murder mystery}

\section{Task description}

As part of a Murder Mystery unit, students were completing a Suspect booklet which contained profiles of potential suspects. They were reading and processing information that had been given to them in a worksheet entitled "Suspect clues 2."

Year 11 (approx. age 15)13 students of Japanese (questionnaires completed by seven students).

\section{task objectives/goals}

Establish who each suspect is for the Murder Mystery Unit as they use the language of descriptions

\section{learning intentions}

Start to determine the murder suspects

\section{skills involved}

Reading comprehension (main focus)

\section{relationship to previous work}

Students working on a Murder Mystery Unit in a flipped mastery classroom. They need to establish who murdered the deputy principal in their school, where and their motivation for doing so.

\section{pre-task}

Work completed previously, see "other phases of the lesson"

\section{task input/resources}

Worksheet "Suspect Clues 2" containing clues about suspects, Suspect book (both written entirely in hiragana/katakana/kanji).

\section{Suspect Clues 2}
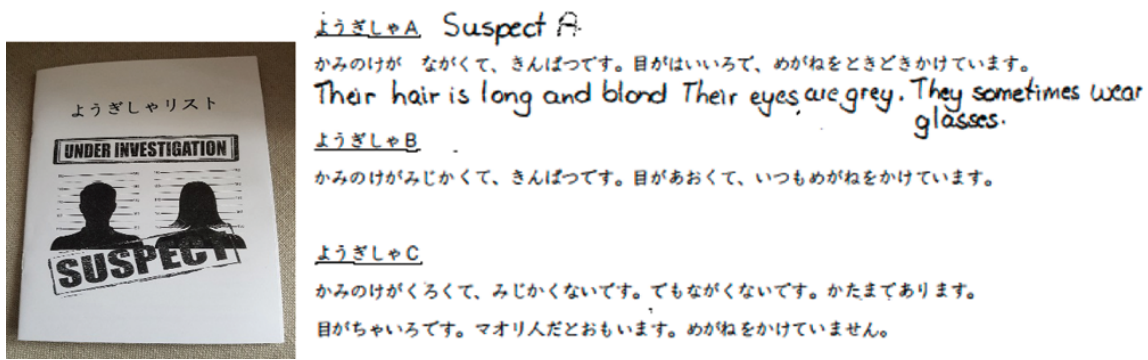

\section{Task implementation}

(time taken undetermined, as students worked at own pace) Students working mainly in pairs. They have a worksheet (see Suspect Clues 2, above, with translation included for the reader) and are using it to fill out their Suspect book (see above). Students take their book to the teacher who checks that all entries are correct. 
Table 39. Evaluation against task criteria

\begin{tabular}{lll}
\hline Criterion & Fulfilled & Comment \\
\hline focus on meaning & yes & $\begin{array}{l}\text { Students functioning as language users decoding language } \\
\text { to establish murder suspects }\end{array}$ \\
$\begin{array}{lll}\text { some kind of gap } \\
\text { rely own resources }\end{array}$ & no & $\begin{array}{l}\text { They did not know who the suspects were } \\
\text { They were learning the language (of description) they } \\
\text { needed for the task as they worked at it } \\
\text { outcome }\end{array}$ \\
\hline
\end{tabular}

\section{Comments}

Shona's students were working at a Murder Mystery unit, aiming to solve who had murdered their deputy principal and with what motive. In this flipped mastery classroom, students completed a series of situational grammar exercises, activities, and tasks as they worked, mainly in pairs, through the unit. The unit was scheduled to extend over 4 to 5 weeks. In the lesson observed, two pairs of students were working on Chapter 2 of the unit in order to establish the murder suspects. The task described above was part of this chapter, and one that a number of students were working on. It did not take the whole focus of the lesson.

This was rated as a focused task. It did not fulfil Criterion 3 (see Table 39), because students had been taught the language that they needed, immediately prior to working at the task. It was one of only three tasks in our data set that was input-based, requiring students to decode written text in Japanese.

\section{Other phases of this lesson}

Immediately before this task, students had completed a series of activities or situational grammar exercises, with the aim that they would learn the different verbs for "to wear". They had:

- watched a video about verbs "to wear"

- written notes on verbs "to wear"

- completed (situational grammar) exercises in their workbook

When these exercises had been checked off by their teacher, students worked on the task described above.

After completing this task, students sat a vocabulary quiz, and then a "Descriptions mini test" at which they had to gain at least 75\%. In this test they had to give the English for a number of Japanese words, list the verbs for "to wear," and write a description of someone in Japanese given some key descriptive words in English. They worked at this test in pairs. 


\section{The task-as-process}

The teacher was recorded, as were three pairs of students who worked at this task. The fourth pair was not recorded because one student had not consented to be involved in the study.

During the lesson, all three pairs of students took their Suspect booklet to the teacher who checked it and established that everything was complete and correct.

An interesting aspect of this lesson was that, in the interview, the teacher explained that the students were free to use whichever language they liked. Consequently, there was more English language use than in other tasks. This may also have been a reflection of the stage of the task. All pairs of students had completed the "Suspects Clues 2" worksheet and were working together to establish, using a photo and list of teaching staff at their school, who the six suspects were. They did this almost exclusively in English and only used Japanese when addressing the teacher, Shona.

There was a total of 9 LREs during the task phase of the lesson, seven out of which involved the teacher, who almost exclusively spoke to the students in Japanese.

\section{Student feedback}

Five students reported learning who the suspects were. Students also reported learning aspects of language associated with objectives for Chapter 3 (i.e., "before" sentences, daily verbs, plain form of verbs), which they moved on to work at after completing Chapter 2.

There were two main aspects of this lesson that the seven students reported enjoying. These were:

- establishing the murder suspects (four students)

- $\quad$ working at their own pace (three students)

Four of the students said that the lesson was fun. One reported: "having fun while incidentally learning Japanese."

Five of the students rated this lesson at 5 , as very enjoyable. The total rating for the seven students was 4.3.

\section{What we would conclude from Shona's lesson containing Task 8}

Shona's flipped mastery classroom was very different from the others we observed. The first obvious difference was that students were working at their own pace, in pairs or small groups, through the Murder Mystery unit Shona had designed. The second difference was that there were two levels of task (see Chapter 6). The first was the "target task," at the level of the unit, where students had to solve the Murder Mystery. 
Within this target task, were other smaller tasks, which we call "pedagogic tasks," such as the one we describe in this lesson. However, there were also examples of activities that would not meet our criteria of task. We referred to these as situational grammar exercises because the students were focused on formS, working with language that was decontextualised, and functioning as language learners rather than language users.

There are several important points to highlight about the attention to language formS and to language as object. Firstly, the decontextualised language activities (including tests) that students worked at enabled them to learn the language required to decode the clues they needed to solve the Murder Mystery, a task which was cognitively demanding in that it required the processing and analysis of a wide range of information. So, the language formS were not only necessary, but also became contextualised in the context of the Murder Mystery. In other words, they enabled learners to establish meaning, bridge a communicative gap and, ultimately, arrive at an outcome (who killed the deputy principal). Through this process, the students alternated between functioning as language learners and language users.

Despite the considerable focus on language as object, the seven students rated the lesson as enjoyable, with five reporting that it was highly enjoyable. Interestingly, it seems that the student who reported having fun "while incidentally learning Japanese" may have considered completing the quizzes and tests as part of this experience. The learners appeared happy to work at decontextualised language activities (including tests) so as to learn the language required to decode clues. In other words, the cognitive challenge of solving the Murder Mystery seemed to lead to learner engagement. The student who was "so excited" and whose quote is referenced at the beginning of Chapter 6 is evidence of this. The fact that students also worked in pairs and that there was evidence of competition (in the transcripts) may have contributed to the enjoyment.

In our data set, the incidence of LREs as students completed the task, at an average of 0.25 per minute, or 1 every 4 minutes, was low. On the other hand, the rate of opportunities to attend to language during the "descriptions test" phase of the lesson where students were functioning as language learners rather than language users, was much higher, at an average of 1.4 per minute. During this second phase, students collaborated to write a description, in Japanese, of a fictional person called "Kate," according to information given. There were also instances of students scaffolding each other to co-construct this written description.

What stands out, is that the students were not under any requirement to use Japanese as they interacted and worked together. This could, perhaps, be seen as all the more surprising, given that these Year 11 students were in their third year of learning the language, and consequently more proficient in the language than students in some of the other classes involved in this study. They were, of course, required to use Japanese to complete the various worksheets, quizzes and tests that constituted the different chapters or sections of the unit.

In summary, the students in Shona's class were working at a task within a task. The target task was to solve the Murder Mystery, and, as part of this, they had to complete 
the smaller (pedagogic) task of establishing a profile of murder suspects. They were also completing situational grammar exercises which introduced them to new language. They therefore moved back and forwards between the roles of language learner and language user. The cognitive challenge of the target Murder Mystery task appeared to account for the fact that they seemed to find all aspects of the lesson, whether the focus was on language as object or on language as a tool to communicate, enjoyable.

We now turn to Toby's class as we focus on the last two tasks in the series of 10 that we are describing in this chapter.

\section{Toby's classroom: Task 9. How well do you know your classmate?}

\section{Task description}

Students were each given the name of one of their classmates. They had to answer a series of 20 questions in Spanish, which asked about a range of preferences, giving the answers that they imagined this classmate would give. Next, they had to go and actually ask this classmate the same questions and compare actual responses with the ones they had guessed. The aim was to see how many answers they had guessed correctly.

Year 10 (approx. age 14) 24 students of Spanish (questionnaires not completed for this lesson).

Ask for and give opinions

task objectives/goals

\section{learning intentions}

(explained to students)

Ask for and give opinions/ speak a lot of Spanish

skills involved

Listening comprehension \& spoken production

\section{relationship to previous work}

Information not available

\section{pre-task}

Students had to complete three sentences where they had the chance to express an opinion. E.g., la música de Justin Bieber es... [Justin Bieber's music is...]

\section{task input/resources}

A handout with the 20 questions; each student received a piece of paper with a classmate's name.

\section{Task implementation}

(22 mins., $37 \%$ of class time)

Teacher assigns a classmate to each student. He reads out the 20 questions and checks that students understand them. Students write the responses to each question that they think their classmate would make.

Examples of questions are:

¿Prefiere el verano o el invierno? [Does s/he prefer summer or winter?]

¿Le gusta más perros o gatos? [Does s/he like dogs or cats most?]

The teacher then tells students they have to go and ask their classmates these questions, compare the answers they get with their guesses, and see how many they got right. 
Table 40. Evaluation against task criteria

\begin{tabular}{lll}
\hline Criterion & Fulfilled & Comment \\
\hline focus on meaning & yes & $\begin{array}{l}\text { Students answering questions according to what they } \\
\text { think their classmates' preferences are. }\end{array}$ \\
some kind of gap & yes & $\begin{array}{l}\text { It is unlikely they will know the preferences of their } \\
\text { classmate. }\end{array}$ \\
rely own resources & no & $\begin{array}{l}\text { There is very little opportunity for students to rely on } \\
\text { their own language knowledge; the questions are on the } \\
\text { whiteboard and on the handout. } \\
\text { outcome }\end{array}$ \\
& yes & $\begin{array}{l}\text { To discover how accurate they were in guessing their } \\
\text { classmate's preferences. }\end{array}$ \\
\hline
\end{tabular}

\section{Comments}

This was a focused task. It did not fulfil the third criterion (see Table 40) because the teacher went through each question, ensuring students knew the relevant vocabulary, and because students had a handout listing all questions (e.g., ¿prefiere tarta o galletas?), so they were not encouraged to formulate any independently.

The pre-task was considered to be the only one in our data set that activated the language needed for the task according to discourse type, that is, expressing an opinion or preference.

\section{Other phases of the lesson}

After the task the students completed an online quiz where they had to express opinions and give reasons for these in Spanish. They then did an exercise where they listened to a dialogue and completed sentences. Finally, they were put into pairs where they had to give an opinion about a singer whose picture was displayed on the whiteboard. They were encouraged to state reasons for their opinion.

\section{The task-as-process}

After Toby had finished going through the 20 questions (approximately 10 minutes), he reminded students, before they moved into pairs, to change them from the "he and she" form to the you informal form "te gusta" (do you like?). He also checked that students understood how to answer these questions, eliciting from students the forms "me gusta" (I like) and "prefiero" (I prefer). Toby also encouraged them to extend their language by adding a reason for why they liked something. At the end of the task, Toby asked students how many correct guesses they had made. The student with the most (19), was given a sweet. 
During the approximately 7 minutes students were interacting in pairs, we identified five LREs in the teacher-student interaction discourse. See Example (18), which contains a LRE and an example of Toby encouraging a student to produce pushed output.

Example 18. LRE from Task 9

\begin{tabular}{|c|c|c|c|c|}
\hline Turn & Interlocutor & & Translation & Researcher comments \\
\hline 1 & Student & $\begin{array}{l}\text { Me gusta más } \\
\text { Superman. }\end{array}$ & $\begin{array}{l}\text { I like Superman } \\
\text { more. }\end{array}$ & \\
\hline 2 & Teacher & $\begin{array}{l}\text { ¿Por qué } C \text {, ¿por } \\
\text { qué? }\end{array}$ & Why C, Why? & $\begin{array}{l}\text { Teacher pushes student to give a } \\
\text { reason for his preference. }\end{array}$ \\
\hline 3 & Student & $\begin{array}{l}\text { Ahhh... I am not } \\
\text { sure. }\end{array}$ & & Student replies in English. \\
\hline 4 & Teacher & Vale. No sé & Ok. I don't know. & $\begin{array}{l}\text { The teacher provides scaffolded } \\
\text { help by giving the correct form. }\end{array}$ \\
\hline 5 & Student & No sé. & I don't know. & $\begin{array}{l}\text { The student uptakes this language } \\
\text { form. }\end{array}$ \\
\hline
\end{tabular}

The interactions of four students were recorded as they asked and responded to the questions that were part of the task. Table 41 presents the number of utterances produced during this task by these students. This data does not include utterances produced by the different conversation partners. An example of a question that Christopher asked was: “¿Prefieres panqueques o gofres?” (do you prefer pancakes or waffles?) and an example of an answer, in response to another question was: "Me gusta el verano" (I like summer better).

Table 41. Student output of target language

\begin{tabular}{lccc}
\hline Student & $\begin{array}{c}\text { No of questions asked } \\
\text { re preferences }\end{array}$ & $\begin{array}{c}\text { No of answers stating } \\
\text { preferences }\end{array}$ & $\begin{array}{c}\text { Total no of } \\
\text { utterances }\end{array}$ \\
\hline Christopher & 11 & 5 & 16 \\
Sarah & $18^{*}$ & & 18 \\
Imogen & $6^{*}$ & 6 \\
Annabelle & Little interaction, spoke English only & \\
\hline
\end{tabular}

* Sarah and Imogen only recorded, in their interactions, the questions they asked their conversation partners. 


\section{Toby's classroom: Task 10. Finding a friend}

The lesson in which this task features took place 7 days after the previous lesson. Workload and timetabling issues did not allow for the researcher to return any earlier to Toby's class. There were between three and four intervening lessons between Tasks 9 and 10.

\section{Task description}

Students gave, in writing, their opinion about a genre of TV programme (e.g., el telediario, news; programas de deportes, sports programmes etc.) presented at five different stations located around the room. They had to put their name next to each written opinion. Students were then given the opportunity to go and visit each station, read what had been written and decide who was compatible with them in terms of preferences, that is, who might be "a good friend."

Year 10 (approx. age 14) 24 students of Spanish (all completed questionnaires).

\section{task objectives/goals}

Ask for and give opinions.

\section{learning intentions}

(explained to students)

Ask for and give opinions/ find some new friends.

\section{skills involved}

Reading comprehension and written production.

\section{relationship to previous work}

Clear connection to Task 9, carrying on with goal of having students express and ask for opinions.

$$
\text { pre-task (5 mins.) }
$$

Quiz competition requiring recall of some of vocabulary used in task.

\section{task input/resources}

Big sheets of paper at each station, listing a TV genre.

\section{Task implementation}

(30 mins., $50 \%$ of class time)

Teacher numbers students (1-4) to form the groups that will go together to each station. At each station there are different TV programme genres, e.g., news, horror shows, reality shows, soap operas, written on big sheets of papers. Students need to write a sentence in Spanish giving their opinion about each type of programme.

Before beginning the task, the teacher checks understanding of words and formulaic expressions: me gusta; porque; creo que; pienso que; me da igual.

Examples of written student responses are:

${ }^{\star}$ En mi opinión los documentales es muy aburrido [I think that documentaries is very boring] En mi opinión me gusta mucho telediario porque es interesante [I really like news because it is very interesting]

*En mi opinión no me gustan los telenovelas porque son muy mal [I don’t like soaps because they are very bad]

After all students have had a chance to write responses at each station, the teacher gives them the opportunity to read what has been written and decide who might suit them as friends. 
Table 42. Evaluation against task criteria

\begin{tabular}{lll}
\hline Criterion & Fulfilled & Comment \\
\hline focus on meaning & yes & $\begin{array}{l}\text { Students answering questions according to their TV } \\
\text { programme preferences. } \\
\text { They will have to read about others' preferences that are not } \\
\text { known in advance. }\end{array}$ \\
$\begin{array}{l}\text { rely own } \\
\text { resources } \\
\text { outcome }\end{array}$ & yes & $\begin{array}{l}\text { Language is activated but not taught and they do not have } \\
\text { language resources to refer to as they write. } \\
\text { Tye discover who their friends are based on viewing preferences, } \\
\text { however, there is little evidence of discussion of this. }\end{array}$ \\
\hline
\end{tabular}

\section{Comments}

This was coded as a focused task. It fulfilled three criteria and a fourth, partially or weakly, only (see Table 42). The outcome was planned as an opportunity for students to discover who was like them in terms of their TV watching preferences, but there was limited evidence of classroom discussion of this in the data.

This was the only task, of the seven output-based tasks in our data set, which involved written production as a main focus.

\section{Other phases of the lesson}

In the last 20 minutes of the lesson, students played a game where in pairs they made up sentences comparing TV shows. They were allowed a turn in the game if they said something in Spanish.

\section{The task-as-process}

Immediately before the task, the teacher reviewed some of the formulaic expressions students might need. From the sheets of written output that we saved from each station, we ascertained that students wrote a total of 85 statements, an average of 3.5 per student. Of these, (see examples below), 32 gave a reason for a preference, involving in each case a complex sentence with a subordinate clause (see sentence b).

a. Me encantan las comedias (Comedies are fascinating)

b. ${ }^{\star}$ No me gustan programas de deportes porque son aburrido (I don't like sports programmes because they are boring) 
There were an additional 20 written expressions of agreement or nonagreement, which involved formulaic utterances, such as, estoy de acuerdo (I agree).

As students wrote their opinions, the teacher moved around and interacted with individuals. Over a 13-minute period there were at least two examples of the teacher encouraging students to give pushed output and at least 10 LREs, at a rate of one every 1.25 minutes. Some of these extended over several turns and included examples of the teacher, Toby, scaffolding learner production. See Example (19).

Example 19. Teacher scaffolding student production in Task 10

\begin{tabular}{|c|c|c|c|c|}
\hline Turn & Interlocutor & & Translation & Researcher comments \\
\hline 1 & Teacher & $\begin{array}{l}\text { Bien. Comedias. } \\
\text { ¿Qué opinas? }\end{array}$ & $\begin{array}{l}\text { Good. Comedies. } \\
\text { What do you think? }\end{array}$ & $\begin{array}{l}\text { Teacher asks student his opinion } \\
\text { about comedy as a genre. }\end{array}$ \\
\hline 2 & Student & Me gusta & I like & \\
\hline 3 & Teacher & $\begin{array}{l}\text { Ahh. ¿Si? ¿Te } \\
\text { gusta? }\end{array}$ & Ahh. Yes? You like? & $\begin{array}{l}\text { The teacher clarifies what the } \\
\text { student has said with rising } \\
\text { intonation which is encouraging } \\
\text { him to give more information. }\end{array}$ \\
\hline 4 & Student & $\begin{array}{l}\text { Ahh, porque es } \\
\text { ahes }\end{array}$ & $\begin{array}{l}\text { Ahh because it is } \\
\text { ah it is }\end{array}$ & $\begin{array}{l}\text { The student starts to give a } \\
\text { reason but is struggling with the } \\
\text { wrong verb "is" instead of "are." }\end{array}$ \\
\hline 5 & Teacher & $\begin{array}{l}\text { Son because they } \\
\text { are son }\end{array}$ & $\begin{array}{l}\text { They are because } \\
\text { they are }\end{array}$ & $\begin{array}{l}\text { The teacher recasts and gives } \\
\text { metalinguistic explanation. }\end{array}$ \\
\hline 6 & Student & $\begin{array}{l}{ }^{\star} \text { Porque son } \\
\text { divertido }\end{array}$ & $\begin{array}{l}{ }^{*} \text { Because they are } \\
\text { entertaining }\end{array}$ & $\begin{array}{l}\text { Student uptakes "son" correctly } \\
\text { and gives a reason but the } \\
\text { adjective he uses is incorrect. }\end{array}$ \\
\hline 7 & Teacher & $\begin{array}{l}\text { Muy bien. } \\
\text { Divertidas. }\end{array}$ & $\begin{array}{l}\text { Very good } \\
\text { entertaining }\end{array}$ & $\begin{array}{l}\text { Teacher acknowledges and gives } \\
\text { explicit correction. }\end{array}$ \\
\hline
\end{tabular}

\section{Student feedback}

Students' reported learning for this lesson that can be directly related to this task is documented in Table 43. Two students said that they did not learn any new language but that they revised language they already knew.

Table 43. Student report of learning during Task 10

\begin{tabular}{lcccc}
\hline $\begin{array}{l}\text { How to express } \\
\text { an opinion }\end{array}$ & $\begin{array}{l}\text { How to make } \\
\text { a comparison }\end{array}$ & $\begin{array}{c}\text { How to express } \\
\text { a reason }\end{array}$ & $\begin{array}{c}\text { What other } \\
\text { people like }\end{array}$ & $\begin{array}{c}\text { How to make } \\
\text { new friends }\end{array}$ \\
\hline 13 & 13 & 2 & 3 & 2 \\
\hline
\end{tabular}


Students reported enjoying/not enjoying the following aspects of this lesson (see Table 44).

Table 44. Student affective responses to Task 10

\begin{tabular}{lc}
\hline Students reported enjoying & No. of “likes” \\
\hline Finding out what other people liked watching & 2 \\
Writing opinions rather than saying them & 3 \\
\hline Students reported not enjoying & No. of “didn't likes" \\
\hline Being put into groups (without friends) & 3 \\
\hline
\end{tabular}

Overall, students rated this lesson at 4.6, as between enjoyable and highly enjoyable.

What we would conclude from Toby's lessons containing Tasks 9 and 10

These were Year 10 students with limited proficiency, as they were in only their second year of language learning. In both these tasks, it is, arguably, the opportunity to rehearse and recycle language that was most significant for learning. In Task 9, these opportunities were for use of spoken, and, in Task 10, written language. In both cases, students had opportunities to express preferences or opinions and give reasons for these in Spanish. At the same time, because students had opportunities to both listen to (Task 9) and read language output (Task 10), they were exposed to considerable amounts of language input. We documented instances of LREs and examples of where students were pushed and scaffolded in their attempts to produce language output. The role the teacher played in moving around the class and interacting with students, at the same time as he monitored task performance, was crucial.

Task 10 involved written Spanish and three students reported appreciating the opportunity to write rather than speak. They rated this lesson highly in terms of enjoyment.

In each of these lessons, the tasks, clearly identified as such by the teacher, took a proportion of the lesson time only, 50\% for the second and 37\% for the first lesson. The lessons were very structured and the other lesson phases provided opportunities either for revision of language (involving online games, which students enjoyed) or for the use of language that tended to be decontextualised and where learners were operating more as learners than as language users.

In summary, in Toby's lessons the language use was highly preselected and predetermined. Yet, the repetitive nature of this language created affordances for language learning. The constant recycling of language in the context of a task gave students opportunities to engage meaningfully with language, both as input and output. 


\section{Conclusion}

In drawing conclusions from our analysis of the 10 tasks described in some detail in the preceding sections, we start by emphasising that the choices that teachers made in the way they used tasks in their classroom practice were strongly influenced by the contexts in which they worked. Some students were in their first full year of study of the language, where exposure to the language in timetabled classes was no more than several hours per week. We call these students beginners, and note that our definition of beginner may differ from that sometimes used in the literature. For example, the Year 10 students in these classes would not have all been "able to understand and use basic everyday expressions while making conversation on topics related to their personal life," a definition of "intermediate beginner" adopted by Vandommele et al. (2018, p. 169). The level of language proficiency of the students may explain therefore why most of the teachers used focused tasks requiring the use of preselected language. The use of unfocussed tasks presupposes a language repertoire which these beginner learners had not had the time to develop. Teachers therefore, designed and taught tasks to encourage the comprehension or elicit the production of particular language forms which the students had been previously taught.

We would claim, however, that while the teachers may have designed tasks with the intention that students use preselected language structures, this did not always mean that there was no opportunity for use of unpredicted language. Margaret, for example, designed tasks that required use of the French "imperfect" (Tasks 3 \& 4), yet, the data we collected demonstrate that they also allowed for some creativity and unpredictability, thus opening up possibilities for incidental (i.e., the learning of forms not explicitly targeted by the task), as well as intentional, learning (Long et al., 2019). This use of language led to the kind of interactions known to promote language learning: negotiation of meaning, recasts, explicit metalinguistic information, pushing of output and scaffolding. All these interactions took place in a context where learners were using the language as a tool to communicate and thus potentially constructing form-meaning-function relationships that would facilitate acquisition. Another example was Tania (Tasks $1 \& 2$ ) who was teaching less proficient students at a lower year level. Her first lesson was planned for preselected language use, while her second lesson, with its focus on having a conversation, was less predictable. Both of Tania's lessons led to opportunities for language learning as students received elaborated and extended input and explicit metalinguistic information. Both Tania and Margaret joined groups of students as they interacted in the target language, asking them about their real-life experiences, scaffolding their language use, answering queries and providing encouragement.

Another important point to make about these focused tasks is that, even where the use of language was highly predetermined and there was little opportunity for 
unpredicted or creative language use, we found evidence of another way in which acquisition was promoted. This was in the opportunities that students had to be exposed to the same language forms repeatedly, both as language input and as language output. We observed tasks that afforded learners the opportunity to encounter the same form-meaning relationships over, and over again, catering to the fact that language learning is a gradual process and that learners need the chance to recycle language if they are to acquire it. Examples were the tasks from Emily's (Tasks $6 \& 7$ ) and Toby's (Tasks 9 \& 10) classrooms. In both these lesson sequences, students reported that the lesson had afforded them opportunities to revise language they already knew.

Shona, as we have seen, used the notion of task in yet another way. She designed a (target) task at the level of the unit. This task was cognitively demanding, requiring students to solve a Murder Mystery. However, it had students working at completing grammar exercises where meaning was decontextualised, characteristic of a focus on formS approach. Yet the students observed worked assiduously to complete these exercises in order to have the language that they needed to decode key clues (e.g., descriptions of the murder suspects). When they used the language in this way to solve clues, they had the opportunity to engage with contextualised meaning, no longer completing exercises, but rather tasks (Widdowson, 1998). As students alternated between working at situational grammar exercises and tasks, they were moving back and forwards between being language learners and language users. For Shona, the task appears to have had two main functions. Firstly, it was a crucial motivator. At the same time, it provided the communicative outcome, the target task, towards which the students were to work, using language as a tool, as they solved the Murder Mystery. Shona's approach to task could be seen as an example of how the kind of mutually exclusive dimensions that tend to be discussed in much of the literature, for example, meaning or form, accuracy or fluency, are insufficient to account for the pedagogic spaces that lessons such as these afford (Van den Branden, 2009).

One teacher stands out for a different approach that we could claim is more typical of that often represented in TBLT literature. This was Linda, the teacher who had amassed a considerable amount of knowledge about TBLT prior to trying it out in her classroom during TPDL. Linda combined TBLT with content-integrated language learning (CLIL). This was, however, in the context of the language classroom, rather than, as is typically the case, through the learning of another subject (Ortega, 2015). The interview data we collected did not provide information for why Linda chose this approach or to what extent it was her consistent approach to language teaching. In Linda's classroom, it is perhaps not surprising then that we did not find evidence of a focused task, nor of preselected domains of language use. Yet, at the same time, we are unable to present evidence that the students in her lesson were afforded more opportunities for language learning than those in the other classrooms we document. 
Ellis et al. (2020, p. 1) claim that the essential feature of TBLT is that learners acquire "language incidentally as they engage with language as a meaning-making tool" and that it contrasts with structural approaches where language is "an object to be systematically taught and intentionally learned." In the lessons observed in this study, the opportunities for language learning were both incidental and intentional. There was evidence of systematic planning on the part of teachers. There was also evidence on the part of learners that they were very aware of their progress as language learners, and that being able to document their progress in terms of the learning that the teachers had planned and intended for them was important (e.g., learning of French imperfect, learning of katakana). Our conclusion, therefore, is that what we observed does not fit neatly with a definition of task and TBLT that discounts the intentional. We see this as a challenge to the way that some (e.g., Ellis et al., 2020) have, therefore, defined the implementation of TBLT (Bygate, 2020).

The crucial contribution that TBLT did make to language learning in these lessons was that it replaced a focus on language in isolation with a focus on using language for communicative purposes and thus created opportunities for the formation of form-meaning-function relationships. This also allowed for an emphasis on allowing space for social interaction in the classroom. This is important because it would seem that the opportunity to work with peers is a crucial motivating factor for adolescent learners (Philp et al., 2014). The data in this study showed that learners consistently reported that they liked interacting together and working in groups.

The questionnaire data, where we ascertain what students learnt from the lessons and how they felt about them, demonstrate the diversity of outcomes that can arise from a task. As Breen (1987) describes, a task may have both message or communicative potential and code or metacommunicative potential. This was very evident in this study. In the same lesson, while working on the same task, students reported both communicative outcomes (e.g., finding out facts about their classmates) and code or language outcomes, where they described learning an aspect of language.

We also emphasise the importance of the role that the teachers played as they implemented tasks in their classrooms. The teacher was a crucial interactional partner and conversational supporter, feeding the needs of different students in a variety of ways. We also suggest that it is quite possible that it was the use of a task that required the teacher to adopt this role, and motivated the ways in which they enabled learning opportunities for their students.

We argue, in conclusion, that the data from the lessons described in this chapter demonstrates that the tasks the teachers used created a "rich pedagogical space" (Van den Branden, 2009, p. 264). In this pedagogical space there were many opportunities for language learning. In the next chapter we turn to examine the 10 tasks we describe in this chapter in greater detail. In particular, we explore the types of tasks that these teachers used and the extent to which their practice reflected principles documented, in literature, as consistent with the implementation of TBLT. 



\section{An evaluation of the use of tasks in the classroom}

And I'm so excited because now we have all the suspects and all their names. Now we can figure out who the hell killed (the deputy principal).

(Yr. 11 student, comment to the researcher as she completed Task 8 Murder Mystery)

In this second part of the book, we focus on how teachers implemented tasks after learning about them (the principal focus of Part 1). In the Introduction to Part 2, we describe how we identified 10 tasks in 15 lessons taught by six teachers, some years after learning about tasks and TBLT in the TPDL professional development programme. Chapter 5 described these 10 tasks in some detail.

In this chapter, we continue to focus on these 10 tasks. However, we also draw on the bigger data set of the 15 lessons that we observed, as taught by the total participant group of eight teachers. In five of these lessons, as we documented in the Introduction to Part 2, we claimed that we found activities, but not tasks. We are, nonetheless, interested in investigating teacher practice both in lessons where we did and did not find evidence of tasks. The questions we address are:

- What are the characteristics of and types of activities and tasks that the teachers in our study were using?

- To what extent is there evidence that their practice was consistent with Long's (2015) principles of TBLT?

We therefore continue to focus on teacher practice, both in relation to the use of tasks but also with a wider lens, investigating to what extent overall practice might have been consistent with TBLT. The analysis we present in this chapter will contribute to our ongoing understanding of the ways in which teachers use the task as a pedagogic tool. 


\section{Data sets}

In order to answer the above research questions, we draw mainly on transcripts of student and teacher discourse as we observed the 15 lessons, along with observation notes. However, wherever possible, we also draw on teacher interview data (see Introduction to Part 2 for more information about these data sets).

\section{Evidence of teacher fulfilment of task criteria}

In this section, we look at the extent to which the activities which teachers taught in the lessons we observed, satisfied task criteria. We describe, in the Introduction to Part 2, how we started by taking an activity from each of the 15 lessons and coding it against task criteria (Ellis \& Shintani, 2014, p. 135), included in Chapters 1 and 3. A criterion was only considered satisfied if it was coded "yes," that is, those criteria which were only considered partially fulfilled were not tallied as satisfied. The results of our coding are documented in Table 22 in the Introduction to Part 2. We concluded from the data we presented in this table that of the 15 activities, 10 (66\%) could be considered tasks, because they fulfilled three or more criteria. Fulfilling three of the four key components of task design, it has been argued (Erlam, 2016a), means that a given activity is more "task-like" than "activity-like," belonging more towards the focus on meaning end of Littlewood's (2014) continuum, at the other end of which is a situational grammar exercise that would encourage a learner to focus on formS (Long, 2015).

Table 45 presents a summary of the extent to which these 15 lessons contained activities and tasks that satisfied the different criteria outlined by Ellis and Shintani (2014).

Table 45. No. of lessons with activities/tasks satisfying Ellis and Shintani (2014) criteria

\begin{tabular}{|c|c|c|c|c|c|}
\hline $\begin{array}{l}4 \text { criteria } \\
\text { satisfied }\end{array}$ & $\begin{array}{l}3 \text { criteria } \\
\text { satisfied }\end{array}$ & $\begin{array}{l}2 \text { criteria } \\
\text { satisfied }\end{array}$ & $\begin{array}{c}1 \text { criterion } \\
\text { satisfied }\end{array}$ & $\begin{array}{c}0 \text { criteria } \\
\text { satisfied }\end{array}$ & Total \\
\hline 3 & 7 & 1 & 1 & 3 & \\
\hline $20 \%$ & $46 \%$ & $7 \%$ & $7 \%$ & $20 \%$ & \\
\hline \multicolumn{2}{|c|}{$\begin{array}{c}\text { designated as tasks } \\
\text { total }=10\end{array}$} & \multicolumn{3}{|c|}{$\begin{array}{c}\text { designated as activities } \\
\text { total }=5\end{array}$} & 15 \\
\hline
\end{tabular}

Out of the eight teachers, all but two taught a task that satisfied three or more criteria. Of the two that did not, one taught, in one of the lessons observed, an activity that satisfied two criteria and, partially, two more. The other taught an activity that did not satisfy any task criteria. 
A subsequent analysis investigated, for each specific criterion, the extent to which it was respected, allowing for some understanding of the criteria that were more and less in evidence in teacher practice in the classrooms observed (Erlam, 2016a). Results are given in Table 46.

Table 46. Fulfilment of individual task criterion in activities analysed against task criteria

\begin{tabular}{lcccc}
\hline & $\begin{array}{c}\text { Criterion 1 } \\
\text { Focus on } \\
\text { meaning }\end{array}$ & $\begin{array}{c}\text { Criterion 2 } \\
\text { Some kind } \\
\text { of gap }\end{array}$ & $\begin{array}{c}\text { Criterion 3 } \\
\text { Relying on own } \\
\text { resources }\end{array}$ & $\begin{array}{c}\text { Criterion 4 } \\
\text { An outcome }\end{array}$ \\
\hline No. satisfied out of 15 & 12 & 10 & 6 & 8 \\
Total percentage & $\mathbf{8 0 \%}$ & $67 \%$ & $40 \%$ & $53 \%$ \\
\hline
\end{tabular}

The criterion least in evidence in the activities analysed was the one that "required learners to rely on their own linguistic and non-linguistic resources" (see Table 46). This was fulfilled in just six out of the 15 , or $40 \%$ of the lessons observed. This result is very similar to data from Part 1 of this study, where this criterion was fulfilled in just 39\% of task designs (see Chapter 3). It is also similar to data reported in Erlam (2016a), in a study where, like this one, most of the learners were beginners. In both studies it was particularly challenging for teachers in our study to know how to set up opportunities for use of the target language with the limited language knowledge learners had, and, at the same time, know what level of language support to provide. We stress that this criterion, "rely on own resources" needs to be interpreted in the context specific to that under investigation. Given that the learners were, as we have termed them, beginners, with some in their first year of study of the target language, it was not realistic to expect open-ended or creative use of language in all the lessons we observed. As evidence for this criterion then, we were looking to see that (a) students were not taught new language structures that they were immediately expected to use communicatively and (b) they had an opportunity to automatise language they were already familiar with. With respect to (a), teachers who completed TPDL (post 2016) were taught, as described in Chapter 3, to differentiate between itembased learning and rule-based learning (Loewen \& Reinders, 2011) in task design. The decision to teach this distinction was informed by former research (Erlam, 2016a) demonstrating how difficult this criterion was for teachers to implement in task planning. Teachers were told that new language that constituted item-based learning (e.g., words, phrases) was considered appropriate to incorporate into task design but that rule-based learning (e.g., grammatical structures, systems) was not. It is important to point out, however, that the teachers whose practice we are now describing in this Part 2 of the book, and who had all completed TPDL prior to 2016, had not been given this advice. 
In coding for (b), that is, opportunities to automatise language, we, at times, decided that students could have been scaffolded to try to use language with a greater degree of independence than they were. An example in point was Task 7, Working With Mazes (Chapter 5), where, after repeated exposure to preselected language, students had this language on the same worksheet that contained the task and task instructions.

The second criterion that was least in evidence was that of a "clearly defined outcome" (53\%). In Erlam (2016a), this criterion scored highest in terms of task fulfilment and in Part 1 of this study, it was fulfilled in 69\% of task designs. The difference could be due to the fact that in Part 2 we were able to observe the tasks as they were taught, rather than as they had been planned (i.e., task-as-process rather than task-as-workplan). In at least three tasks observed, an outcome was intended, or planned, but not realised, perhaps due to time constraints. Or it may have been that the outcome functioned perhaps only as the hook, designed by the teacher to get students to be prepared to work at it. Andon and Eckerth (2009) point to Prabhu's argument (1987) that, from the point of view of acquisition, the task outcome is not important. It is the process of task completion that is crucial, rather than its product.

The criterion that was most in evidence was the one that specified a "focus on meaning" (80\%). This was also the criterion most incorporated in the tasks designed by the teachers in Part 1 of this study. The next criterion most in evidence was the need for some kind of gap (67\%). Arguably these two criteria, along with a "clearly defined outcome" (i.e., Criteria 1, 2, \& 4), are the most crucial in that they are most likely to determine whether meaningful communication has taken place and whether the learner has had the opportunity to function as a language user.

In this study, all percentages for criterion fulfilment are lower than in Erlam (2016a), for perhaps a number of reasons. The first of these could be the fact that, in the earlier study, teachers were specifically required to design a task and in this study they were not. Secondly, the teachers in the current study were observed a number of years subsequent to the professional input they had received on TBLT and so may have forgotten aspects of task design or lost some motivation for implementing tasks in their practice (see Chapter 7 for a more detailed discussion). Lastly, as previously mentioned, in this research, the task observed was as it was taught (in process) rather than as it had been planned (as work plan). There is potentially a gap between how a task was intended and planned to be taught, and how it was actually implemented and translated into classroom practice (Breen, 1989).

In summary, in this section we established that the criterion that was most in evidence in the 15 lessons we observed was the one where the students were focused on meaning and functioning as language users and not just as learners. Three of the four task criteria were in evidence in over $66 \%$ of lessons, these were: focus on meaning, some kind of gap and an outcome other than the use of language. We suggest that it 
is these three criteria that could be considered the most crucial in determining how task-like teacher practice is. The finding that the criterion least in evidence, that is, that learners "rely on their own linguistic and non-linguistic resources during task completion", replicates research findings (Erlam, 2016a) and is also the criterion that the teachers in Part 1 of this book incorporated least in their task design. This finding has implications for teacher education. It would suggest that teachers need more guidance on how to use tasks, at least tasks that require language output, with language learners who have very limited proficiency.

In the following part of this chapter, we continue to investigate the characteristics and types of tasks that the teachers implemented in their classroom practice. The main focus is on the 10 lessons that were judged, by the researchers, to contain tasks. As we analyse in greater detail the 10 tasks, we investigate aspects that were likely to have been part of the design process and informed by teacher decisions. In some instances, we have insights from the teacher interview into some of these decision-making processes, in others we need to make inferences from the task-inprocess as we observed it in the classroom. Some of the task characteristics that we investigate and about which we present data in the following sections of this chapter are: the level (i.e., unit or activity) at which the task was implemented, the extent to which language use was preselected or not (i.e., focused or unfocused), the communicative orientation of task goals, and the extent to which the task was used within a task cycle. We also categorise the tasks against Willis and Willis's taxonomy (Willis \& Willis, 2007).

It is important to remind the reader that, for each teacher in our data set, we were only able to observe two lessons. We were, therefore, able to obtain only a very narrow snapshot of teacher practice. In some instances, the interview data gives us a fuller picture of teacher practice in relation to the different issues we discuss, however, this self-report data is less reliable than observed practice.

\section{Target tasks and pedagogic tasks}

In observing and talking with teachers about these lessons, it was obvious that there were at least two levels at which the concept of task could be implemented, that is, the task at the level of the unit and the task at the level of activity. The research literature also differentiates between these two levels, using the terms "target tasks" and "pedagogic tasks." The term target tasks refers to those that are determined at syllabus level and towards which students will work as an ultimate goal, while the term pedagogic tasks refers to the classroom tasks that learners will complete as they work towards achieving the target tasks (Long \& Crookes, 1992). 
Three teachers appeared to be implementing target tasks in six of the lessons observed, in that they specified a goal that learners were working towards at the end of a unit of work. For two teachers, the task was described in reference to an external assessment standard. For example, Margaret's students were working towards the ultimate goal of first interviewing a family relative and then comparing, in a piece of writing in French, this relative's life with their own. Table 47 presents the target tasks which provided the wider context for six of the lessons we observed. Note that, from a discussion with one teacher, Linda, it was clear that there were two target tasks (both related to NCEA assessments) within the one unit (see 2a \& b in Table 47).

Table 47. Target tasks in the classrooms observed

Teacher \& year level Description of target task

\begin{tabular}{ll}
\hline Margaret & $\begin{array}{l}\text { 1. Students to interview a parent or grandparent and write about how } \\
\text { different their life was from theirs today. } \\
\text { [to contribute to a NCEA* writing assessment] }\end{array}$ \\
Linda & 2(a) Students to rewrite a preferred ending to the film Viva Cuba [the \\
teacher explains that the ending is "not what you would want"]. & [to contribute to a NCEA* writing assessment] \\
& 2(b) Students to have a conversation on the topic of friends/friendship. \\
& [to contribute to a NCEA* speaking assessment. They will have to speak \\
for 1 minute] & 3. As part of a Murder Mystery unit, students to establish which teacher \\
in their school has been murdered, with what motive, how and by \\
Year 11
\end{tabular}

* NCEA refers to New Zealand Certificate of Educational Achievement; an assessment that students complete in Years 11-13.

For all these teachers, within the overall target task, determined at the level of the unit, there were also examples of pedagogic tasks. As Shona herself said, the lessons observed formed part of a (Murder Mystery) unit which was "a task within itself, and then there are myriad tasks within the unit." In each lesson it was the pedagogic task that we evaluated in order to establish whether there was evidence of a task in classroom practice. It is important to document that these three teachers who had designed units around target tasks, were all teaching Year 11 students, which is the level at which New Zealand students take part in national assessments (NCEA). This explains the focus on assessment outcomes. The fact that these three teachers were teaching more advanced students fits with Brumfit's (1984) integrated curriculum model, demonstrating that, with greater proficiency, it was possible to have an emphasis on project work and on developing fluency. 
In conclusion, three of the six teachers we observed were using tasks at the level of the unit (target tasks) and at the level of activity (pedagogic tasks). This means that the students in these lessons were working towards an overall "unit end" outcome that involved the meaningful use of language and the bridging of some gap through the communication that took place and, at the same time, were working at smaller tasks that met most or all of these criteria. The remaining teachers in our study implemented pedagogic rather than target tasks.

\section{Task goals}

In this next section, we investigate the goals that the teacher specified for the 10 lessons we observed which contained tasks. We, first, look at whether the tasks were focused or unfocused, and then at the extent to which they were oriented towards communicative goals.

\section{Focused or unfocused tasks}

A key issue in task design is the starting point in terms of teacher focus (Van den Branden et al., 2009). Teachers can design focused tasks, intending that learners will have the opportunity to use particular, preselected language structures or domains, or unfocused tasks, which will allow learners to deploy an unspecified range of language forms and structures, as best fit with their communicative needs (Ellis, 2003). Ellis and Shintani (2014) point out that a key feature of focused tasks is that the linguistic focus is hidden, that is, learners are not told what it is.

In this study, the majority of tasks appeared to be focused rather than unfocused (Ellis, 2003). Examples were Tasks 9 and 10 in Toby's lessons, which were designed to require learners to use language that they had been focusing on in previous lessons. Students had to give opinions about preferences, and were given language forms such as in Example (20), to help them:

\section{Example 20.}

\begin{tabular}{ll}
\hline Spanish & Translation \\
\hline ¿Prefiere... o...? & Does s/he prefer... or...? \\
¿Le gusta mas... o...? & Does s/he like... more... or? \\
\hline
\end{tabular}

In a number of focused tasks, such as the ones referred to above, students were aware of the language forms the teacher intended them to use; these were not hidden, as Ellis and Shintani (2014) claim they should be. The most obvious example was 
Margaret's lessons (Tasks 3 and 4) where students were openly told that the focus was the imparfait, although within Margaret's lessons, there were plenty of opportunities for students to use a wide range of language structures.

The best example of an unfocused task was in the lesson taught by Linda (Task 5), where there were no preselected language structures, although, given that students were required to make predictions, the language used was tailored to this function.

The fact that most tasks were focused is perhaps not surprising given that the criterion that was least in evidence in our data set of 10 tasks was the one that allowed learners to use their own resources. In considering how language focused many of the tasks in this study were, it is important to remember that most of the students in these classes had been learning the target language for less than 2 or 3 years. They had also been learning in an acquisition-poor environment, at the rate of no more than 4 hours per week, with little or no contact with the language outside of the classroom context. At the same time, while the tasks were focused, the focus tended to involve the wider use of language within a domain (e.g., expressing preferences/opinions and giving directions) rather than the more limited use of single language structures.

In Figure 5 we visually represent the focus of the 10 tasks and five activities that we identified, as explained in the Introduction to Part 2. Figure 5 places these tasks and activities as they are evaluated against two criteria (drawing on both interview and observation data), presented as two axes. These are: whether the focus was on meaning or formS (Long \& Crookes, 1992) and whether they were focused or unfocused (Ellis, 2003). It is obvious from Figure 5 that most tasks were focused, while at the same time requiring the learner to encode and decode messages (i.e., focus on meaning) rather than focus on linguistic form (i.e., focus on formS). Two activities allowed for a focus on meaning, while the other three had a focus on language formS.

Samuda (2001, p. 119) distinguishes between "language-activating" and "fluencystretching" tasks on the one hand, and "knowledge-constructing" tasks, on the other hand. In other words, tasks can be designed to require students to "activate, stretch and refine" their current language resources (Samuda, 2001, p. 119) or designed to enable new language learning and new form-meaning connections to be made. In our data set, the tasks seemed to be language activating and fluency enhancing, in that they were designed to have students use language with which they were already familiar. A limitation of our data set is that we observed only two lessons and so were unable to have a complete picture of how these lessons and tasks were integrated within a wider unit.

In summary, all but two of the 10 tasks in our data set were focused. In Part 1 of this study, we also documented that most of the tasks that teachers designed, as part of their learning inquiries, were focused with specific linguistic goals (see Table 8, Chapter 3). 


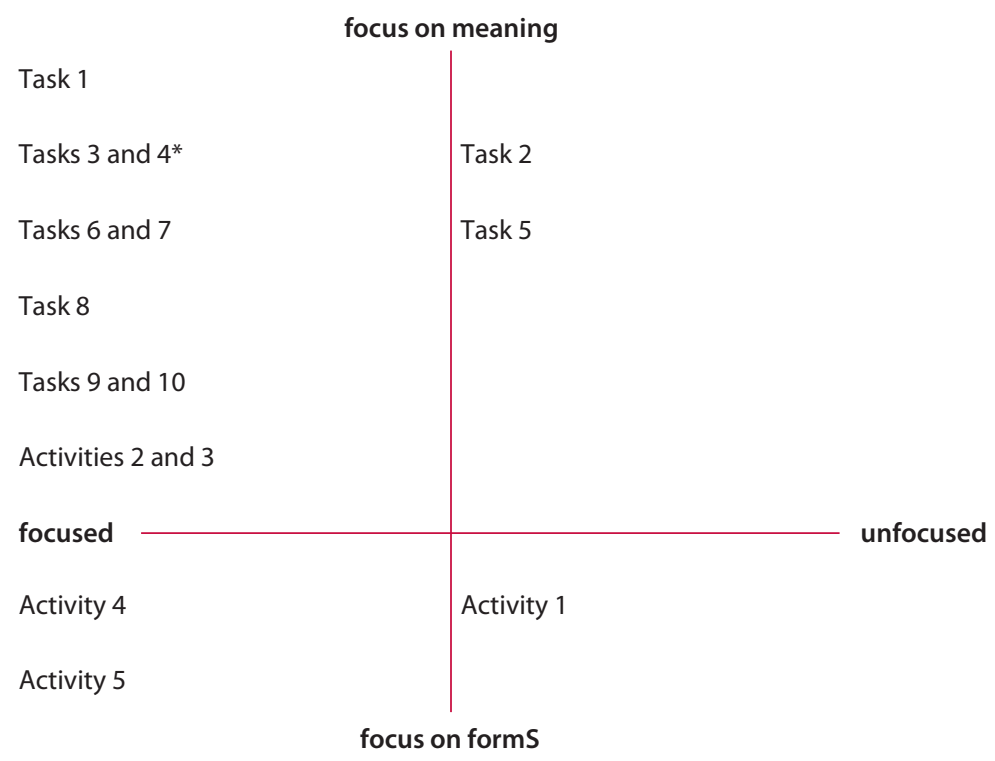

Figure 5. The foci of the 10 tasks and five activities in terms of language use *tasks and activities that are listed together were taught by the same teacher

\section{Communicative goals}

At the same time, we were interested to see to what extent teachers were focused, in their use of tasks, on communicative goals. In Table 48, we list, in the first column, the learning intentions or lesson foci that were communicated to students for each of the 10 lessons that contained tasks. These were mostly, but not in all cases, written on the board for students. In the adjacent column, we list information that teachers gave about lesson goals in the interview. As lesson plans were not part of the data set informing this study, we relied on interview data to establish information about task planning, that is, how teachers conceived of the task-as-workplan.

All but one of the six teachers specified a goal for their lesson(s) that suggested that the language was being used for communicative purposes. Margaret was the exception, specifying only that she wanted her students to "learn to use the imperfect" and work towards a writing assignment. However, in each of her two lessons, she taught a task that was, indeed, communicative and that satisfied all task criteria.

In the following section, we investigate the extent to which the teachers in this Part 2 of the study made use of the task cycle in the way that they implemented pedagogic tasks in their classrooms. They had been introduced to the concepts of pre-task 
Table 48. Teachers' goals for the lessons observed that contained tasks

\begin{tabular}{|c|c|c|c|}
\hline $\begin{array}{l}\text { Teacher \& } \\
\text { year level }\end{array}$ & Task & $\begin{array}{l}\text { Learning or lesson } \\
\text { intentions or focus } \\
\text { communicated to students }\end{array}$ & $\begin{array}{l}\text { Goal specified by teacher } \\
\text { in the interview }\end{array}$ \\
\hline \multirow[t]{2}{*}{$\begin{array}{l}\text { Tania } \\
\text { Year } 10\end{array}$} & $\begin{array}{c}1 \\
\text { Categorising Sports }\end{array}$ & $\begin{array}{l}\text { talking about sport; } \\
\text { categorising - team/ } \\
\text { individual/pair }\end{array}$ & $\begin{array}{l}\text { produce language } \\
\text { independently and naturally }\end{array}$ \\
\hline & $\begin{array}{c}2 \\
\text { Conversation }\end{array}$ & $\begin{array}{l}\text { extended and natural } \\
\text { conversation }\end{array}$ & $\begin{array}{l}\text { free conversation and } \\
\text { opportunity to talk in the } \\
\text { third person }\end{array}$ \\
\hline $\begin{array}{l}\text { Margaret } \\
\text { Year } 11\end{array}$ & $\begin{array}{c}3 \\
\text { The Teacher at Age } 6 \\
4 \\
\text { My Childhood }\end{array}$ & $\begin{array}{l}\text { use of imparfait (imperfect } \\
\text { tense) } \\
\text { prepare students for NCEA } \\
\text { writing assessment. }\end{array}$ & $\begin{array}{l}\text { learn to use the imperfect; } \\
\text { work towards NCEA } \\
\text { assessment standard }\end{array}$ \\
\hline $\begin{array}{l}\text { Linda } \\
\text { Year } 11\end{array}$ & $\begin{array}{c}5 \\
\text { Making Predictions }\end{array}$ & $\begin{array}{l}\text { to think about what to take } \\
\text { when running away }\end{array}$ & $\begin{array}{l}\text { learn about life and culture } \\
\text { as they learn about language }\end{array}$ \\
\hline \multirow[t]{2}{*}{$\begin{array}{l}\text { Emily } \\
\text { Year } 10\end{array}$} & $\begin{array}{c}6 \\
\text { Treasure Hunt }\end{array}$ & treasure hunt & $\begin{array}{l}\text { find directions; work } \\
\text { independently in teams }\end{array}$ \\
\hline & $\begin{array}{c}7 \\
\text { Working With Mazes }\end{array}$ & finding directions & $\begin{array}{l}\text { give directions in spoken } \\
\text { output }\end{array}$ \\
\hline $\begin{array}{l}\text { Shona } \\
\text { Year } 11\end{array}$ & $\begin{array}{c}8 \\
\text { Murder Mystery }\end{array}$ & $\begin{array}{l}\text { to start to determine the } \\
\text { suspects for the murder }\end{array}$ & $\begin{array}{l}\text { establish who each suspect } \\
\text { is, using language of } \\
\text { descriptions }\end{array}$ \\
\hline \multirow[t]{2}{*}{ Year 10} & $\begin{array}{c}9 \\
\text { How Well Do You } \\
\text { Know Your Classmate? }\end{array}$ & $\begin{array}{l}\text { asking for and giving } \\
\text { opinions - speak a lot of } \\
\text { Spanish }\end{array}$ & ask for and give opinions \\
\hline & $\begin{array}{c}10 \\
\text { Finding Friends }\end{array}$ & find some new friends & \\
\hline
\end{tabular}

and post-task during the TPDL programme; however, we wanted to see whether or not they were using these sequences in their lessons, and if so, how. This would contribute to an understanding of how they were implementing TBLT in their practice. 


\section{The task cycle}

The design of a task-based lesson may involve planning for different phases in the task sequence, most commonly, the pre-task, main task and post-task phases (Ellis, 2003). These phases, which are characteristic of a pedagogic task framework, constitute what Willis (1996) refers to as a task cycle. For the 15 lessons we observed in this study, we did not have access to lesson plans, therefore we needed to infer to what extent teachers implemented components of this cycle. For all but one task (i.e., Task 8 ) it was possible to identify a stage or focus in the lesson immediately preceding the task that could be identified as the pre-task. However, given that only one teacher referred to a pre-task in her lesson when discussing it in an interview with the researcher (for further information see Chapter 7), it is important to emphasise that the decision to consider a lesson phase as a pre-task, was the researcher's and may not have reflected the views of the teacher.

Table 49 lists the aims, as they appeared to the researcher, of the part of the lesson presumed, in each case, to be the pre-task.

Table 49. Presumed aims of the pre-task

\begin{tabular}{ll}
\hline Pre-task aim & Tasks \\
\hline activate vocabulary useful for task completion & Tasks 1, 6, 10 \\
activate language structures useful for task completion & Tasks 2, 4, 7 \\
activate discourse type (e.g., giving an opinion) & Task 9 \\
orient learners to task content & Tasks 3, 5 \\
\hline
\end{tabular}

It is interesting to note that, in all but two tasks, the focus of the lesson identified as the pre-task was on language. This is not surprising, given the fact that the majority of the tasks were focused, that is, intended to require the use of predetermined language features. However, it is important to point out, that in these cases, the emphasis was on activating language rather than on teaching new language structures. The latter would be typical of a PPP approach to language teaching (Gower \& Walters, 1983), rather than a TBLT approach. The remaining two tasks in our data set had a focus on content, rather than language.

There was not, in most of the lessons that we observed, evidence of a post-task phase. One exception was Task 3, where at the end of the task, Margaret asked the class:

\section{Example 21.}

Teacher discourse

Bien, okay est-ce que vous avez des questions? Des questions? Anything that you wanted to say but you didn't know how to say it?

\section{Translation}

Good, okay, do you have any questions? Any questions? 
This led to an explanation of how to conjugate the irregular verb "vouloir" - to want - in the imperfect tense.

In summary, it appears that the lessons where teachers in our data sets taught tasks did include a pre-task phase. In the majority of cases, the focus was on activating language that students already knew. Only one teacher seemed to incorporate a post-task phase into the use of a task. We will return, in Chapter 7, to the notion of task sequence and the extent to which teachers were aware of the concept of task cycle.

\section{Task type}

In this section, we continue our investigation of the characteristics and types of the 10 tasks that teachers in this Part 2 of the book were using. This will give us more information about how teachers were using tasks as a pedagogic tool in the classroom. We will start by looking at the types of language skills that teachers catered for as they used tasks.

\section{The language skills tasks focused on}

There is evidence that teachers tend to see tasks as requiring learners to produce language output, rather than being aware of the importance of using tasks that allow learners, especially at the beginning stages of language learning, to process language input (e.g., Erlam, 2016a; Erlam \& Ellis, 2018, 2019; Shintani, 2016). Given that the teachers in our data set were working with beginner language learners in contexts where there was little exposure to the target language outside of the classroom, we wanted to see to what extent there was a balance in terms of the skills tasks were oriented to, and whether input-based tasks were used. We present, for each task, the language skills that appeared to be the main focus. For example, in Task 10, students had to read questions and write their opinions about types of television programmes. However, because they spent most of their time writing responses to the questions, the main focus was listed in Table 50 as written production.

Table 50. Main language skill focus in tasks observed

\begin{tabular}{lll}
\hline Main language skill focus & & Tasks \\
\hline Output-based tasks & Spoken production & $1,2,4,5,7,9$ \\
& Written production & 10 \\
Input-based tasks & Listening comprehension & 3 \\
& Reading comprehension & 6,8 \\
\hline
\end{tabular}


It was encouraging to find examples of tasks that focused on all language skills, including three that were input-based. However, while we did find evidence of tasks that catered to all language skills in our data set, the predominance (i.e., six of 10) of tasks focusing on spoken language production would suggest a greater need, in professional development, for a focus on equipping teachers to understand how to design and use input-based tasks in the language classroom, as well as a reminder that production includes writing.

As part of our ongoing understanding of how teachers were using tasks and implementing TBLT, we used a pedagogic classification of tasks against which to examine our data set of 10 tasks.

Willis and Willis's taxonomy of tasks (Willis, 1996; Willis \& Willis, 2007)

This classification was inspired by Willis' (1996) attempt to analyse the types of tasks commonly found in textbooks. It is based on the kind of operations (Ellis, 2003) and cognitive processes that learners engage with, as they carry out tasks. Willis and Willis (2007) list seven task types (see Table 51) which are ranked in order of cognitive demand. They describe listing as the "simplest type of task" (p. 66) and specify that ordering and sorting, which often follow on from listing, require more cognitive effort. They also describe how the last ranked task type in their list, that is telling a story or anecdote, might involve cognitive processes associated with previous task types, for example, selecting and sequencing events (listing and ordering) and deciding how to make the ending as engaging as possible (creating). It is clear, therefore, that Willis and Willis's seven task types are not mutually exclusive, but rather might involve a number of cognitive processes. They are also, in the words of Willis and Willis themselves, "broad" and not "water-tight" (pp. 63, 107).

A reason for choosing this particular taxonomy, rather than other task frameworks (e.g., Skehan et al., 2012) was that TPDL teachers had been referred to Willis and Willis (2007), in which this classification is explained, as a key reference text. Furthermore, some of them also, during TPDL, had read Erlam (2013), "Listing and Comparing Tasks in the Language Classroom: Examples of Willis and Willis's (2007) Taxonomy in Practice."

In Table 51 we classify the 10 tasks we observed according to Willis and Willis's taxonomy.

There are a number of interesting observations that can be made from the distribution of task type in Table 51. Firstly, all but one, (i.e., projects and creative tasks) of Willis and Willis's seven task types are represented in these 10 lessons. This demonstrates the creativity and diversity with which teachers adapted understanding of TBLT and tasks to their own classroom contexts. The next observation is that the 
Table 51. Tasks classified according to Willis and Willis's (2007) taxonomy

\begin{tabular}{llcc}
\hline & Task type (Willis \& Willis, 2007) & Tasks & Year level \\
\hline 1 & Listing & Task 5 & 11 \\
2 & Ordering and sorting & Task 1 & 10 \\
3 & Matching & Task 7 & 10 \\
4 & Comparing and contrasting & Task 9 & 10 \\
5 & Problem-solving tasks and puzzles & Tasks 6, 8 & 10,11 \\
6 & Projects and creative tasks & & \\
7 & Sharing personal experiences, story, anecdote telling & Tasks 2, 3, 4, 10 & $10,11,11,10$ \\
\hline
\end{tabular}

most commonly used task type was the last, that is, "sharing personal experiences, story, anecdote telling." The tasks classified as this seventh task type tended to involve sharing personal information rather than personal experiences. In other words, they represented weak versions of this category and are unlikely to have involved cognitive processes that were more demanding than those involved with lower-ranked task types. Given the students' limited proficiency in the target language, it is not surprising that they would be more able to share personal information than experiences. This also fits with the fact that these learners were adolescents; the literature tells us that this learner group enjoys opportunities to speak, write and act as themselves (Legutke, 2012). Another observation that could be made from information presented in Table 51 is that, with one exception, Year 11 students (in their second or third year of language learning) tended to be engaged in tasks which were predicted to require higher-order cognitive processes.

In summary, the teachers in this study were creative in designing tasks that involved students in a range of cognitive processes using different language skills. A majority of tasks, however, had students sharing personal information, reflecting the fact that they were beginners with limited proficiency in the target language.

\section{Implementation of principles of TBLT}

In the next part of this chapter, the lessons and tasks, are considered in relation to the following question:

To what extent is there evidence that the practice of the teachers we observed was consistent with Long's (2015) principles of TBLT?

In this section, our analysis includes all of the 15 lessons which we observed, not just the 10 in which we found tasks. We were interested to see to what extent overall teacher practice accorded with the main tenets of TBLT. We first needed to decide on the criteria against which we would evaluate these lessons. The instrument which 
we chose was the same which Vandommele et al. (2018) used in their evaluation of how teachers worked with a TBLT syllabus developed for adolescent newcomers to Flanders. However, while they chose just five of Long's (2015) methodological principles, we elected to use all 10.

This list of methodological principles (MP) was set, by Long, as a standard for "what should be done" (Long, 2015, p. 301) in the TBLT classroom; although, Long argues, they are useful for any approach to language teaching. We will here consider to what extent the tasks we observed may have provided evidence of these principles (bearing in mind the limitations of making claims, for each teacher, on the basis of two lessons only). There are obvious parallels between these principles and the Ellis (2005) principles with which the teachers were familiar. However, one of the reasons for using Long's, rather than Ellis's principles, was that they are specifically intended for the TBLT classroom whereas Ellis's principles were written more generally as applying to all instructed learning contexts. In using Long's principles, we might also be able to consider how useful and relevant they are when applied to contexts such as the present one.

1. MP1: Use task, not text, as the unit of analysis

Long (2015) underlines the importance of having tasks constitute syllabus content and of having lessons that are built around these. He argues against a covert grammatical syllabus.

In this study, there was no evidence of teachers following a syllabus defined by tasks. The teachers were very aware of the language that learners needed to know for their national, NCEA exams. In planning lessons and units, they, therefore, perhaps, not surprisingly, seemed to start with thinking about language rather than task. Furthermore, we wonder how feasible Long's task-based syllabus might be, in this context, given the requirements of the external assessments.

However, there was evidence that some teachers were teaching lessons oriented towards tasks, even if not following a syllabus defined by tasks. This was particularly the case for teachers of older, Year 11, students. They structured units around a target task, which for two teachers was determined by a NCEA assessment standard. In these cases, it would seem that the teachers had started by thinking about the task, and subsequently considering the language students might need. The evidence for this comes from Shona's comment in the interview: "I started with the task and looked at what language would fit within the task." She then went on to say that the task was a way for students to learn the specific language within the curriculum. While this approach falls short of Long's stipulation that teachers follow a syllabus determined by tasks, it would, nonetheless, seem an important step towards using tasks to structure teaching and learning. 
2. MP2: Promote learning by doing

Learners need to use language that is context-embedded and do something with this language. They need to function as language users and not just language learners. This principle seems closely related to Criteria 1 and 2, against which all tasks were coded. Criterion 1 required that learners use language to communicate meaningfully. Criterion 2 specified that learners bridge a gap through the communication that takes place.

When all 15 lessons are considered, Criteria 1 and 2 were the most in evidence in classroom practice, at $80 \%$ and $67 \%$ respectively. What is more, all 10 lessons in which we found evidence of tasks fulfilled the first criterion and only one did not completely fulfil the second. Therefore, it seems reasonable to claim that there was evidence of learning by doing.

3. MP3: Elaborate input

Long argues that elaborated input, which improves comprehensibility, is more appropriate than either simplified or genuine (authentic) input. It is better suited to learners' processing capacity and therefore is more likely to be learnt.

In most of the tasks observed, there was evidence of elaborated input. This was discernible in the transcripts of the teacher discourse, where we saw teachers modifying and extending language input as they interacted with individuals (more evidence of this is presented in Chapter 5). We therefore claim that there was some significant, if not consistent, evidence of this principle.

4. MP4: Provide rich input

Long (2015) refers to samples of language which are context, domain and task specific, as opposed to the language found in traditional pedagogic materials and in most commercial textbooks. He argues for language that is genuine, relevant, and not limited in either variety, quality, or quantity.

It is hard to argue from the lessons we observed that there was consistent evidence of rich input. This is because only three tasks $(3,6,8)$ were input, rather than output based. In these three input-based tasks, the input used with the learners was rich in that it was context and task specific. We therefore coded this principle as another that was partially fulfilled.

The fact that we found in our data set relatively few input-based tasks resonates with other literature which reports that teachers tend to work with tasks that have students produce output rather than decode input (Erlam, 2016a; Erlam \& Ellis, 2018).

5. MP5: Encourage inductive "chunk" learning

Long (2015) argues that formulaic language and collocations are important; collocations, in particular, remain a major problem for language learners as errors persist even with advanced L2 speakers. He argues that these need to be learnt as intact wholes. 
In our data set there were lots of examples of students having exposure to formulaic language. This was the case for all tasks, but in greater evidence for the six tasks $(1,2,6,7,9,10)$ we observed that were taught to learners in Year 10 (in either their first or second year of language learning). We therefore coded this principle positively. A main reason for the use of formulaic language in classroom practice in this study, was, no doubt, the emphasis given to the use of formulaic language in the TPDL programme (see Chapter 1) meaning that the teachers understood its importance in language learning.

6. MP6: Focus on form

Long (2015, p. 317) claims that focus on form is reactive and draws "learners' attention to linguistic problems in context, as they arise during communication, thereby increasing the likelihood that attention to code features will be synchronised with the learner's internal syllabus." He maintains that even the explicit provision of a grammar rule can meet the requirement for focus on form if it is provided during the context of, or arising out of the context of, a communicative exchange.

In all the tasks in our data set there were examples of focus on form. We therefore coded this principle as fulfilled. However, there was considerable variety in terms of the frequency of opportunities that learners had access to for attending to form. There were also examples of occasions where the attention to form would fit more with Long's definition of focus on formS. This was where learner attention was drawn to language before this language was encountered in the context of communication (where the students worked more with language as an object than as language users). See Chapter 5 for more information about how teachers drew learners' attention to form as they worked at tasks.

7. MP7: Provide negative feedback

There is compelling evidence, Long (2015) argues, for the necessity of negative evidence or evidence about what is not possible in a language. This is, most often, in the form of corrective feedback. This may involve, for example, a recast, a request for clarification, or an explicit grammatical explanation.

All the teachers in our data set provided corrective feedback in the form of negative evidence to their learners, although there was not necessarily evidence of this in every task. In the majority of cases, this negative evidence was in the form of recasts. We also found examples of students recasting errors for each other (we state that, at times, classroom noise meant that some discourse could not be clearly decoded and so some examples of this type of feedback could have been missed). We coded this principle as fulfilled.

8. MP8: Respect learner syllabi and developmental processes Long (2015) outlines a number of ways of implementing this principle in classroom practice. Firstly, he argues, it is important that instruction is pitched 
appropriately for a learner's developmental stage, rather than being determined by a linguistic syllabus. Long even argues against a covert linguistic syllabus, as in task-supported language teaching. Secondly, he argues, it is important to recognise the inevitability of errors in learning. Lastly, the focus on form must be reactive and in response to learner errors (see MP6).

All teachers recognised errors as an important part of the learning process (one teacher specifically referred to this as a learning outcome for her during TPDL), and all teachers provided opportunities for learners to focus on form. However, these opportunities were not all reactive, in that teachers did plan for tasks to focus on specific language forms. We therefore considered that there was some evidence for this principle in the classroom practice we observed.

9. MP9: Promote cooperative/collaborative learning Long (2015) argues that cooperative collaborative learning is advantageous for language acquisition. Pair and small group work allows for scaffolded discourse and allows learners to try out language. The type of interaction that results is likely to lead to instances of negotiation of meaning, and so afford opportunities for language acquisition.

In all but one task (5), students in the tasks we observed worked in pairs or small groups. We coded this principle "yes" considering that it was in evidence in our data set.

10. MP10: Individualise instruction

TBLT is learner-centred (Long, 2015). Course content is determined by learner needs and respects the learner's internal syllabus. Long also recommends that individualisation occur in the form of modifications of the pace and manner in which instruction is delivered.

In most of the classes we observed there appeared to be little evidence of individualised instruction (it is possible that this lack of evidence was due to the limitations of our data-collection approach; in the interview, regrettably, we did not specifically ask about individualised instruction). Exceptions were Shona and Annabel's classrooms, where learners completed tasks and activities in their own time. Furthermore, the Treasure Hunt task (Task 6) enabled the pace and manner of learning to be determined by the learners themselves. However, additional indication that this principle may have been one that was less in evidence in this study comes from a claim made by one of the teachers (Tania) that a problem in implementing TBLT was that it was difficult to cater for individual learners. We therefore coded this principle as partially fulfilled. 


\section{Summary}

Table 52 presents a summary of the extent to which there was evidence of Long's (2015) methodological principles in the lessons containing tasks that we observed.

Table 52. Evidence of implementation of Long's (2015) principles

\begin{tabular}{lllllllllll}
\hline Evidence & MP1 & MP2 & MP3 & MP4 & MP5 & MP6 & MP7 & MP8 & MP9 & MP10 \\
\hline & no & yes & some & some & yes & yes & yes & some & yes & some \\
\hline
\end{tabular}

From the data we collected, the five principles that the teachers in this project consistently embodied in their practice were: 2 . learning by doing, 5 . inductive chunk learning, 6. focus on form,7. negative feedback, 9. cooperative/collaborative learning

In a study where they investigated the teaching practice of four teachers of beginner-level adolescent learners of Dutch, Vandommele et al. (2018) found that "promoting learning by doing" and "focus on form," were implemented frequently. On the other hand, they did not find evidence of "negative feedback." Interestingly, Vandommele et al. (2018) found that "individualise instruction" was rarely, or almost never, a part of the classroom practice of the two teachers in their study that they considered less experienced. In their view this was surprising given that this principle is one that is not exclusive to TBLT.

To summarise, there was evidence of all but one of Long's 10 principles in the classroom practice of the teachers in our study. Five principles appeared to be consistently embodied in practice, for another four, there was some evidence. The one principle that was not in evidence was the first, that is, "use task not text as unit of analysis." Closely linked to this principle was the eighth: respect learner syllabi and developmental processes; it seems highly likely that if teachers were not using task as a unit of analysis, that they may not be respecting learner syllabi. At the same time, in this study, we did find evidence of teachers teaching lessons and units oriented towards tasks and claim that this is an important step towards using tasks to structure teaching and learning. Moreover, in the context of this research, we wonder to what extent it was realistic to expect teachers to implement a task-based syllabus. This raises the issue of the extent to which Long's principles can be suitably applied across all learning contexts, given that the differences between these can be very great. At the same time, we would make one exception to the notion that a task-based syllabus may not be appropriate for beginner learners. We suggest that the use of input-based tasks, rather than output-prompting tasks, could be used to successfully implement a task-based syllabus with beginner learners (Shintani, 2016). Giving teachers the skills to work with input-based tasks is something that we would place greater emphasis on in professional development aiming to equip 
teachers to implement TBLT. This conclusion is also suggested by the inconsistent evidence that we found for elaborated and enriched input (MP3 \& MP4). Finally, in closing this section, we need to remind the reader that the conclusions we have made for evidence of Long's principles needs to be tentative, given that we observed no more than two lessons in each instructional context.

\section{Conclusion}

In this chapter, we have focused on describing the characteristics of the 10 tasks that the teachers we observed in this study were using. The aim has been to allow us to draw conclusions as to how they were using tasks in their classroom practice. We have also investigated the extent to which the classroom practice of these teachers was consistent with the principles of TBLT. To address this second issue, we drew on our observations of the 15 lessons taught by these teachers, as part of their current teaching programmes and assumed to be examples of their regular teaching practice.

Before we focus on our findings, we need to point out that, in those lessons where we found tasks, these tended to represent a proportion only of the total lesson time. In fact, on average over these 10 lessons, tasks took 32 minutes, just over half of the lesson time (in each case, class routines at the beginning and end of lessons meant that there were less than 60 minutes for the lesson). This is typical of the school classroom context, where there are different types of routines and attention to the development of different skills. Tania and Shona, for example, both Japanese teachers, started each lesson with a focus on the learning of words in katakana script. It is important to remember, therefore, that some of the conclusions we draw are based on only a proportion of the classroom practice we observed.

As we have outlined in the previous chapter, we considered any activity that fulfilled three or more of the Ellis and Shintani (2014) criteria could be considered a task. We suggested that, of the four criteria, three were more important in determining the "task-likeness" of a given activity. These were: focus on meaning, some kind of communicative gap, an outcome. In our data set, $66 \%$ of the 15 lessons we observed contained tasks that fulfilled these three, of the four, criteria. We conclude that this is an encouraging result, especially given the fact that the teachers had completed the TPDL programme where they had the opportunity to learn about and use tasks, on average 4 years previously. This finding suggests that teachers had been able to retain knowledge of the salient features of tasks, and furthermore, use this knowledge to design and use tasks in their classroom practice.

The finding that the criterion, "students need to rely on their own linguistic and non-linguistic resources" seemed to be the one less in evidence, was not a surprise, as it is reported elsewhere in the literature (Erlam, 2016a) and, indeed, in Part 1 
of this study. In coding for evidence of this criterion, we were, firstly, establishing that students were not taught, immediately before the task, new language structures that they were expected to use communicatively. We were then establishing that students had opportunities to automatise language they already knew and that they were being encouraged to do this as independently as possible. The difficulty that teachers continue to experience with this criterion suggests the need for a greater focus on supporting teachers to design tasks with appropriate language demands, particularly in contexts when teachers are working with beginner students who have a limited language repertoire on which to draw. At the same time, in our opinion, teachers need help to know how to gradually withdraw scaffolded assistance so as to encourage students to use language independently. We observed lessons where students, after repeated exposure to language input and opportunity to produce this language, then had it provided for them, meaning that they did not need to try and access this language for themselves. As we have already noted, the difficulties teachers had in implementing this criterion has implications for professional development.

We saw tasks being used at two levels, at the level of the unit (i.e., target tasks) and at the level of activity (i.e., pedagogic tasks). Three teachers used tasks at both these levels. They began planning their unit by thinking of the task, either in terms of how it would fulfil specified assessment requirements or in order to set an achievement target for the unit (Samuda \& Bygate, 2008). At the same time, within the target task, there were also smaller or pedagogic tasks. These teachers were all teaching older, Year 11, students. We claim that their approach demonstrates a step towards using a task-based syllabus.

The teachers in this study used tasks with the primary goal of allowing students to "activate, stretch and refine their current language resources" (Samuda, 2001, p. 119), rather than with the goal of creating opportunities to enable new language learning and new form-meaning connections to be made. At the same time, as we have seen in the previous chapter, the tasks did also appear to create opportunities for new language learning and for new form-meaning connections. The fact that teachers used tasks to activate language with which they were already familiar, and develop fluency, may perhaps be due to the fact that many, if not all, were very familiar with a PPP lesson format (Richards \& Rodgers, 2014). Their use of tasks equated with the final PPP stage which allows for freer language production. However, the fact that they had not designed tasks which required the communicative use of newly taught language structures, demonstrates to what extent their practice deviated from this approach.

While, on the one hand, allowing for activating language and encouraging fluency, the majority of tasks that were observed in this study were focused on preselected language domains, with, in most cases, the attention of the learners drawn to 
these in the pre-task phase of the lesson. In designing pedagogic tasks, the teachers did not appear to start with the task, rather they started with the language features, linguistic notions, functions or vocabulary that they intended to be the focus of the lesson. In this respect, the practice of the teachers in this study did not fit with the first of Long's 10 principles for the TBLT classroom (2015, p. 305), that is, "use task, not text, as the unit of analysis." Ellis (2019) claims that one feature of a TBLT approach is that, while tasks may be focused, there is no attempt to draw learners' attention to intended language features. In the classrooms we observed, however, learners' attention was drawn to preselected target language, and furthermore, the learners were often very aware of these language forms. The most likely reason for the approach taken by teachers in this study, is that, they felt constrained to some extent, by the assessment system, in terms of what they were free to teach. In such a context, full implementation of a task-based syllabus is unlikely to be possible (results in Part 1 of this study endorse this conclusion). It has been suggested that, with young learners of foreign languages, a task-based syllabus is not feasible (Cameron, 2001). It is interesting to note that Nunan's (1989) view of TBLT is more nuanced. He claims that a traditional syllabus, with a predetermined set of language and structures that need to be taught, could fit with a TBLT approach. However, he suggested that it would be used as a checklist, rather than as a list of directives. In his view also, the task, rather than the language, would be the starting point.

We were interested to see to what extent teachers made use of the task cycle in the lessons we observed. For most tasks, the researcher identified a component that could have been considered a pre-task, and that was used to orient students towards, or activate, the language or topic content of the task. Other than this, there was little evidence of implementation of a task cycle in the practice we observed. Only one task had a post-task phase including an opportunity for learners to focus on language form. At the same time, however, there were opportunities during the task completion phase in lessons we observed, for students to attend to language form.

We found evidence of both input-based tasks and output-based tasks. However, most tasks were output-based $(n=7)$ and oriented towards spoken $(n=6)$, rather than written production. A conclusion of this research is that teachers need greater encouragement to understand the importance of input-based tasks and greater support in learning to design them. This is all the more important in an acquisition-poor context, with beginner learners who have little exposure to the language outside of the classroom and who have a very limited language repertoire.

In the classrooms in which we observed, there were tasks that corresponded to all but one of the seven categories of Willis and Willis's (2007) taxonomy, demonstrating the creativity and variety with which this group of teachers was able to use tasks in their particular contexts (Erlam, 2013). A majority of tasks required the sharing of personal information which was perhaps not surprising given the fact that 
the learners in our study were all adolescents. Research literature on the adolescent language learner documents that they like to engage with tasks that are personalised (Legutke, 2012). A conclusion we would make is that, in our study, students may have lacked the language they needed to complete tasks that were more cognitively and linguistically demanding. There was, however, student enthusiasm, as we reported in Chapter 5, for the completion of tasks that involved problem-solving even if, at times, students were unable to rely totally on the target language as they completed these.

There was evidence from the classroom data of either consistent or partial fulfilment of all but one of Long's criteria (2015, p. 301) for the type of practice that should be evidenced in TBLT classrooms. This one criterion, that of the implementation of a task-based syllabus, we have discussed above. There was strongest evidence of learning by doing, inductive chunk learning, opportunities for focus on form, provision of negative feedback and collaborative learning. A further four criteria were partially fulfilled. There are a number of reasons which could possibly account for the fact that the approach to implementing tasks in the classroom only partially complied with Long's (2015) methodological principles. Firstly, in the TPDL course, in which some of the teachers in this study were introduced to TBLT for the first time (see Chapter 7), TBLT was deliberately not promoted as a "best method" approach to language teaching. Indeed, arguably, the way that TBLT was presented to teachers fitted more with a TSLT, than a TBLT approach (see Chapter 1). Secondly, the exposure to TBLT and tasks, was, unfortunately, for most teachers, limited to the duration of the course, which meant that there was not as much opportunity to present as many aspects of TBLT as would have been ideal. We have already documented some of the gaps that we would want to address in teacher professional development, these are: the importance of input-based tasks, how to ensure that the language demands of a task are appropriate and that students are suitably scaffolded to meet these. There were other limitations in the information and support that teachers received which may have limited their ability to implement TBLT. We did not for example, help them see how TBLT could fit with other aspects of classroom practice that might be important to them, such as memorisation or differentiating between learners in terms of level or learning style. Bygate (2020) identifies these as important aspects of classroom practice about which TBLT has, to date, been largely silent. Another reason, for the results we document, is that the teachers in this study were experienced and had completed TPDL after an average of 13 years of prior teaching experience. Changing their practice after such a long time of teaching more traditionally, is arguably more difficult than for teachers who may be less entrenched in their classroom practice. At the same time, we have made the argument that not all aspects of the practice that Long (2015) recommends are necessarily appropriate to the context in which our teachers were practising. 
We would conclude that, in this study, we found evidence that teachers were able to design and use tasks a significant time period (on average 4 years) after having learnt about them during professional development. They did not always use tasks in ways that are commonly documented in some of the research literature; nevertheless, they used them to open up possibilities for learning (Samuda \& Bygate, 2008). We argue that the teaching and learning context that we describe in this project, one that is underrepresented in the literature, plays a significant role in accounting for differences we observed in the use of tasks and the implementation of TBLT.

In this and the previous chapter, we have documented and discussed what we observed in the classroom practice of the eight teachers in our study. In the next chapter, we give these eight teachers a voice, in that we present their perspectives on tasks and TBLT and on the relevance that they believe these have for their classroom practice. 


\section{The teachers' perspectives}

There's probably lots of slightly different interpretations of what a task is and what is task-based teaching. And then, secondly, is how you implement it in your situation. And some people who are closer to the textbooks and things, [it] would be more of a bigger ask [to implement task-based language teaching].

There's lots of different ways you can slot [TBLT] in too. And to varying degrees I think. It's all helpful. (Linda speaking to the researcher in the interview)

In this chapter, continuing our investigation of whether and how teachers were using tasks and implementing TBLT in their teaching contexts, we focus on what the teachers say about tasks and TBLT and their teaching practice. We address the following main questions:

- What priority and importance did the teachers accord to learning about TBLT?

- How did the teachers understand tasks and TBLT?

- What role did they see for tasks and TBLT in their classroom practice?

- What were the factors they reported that either facilitated or constrained the use of tasks and implementation of TBLT in their classroom practice?

We draw on our interviews with the eight teachers whose classroom practice we observed and about whom we give information in the Introduction to Part 2 (see Table 25). In the two preceding chapters (5 and 6), we have been primarily focused on the six teachers who used tasks that fulfilled three or more of the criteria established for the definition of a task (Ellis \& Shintani, 2014). In this chapter, however, the focus is on all eight teachers, because it was considered important to get perspectives and understandings about tasks and TBLT from all the teachers in our data set.

All teacher interviews were recorded by the researcher and transcribed by a research assistant. Each transcript was subsequently sent to the relevant teacher who was invited to make any changes or to add comments in order to better reflect his/her viewpoint, but not all teachers responded to this invitation. The transcripts were then analysed, following the predetermined themes that had informed our interview questions. However, within these themes an inductive approach was taken, drawing on Creswell (2009), as well as Ellis \& Barkhuizen (2005). In other words, we looked for patterns of other themes that were emerging from the data we were coding. Finally, we returned to the data a number of times to further refine and subsequently verify conclusions made, and to interpret findings in relation to the classroom practice we observed. 


\section{Teacher orientation to tasks and TBLT}

In beginning our interviews with teachers, we were first interested in the extent to which they might be oriented to tasks and to TBLT. In other words, we wanted to know whether or not the teachers referred, without prompting and of their own volition, to tasks, or to TBLT, because this would give some indication of the salience and importance that TBLT had for them when they were given the opportunity to reflect on their practice.

In inviting these teachers to be involved in our research project, we had not referred specifically to TBLT, other than specifying that we hoped to see communication tasks when we visited them (see Introduction to Part 2). The first part of the interview, therefore, inquired about their general teaching practice, and only subsequently did we move on to questions that asked specifically about tasks and TBLT.

This section reports on what the teachers stated were their priorities as language teachers. It then documents the learning that they reported was most significant for them during the TPDL course and the way that they believed that that learning had impacted on their practice. We will discuss our findings and conclusions in relation to the predetermined themes that informed out interview questions, later in this chapter.

\section{Priority as a teacher}

We first asked teachers about their priorities. (Regrettably, we do not have this information for one teacher, Shona, as she was interviewed before the interview questions were finalised). Answers tended to fall into two broad categories. Teachers mentioned personal attributes and goals for themselves in their classroom practice and goals that they had for their students. The most common attributes mentioned by the teachers are listed below, along with the number of teachers (out of a total of seven) who referred to this personal goal.

- be passionate or enthusiastic (5 teachers);

- have caring or positive relationships with students (5);

- know and use the target language in class (4).

One goal was referred to both as an attribute that teachers aspired to and as a goal in relation to the learning experiences that they wanted for their students. It was:

- be a fun teacher or have students have fun in class (5). 
The teachers specified the following goals as being the most important for students:

- have the chance to talk a lot in the target language (3);

- use the language for real purposes (2);

- have the opportunity to learn along with the teacher (principle of "ako," understood in the New Zealand context as reciprocity between teachers and students) (2).

\section{Learning on the TPDL course}

In the next section of the interview we asked the eight teachers to tell us what they thought was most significant relative to their learning on the TPDL programme. Teachers mentioned the following as the most important learning (most gave more than one answer to this question):

- $\quad$ the need to use the target language more in the classroom (7);

- TBLT or tasks (6);

- the need to create opportunities for students to speak (2);

- Ellis's 10 principles (Ellis, 2005) (2).

A number of aspects of learning were mentioned once only. However, interestingly, three of these referred to the teaching of grammar (these perspectives will be discussed more fully in a later section of this chapter):

- teaching grammar followed by written activities is not best practice/need for both implicit and explicit grammar teaching/need to make learning grammar more fun.

One teacher reported learning from reading recent research.

Of interest in this section is the fact that six out of the eight teachers we interviewed reported that learning about tasks and/or TBLT was significant during their professional development experience.

\section{Impact on practice}

We asked the eight teachers how they thought that the learning gains that they had made during the TPDL programme had impacted on their classroom practice. The most common answers were as follows:

- now implementing TBLT or using tasks (5);

- speaking in the target language more (3);

- incorporating Ellis's 10 principles in classroom practice (2). 
Other changes in classroom practice received one mention each. These were: not using a textbook and linking lessons to real life; a student-based approach to learning; allowing mistakes; raising awareness of grammar before explaining it.

In conclusion, the interview data show that most of the teachers in this study reported learning about tasks and TBLT as significant for them during the TPDL professional learning that they had undertaken. This finding replicates the finding in Part 1, where seven of nine teachers reported learning about tasks as significant. In this second part of the study, five of the eight teachers reported that this learning had impacted significantly on their practice. These responses were, as has already been mentioned, at the stage of the interview where we had not explicitly referred to tasks or to TBLT. Only two of the teachers (Tania and Margaret), did not mention that tasks and/or TBLT had made an impact on their practice. However, they both taught tasks, as we have documented in Chapters 5 and 6. Furthermore, Margaret referred to, as key learning, raising learners' awareness of, and need for, a particular aspect of grammar before explicitly explaining it, a principle that is a feature of TBLT practice. We can conclude therefore, that for seven of the eight teachers we observed and interviewed, tasks and TBLT had made an impact on their learning and/or practice.

In the following section we document the teachers' learning about, and reaction to, TBLT and tasks during the TPDL professional development programme.

\section{Learning about and reaction to TBLT during professional development}

\section{Prior knowledge of TBLT}

We first established to what extent teachers knew about, or had heard about, tasks or TBLT prior to their enrolling in the TPDL programme. Four teachers said that they had never heard of tasks or TBLT (Margaret, Sonia, Tania, and Toby). Three teachers reported that they had some knowledge, but that this understanding of tasks or TBLT was not informing their classroom practice (Annabel, Emily, and Shona).

One teacher (Linda) stood out from the others in her prior knowledge. She said that she had been to the TBLT conference when it was held in Auckland (in 2011), however, she had found it quite boring and had realised that it was intended more for academics than for classroom practitioners like herself. She also said that she, along with other colleagues in her school languages department, had read Willis and Willis (2007) and had had the opportunity to attend some TBLT workshops before enrolling in TPDL.

In summary then, all but one of the teachers in this study had either never heard of tasks or TBLT before enrolling in TPDL or had limited knowledge that was not informing their practice. The remaining teacher had considerable knowledge. 


\section{Learning about tasks and TBLT during the TPDL programme}

In this section of the interview, we asked teachers to recall what they had learnt about TBLT during TPDL. It is important to remember that all teachers had completed TPDL on average 4 years previously, with a range of between 2 and 6 years across the group. We also asked them to indicate how they felt about TBLT and the extent to which it accorded with, or did not accord with, their beliefs about, and their approach to teaching and to language learning. Some of the answers to these questions we will present in the section where we discuss the roles and benefits that teachers described for incorporating tasks in their classroom practice.

In talking about their learning, six teachers mentioned features of tasks that had become salient for them during their professional development opportunity. These features, which we label as task criteria, are listed in Table 53, in decreasing order of mention.

Table 53. References to task criteria

\begin{tabular}{lcccccc}
\hline Criterion & $\begin{array}{c}\text { A } \\
\text { purpose } \\
\text { for using } \\
\text { language }\end{array}$ & $\begin{array}{c}\text { Authentic, } \\
\text { "real life" } \\
\text { language } \\
\text { use }\end{array}$ & $\begin{array}{c}\text { Learners } \\
\text { rely on } \\
\text { own } \\
\text { resources }\end{array}$ & $\begin{array}{c}\text { Communicative } \\
\text { gap }\end{array}$ & $\begin{array}{c}\text { Focus on Outcome } \\
\text { meaning }\end{array}$ & \\
\hline $\begin{array}{l}\text { No of teachers } \\
\text { who mentioned } \\
\text { each criterion }\end{array}$ & 5 & 3 & 2 & 1 & 1 & 1 \\
\hline
\end{tabular}

One teacher, Emily, also mentioned that, for her, a task needed to be interactive. Two teachers, Margaret and Linda, described previous professional development initiatives where they had been exposed to TBLT. Margaret described how a very experienced teacher had presented TBLT at a course she attended, and she had thought: "Oh, that looks good.... but you know, one... session of 2 hours isn't enough to learn a new way of doing things." Linda, the TBLT informed teacher who had been to the Auckland conference, read Willis \& Willis (2007) and attended a workshop, said that she had had "little bites at [TBLT]" but that it had been quite a struggle for her because it involved such a change in mindset. She attributed the fact that she was finally able to implement TBLT after completing the TPDL programme, to two factors. The first of these was the fact that she had had the opportunity and time to think more about TBLT. The second was the fact that, as part of the assessment requirements of the programme, she had had to design a TBLT unit and present it to the other programme participants.

One teacher, Sonia, said that tasks were "really hard" for her because she still had difficulty understanding what a task was. She said that, although she tried to design and use tasks in her classroom, she felt that her task might "not tick all the 
boxes" in terms of measuring up against the criteria. She described difficulty in making an activity into a task so that it was real and relevant for students.

Teachers reported other aspects of learning about TBLT that was significant for them during the TPDL programme. One teacher reported realising that there was a strong link between TBLT and the New Zealand Curriculum competencies of "managing self" and "participating." Margaret said that she felt very encouraged to realise that TBLT was supported by so much research. Shona said that it had taken quite a while for her to grasp the notion of teaching grammar at the end (of an activity or task), rather than at the beginning. Linda talked about understanding that it was possible to adapt an activity slightly to make it into a task.

We asked all teachers if they thought that tasks and TBLT were successful in promoting language learning. All said yes, although one teacher, Sonia (who, as we mentioned above, had difficulty understanding the task construct), qualified this by saying that she did not think that a class working with tasks would acquire language more effectively than one without. She suggested that the key benefit of tasks was that younger students might find them more motivating. We did not observe Sonia teaching a task in her classroom, so she may not have had the chance to experience any of the learning benefits of implementing tasks in her context. Another teacher, Margaret, qualified her answer by saying that she felt that TBLT tended to privilege speaking and overlook listening, and emphasised the importance of exposing learners to lots and lots of input.

In summary, the task criteria that seemed least salient for these teachers ("a focus on meaning" and "a communicative gap") appeared to be the ones they found easiest to implement in teaching tasks (included in $87 \%$ and $67 \%$, respectively, of activities coded against task criteria as reported in Chapter 6). Two teachers reported that it was the requirement for them to design and teach tasks that had been most significant in their journey of learning about tasks and TBLT. All but one teacher reported that they felt that TBLT promoted language learning.

\section{Teachers' understanding and implementation of TBLT}

In this section, we present conclusions that we made from the interview data about the eight teachers' understanding of TBLT. We use Carless's (2015, p. 368) definition of understanding as it relates to TBLT: “...the ability to engage with the principles of TBLT and an awareness of classroom applications of these principles.”

In order to decide whether teachers were engaging with TBLT principles and knew how these might be applied in their classrooms, we drew on their answers to specific questions in the interview, such as: 
- What did you learn about TBLT during TPDL (professional development programme)?

- To what extent did it fit with your approach to teaching when you first learnt about it?

- Do you implement TBLT in your classroom now? Can you explain how? If not, why not?

- Can you please describe a task you have taught recently?

From the teachers' answers to these questions we were able to ascertain those aspects of TBLT that were most salient for them and thus their understanding of the principles of this approach. We were also able to establish if they implemented TBLT and how. Answers to questions such as these complemented the limited perspective that we had been able to gain of their practice from the observation of just two lessons.

\section{The target task versus the pedagogic task}

In Chapter 6, we identified that three teachers implemented, in their classroom practice, tasks at two levels: the level of unit, which we referred to as "target tasks," and the level of activity, which we referred to as "pedagogic tasks" (Long, 2015; Long \& Crookes, 1992). Two of these teachers (Shona and Linda) also differentiated, in the interview, between the notion of the big task which might extend over a longer time period and/or constitute the goal of a unit and the little task that you might teach in one lesson. Shona said that her Murder Mystery unit constituted a task in itself and that, within it, there were a myriad of tasks. Another of our participants, Emily, did not specify a target task towards which the students were working in the lessons we observed (Tasks 6 and 7), however, she did refer to target tasks, or "big tasks," that her students, had completed. She described a MasterChef unit, which all languages classes took part in, where students had to make videos of themselves cooking and describing in the target language a dish reflecting their cultural heritage, and a poster about their dish. One winner per language was chosen as a finalist and the finalists had to bring their dishes to be judged by a panel at school assembly where, at the same time, the videos of these finalists were played and the posters were displayed. Emily was pleased to say that a pupil from her class had won this competition. This interview data demonstrates that four of the teachers in our data set of eight were using target tasks in their implementation of TBLT. Furthermore, in Emily's case, the target task was implemented at school level, involving all language classes and including other teaching and school management staff. The use of the task in this way had the potential to raise the profile of, and highlight the value of, language learning across the school. 
Teachers also differentiated, at the level of activity, between bigger and smaller pedagogic tasks. Three teachers made this distinction, using terms such as "full-blown" and "in-depth" to refer to bigger tasks, and "mini" to refer to smaller tasks. Four teachers, in talking about tasks, referred to class "surveys." Shona, perhaps, spoke for all, when she referred to the survey as "standard task-based," giving as an example, a survey to see where everyone in the class lived. Both Toby and Annabel gave surveys as examples of smaller tasks; Toby used the example of students going around and asking each other about foods they liked. The fact that these teachers referred to class surveys could be due to the fact that this type of task had been modelled for them during the TPDL programme.

Four teachers appeared to use tasks as assessments at the end of a unit of work. Two of these, documented in Chapter 6, involved NCEA assessments. In other words, the target task also doubled as the assessment. Linda mentioned, in the interview, that this was an aspect of TBLT that she really liked: "if you can complete that task, basically that's the assessment done,... so I really like that as well." Emily stated that, with her senior classes, she often did extended reading and writing tasks, which aligned well with NCEA assessments. The fourth teacher, Annabel, did not refer to an assessment task, but, in fact, she described an assessment that could be seen as fulfilling the criteria for a task (Erlam, 2016a). She referred to a "mastery check" at the end of a unit on clothes, which students had to complete successfully before they moved on to another unit: "they had drawn a person, a stick figure with clothes on it, different colours and they had to describe the picture to me and I had to draw it and if it matched up, they passed."

To conclude, four out of the eight teachers used or described target tasks, as well as pedagogic tasks. Three teachers distinguished between bigger and smaller (pedagogic) tasks. Four teachers used tasks as assessments at the end of a unit of work. Only one teacher in our data set of eight did not either refer to or use target tasks/tasks for assessment or distinguish between bigger/smaller tasks.

\section{Teacher awareness of the task cycle}

In the interview, we did not ask teachers specifically about the task cycle, so any reference to this was teacher-motivated. As documented in Chapter 6, only one teacher, Annabel, referred to a pre-task in discussing her lesson with the researcher. Another teacher, Emily, did not designate any aspect of the lesson that the researcher observed as a pre-task phase, however, she did mention that she often included, in her lessons, a pre-task prior to a "real task." No teacher referred to a post-task in the interview; we have documented in Chapter 6 that Margaret, alone, implemented a language focus phase at the end of Task 4 , in what would seem to resemble a post-task. It is, 
perhaps, surprising that not more teachers used post-tasks, because a post-task is the most obvious context for form-focused activities (Ellis et al., 2020). However, Linda, who was the most informed of all our participants, did refer explicitly to the concept of a task cycle. She talked about a workshop she had taken with a facilitator (prior to her involvement on the TPDL programme) who had described five steps involved in implementing a task cycle. She commented that she, personally, had not found that approach especially helpful.

Given the fact that the interview questions did not specifically ask teachers about the task cycle, we cannot conclude that teachers were not aware of it, or that they did not give it any importance. At the same time, however, there is some evidence that it may not have been a strong focus in their understanding of TBLT.

The starting point for the task

Long (2015) maintains that the TBLT syllabus is determined by tasks, and not by a sequence of language forms. In Chapter 6, we documented that, out of the 10 tasks we observed, eight were focused (Ellis, 2003), in that they were designed with the intention that learners would have the opportunity to use particular, preselected domains of language. In the interview, we were interested to hear more specifically about where teachers started in terms of thinking about using tasks in the classroom and what place a focus on language took in the task designing phase. We will start by looking at the approaches that the three teachers whose students were at Year 11 took in our study. These students, in their third year of language study, had greater proficiency in the language, which gave teachers greater flexibility in designing tasks.

One teacher, Linda, described an approach to task design that did fit with a TBLT syllabus (Long, 2015). Linda described the unit she was teaching as a "film study" and gave, as a goal, that students would learn about Cuba and that their language would "grow exponentially" at the same time. The task (Task 5, Making Predictions) we observed, that was part of this unit, was unfocused. During the interview, Linda described another unit that she had taught with her Year 10 students, where she started with an analysis of what they would need for a trip to New Caledonia. She described how the unit was based around the experiences that students would have, for example, going shopping, meeting their host families, talking about food preferences, and so on: "so for my Year 10 course for French this year, I've set it up totally around the trip to New Caledonia that we're going on in October." Arguably, this approach to planning would seem very similar to how the design of a task-based syllabus might proceed. However, at the same time, Linda also seemed to be somewhat guided by a syllabus that referenced language forms. She talked about a previous unit, that the students in the present study had completed, where the topic was on 
holidays and where there was a focus on teaching the past tense. She explained that in addition to past tense, "looking to the future" and "predicting or saying what could or would be" was also a focus in the unit in the present study. Furthermore, Linda was very aware in her planning of how tasks might align with NCEA assessment requirements. Nevertheless, of all the participants in our study, Linda was the one who appeared least guided by language forms in task planning, starting rather with ideas about the content that students would learn or the experiences that the students would have.

Shona's approach was different, in that, while she said that she first started with the task, in designing her Murder Mystery unit, there was a strong focus on language. Shona described three chapters as part of this unit. The first focused on prepositions, the second on descriptions, and the third chapter focused on timing and required learning about "before and after structures" in Japanese. Shona was very aware of needing to cover the language students needed for the curriculum and for their assessments, describing this as a constraint with senior students. She said that she felt that there was quite a lot more freedom with junior students in Years 9 or 10.

But with seniors, they've got all these NCEA assessments and...I feel it needs to feed in to either... an assessment, or that they are learning stuff that's in the curriculum that they need for the end of the year. So it's kind of looking at what things I can include that ticks off those things that they need to know for the exams at the end of the year, language-wise.

In the unit we observed, Shona said that, although her students were working at Level 1 in the curriculum, she had decided to teach some Level 2 language structures, because the students needed them. It would seem that, from these examples (i.e., Linda and Shona), it is perfectly possible for teachers to plan units at a level where there is consideration and emphasis given to both task and language forms.

Margaret, also teaching Year 11 students, said she liked to know that she had covered certain structures in her teaching and said that her tasks tended to be "focused on assimilating a point of grammar" and not be "terribly free." She appeared almost apologetic about this: "I do have an idea of the progression of grammar I want to get through... and I can't shake that off." Furthermore, in the interview, Margaret was able to articulate the two different approaches to using tasks: "you just give a task and it's the task that's the most important thing, and the students will kind of get from it what they want to get... [and] where you know what you want to teach, um, but you do it through tasks. And that was much more my approach." Interestingly, she was so focused on the use of language in the tasks she taught for the present study (Tasks 3 and 4) that she described the outcome as grammatical for her, while saying that for the students the outcome was that they would learn more about each other when they were aged six. It would appear, from the example of Margaret's practice, that it is possible to determine task outcome at two distinct 
levels, with both operating in parallel. The first would be the outcome for the students, and the second, the outcome for the teacher.

The second group of teachers were working with students in Year 10, in their second, or, as in Tania's case, their first year of language study. In this group, Emily was the teacher whose approach most closely resembled that of a task-based syllabus (Samuda \& Bygate, 2008) in that she spoke, in the interview, about tasks as the starting point in terms of planning. We have discussed earlier her description of the MasterChef unit. In the lessons we observed, however, even though she saw the task as the starting place for her planning, Emily taught tasks which were heavily prescribed in terms of language use. Perhaps Emily, like Margaret, was also able to work with both task and language in parallel focus in her planning. In some of the literature dealing with task planning (e.g., Long, 2015), there is tension between whether the primary focus is the task or text (i.e., language), but a more complementary synthesis of both levels operating in parallel may be more helpful and reflective of actual practice.

Perhaps unsurprisingly, the other teachers of students at this level also seemed focused on language in discussing their lessons. Tania was very clear about the lessons that she would teach following on from the ones we observed on the topic of sports. She said that students were going to focus on "where" and "who with" and "when do you do it" and "for how long." She also said that they would do sentence building and particles, "putting it all together and making sentences." In describing her flipped mastery classroom (where students worked at their own pace through a unit), Annabel talked about the grammar and new structures (asking and answering questions about daily routines) that would be the focus. While acknowledging, on the one hand, that the New Zealand Curriculum is quite open, Sonia and Toby both seemed to have very clear ideas about the language they wanted their students to learn. They both planned focused lessons that had learners working with specific language structures. Toby described how he looked at a topic and what he was going to cover and then: "I try and work out what kind of task we could create from that." He also described the types of activities that he would have leading up to a task. He talked about covering "a lot of vocab," having students match things, using speaking prompts and so on. Toby acknowledged that this approach was "more... task supported," than task-based. The planning approach taken by these teachers seems to be one where they worked from the topic to the language, and finally to the task.

To conclude, teachers varied in terms of whether they reported starting with the task or language in their planning for using tasks in the classroom. Some teachers were very clear that they started by thinking about language. Other teachers reported starting with the task, however, on closer investigation it appeared that they also had very clear ideas about the language that they intended would be the focus during task implementation. It seemed as if these teachers could work holding both task and language in parallel focus during planning. 
Focus on language form in TBLT and tasks

Three teachers in our data set of eight, referred specifically to a shift, in their approach to teaching grammar, as a result of doing TPDL. Teachers had been taught that in a TBLT approach it was preferable that learners encounter forms in a meaningful context before they were given any explicit teaching or explanation about these (Willis, 2004), and also that students should be encouraged to generate their own explanations and conclusions about language forms they had encountered (see Chapter 1 for more information about the TPDL programme).

The teachers did not all say that it was their learning about TBLT that had motivated the changes that they said they had made in classroom practice in the ways in which they focused on language forms. The changes they described, however, reference the way that TBLT approaches a focus on form in language learning.

Margaret, for whom knowing that she had covered what she considered were the important aspects of grammar in her teaching was crucial, explained that she: "started much more thinking how can I raise students' awareness of the grammar and of their need for the grammar... before actually explaining it?" Annabel also described trying to get students to notice aspects of language for themselves. It would seem that these teachers had moved from focus on formS, where the initial focus on language was decontextualised, to a focus-on-form approach, where a focus on language form arose out of a context where the initial attention was on meaning. This was, indeed, evident in Margaret's practice. For Annabel, evidence of this was that she talked about the importance of an implicit focus on language form, as well as an explicit focus. She also described what could be seen as an inductive approach to explaining grammar. She outlined her practice as follows: "get them to look at sentences and notice stuff first and then maybe come up with their own... formula for a sentence. I won't just say, "this is how you do it." At the same time, in her practice, Annabel described making place for an explicit focus on language forms and, in her flipped mastery classes, explained that each unit started with students watching a video explicitly introducing "new grammar, new structures, new characters, vocabulary."

Shona reported moving from being a PPP teacher to one who implemented what she called a discovery grammar in her classroom. She said that the advantage of this was that it helped students learn more effectively because they had to figure out how the language operated for themselves. She described the sequence of discovery that the students working on the "before and after structures" went through in the lesson that we had observed: "they had the before sentence... which they had to figure out... in English... and then how they would structure it, and write a sentence, and then they played [a] game, before watching the [video] to clarify things." However, there seemed to be some ambiguity in the way Shona approached 
dealing with language form and/or forms in her classroom practice. For example, in the chapter dealing with prepositions, students were instructed to "watch the video about prepositions" before using prepositions to work out which teacher was in each office (on an "office layout sheet") and who the murder victim was. The practice of dealing with grammar at the end, as in TBLT, rather than at the beginning of a lesson or task, did not seem to be a consistent aspect of her practice.

For three of the eight teachers in our project then, it seems that there had been, perhaps, some shift in the way they focused on language form in the classroom through learning about TBLT. They had moved from a focus on form, in a decontextualised context, to one where attention to form arose out of a focus on meaning and where students were encouraged to induce or discover patterns for themselves. However, there was evidence also that there continued to be some ambiguity in the way that this was implemented in classroom practice.

\section{Implementing TBLT and including tasks in lessons}

In the interview, we asked teachers how often they thought they taught a task. Only one teacher, Emily, said that she incorporated a task into every lesson. She claimed that, in each lesson, there were either two tasks, or a pre-task and a task and that, from her point of view, TBLT was the only way of teaching.

For two teachers, Linda and Shona, the task was present in the lesson at the level of the unit. Students would be working, therefore, towards a target task, but not necessarily completing a pedagogical task, in each lesson. Shona did not think that TBLT should be the only approach to language teaching. The comment below, however, reveals some ambiguity in how much emphasis she thought could, and should, be given to TBLT in the classroom and suggests that her viewpoint could be changing:

I don't feel that everything can be done task-based, and I don't think that everything should be done task-based... so you try and do as much task-based as you can, as long as it fits in with what you can do... and the more you think about it the more you realise...the more things you can do in a task-based manner.

Two teachers were noncommittal in describing whether or not they regularly used tasks. They tended to describe teaching partial tasks, that is, they incorporated features of tasks. Margaret said that every lesson, rather than thinking "Oh what task am I going to do?", she always thought about what message needed to be conveyed and whether there was a purpose beyond just the practising of language: "I think that I think most about student interests really. How is this going to interest the kids? I think that's my priority... and I think usually that results in some kind of message being conveyed." 
Tania did not think that she would use a task every lesson. She said that she spent a lot of time on reading and writing activities and tried to make them as taskbased as possible. She also said that she used, in her practice, a lot of activities that once she would have thought were task-based, but which she now knows are not. Tania said that when she had first done TPDL she had been using tasks all the time: "[When] I did the course it was like, fully, I was doing it all the time, I have to say I've got a bit slack."

Two teachers said that they implemented tasks approximately once a week. Annabel explained that she had tried implementing TBLT but found that it had not been viable for her to do every single lesson "fully task-based" because of the time involved in preparing and making resources (this will be discussed again later). A third teacher, Toby, estimated that he used a task once or twice a week. For these teachers, tasks were used as pedagogical tools (Samuda \& Bygate, 2008) to allow practice for semiauthentic communication purposes. The way teachers incorporated tasks into a learning cycle was suggestive of a task-supported approach to implementing TBLT. Toby, as we have discussed earlier, even referred to his practice as being task supported, demonstrating an understanding of how this differed from TBLT: "it's more kind of task supported. Um, at the end of the week we will look at the task, and it works really well, period five on a Thursday."

Three teachers in our study incorporated TBLT with other methodological approaches to language teaching. While she did not ever use specific terminology to refer to her approach, Linda was very focused on having her students learn content at the same time as they learnt language, she described this as: "task-based taken perhaps even a step further."

Shona and Annabel, were both implementing a flipped mastery approach to language teaching, where students worked through a unit at their own pace and where explicit information about language (grammar, structures, characters, vocabulary) was provided in an online video students could access in their own time. Their respective use of tasks, though, was quite different. Shona planned a target task at the level of the unit, with other pedagogical tasks incorporated along with activities. Annabel did not describe a target task at the level of the unit but incorporated pedagogical tasks within a flipped mastery unit so that students would be able to "use what they had learnt" during the individual periods where they worked on their "mastery work." Interestingly, Annabel describes how initially she had not planned to include tasks in her flipped mastery approach, but that her students had requested more opportunities to use the language orally. She decided that incorporating tasks in her flipped mastery units would enable her to meet this request.

To summarise, just one teacher described her practice as totally task-based, with a task incorporated into every lesson. For two teachers, students were working in every lesson towards the completion of a target task, and also completed 
pedagogic tasks from time to time. Two other teachers claimed that, in all or most lessons, they taught partial tasks or that their practice reflected aspects of TBLT. Finally, three teachers claimed that they used tasks approximately once a week.

\section{The benefits of and role for tasks}

In the interview, we asked teachers what benefits TBLT as a teaching methodology might have for the language classroom. In answering this question, the teachers tended to refer to what their classroom practice had been like prior to learning about tasks and TBLT, and having the opportunity to design and use tasks in their classroom practice.

There were three main benefits that teachers documented, for the use of tasks and TBLT. The first of these, and seemingly, the most significant, in that it was mentioned by six of the eight teachers, was that task-based lessons were more fun and motivating for their students. Emily and Toby both claimed that, since they had been teaching with tasks, there had been better retention in terms of students choosing to continue with learning the language in subsequent years. Emily, who said that all three Chinese teachers in her school used tasks, claimed that Chinese had the best retention rate of all languages taught. For these teachers this result was highly significant in a context where there is no requirement that students study a language other than English and where many language teachers are faced with diminishing class sizes as students choose STEM (science, technology, engineering, mathematics) subjects. Toby described how Spanish was not established when he arrived at the school he was teaching at, but that, due to the high retention rates for students who had been in his classes, every year he had been able to have a Spanish class introduced and taught at a new level of the curriculum. Interestingly, for another teacher, Margaret, enjoyment was not only mentioned in terms of the student experience, she also said that teaching tasks was more enjoyable for the teacher.

The second main benefit for tasks and TBLT was that the language learner became a language user. Four teachers referred to the fact that tasks allowed for more authentic language use and that students had a reason to use language for more than just practice; they could use it for real-life purposes. Linda, who, as we have documented earlier, described using the language to teach content, referred to this as a revolution from the old days of decontextualised sentences and learning for the sake of it. She emphasised how, in her opinion, the opportunity for making meaning was really important and she identified this as a crucial factor for student retention: "really that's the only thing that students relate to. They will definitely walk with their feet if you're just giving them boring sentences" (the expression "walk with their feet" refers to learners making a choice not to continue learning 
the language). Tania described how her husband contrasted his own experience of learning te Reo Māori (the indigenous language of New Zealand) with her lessons, as they were described, by her, to him: "Wow, I wish I was in your class. Because I don't know how to say anything in te Reo. But I know your kids are learning how to say stuff and actually use it!"

The third main benefit of tasks was that they allowed students free, rather than controlled, language use. Three teachers mentioned this aspect. Linda described how she had been "blown away by what the students gave me back" when she had "let go" rather than controlling and restricting the level of language that she used with her students. Tania described how learning about TBLT had inspired her to give students the freedom to use language and to stop "holding" or limiting it. She recounted an incident that had taken place during the unit on sport, which the lessons we observed in this study formed part of. She described how she had taught her students the phrase in Japanese for "I think it's a sport," even although normally she might have thought that this phrase would be too hard for them. As a phrase at Level 2 of the curriculum, it was not part of the language that they were supposed to be learning. She then recounts how she was walking around the class and one student said to her, in Japanese:

"So Miss, do you think such-and-such is a sport?" and I said "Ohh, no I don't think it's a sport" and she said "Well I do!" I was like "Okay! That's amazing! Do you?" I didn't know what to say after that, I was so shocked.

I was just so shocked she was even having an argument with me, but I could see when she said that, she'd set it up so that she could actually have an argument with me, cause she wanted to test it out and see if it worked with someone who really spoke the lingo. That's what she was keen to do.

For Tania, this experience was proof of the importance of not limiting the language that she exposed her students to. Another teacher, Shona, did not specifically refer to free language use, but reported that a benefit of implementing TBLT in her classroom that she had noticed, was that her students were less afraid to speak in the target language.

In mentioning the key benefits that they saw for the use of tasks in their classrooms, the teachers in this study were focused on the learner. Benson (2016) identifies a shift in attention away from what the teacher does to what the learner does, as one of the principles of TBLT. With the understanding that what is taught does not necessarily translate to what is learnt, there is a greater recognition of the importance of the learner and the processes that s/he engages in.

There was a final benefit for using tasks, identified by one teacher. This was that they corresponded well with the aims of the New Zealand Curriculum. They gave learners opportunities to interact with and to relate to each other. They also required 
students to make contributions and to use the symbols of language and text, all identified as curriculum aims or competencies (MOE, 2007b).

To summarise, teachers reported that tasks made lessons more fun and motivating for students and enabled them to use language in authentic ways rather than just functioning as language learners. Learning about TBLT had helped them understand that they should not limit the language that they exposed their students to, with the result that they had been astounded by the learning gains their students had demonstrated that they were capable of.

\section{Factors motivating or constraining implementation of TBLT and use of tasks}

Towards the end of the interview, we asked teachers whether there were factors that had either enabled or constrained the implementation of TBLT or tasks in their particular teaching contexts. We present below their responses, analysed based on factors identified by Carless (2013) as those that either support or threaten the implementation of TBLT. These are: factors at system, teacher and student levels.

\section{System level factors}

A factor that four teachers mentioned positively as facilitating the implementation of TBLT was the New Zealand Curriculum. Toby said that the curriculum focus on communication meant that it aligned very well with TBLT, and Sonia mentioned the open nature of the curriculum as an enabling factor. Emily, as has already been mentioned, felt that TBLT aligned very well with the curriculum (an observation also made by teachers in Part 1): "You have to interact with each other, you have to mentor yourself, you're relating to each other, you have to make contributions, contributing to the wider society." In listing these she was most likely referring to the curriculum key competencies of "managing self" and "participating" (MOE, 2007b, pp. 12-13). Toby also referred to the alignment between TBLT and key curriculum competencies. The role of TBLT and tasks in enabling students to become more aware of themselves and of the social roles that are possible for them has been acknowledged in the research literature (Candlin, 1987).

Linda discussed the freedom of being able to design her own language courses around what she felt was interesting rather than using a textbook. She described the frustration she had experienced in not finding a textbook that she liked and of "nothing really fitting exactly." 
The New Zealand assessment system, NCEA, was also seen as fitting well with TBLT and tasks. Three teachers referred to this. Annabel described the ability to communicate as the main assessment focus of NCEA and Linda mentioned that you could design tasks that corresponded well to what students need to know for NCEA assessments.

Ellis (1997) lists a number of factors that are likely to influence the uptake of an innovation. One of these is relevance, the extent to which the innovation is "viewed as matching the students' needs" (p. 29). For the teachers whose viewpoints we have documented in this section, TBLT was perceived as relevant because it aligned well with curriculum and assessment goals. The fact that there was uptake in implementing TBLT on the part of these teachers is an example of how professional learning is effective when it is linked with curriculum and assessment (Darling-Hammond \& Richardson, 2009).

Two teachers referred to what is known as the "BYOD" (Bring your own device) policy. Linda claimed that the fact that students had their own computers in class made access to films, songs, and multimedia easier. For her this was positive, making it easier to use tasks in the classroom. However, another teacher referred to this as a possible negative factor in terms of consequences for using tasks in the classroom. Margaret wondered whether the use of laptops in class might have the consequence that students would be less inclined to interact. For her this was a hypothetical problem, as she did not have, at the time, students using devices in her class. Rather, she reported her observations of a colleague's class, and mentioned that it was a concern for him as well:

when I go into his class, they're... they're all in front of their laptops doing stuff on there, and, you know, they're listening to songs, which is fantastic, and they're reading about Paris and things. But... it just seems to me that they're not getting so much interaction with each other... I'm just worried it's going to be a lot of work to see how I can combine technology and... tasks.

By far the most significant constraint, of all of those that teachers mentioned, was time. All but one of the eight teachers mentioned time as impacting negatively on their ability to implement TBLT and tasks in their educational contexts. For most teachers, five out of the eight, time was mentioned in relation to preparing and making resources. On a more positive note, Tania and Toby both said that once resources had been made they could be recycled. Linda and Shona referred to a lack of time to think and plan, rather than a lack of time for resources. Linda mentioned time to "slightly adapt" a classroom activity so that it was "more task-based and real." She said that sometimes she would resort to a grammar or listening lesson because she hadn't had time to plan an alternative. For her, a key benefit of the TPDL programme was that it gave her time to think of tasks and to plan a TBLT unit, which she said she 
used every year. At the same time Linda acknowledged that increasingly, textbooks were being produced that incorporated tasks. Margaret, not only referred to the time needed to "invent" a task, but also the time needed to anticipate how it might be used in the classroom: "you have to think it through, and you have to imagine what's going to happen, what the kids are going to get out of it, where things could go wrong."

In Part 1 of this study, teachers also mentioned the time that was needed for planning tasks as a limitation to their implementation of TBLT. This reference to time as a constraining factor, both in terms of its impact on making resources and on thinking and planning for tasks, has been documented previously (e.g., Carless, 2003; Erlam, 2015a; Ogilvie \& Dunn, 2010; Pham \& Nguyen, 2018; Van den Branden, 2006; Yim, 2009). It speaks to another of the factors that accounts for the uptake or lack of success of an innovation, that is, the degree of originality required on the part of teachers for its implementation. Having completed the TPDL programme, the teachers in this study had no ready access to TBLT materials that they could use in their specific contexts. They were required to demonstrate a high degree of originality in creating these, a factor which, Ellis (1997) suggests, is not likely to predict success for uptake. Obviously, the teachers in this study needed more support in order to be able to use tasks successfully in their classroom practice.

\section{Teacher level factors}

In the category of teacher factors, two issues were mentioned as constraints on the implementation of TBLT and use of tasks in the classroom. The first of these was the difficulty of understanding what a task is and of conceptualising all the components of a task. This is an example of how, as an innovation, TBLT was difficult for these teachers to grasp (Erlam, 2016a). Complexity is another of the factors that Ellis (1997) identifies which can account for the success or failure of an innovation. Two teachers referred to this issue; we have already mentioned how Sonia reported difficulty understanding what a task was and designing one that fulfilled all criteria. Toby said that sometimes he found it hard to differentiate a task from an activity. In Part 1 of the study, teachers mentioned difficulty in changing their practice so that it was consistent with principles of TBLT and referred to the need to persevere. Samuda and Bygate (2008, p. 195) claim that the problem of "conceptual unease" in terms of the construct of task (Littlewood, 2007) and what TBLT involves, may be underacknowledged in the research literature.

In terms of task design, Annabel did not mention time as a constraint, but the fact that she found it challenging to come up with ideas which were not just "the same old class survey." In Part 1 of the study teachers mentioned familiarity and experience with teaching tasks as a possible limiting factor. 


\section{Student level factors}

In an earlier section in this chapter, we have reported how teachers identified that a key benefit of using tasks and TBLT was that students enjoyed lessons and found them motivating (also reported by teachers in Part 1, Chapter 4). Shona reported that, for this reason, some classroom management issues tended to "go away."

At the same time, teachers mentioned a number of constraints. There were two issues that were raised by more than one teacher. The first of these was the challenge of catering for individual needs. Tania reported that, as the literacy challenges got bigger in Japanese, it became harder to design communicative activities that would work well for all learners. She reported that, in her classroom, she had students who did not have a high standard of literacy in English, and that learning to read Japanese was a huge challenge for them. Annabel also said that variation in ability levels had been a constraint for the implementation of TBLT in her classroom. She felt that, with TBLT, students were not able to work at their own pace, something that had motivated her to implement a flipped mastery approach. The importance of individualising instruction is included as one of the 10 methodological principles of TBLT (Long, 2015). It is interesting that these teachers did not see how TBLT could cater to individual differences in the way that they wanted for the learners in their classrooms. This is, perhaps, an example of one way in which there is a need for theory to be translated into practice in a way that addresses the concerns of practising teachers (Bygate, 2020). Interestingly, teachers in Part 1 of this study did not describe this issue as a limitation of TBLT; in contrast, they described tasks as allowing for differentiated learning. Furthermore, in suggesting revisions of their tasks after teaching them as part of their inquiries, five discussed ways that their tasks could be adapted to cater for the needs of diverse learners.

The second issue related to student behaviour. Interestingly, two teachers said that some students, in particular those who did not want to be learning a language and may be embarrassed about speaking it in front of their peers, did not want to interact or speak and work at tasks that required this. These students could resist taking part in tasks, and often preferred to just copy from the board, being happy with very traditional activities.

Emily reported that a minor constraint was that students might need training if they had had no experience with tasks. She believed that this might be the case if they were not used to hearing the target language exclusively in class. Tania also said that she found that using tasks was hard "at the beginning" when working with students who were new to learning the language, because they "don't have very much language." Designing tasks that allowed for natural language use for these beginner learners was a challenge. 
To summarise, a feature accounting for the successful uptake of TBLT, according to teachers, was its relevance (Ellis, 1997) in terms of its correspondence to the New Zealand Curriculum and assessment requirements. At the same time, however, a lack of relevance, in terms of how it was perceived to inadequately support individual learner needs, was also seen as a reason constraining its implementation. Another feature mitigating the implementation of this innovation was originality; teachers lacked materials and needed to design their own tasks. Finally, for some teachers, complexity was a constraint in that they found it difficult to understand what a task was and to design tasks that satisfied task criteria. An obvious conclusion is that teachers need adequate support to implement an innovation such as TBLT, with help in the provision of materials and in understanding how this approach might be adapted to meet individual student differences.

\section{Embracing TBLT and tasks in the classroom: Accounting for change in teacher practice}

In this section, we discuss any evidence in the interview data which may explain why these teachers were prepared to, and able to, change their teaching practice, either as a result of participating in TPDL or for another reason. In her 2012 book, Teacher Development in Action, Kubanyiova offers advice to teacher educators on how to create conditions for conceptual change that may lead to transformation in practice. The first of these is to inspire teachers with a vision of what they would like to become. For three teachers, a vision of the type of teacher they would like to be may have led to openness to a new way of teaching. Margaret, reported that she was unhappy with the image that she had of her teaching, as she reflected on it during the TPDL programme.

I often felt that my lessons weren't actually that fun... and so task-based language teaching... gave me a way to make it more enjoyable for me and my students... it made the grammar teaching so much easier and... more fun.

Margaret reported that her eyes had been opened to other ways of how she could be a better teacher. One way she thought that she needed to change was to give students more opportunities to speak. Her vision of the type of teacher she wanted to become was also, perhaps, shaped by the experience she had had of learning languages, which, she reported, "hadn't been great."

For Toby, the image of the type of teacher he wanted to become was, arguably, a reaction against the experience he had had of learning Spanish. He described being shocked to discover what he could not do as a result of all the hours he had put into learning Spanish. 
I learned how to conjugate a verb one hundred thousand ways and then when I arrived in Spain I didn't even know if someone was asking me if I wanted some water... and I was like, what did I waste all that time for?

For him, his failure in learning the Spanish that would have been useful to him in a Spanish-speaking context had motivated him to become a very different kind of teacher. Later in the interview he contrasted his teaching approach with how he had learnt:

if my classes were anything like the classes that I run with my students I would have got so much more out of having studied Spanish and I would have learned a lot more as well. And I think "man, kids don't know how good these lessons are sometimes!"

Similar comparisons between teachers' experiences of learning a language and the type of classroom practice that would result from the implementation of TBLT were evident in the data set of Part 1 of this study. At least three teachers (see Chapter 2) negatively compared their language learning experiences with the type of practice that TBLT would support.

Another teacher who had a vision of the type of teacher she wanted to be was Linda. She shared her vision of teaching language through content, talking about a bilingual teaching context, which she described as a "bit of a dream." She referred to: "where you can be using the language as a vehicle to teach something else, and then it's just a tool."

The second key factor that Kubanyiova (2012) suggests may create conditions for conceptual change leading to transformation in classroom practice is "dissonance." She argues for teachers needing to be shaken out of their comfort zones. We have documented in Part 1 (see Chapter 2) how the teachers, as they were introduced to, and started to learn about, TBLT, began to compare their growing understanding of TBLT in relation to their own practice (Farrell, 2016). In this Part 2 of the study, some teachers reported experiences where they were deeply unsettled as they reflected on their practice; this dissonance may have accounted for preparedness to adapt to new teaching approaches, including incorporating tasks and TBLT into their practice.

Toby told of the experience of being shocked to realise how little of the target language, Spanish, he was using in the classroom. He recounted how one of the TPDL facilitators came to his classroom and wrote down everything he said: "and that was quite an eye-opener. I thought "Oh gosh, I'm speaking English the entire time." Annabel also reported a key event that had caused her to reflect on, and change, her practice. She described how she had invested heavily in setting up a flipped mastery programme, and that, at the end of a semester she was shocked to receive complaints from her students. She said she was "going for it with guns blazing with everything flip mastery," and then she got feedback and thought: "Oh what 
am I doing? I'm a terrible language teacher." The feedback, where students asked for opportunities to use the language they had been learning in flipped mastery, led her to incorporate tasks into her programme.

We have reported how both Linda and Tania talked about being "blown away" by how much the students could do with language when you allowed them control over it. For them, the dissonance had come from realising that, in their teaching practice they had actually limited their students' learning by restricting their access to language. In the TPDL programme they had been challenged to let go and allow students' control over the language, and the results were very different to what they had expected. Tania said: "that's what I discovered... I think before, what I did was, I held the language and only gave it to them when I thought they should have it." She then went on to describe how her practice had changed: "so I can just let them know things they want to know how to say, even if they're level 2 language... "Why did I never do that before?" it's such an obvious thing to do really." Linda also talked about TBLT as a "revolution" - she described it as: "a far cry from the days when students were just given sentences."

In summary, three of the eight teachers in this study had an idea of what, for them, the ideal teacher was. For two, this embodied, to some extent, a rejection of the type of teaching they had had in their own language learning experiences as younger people. The fact that they had, and aspired to an ideal of the type of teacher they wanted to be, may have accounted for their openness to and willingness to embrace TBLT. Four teachers reported experiences that unsettled them, led them to question their practice and to make changes to their approach to language teaching. For these teachers, it would seem that the dissonance of being shaken out of their comfort zones may have led to an openness to TBLT (Kubanyiova, 2012).

\section{Conclusion}

In this chapter we draw on interview data with the eight teachers who participated in this part of the study and we focus on what they say about tasks and TBLT in relation to their teaching practice. While none of them mentioned tasks or TBLT in discussing their priorities and goals for classroom practice, six reported that learning about TBLT and tasks had been a significant aspect of their experience during the TPDL professional development programme. Five explicitly mentioned that this learning had impacted significantly on their classroom practice. We found evidence of this impact in previous chapters (5 and 6), where we claimed that six teachers were using tasks in the lessons we observed. Four teachers reported no knowledge of TBLT or tasks prior to their involvement in TPDL and three reported partial knowledge only. None had used tasks; it seems that the requirement to design and 
teach tasks during the TPDL programme had been a necessary prerequisite for the implementation of tasks in their practice. In summary, all but one teacher felt that the exposure to tasks and TBLT during their professional development experience had been significant for their learning or practice, a conclusion which is supported by findings from previous chapters.

Teachers (five of the eight) most commonly mentioned that tasks gave learners a purpose to use language. Three mentioned that a task allowed for authentic use of language. A rationale they reported for using tasks in their classrooms was that they gave learners the chance to be users of the language, to communicate meaningfully as they might in real life. Another main rationale for the use of tasks was that they were motivational. The teachers consistently referred to the impact that tasks had on student enjoyment of lessons and to the positive consequences for student retention. We reported data in Chapter 5 that demonstrated that students, did, indeed enjoy lessons where they participated in tasks. The fact that tasks were motivating and engaging was also a common theme reported by participants in Part 1 of the book. Another benefit for using tasks, that teachers reported, was that they had positive language consequences for language acquisition. These findings replicate other research demonstrating that these key principles are important characteristics of TBLT for teachers (Andon \& Eckerth, 2009). Several teachers mentioned the impact on learning of allowing students greater freedom to use the language they wanted to use, rather than controlling their access to, and use of, language. They identified this letting go of control of the student use of language as a key aspect of implementing TBLT.

Teachers reported using tasks at both the level of the unit (i.e., target tasks) and the level of activity (i.e., pedagogic tasks) in their classrooms. Some reported using tasks for assessment purposes (as in Part 1). In terms of unit and syllabus design, only one teacher reported practice that would seem to accord with the principles of a task-based syllabus, starting with a task and then establishing what language learners might need for the task. Other teachers started with thinking about the particular L2 language forms and functions they wanted their learners to learn, rather than first starting with a task and then selecting their language focus on the basis of task requirements. However, some teachers appeared to work with both task and language in parallel focus during their planning. We have suggested that the tension in some of the literature (e.g., Long, 2015) on whether the primary focus, in task design, is the task or text (i.e., language) is unhelpful and that a more complementary view of both levels working in parallel may be more reflective of the realities of practice. Also relevant to task planning is the finding that for one teacher at least, the task outcome was determined at two different levels with both operating in parallel. The first was the (communicative) outcome for the students, and the second was the (linguistic) outcome for the teacher. 
In explaining the approach that teachers took to task planning, it is important to remind the reader of the context in which this study was conducted. Teachers explained that the necessity of teaching students specific language forms was imposed on them by the curriculum, and especially, assessment requirements, even though there was general consensus that the open nature of the New Zealand Curriculum aligned well with TBLT. A tension between, on the one hand, acknowledging that the acquisition of particular forms cannot be controlled by the teacher and therefore relinquishing an attempt to teach a syllabus dictated by forms and, on the other hand, using focused tasks to target specific structures is reported elsewhere (Andon \& Eckerth, 2009).

Several teachers reported, as a result of their professional development learning, a shift, which could be considered consistent with TBLT principles, in the way that they implemented a focus on form in their classroom practice. They reported, firstly, a shift from a focus on language form in a decontextualised context to one in which it was contextualised. They also reported change that seemed to correspond to an inductive approach to teaching language form; they described requiring learners to work to discover language form for themselves. The classroom observations, which we reported in detail in Chapters 5 and 6, however, tended to indicate that these practices were not consistently implemented; they may, instead, have been part of the teachers' repertoire in approaches to dealing with focus on form.

There was considerable range in the teachers' reported use of tasks in the language classroom, from consistent use every lesson to incorporation of a task once a week or every few lessons. At least two teachers reported using partial tasks or tasks that fulfilled some, but not all criteria.

We used Ellis's (1997) identification of key factors which determine the success of an innovation as a framework against which to interpret teachers' claims about reasons for uptake or non-uptake of TBLT. TBLT was seen as relevant in that it corresponded with the curriculum; although at the same time it lacked relevance for some in that it did not cater for individual learner needs. Time to make resources and plan tasks was mentioned as a key constraint and one that is reported elsewhere (e.g., Ogilvie \& Dunn, 2010; Van den Branden, 2006). This issue speaks to the factor of originality. A high degree of originality was required of teachers in our study if they were to design their own TBLT materials. For some teachers, complexity was a constraint in that they found it difficult to understand what a task was, and to design tasks that satisfied task criteria, another finding that is reported in other studies (Erlam, 2016a; Littlewood, 2007). There are obvious consequences for professional development that aims to introduce and educate teachers about innovations such as TBLT.

We suggested that teachers may have been encouraged to adopt TBLT and implement tasks in their practice for two main reasons (Kubanyiova, 2012). The first 
of these was that TBLT inspired them with a vision of the type of teacher that they wanted to be. Furthermore, for some teachers, the examples of classroom practice that were presented to them, as they learnt about TBLT, highlighted, in contrast, their own unsatisfactory experiences of language learning. The second reason, for some teachers, was that they were confronted with evidence that their practice did not accord with the beliefs that they had formed of themselves as language teachers.

We conclude that, as in Andon and Eckerth (2009), the eight teachers involved in this project were generally well-informed of the main principles of TBLT, as evidenced by the way they talked about tasks and TBLT, and by the way that they implemented tasks and TBLT in their classroom contexts. These teachers, like those in Andon and Eckerth's study, had experimented with and adopted some aspects and principles of TBLT, discarded others and, even combined aspects with other pedagogical approaches. In this way, they had tended to treat TBLT as "provisional specifications" (Ellis, 2003) that they had further adapted to their own instructional contexts. Littlewood (2007), as cited in Ellis and Shintani (2014), has questioned the feasibility of introducing TBLT in contexts where both teachers and students have traditionally seen language as an object to be studied rather than as a tool for communication. However, the data from this study would seem to provide some evidence that it is, indeed, possible. 


\section{Conclusion}

\section{Introduction}

The research presented in this book is situated in the vast literature on TBLT, specifically within pedagogically informed research into the real world of TBLT practices. We addressed two main issues. We started by investigating how teachers learned and developed understandings of tasks and TBLT during an in-service teacher education programme. We next moved inside real classrooms to document whether, and how, teachers implemented TBLT. As we documented in some detail how these teachers used tasks, we also investigated how their use might support learning outcomes for students. In acknowledging the crucial role that teachers play in implementing TBLT as an innovation, we aimed to contribute to bridging the divide that often exists between theory and practice.

Based on the literature on teacher learning and TBLT, as well as on our experience as researchers and language teacher educators, we identified the following gaps that we aimed to address. Firstly, the study is situated in a foreign language learning context which we describe as acquisition-poor, where access to, and learning of, the target language is typically limited to the classroom context. Secondly, we investigated the implementation of TBLT and use of tasks across a range of foreign languages; this may be the first TBLT study of this nature to have such wide coverage across languages. Thirdly, the educational context of this book is the school setting, an underrepresented sector in TBLT studies. Finally, these learners were all operating at beginner level, which provided both opportunities for, and constraints on, the use of tasks. While the study was conducted in New Zealand school classrooms, the characteristics of this context are not unique to New Zealand and the results of our study are applicable to many other foreign language contexts. As we have emphasised throughout the book, the gaps we describe above are realities worth investigating if we want to understand the different factors that either enable or constrain teachers in implementing TBLT.

Part 1 of the book focused on documenting teacher learning about tasks and TBLT. Our participants were language teachers who had been in a year-long professional development programme (TPDL) which included a university course aiming to integrate disciplinary knowledge into pedagogical practice. Teachers were positioned as reflective professionals who judiciously translate new ideas into their own 
systems of practice (Scarino, 2014). The programme presented TBLT as an approach to language teaching strongly aligned with the expectations of the New Zealand national languages curriculum, the main goal of which is the development of communicative competence. In the programme, tasks were presented as ways to embody Ellis's (2005) Principles of Instructed Second Language Acquisition in classroom practice. By analysing two of the course assignments, we examined how teachers understood "task-in-theory" and then how they enacted this understanding into their own practice, thus implementing "tasks-in-action." We then followed up with some of these teachers in the year immediately following the TPDL programme, drawing on both self-report and classroom observation data, to establish whether they were using tasks and, if so, how they used them in their teaching contexts. In other words, we examined how TBLT as an innovation was being brought to classrooms after the in-service programme. By grounding our examination of TBLT in the activities of teaching and learning in real classrooms, we were able to examine the factors that both enabled and constrained initial implementation of TBLT.

In Part 2 of the book, we embarked on a more comprehensive examination of the implementation of TBLT with a different group of teachers, all eight of whom had completed the TPDL programme (on average, 4 years) previously. We investigated their understanding and use of TBLT and tasks through observing their classroom practice. For those classrooms where we considered, according to criteria we used (Ellis \& Shintani, 2014), that we saw evidence of a task, we investigated opportunities for student learning. Our data set included transcripts of classroom discourse and information from student questionnaires, the latter providing us with student perspectives. Our investigation also included teacher interview data so that we could gain information beyond that afforded by the brief investigation into their practice. We explored their viewpoints on tasks and TBLT, its relevance in their teaching contexts, and those factors which they also considered might enable or constrain its implementation. Part 2 therefore gave insight into how tasks and TBLT might be evidenced in classroom practice in a time frame considerably distanced from the professional development opportunity in which the teachers had previously learnt about and used tasks.

\section{Learning about tasks}

As described earlier, Part 1 of the book used the lens of professional learning to describe how volunteer participants drawn from a cohort of teachers who participated in an in-service education programme (TPDL) learned about and understood TBLT and tasks. As practising teachers, they began the 1-year programme with a range of experience and expertise in learning and teaching languages. Documentation 
of these teachers' learning about tasks started by examining how they developed initial understandings of tasks and TBLT in a university course, specifically by responding to a reflective reading log and by reporting on a small-scale inquiry into their own teaching with tasks. From the cohort of 43 teachers, 14 agreed to us using this coursework for research purposes. Our analysis indicated that, for many of the participant teachers, coursework and readings presented new understandings about language learning and teaching that required professional reflection and challenged some of their own approaches to practice.

Analysis of the reading log assignment (see Chapter 2) provided evidence of the processes by which the participating teachers started to incorporate their emerging understandings of theory and research into their existing knowledge and practice (Loughran, 2010). Firstly, as reflective practitioners, these teachers developed awareness of their own, often tacit, theories about language learning and language teaching while they were interpreting new content presented in the readings (Borg, 2006; East, 2014a; Loughran, 2010). Secondly, the analysis indicated that the teachers were critically reflecting on their own practices and expressed willingness to extend their professional knowledge and consider using tasks and principles of TBLT in their teaching. Thirdly, they articulated their initial understandings of TBLT and started to realise that, compared to their established practices, implementing TBLT meant that both teachers and learners were more focused on using the language for communication. Fourthly, the teachers recognised the alignment between TBLT and the New Zealand Curriculum in that both are experiential, student-centred, and promote learning by doing. Although identifying pedagogical alignment did not, in itself, guarantee the teachers' uptake of tasks, it was an important professional realisation that could support the implementation of TBLT as an innovation to their established practices (Andon \& Eckerth, 2009). We concluded in our analysis of the reading logs that, at this stage, the teachers were at the "task-in-theory" stage in their learning with some glimpses into the potential role they saw that tasks could play in their practices.

Towards the end of the 1-year course, the teachers wrote reports on a small-scale inquiry into their classroom practice. In the New Zealand context, professional inquiry is seen as a mindset and a characteristic of effective pedagogy, and teachers are encouraged and supported to embark on inquiries into their own teaching. For research purposes, we examined the participant teachers' inquiry reports (see Chapter 3), analysing them according to the stages followed by the teachers: identification of a focus for the inquiry, planning, implementing, evaluating, and revising. We considered that their reflections on the learning process, afforded by their inquiries, provided evidence of their understanding of tasks, as well as initial perspectives on the opportunities and limitations of implementing TBLT in their teaching contexts. 
Not surprisingly, given the contextualised and situated nature of inquiries, the design and implementation of these varied widely, precluding the drawing of any generalisations. However, guided by our first research question, we were most interested in establishing what the teachers' learned through the inquiry process. There appeared to be two main stages in the teachers' learning processes. The first was identifying aspects of their teaching that could be improved or enhanced by the use of tasks. As Timperley (2011) suggested, the teachers seemed to be open to being challenged. The second stage was to highlight ways in which the tasks could be modified after they had been taught. Our examination of the design and implementation of the tasks indicated that the teachers were still developing their understandings about tasks, given that, in our analysis, many did not meet task criteria. We then examined the teachers' own evaluation of their tasks. Some teachers had set ambitious, but unrealistic, targets for their inquiries, such as comparisons between TBLT and other approaches. However, a consistent focus was interest in examining how students responded to, and engaged with, tasks. Reports of higher student motivation and engagement seemed to have resulted from those tasks where the students had opportunities to use the language to interact with peers and to share personal information, often for the first time. From what we gleaned in the inquiry reports, these emerging illustrations of interactional authenticity (Ellis et al., 2020) resulted from careful task design on the part of the teachers.

Our analysis of the teachers' conclusions indicated that their inquiries were catalysts for an awareness of the range of pedagogical issues that they would need to address when designing and implementing tasks. The process of going through an inquiry cycle to collect evidence on the impact of using a task (or what they considered a task) in their language teaching allowed the teachers to experience first-hand the connection between theory and practice as well as their role as inquiring professionals. As documented in the literature (Wedell, 2009; Wyatt \& Borg, 2011), the inquiries allowed teachers to implement their learning in their instructional contexts. They provided an opportunity for the teachers to develop insight into the potential tasks might have for their language teaching practice as well as a better understanding of how to implement tasks so as to maximise students' learning.

In a professional learning programme with a focus on tasks and on TBLT, as teacher educators we would have wanted the teachers' inquiries to demonstrate more robust knowledge in understanding the construct of task and using the criteria for task design. The implications for teacher education are twofold. Firstly, teachers may need more guidance at key stages in their inquiries. In our case, we think that, with more time, we would have better supported teachers in setting the scope of their inquiries and in ensuring that their tasks had met the criteria. Additionally, we learned that the inquiry cycle is most successful when teachers have the time to identify and make revisions to how their task is implemented. In other words, 
as with all teaching, they need to have the opportunity to refine their practice by redesigning and reteaching.

The experience of teaching a task, observing their learners' positive responses, and, in some cases, encouraging indications of language learning outcomes, provided a foundation for the teachers' learning. The final conclusions drawn by the majority of the participating teachers in their inquiry reports indicated that most of them had finished the course with a positive view of the potential of implementing tasks and TBLT in their language teaching practices. As we explained in Chapter 1, the way TPDL and the pedagogical course were framed did not mandate TBLT as the approach that the teachers should adopt in their classroom practice. Therefore, the teachers' interest in incorporating tasks in their practice indicated that they were taking ownership of tasks and planning how to implement change in their contexts (Van den Branden, 2006). At the same time, however, as they indicated willingness to use tasks, they also clearly identified challenges, including lack of time to design tasks, as well as curriculum or assessment demands.

We followed some of these teachers the year after the course in order to document the realities of implementing TBLT in contexts where teacher autonomy is severely limited by factors beyond their control. After the scaffolded experience of using tasks in their inquiries, we wanted to establish whether, and to what extent, the participating teachers had decided to implement TBLT within their classroom contexts. From the 14 teacher participants in Chapters 2 and 3, nine agreed to participate in interviews in the year following TPDL. At the end of these interviews, we asked those teachers who said they were using tasks if we could observe them. From five who accepted, we were able to observe the practices of three. Our analysis of the interview data showed that teachers reported using tasks as pedagogic tools. In other words, they reported using tasks with different degrees of regularity; at the same time, these seemed embedded in teaching sequences that also included other types of language learning activities. The implementation of tasks was impacted by different factors. Teachers considered lack of time to design and resource tasks to be the most influential barrier to their use of tasks, one that is significant in school contexts where time for learning languages is so limited.

In relation to what the teachers learned, perhaps the most salient finding in Part 1 of the study was that the teachers demonstrated a shift to seeing language learning as focused on communication with the students' use of the language as paramount. The teachers seemed to have become acutely aware of the importance of using the target language (a key focus of their professional learning programme) and of incorporating tasks where students used the language for communicative purposes. These changes in the teachers' practices were acknowledged by the students whose voices we documented in the three classrooms we observed (see Chapter 4). Furthermore, our analysis of the tasks taught confirmed that the teachers had 
learned to design tasks that met the task criteria. In particular, they were able to design tasks that, arguably, embodied the three most crucial criteria, that is, focus on meaning, a communication gap, and an outcome.

In Part 1 of the book, we investigated the processes of learning about, and implementation of, TBLT by teachers in FL programmes in schools, thus contributing to evidence of seeing the transition from task-in-theory to task-in-action (East, 2018). We drew mostly on data from the teachers' coursework, self-reported reflections, and practices as a way of understanding the teachers' perspectives on their own learning. Our interest was to explore how real teachers went through processes of learning, given that a focus on teacher learning is fundamental to the growth of TBLT as a researched pedagogy (Samuda et al., 2018). We also presented some data showing how this learning was evident in the emerging practice of a small number of these teachers (see Chapter 4). We, therefore, started collecting evidence of the challenges involved in putting TBLT principles into practice in real classrooms. We could already see glimpses of the practices, demands, and perspectives of teachers as they implemented TBLT to meet the characteristics and needs of students in their own instructional contexts (Ellis et al., 2020). We examine some of these later in this chapter.

\section{Implementing tasks in the classroom}

In Part 2 of the book, we investigated the practice of eight teachers, on average 4 years after the professional development opportunity (TPDL) where they learnt about tasks and TBLT. All but one of these teachers reported that learning about TBLT during the TPDL programme had been significant for their learning and/or practice. From observing the classroom practice of these teachers, we concluded that the majority $(n=6)$ had been able to retain knowledge of the salient features of tasks and use this knowledge to design and use tasks in their classroom practice. A significant finding was that they did not always use tasks consistent with recommendations made in some of the TBLT literature. At the same time, we argue that these teachers used tasks to create a "rich pedagogical space" (Van den Branden, 2009, p. 264). In this pedagogical space, described as one which teachers and students construct and "navigate" together as a task unfolds (Andon et al., 2018, p. 238), there were, we claim, many opportunities for language learning. In the following section, we will explore the ways in which teachers used tasks to create learning opportunities for their students, also drawing on some of the class observation data from Part 1 of this study (where teachers used tasks in the year following their professional learning). 


\section{Tasks opening up “pedagogical spaces” for language learning}

\section{Communicating with the language: Giving learners control}

Firstly, the teachers in our study used tasks to give students opportunities to use the language they had been focusing on in class as a tool for communication. They therefore tended to design focused tasks which predisposed students to use either specific language structures or specific language domains, consistent with the classroom focus that had pre-dated the implementation of the task. The use of focused tasks, where students had opportunities to reuse language they had previously learnt, is explained by the fact that these learners were beginners. Even where a task appeared to be unfocused in its language use (e.g., Task 2: Conversation, Chapter 5), students still needed to use language they had previously learned in class, because of the limited nature of their language repertoire.

At the same time, however, these focused tasks did not limit students to using only the preselected and predetermined language forms chosen by the teacher. They opened up opportunities for the use of unpredicted language, and in these instances of unpredictable and creative language use, we found examples of the many kinds of interactions known to drive language learning. We found (see Chapters 5 and 6) examples of the teacher providing elaborated and extended input (see also Chapter 4) and giving explicit metalinguistic information. We documented instances of learners negotiating meaning, and receiving, from their peers and/or from the teacher, corrective feedback and scaffolded support to produce language output. In all of these examples, we argue that there were opportunities for learners to attend to language in a meaningful context and that these had the potential to drive language acquisition.

We acknowledge the role of student agency in the different ways that learners approached tasks to construct opportunities for language learning. The learner's decision about how to complete a given task interacted with their limited competence (i.e., the limited range of target language forms available to them) and their capacity to make use of both predictable and less predictable language. At the same time, the teacher played a crucial role in being an active conversational partner with students, moving around the class, monitoring and supporting them in their interactions with each other. As a result, learning opportunities were co-constructed between the teacher and the learner (as well as between learners, as mentioned above). We documented many of these learning opportunities in the "language related episodes" that we found in the classroom discourse. For example, in Margaret's class, we claim that the incidence of language-related episodes was high (Erlam \& Pimentel-Hellier, 2017), at a rate of nearly two per minute of the classroom discourse which we were able to record (a sample which we claim was potentially under-representative). This 
high incidence of attention to language in Margaret's classroom was all the more surprising in that the tasks were highly oriented to the learning of specific language forms (i.e., the imparfait in French). In other words, in a context where the teacher was very intent on learners having opportunities to use a specific grammatical structure, there were still many opportunities for learners to focus on language, both the targeted language, but other language as well, in a meaningful context.

The practice we observed was consistent with what teachers said about tasks in the interviews. They acknowledged the importance of giving learners opportunities to use the language to communicate and highlighted the fact that tasks allowed them to do so. Indeed, for them, allowing learners the opportunity to become users of the language they were learning and to use it for authentic purposes was the second most significant benefit for the use of tasks in the classroom. Tasks led to interactional authenticity (Ellis et al., 2020), because they allowed for language to be used similarly to how it is used in the world outside the classroom. Perhaps unsurprisingly then, the characteristic that was most salient for them when they were asked to describe a task, was that it gave learners a purpose for using language.

At the same time, using tasks in this way was rewarding for teachers because it was highly motivating for learners. This was the most significant benefit for using tasks identified by our teacher participants. For learners, being able to use language communicatively, meaningfully, and creatively, made language learning fun and enjoyable. Undoubtedly, a key factor was the use of language for social interaction; the opportunity to work with peers is highly motivating for adolescent learners (Philp et al., 2014), a finding endorsed by the questionnaire data we collected. Several teachers (Toby and Emily, for example) described increased class sizes resulting from their use of tasks.

While teachers were very aware of the motivational impact of ensuring that, within the classroom, language be treated as a tool for communication and not just as an object of study, they also acknowledged that this type of language use could drive language acquisition. Two teachers, in particular, recounted the astonishment of discovering just how much students learnt or gave back when teachers allowed them freedom to use the language they wanted to, or stopped holding it from them. They were aware of the potential for learning of allowing students opportunities to experiment with and use language that went beyond what they had been introduced to in class. 
Repeated encounters: Recycling the language

The second main way in which teachers used tasks was to give learners repeated exposure to the same language in a meaningful context. We differentiate this from the use of tasks we describe earlier because, in the lessons in which we observed tasks used in this way, we found fewer opportunities for incidental language learning and for creative language use. However, we claim that this second way in which tasks opened up pedagogical spaces also drove language learning. We describe tasks that allowed learners repeated exposure to the same language input (see Tasks 7 and 9, Working With Mazes and How Well Do You Know Your Classmate?, Chapter 5). We argue that these tasks, which could be seen by some to be "structure trapping" (having learners practise and display language formS, Skehan, 1998) catered to an important second language acquisition principle. Researchers claim that language learning is gradual, that learners need to be exposed to massive amounts of input so that linguistic items are reinforced in the learner's cognitive system (Ellis \& Larsen-Freeman, 2009). These tasks were designed so that learners could have repeated exposure to preselected language structures in a context in which they had to process them for meaning and provide some sort of response, in the same way that task repetition functions to promote opportunities for learning (Bygate, 2018). We would claim then, that in these tasks, the use of language was far from being structure trapping. Learners were not just practising and displaying language forms for their own sake, they were processing language for meaning. In so doing, they had many opportunities to encounter the same meaning-form-function relationships (Dupuy, 1999; N. C. Ellis \& Wulff, 2015; Keenan \& MacWhinney, 1987; Lightbown, 2014). Furthermore, because the students who worked at these tasks had no, or a very limited, linguistic repertoire, repeated exposure to this language was an acquisition-enriching, rather than stultifying, experience.

We also provide examples of how teachers moved learners from working at tasks where they processed language input in meaningful contexts to output-based tasks where they used the same preselected language forms meaningfully in either spoken or written output. An example of a carefully planned task sequence which had students repeatedly encountering the same forms in language input and then led them to use these language forms in output as they interacted in pairs was demonstrated in Emily's classroom (see Working With Mazes, Chapter 5). We claim that these output tasks also opened up "pedagogical spaces" for language learning (Samuda et al., 2018, p. 15) because they gave learners the chance to recycle, by engaging in meaningful practice, the language they had started to acquire (DeKeyser, 2007; Ortega, 2007). As the students in Emily's class, for example, worked at these tasks, they used the language of directions over and over again with progressively 
less scaffolded support (although we suggested in Chapter 5 that the scaffolding could have been reduced even further). In some of the TBLT literature, the use of focused tasks in this way has been portrayed as limiting (as previously discussed) or, even, potentially ineffective. Ellis (2003), for example, claims that it is very difficult to design focused tasks that can only be completed if learners use a particular linguistic feature. This is because, he claims, learners will invariably find a different way of expressing themselves. This was not a possibility in this study because these beginner learners did not have, at their disposal, other linguistic forms allowing them to express the meaning that the tasks required. Rather they needed the opportunity to recycle the same language that the repetition of these similar tasks allowed (Bygate, 2018).

Task as the context for both language learning and language use

In this third use of task, a target task established the context both for the teaching and learning of specific language formS, and also for the meaningful use of these. The best example was Shona's classroom and her Murder Mystery unit (see Chapter 5). Learners in Shona's class had to establish which teacher had murdered their deputy principal, and in order to do so, needed to learn specific language. For example, they needed to learn the language of descriptions in Japanese to draw up a list of potential murder suspects. Consequently, they worked at a series of decontextualised grammar exercises or activities, characteristic of a focus on formS approach. They then used this language to solve clues, in this way working with contextualised meaning, as they completed pedagogical tasks. In these instances, where they were using the language in context to help them solve the mystery, they were no longer completing exercises, or activities, but using tasks (Widdowson, 1998). We argue that these students moved back and forwards between engaging with language as an object, and with language as a tool for communication. The two were highly interdependent, and the activities fed into or informed the tasks. It was in the interlocking, then, of both, that conditions were created that were favourable for acquisition. There are a number of important points to make, drawing on the data we have from her classroom, about Shona's approach to using tasks. Firstly, the students worked mainly with input tasks, where they were decoding written Japanese (and using this language to solve clues); this means that they were not under pressure to use language orally they had previously encountered for the first time. Indeed, a feature of Shona's classroom was that there was no requirement for students to speak Japanese, although she had set up the expectation that they speak to her in Japanese. We argue, in a later section of this chapter, that it is not realistic to expect learners to use communicatively, in output, language to which they have just been introduced. This is especially the case for oral language output, where there is a 
greater time pressure, than for written output. A solution is for teachers to use inputbased tasks. In this way, learners are provided with language from which to decode meaning, rather than having to retrieve forms that may not be established in their linguistic repertoire. The second important point about Shona's classroom is that her target task, solving the mystery, was extremely cognitively demanding for students. This challenge may have been crucial in motivating students to work independently in the way that they did, at both grammar exercises or activities and language tasks. Shona's use of task challenges the framing, in some of the research literature, of TBLT as an approach that promotes engagement with language as a communicative resource, and that precludes engagement with language formS in a controlled and intentional manner.

\section{The task as assessment}

The last main way in which teachers in this study used tasks was for assessment purposes. There were teachers who described use of tasks in this way in both Parts 1 and 2 of the study. At least two teachers, whose practice we observed, designed target tasks which were used as the assessment for the unit. These were presented to students at the beginning of a unit and were a focus as they worked through the unit. Both these teachers, Linda and Margaret, were teaching students in Year 11, who would be participating in external exams. This fact was important in explaining why teachers started by thinking about the task when planning their teaching, a step, we claim, towards the use of a task-based syllabus. The national assessment system is one which is criterion-referenced, rather than norm-referenced, and so particularly suited to the use of tasks where the achievement measures are behavioural outcomes (Long et al., 2019). The use of tasks for assessment purposes was very much aligned to the teaching context of the New Zealand education system.

In this next section, we claim that the way that teachers used tasks in this study needs to be interpreted in relation to the specific teaching context in which they were working, described in some detail in Chapter 1.

\section{The context behind the use of tasks and TBLT}

\section{The beginner language learner}

The learners in our study were beginners, most in their first or second full year of study of the target language. Furthermore, they were learning in an acquisition-poor context, where they had limited exposure to the target language. The challenge for the teachers was that they had to design and use tasks for learners who had no, or 
very little, knowledge of the L2 (Ellis et al., 2020). We have explained that our definition of beginner may differ from the way that this term is understood in the literature. The Year 10 students in our study would not all have been able to "understand and use basic everyday expressions while making conversation on topics related to their personal life" (Vandommele et al., 2018, p. 169). We believe that this context is one that is underrepresented in the literature. Much that is written about tasks and the way that TBLT is implemented assumes that learners already have a repertoire of the language that they are learning. In the beginner language classrooms we observed, learners had no, or an extremely limited, repertoire of language. For this reason, we claim that these tasks, which aimed to have learners processing and using preselected language forms, were particularly suited to the classroom contexts we observed. We would argue, therefore, that in an acquisition-poor context, language learning, at least for the ab initio learner, is likely to be most effective when learners have the chance to encounter the same language forms in a meaningful context, and both notice and re-notice these forms as they are recycled with progressively less scaffolded support.

\section{The New Zealand Curriculum and assessment context}

We have argued in Chapter 1 that the New Zealand Curriculum, with its emphasis on meaningful communication, and the assessment system (NCEA) which was designed to align with this emphasis could, on one level, be seen as providing a context which was favourable to the implementation of TBLT. Another factor that could also contribute to teacher uptake of TBLT, given that tasks were seen as being highly motivating, was the factor that, for most students, learning a language was an option rather than a requirement. Teachers were keen to have classes that students enjoyed and found motivating. This was necessary, because if students did not choose to continue language study, school management would not continue to support the teaching of languages.

At the same time, we claim that it was this context that also acted as some constraint to the implementation of TBLT. The fact that the assessment system, while privileging the use of language for communicative purposes, continued to provide teachers with lists of language that examiners could draw on in writing exams, mitigated against the implementation of a TBLT syllabus. We will argue below, that, in a context such as this one, which is not atypical of many contexts in which learners are first introduced to language learning, the use of a TBLT syllabus may not be realistic. 


\section{Blurring the dichotomies}

In this next section, we consider some of the ways in which the teachers in our study tended to blur dichotomies that are used, in some of the research literature, to differentiate TBLT and tasks from other approaches. Long et al. (2019) differentiate grammarbased and task-based approaches. The key foci of the former are: "L2 as the object of instruction, intentional learning, and explicit knowledge". In contrast, the foci of TBLT are: "L2 as medium of instruction, incidental learning, and implicit knowledge" (Long et al., 2019, p. 501). While these distinctions are intended to describe broad differences and do not preclude allowing for a variety of types of instructional activities that can take place within TBLT (e.g., see Long, 2015), it is important to see how the teachers in our study used TBLT in conjunction with a wider range of learning processes (Bygate, 2020) than might normally be attributed to the TBLT approach.

\section{Object or medium of instruction}

In Shona's classroom, as in some of the other classrooms we visited, language was both an object of learning, and a medium for learning (see Chapter 5, Task 8, Murder Mystery). We document how Shona had students working at grammar exercises, in which they were introduced to and practised language formS. They then used these language formS to solve clues which took them closer to establishing who had murdered their Deputy Principal. At this point the language became a tool for communication and the medium for learning. For Shona, task operated at two levels, at the level of target task and at the level of pedagogic task. We explain how, in operating at both these levels, the task provided a context for both language learning and language use. We have data to demonstrate that students were highly motivated to work with language in this way.

\section{Incidental or intentional learning}

Similarly, in the present study, we document how teachers planned and used tasks with a language agenda in mind (Bygate, 2020). We found teachers who were focused on covering aspects of grammar that they thought their students needed to learn. In Margaret's classroom (Tasks 3 and 4, The Teacher at Age 6, My Childhood), tasks were designed primarily, from Margaret's point of view, so that students would have the chance to learn the imperfect tense in French. For her, the main aim was intentional learning. However, at the same time, we have documented the fact that, in Margaret's classroom there were many opportunities for incidental learning of aspects of language other than the target structure. In other words, the highly focused 
tasks that Margaret taught allowed for a wider range of learning opportunities than could have been determined by the teacher. We documented examples of intentional and incidental learning in other classrooms as well (e.g., Task 1, Categorising Sports).

Teachers also used tasks where there was no intentional language focus (e.g., Task 2, Conversation; Task 5, Making Predictions) and where the attention to language form was incidental. However, there was a greater emphasis in the way teachers planned tasks, in our data set, on intentional learning. Yet even when students appropriated language forms highlighted in advance and which they knew were a focus for their learning, there were opportunities for incidental learning. In this way, the teachers demonstrated the use of TBLT as a pedagogy that has potential for both types of learning.

\section{Implicit knowledge or explicit knowledge}

Some of the literature recommends that, in focused tasks, the linguistic focus is hidden (Ellis \& Shintani, 2014). However, in our data, learners were often aware of the language forms that the teacher intended them to use. For example, the 6-year-old students in Sara's class (see Chapter 4) were able to list, in response to the questionnaire, in Spanish, the words that they had learnt during their task, Set the Table. In Margaret's class (Tasks 3 and 4, Chapter 5), the learners were told that a focus of learning was the French imparfait and their attention was repeatedly drawn to this language form. It was clear from the questionnaire results that they were very aware of this structure as a target for their learning. It seems, therefore, that there was a focus on explicit knowledge and explicit learning in these lessons. And yet, as we have described above (with reference to Margaret's lessons), learners also had the chance to learn implicitly.

Another example of how there could be a focus on both explicit knowledge and implicit knowledge in the same task is demonstrated by data which shows how task performance and outcome is very much determined by the student. The same task will be approached in different ways by different learners and so may result in very different kinds of activity, or be performed in different ways (Ellis, 2003). Furthermore, the same task can lead to very different outcomes, as documented by Breen (1987). We saw, in Chapter 5, how one task (e.g., Task 2, Conversation) resulted in communicative outcomes for some students, where, for example, they learnt interesting facts about their classmates, and language outcomes for other students, where they described an aspect of language form that they had noticed or learnt. This task had message or communicative potential for some students and code or metacommunicative potential for others (Breen, 1987). The teachers in our data set seemed, therefore, in the way that they used tasks, to engage both explicit and implicit learning processes. 
In concluding this section, we claim that the fluidity of the real-life classroom and the engagement that it affords with language accounted for the nuanced way in which teachers incorporated TBLT into their practice and for how they combined it with those processes of language learning, such as intentional learning and explicit language instruction, that are not normally associated with a TBLT approach.

\section{The challenge for TBLT}

The TB syllabus - realistic or not?

In TBLT, a syllabus which specifies a predetermined sequence of language structures that are to be taught, is deemed to be inappropriate, given that such an approach is unlikely to respect learners' internal syllabi (Corder, 1967). The teachers in our study, however, all working within the school system in New Zealand, did not adopt a task-based approach to implementing a language syllabus. In planning for using tasks in their language classrooms, most started first with the language that they wanted their students to learn, moving from this to task design. Margaret conceived of her tasks at two levels, explaining that they (Tasks 3 and 4, Chapter 5) had two outcomes. One outcome (for her), was grammatical, while the outcome for the students was communicative (they would learn about each other's lives when they were 6 years old). Interestingly, though, the grammatical outcome was the one that was clearly explained to learners before they engaged with the task. Shona described, in her planning, starting with the task and then thinking about language. It would seem, then, that some of the teachers in this study were able to hold both task and text in tension in their planning. This is another example of how a differentiated view of whether the primary focus in task design is the task or text (i.e., language), might not be sufficient to depict the reality of the classroom.

From the evidence we gathered, however, no teacher worked with a syllabus which was determined by tasks. On the one hand, this could be seen to be surprising in that most of the teachers in our project felt that TBLT aligned well with the New Zealand Curriculum which does not constrain or prescribe the language that students should learn. However, teachers believed that they needed to ensure, in their teaching, that they had covered the language students would need in order to be able to progress in their language learning and eventually succeed at external assessments. This language, was, as we have explained, determined by lists of vocabulary and language structures that examiners could draw on when writing these assessments (East, 2012). The only teachers who did not feel constrained in this way by the demands of the external assessment system, were the two teachers described in Part 1, Sara and Melissa, who were teaching in a primary school context. 
We wonder to what extent it is appropriate, even feasible, for teachers to use a task-based syllabus in a context where they feel constrained to teach a list of language forms that correspond to external assessment demands. This issue is not unique to our research context - other literature has identified that there are few examples of the implementation of a task-based syllabus (Nation \& Macalister, 2010) and, in particular, that teachers feel that a syllabus determined by tasks is not compatible with a national external examination system (Dao, 2016; Hu, 2013; Yim, 2009; Zheng \& Borg, 2014). We, therefore, suggest that teachers may need support in judiciously integrating TBLT with a syllabus which is predicated upon a requirement that learners will learn certain language forms. It is important, furthermore, firstly, that there is more of an acknowledgement in TBLT literature that this is a reality for many learning contexts. Secondly, it would seem to be crucial that there is ongoing investigation and validation of how tasks might be used in these contexts for positive language learning outcomes. We have demonstrated, we claim, that teachers $d o$ use tasks in these contexts. We have also shown that these tasks feed into a rich and dynamic pedagogical space, and, that learners recontextualise and make use of the opportunities they are provided with for language learning.

\section{TBLT needs to account for a wider range of language learning requirements}

In the lessons in which we found tasks, in both Parts One and Two of this book, the time spent on completing the task accounted for only a proportion of the total time of the lesson. In Part 2, the time spent on the task accounted for, on average, 32 minutes, or just over half of the lesson time. We explain that this is not surprising in a school classroom context where there is attention to routines and to the development of different types of skills. One aspect of classroom practice that was salient in the practice of two of our Japanese teachers was katakana practice, aimed at having learners develop literacy in Japanese. This rote learning, which several students reported as a lesson highlight, is an example of one of the aspects of classroom practice about which Bygate (2020) claims TBLT has little to say or offer. It is also, perhaps, an example of how much TBLT research has often been more interested in processes of language learning than in how learners might cope with the breadth of learning required in acquiring another language (Bygate, 2020). It is not necessarily clear how a TBLT approach to language learning might help learners acquire literacy in a language which has a different writing system. We suggest that teachers need to know how to incorporate a TBLT approach to other aspects of classroom practice. Maybe the first step is that, as Bygate (2020) says, research needs to engage more fully with the practices and demands of the classroom. 


\section{The applicability of task criteria}

Tasks are defined in reference to a set of criteria. While there are several sets of criteria that can be used, in this study we have focused on the criteria set out by Ellis and Shintani (2014). Ellis and Shintani's (2014, p. 198) Criterion 3 has been problematic for teachers in our work with TPDL. It reads: "learners should largely have to rely on their own resources (linguistic and non-Linguistic) in order to complete the activity." The problem with this criterion, is that, as outlined above, in the context in which we were working, the beginner language learners had very few resources and a very limited language repertoire on which to draw.

We therefore interpreted, as we have explained earlier, this criterion to mean that:

a. in working at output-based tasks, students used language they had already been taught, that is, they were not expected to use meaningfully language to which they had just been introduced. This applied to rule-based learning rather than item-based learning. For input-based tasks, the input needed to be structured to allow students to access meaning for themselves or with scaffolded help.

b. in working at a task, students had to rely on the limited linguistic repertoire they had established and to draw on their memory for this language resource. In other words, they should not have all the language needed to complete the task provided for them in written form. At the same time, this did not mean that this language would not be available to them if they needed it. For example, they might consult a book or other resource, refer to the board, or ask a teacher for language they required.

The aim with (a) was that, in order to focus on meaning and use language communicatively, students needed to be familiar already with the language structures they needed to complete the task. Or, in the case of input-based tasks, the task needed to be structured in such a way that they could process meaning with effort, or with scaffolded help. The aim with (b) was that students would have opportunity to draw on the repertoire of language that they were building up for themselves, notice where there might be gaps, and have opportunity to develop fluency with and automatise language they had learnt.

Our conclusion here is that the construct of task is something that needs to be interpreted according to pedagogical context. 


\section{Equipping teachers to implement TBLT and use tasks in their instructional contexts}

In this next section, drawing on our findings, we make recommendations for how teachers may better be prepared to implement TBLT and use tasks in their instructional contexts.

\section{Time for professional learning}

We have documented throughout this book, our involvement with the TPDL professional development programme that introduced the participants in our study to tasks and to TBLT. We were, throughout our contact with these teachers, aware of the limited time that the programme afforded us to introduce them to these new concepts. There were many occasions where we would have liked to do more than we could to help the teachers with their learning. For example, we would have liked to provide them with feedback on the tasks they designed for their learning inquiries, before they taught these. We would have liked to introduce them to a greater number and range of tasks, in particular, input-based tasks. Unfortunately, neither was possible. A recommendation that we would make is that a programme that aims to introduce teachers to an innovation such as TBLT, needs to plan for the time that would be needed for teachers to learn and implement this new learning in their practice. At the same time, however, the TPDL programme was the best opportunity for in-service teachers to learn about tasks and TBLT in the New Zealand context. Over the period of a year, participants received 40 hours of instruction and approximately 10 hours with a TPDL Facilitator (see Appendix 1 for more information about this aspect of the programme). There was no other professional development programme available to practising teachers that offered as many hours of contact over a comparable time frame. While we claim that we would have liked more time, the literature suggests that it is possible to achieve lasting effects for programmes extending more than 30 hours spread out over 6-12 months (Yoon et al., 2007). Furthermore, we suggest that the time limitations that we faced may well be the reality for other professional development initiatives that would aim to equip teachers to implement TBLT.

The recommendations we make below for teacher educators, in terms of how teachers may better be prepared to implement TBLT and use tasks in their instructional contexts, are made in the spirit of the ideal, rather than what might be possible, given time constraints. Had we had the time we would have liked, we may have been able to deal with some of these issues ourselves. 


\section{Preparing students for the language demands of the task}

As we have documented, teachers tended to use focused tasks in their classroom practice. However, designing and teaching focused tasks was not easy for all the teachers in our study. The criterion, documented here and elsewhere (Erlam, 2016a) as most difficult for teachers to implement in task design, was that of having students rely on their own linguistic and nonlinguistic resources. Teachers need help when designing tasks for beginner learners which encourage meaningful communication rather than the practice and display of language.

We noticed three problematic tendencies in the way that teachers in this study dealt with language in relation to the tasks or activities that they used. We use the term "activity" here because at times we considered that we had not seen evidence of a task in classroom practice, for the very reason that the criterion of having students rely on their own linguistic and/or nonlinguistic resources was one that had not been fulfilled. The first tendency (as already discussed) is that teachers tended to use tasks or activities that required learners to produce language output rather than allowing them to process language input. Arguably, here, as also found in Erlam (2016a), learners may not have been at an appropriate stage in the learning process where it was reasonable to expect them to use output meaningfully. The second tendency was that teachers pre-taught the language that students needed immediately prior to performing a task or activity, where they were required to use this language (most often in oral production). This entailed the risk that, as they performed the task, learners were focused on these forms rather than on meaning. Educating teachers about the principle of "task dependency" (Nunan, 2004) may help them understand that a task should grow out of those that have preceded it. Similarly, teaching teachers about the receptive to productive principle could be beneficial. This would help teachers understand that using input-based tasks before output-based tasks would better sequence tasks in relation to student learning (Erlam, 2016a). The third tendency was that teachers provided too much language support, often giving students, in written form, the exact language that they needed to complete the task. In such cases, students did not need to challenge themselves to independently access and draw on the repertoire of language that they were slowly building up for themselves, nor were they challenged to access other language forms that might have been appropriate for task completion. In our opinion, teachers needed help to know how to scaffold, and also withdraw scaffolded assistance gradually, so that students had opportunity to use language independently.

We had already been aware of difficulties that teachers had with this criterion, and had tried to address these in the TPDL programme. We had taught teachers that providing students with vocabulary and phrases (item-based learning) they might need to complete a task was appropriate but that requiring them to use 
new grammatical structures (rule-based learning) was not. However, this emphasis in the TPDL programme was an initiative that postdated the involvement of the teachers whose practice we observed in Part 2 of this study, who had not been given this advice.

In documenting the challenges we observed for how teachers tended to deal with the language demands of tasks, we feel that there is a tension for teachers and one which they do not always find easy to navigate. It speaks to the need to ensure that students have the language they need to complete a task, and at the same time have freedom to use the language that they want to. Some of the teachers in our study documented that learning about TBLT had taught them the importance of not restricting the language to which they exposed their learners. They recounted examples of how they had been "blown away" by what the students gave back, that is, how they used language, when they had been allowed freedom to access the language that they wanted to. Teachers seem to need help to learn how to allow students this freedom and, at the same time, support them with the language they need to complete tasks. Failing to do the latter runs the risk of having students revert to use of the L1 as they work at task completion, or even giving up because the task is too difficult. It is for these reasons that we suggest that assisting teachers of beginner learners with how to deal with the language demands of tasks would be an important aspect of professional development.

\section{Input-based tasks}

One of the key reasons for the fact that teachers have difficulty designing tasks that fulfil the criterion that learners rely on their own linguistic resources, is that they tend to focus on output-based tasks (Erlam, 2016a). In the present study there were some examples of input-based tasks, but relatively few, especially given the context of the beginner language learner. We would claim that one way in which TBLT can be made to work for ab initio learners, who have no established language repertoire on which to draw, is for teachers to use more input-based tasks in relation to output-prompting tasks. There are, increasingly, examples in the literature of how input-based tasks can be designed and used and of the impact that they can have on language acquisition (Erlam \& Ellis, 2018, 2019; Shintani, 2016). One change we would make to an in-service professional development programme that aimed to introduce teachers to TBLT and tasks would be to have a greater emphasis on input-based tasks, helping teachers to understand why they are important and equipping them to design these. They would also need to know when and how it might be best to transition from input-based to output-prompting tasks. However, the challenge going forward could be similar to the one we faced, that is, how, in the 
limited time that practising teachers (most of whom were teaching full time) can make available for professional development, we can adequately equip teachers to understand, design, and use tasks that are appropriate for their individual contexts.

\section{Focus on form in relation to task}

Teachers in our study reported that they had changed their classroom practice in how they dealt with focus on form or the teaching of grammar. They attributed this to learning as a result of completing the TPDL programme where they had been introduced to TBLT. Some of them documented moving from a focus on formS, with an initial focus on decontextualised language, to a focus-on-form approach, with a focus on language form arising out of a context where the initial attention was on meaning. Others referred to a discovery and inductive approach to learning about language form. At the same time, classroom observations did not always demonstrate that the teacher's claims about their change in classroom practice were substantiated. This was perhaps an area that teachers in our study needed more support and help with during their professional learning. In particular, teachers may have needed more education about the different ways in which a focus on form may be incorporated during the task cycle. We observed only one example of a post-task being used as an opportunity to focus on form.

\section{Helping teachers to understand task}

Some teachers indicated that they had trouble understanding the notion of task, a finding from the interview data of both Parts 1 and 2 of this study. This difficulty was also evident in the practice of one of the eight teachers in Part 2. Obviously, for this teacher, the emphasis in the TPDL programme on the notion of task construct, had not been sufficient for her to feel equipped to either understand or implement tasks in her classroom. At the same time, other teachers were both confident and proficient in their use of tasks. It is not immediately obvious why there would be this difference in terms of learning. In teacher development, we would underline the importance of giving teachers opportunities to be language learners and to experience tasks for themselves. In the TPDL programme (which covered content other than TBLT), a constant regret was the lack of time needed to reinforce the learning that we were facilitating for teachers.

At the same time, some of the teachers in our study, in whose classrooms we observed many opportunities for language learning, were less concerned about the "taskness" of the tasks they were using, and more focused on evidence of learning. We would endorse this emphasis, which was consistent with our approach to educating 
teachers about tasks and TBLT. We had started with a broad focus on principles of language learning (Ellis, 2005) and then introduced tasks and TBLT as a way of incorporating these principles in classroom practice. At all times, we wanted our teachers to look for evidence of these principles in their practice and in student learning.

\section{Access to resources}

A constant theme running through this study and through the literature (Erlam, 2015a) is that, for TBLT to be successful as an innovation, teachers need to be provided with resources. In the interviews we conducted, teachers continually referred to a lack of resources and a lack of time to make these resources, as impacting negatively on their ability to implement TBLT. As argued elsewhere (Ellis, 1997), an innovation like TBLT is likely to be more successful if it does not require a high degree of originality on the part of teachers. The teachers in this study mostly designed and taught their own tasks, because they did not have task-based resources available to them. This is a constraint, going forward, to the successful implementation of TBLT in the context we describe.

\section{Differentiating for the learner}

We identified opposing viewpoints on how teachers saw the potential of TBLT to cater for individual learner needs. Some teachers felt that TBLT did not cater sufficiently for individual learner differences. Two teachers had implemented a flipped mastery approach to language teaching, to allow learners to work at their own pace and according to their individual learning styles and preferences. However, as we have described, one of these teachers, Shona, with her Murder Mystery task, had adapted TBLT to fit with this teaching approach. Interestingly, however, teachers in Part 1 of this study reported that they thought that TBLT was particularly suited to a pedagogy that catered for differentiating individual learner needs, and they suggested how the tasks they had taught as part of their inquiries might be adapted for this purpose. Overall, we conclude that enabling teachers to implement TBLT in their classrooms needs to include a focus on helping them adapt tasks for individual learner differences. 


\section{Limitations}

This study has been able to provide a small snapshot of teacher learning and practice. It has focused only on how individual teachers used tasks within a sequence of no more than two lessons. It is therefore only able to provide limited information about the use of tasks within a language curriculum. Furthermore, we cannot claim that our participant sample is representative of the wider cohort of teachers who have, over the years, participated in the TPDL programme. Those teachers who were involved in Part 1 of the study volunteered their participation; those who were approached for possible participation in Part 2 were specifically selected because they were known to embody best practice and/or knew the researchers. For these reasons, therefore, it is very possible that we are presenting a view of teacher understanding and practice that is biased for best.

Another limitation is that, while we were able to identify, as students worked at language tasks, processes from the literature that are known to promote language acquisition, we were unable to provide empirical evidence of student learning or acquisition as a result of completing these tasks. A reason for this is that we were keen, as much as possible, to observe regular lessons in regular classroom practice, and so told our participants as little as possible about what we hoped to see. Investigating student learning would most likely have involved our knowing ahead of time about the lesson we would be observing and preparation of some measure of learning in relation to that lesson.

The limitations we describe are largely due to the fact that we wanted the impact of our investigations to impose as little as possible on our teacher participants. In our experience it is very hard to get extremely busy classroom teachers to agree to participate in research of any nature, and even harder to get access to their classrooms. In another study (Erlam, 2016b), only two teachers volunteered participation out of the 65 who were invited and who were enrolled in the TPDL programme. Of these, only one met the research criteria. Teacher participation was an issue we faced in the present study. In particular, fewer participants allowed us access to their classrooms in Part 1, than we would have liked. We were not always sure why we faced this problem, although we know how busy teachers are. We were, therefore, fully appreciative of the opportunities we were given and keen to minimise the impact of our investigation as much as possible. 


\section{In summary}

Our intent with this book was to contribute to TBLT scholarship by documenting how teachers of foreign languages other than English learn about and implement tasks and TBLT in intact school classrooms, a context which, we claim, is underrepresented in the literature. In the professional learning programme that served as the context for the book, the primary and secondary school teachers we studied first focused on principles underlying effective instructed language learning (Ellis, 2005) and then learnt about tasks and TBLT, as a way of implementing these principles in practice. In observing the practice of these teachers, following on from their learning about TBLT and tasks, we found, as documented elsewhere (e.g., Andon \& Eckerth, 2009; Oliver \& Bogachenko, 2018; Van den Branden, 2006), that they shaped tasks in different ways so as to open up pedagogical spaces for language learning.

The findings of the study show that teachers incorporated TBLT and tasks into their classroom practice in combination with instructional and learning processes that are not normally associated with TBLT. In so doing, some of the dichotomies that have differentiated TBLT from other approaches to language teaching and learning were blurred. We suggest that TBLT theory needs to continue to engage with the realities of actual classroom practice, and to consider how this approach to language teaching may be maximally relevant to the different instructional contexts in which teachers are operating.

Our book also contributes to language teacher education by providing further illustrations of the realities of the support that teachers need to implement curricular innovations. We made a number of recommendations to better prepare and support teachers to implement TBLT in their instructional contexts. We conclude with the words of one of our teacher participants:

You have to structure things quite carefully... I don't feel that everything can be done task-based and I don't think everything should be done task-based... so you try to do task-based as much as you can, as long as it fits in with what you can do... and the more you think about it, the more you realise that actually the more things that you actually can do in a task-based manner. But it takes time. It takes time to think about how you're going to present it in a task-based fashion [and] to build the resources. 


\section{References}

Adams, R., \& Newton, J. (2009). TBLT in Asia: Constraints and opportunities. Asian Journal of English Language Teaching, 19(1), 1-17.

Andon, N., Dewey, M., \& Leung, C. (2018). Tasks in the pedagogic space: Using online discussion forum tasks and formative feedback to develop academic discourse skills at master's level. In V. Samuda, K. Van den Branden, \& M. Bygate (Eds.), TBLT as a researched pedagogy (pp. 235-263). John Benjamins. https://doi.org/10.1075/tblt.12.10and

Andon, N., \& Eckerth, J. (2009). Chacun à son gout. Task-based L2 pedagogy from the teacher's point of view. International Journal of Applied Linguistics, 19, 286-310.

https://doi.org/10.1111/j.1473-4192.2009.00240.x

Bartolomeo-Maida, M. (2016). The use of learning journals to foster textbook reading in the community college psychology class. College Student Journal, 50(3), 440-453.

Baumfield, V., Hall, E., \& Wall, K. (2013). Action research in education: Learning through practitioner enquiry. Sage. https://doi.org/10.4135/9781526402240

Benson, S. (2016). Task-based language teaching: An empirical study of task transfer. Language Teaching Research, 20(3), 341-365. https://doi.org/10.1177/1362168815569829

Borg, S. (2006). Teacher cognition and language education: Research and practice. Continuum.

Brandl, K. (2017). Task-based instruction and teacher training. In N. van Deusen-Scholl \& S. May (Eds.), Second and foreign language education. Encyclopedia of language and education (3rd ed., pp. 1-14). Springer. https://doi.org/10.1007/978-3-319-02246-8_34

Breen, M. P. (1987). Learner contributions to task design. In C. N. Candlin \& D. Murphy (Eds.), Tasks in language learning (pp. 23-46). Prentice Hall.

Breen, M. P. (1989). The evaluation cycle for language learning tasks. In R. Johnson (Ed.), The second language curriculum (pp. 187-206). Cambridge University Press. https://doi.org/10.1017/CBO9781139524520.014

Brumfit, C. J. (1979). Communicative language teaching: An educational perspective. In C. Brumfit \& K. Johnson (Eds.), The communicative approach to language teaching (pp 183-193). Oxford University Press.

Brumfit, C. J. (1984). Communicative methodology in language teaching: The roles of fluency and accuracy. Cambridge University Press.

Brumfit, C. J. (1985). Language and literature teaching: From practice to principle. Pergamon.

Bruner, J. (1973). The relevance of education (2nd ed.). Norton.

Bryfonski, L., \& McKay, T. (2019). TBLT implementation and evaluation: A meta-analysis. Language Teaching Research, 23(5), 603-632. https://doi.org/10.1177/1362168817744389

Burns, A. (2019). Action research: Developments, characteristics, and future directions. In J. Schwieter \& A. Benati (Eds.), The Cambridge handbook of language learning (pp. 166-185). Cambridge University Press. https://doi.org/10.1017/9781108333603.008

Butler, Y. G. (2011). The implementation of communicative and task-based language teaching in the Asia-Pacific region. Annual Review of Applied Linguistics, 31, 36-57.

https://doi.org/10.1017/So267190511000122 
Bygate, M. (Ed.). (2015). Domains and directions in the development of TBLT. John Benjamins. https://doi.org/10.1075/tblt.8

Bygate, M. (Ed.). (2018). Learning language through task repetition. John Benjamins. https://doi.org/10.1075/tblt.11

Bygate, M. (2020). Some directions for the possible survival of TBLT as a real world project. Language Teaching 53, 275-288. https://doi.org/10.1017/So261444820000014

Calvert, M., \& Sheen, Y. (2015). Task-based language learning and teaching: An action-research study. Language Teaching Research, 19(2), 226-244. https://doi.org/10.1177/1362168814547037

Cameron, L. (2001). Teaching languages to young children. Cambridge University Press. https://doi.org/10.1017/CBO9780511733109

Candlin, C. N. (1987). Towards task-based language learning. In C. N. Candlin \& D. F. Murphy (Eds.), Language learning tasks (pp. 5-22). Prentice-Hall.

Carless, D. (2003). Factors in the implementation of task-based teaching in primary schools. System, 31(4), 485-500. https://doi.org/10.1016/j.system.2003.03.002

Carless, D. (2004). Issues in teachers' reinterpretation of task-based teaching in primary schools. TESOL Quarterly, 38(4), 639-662. https://doi.org/10.2307/3588283

Carless, D. (2007). The suitability of task-based approaches for secondary schools: Perspectives from Hong Kong. System, 35(4), 595-608. https://doi.org/10.1016/j.system.2007.09.003

Carless, D. (2012). TBLT in EFL settings: Looking back and moving forward. In A. Shedadeh \& C. Coombe (Eds.), Task-based language teaching in foreign language contexts: Research and Implementation (pp. 345-358). John Benjamins. https://doi.org/10.1075/tblt.4.20car

Carless, D. (2013). Innovation in language teaching and learning. In C. A. Chapelle (Ed.), The encyclopedia of applied linguistics (pp. 1-4). Wiley-Blackwell.

https://doi.org/10.1002/9781405198431.wbealo540

Carless, D. (2015). Teachers' adaptations of TBLT: The Hong Kong story. In M. Thomas \& H. Reinders (Eds.), Contemporary task-based language teaching in Asia (pp. 366-380). Bloomsbury.

Cochran-Smith, M., \& Lytle, S. (1999). Relationships of knowledge and practice: Teacher learning in communities. Review of Research in Education, 24, 249-305.

https://doi.org/10.3102/0091732X024001249

Coffey, S. (2015). Reframing teachers' language knowledge through metaphor analysis of language portraits. The Modern Language Journal, 99(3), 500-514. https://doi.org/10.1111/modl.12235

Cook, V. (2010). Linguistic relativity and language teaching. In V. Cook \& A. Bassetti (Eds.), Language and bilingual cognition (pp. 509-518). Psychology Press.

Corder, S. P. (1967). The significance of learners' errors. International Review of Applied Linguistics, 5, 161-169. https://doi.org/10.1515/iral.1967.5.1-4.161

Costa, A., \& Kallick, B. (2009). Learning through reflection. In A. Costa \& B. Kallick, (Eds.), Leading and learning with habits of mind (pp. 221-235). Association for Supervision and Curriculum Development.

Council of Europe. (2001). Common European framework of reference for languages. Cambridge University Press.

Creswell, J. W. (2009). Research design: Qualitative, quantitative, and mixed methods approaches. Sage.

Dangel, J. R., Guyton, E., \& McIntyre, C. B. (2004). Constructivist pedagogy in primary classrooms: Learning from teachers and their classrooms. Journal of Early Childhood Teacher Education, 24(4), 237-245. https://doi.org/10.1080/1090102040240404 
Dao, T. T. (2016). Perceptions of teachers towards the implementation of task based language teaching: A case study in a Vietnamese University. International Journal of Humanities Social Sciences and Education, 3(12), 48-55. https://doi.org/10.1017/9781108333603.022

Darling-Hammond, L., Hyler, M. E., \& Gardner, M. (2017). Effective teacher professional development. Learning Policy Institute. https://learningpolicyinstitute.org/product/teacher-prof-dev

Darling-Hammond, L., \& Richardson, N. (2009). Teacher learning: What matters? Educational Leadership, 66(5), 46-53.

DeKeyser, R. (1998). Beyond focus on form: Cognitive perspective on learning and practising second language grammar. In C. Doughty \& J. Williams (Eds.), Focus on form in classroom second language acquisition (pp. 42-63). Cambridge University Press.

DeKeyser, R. (2007). Situating the concept of practice. In R. DeKeyser (Ed.), Practice in a second language: Perspectives from applied linguistics and cognitive psychology (pp. 1-18). Cambridge University Press. https://doi.org/10.1017/CBO9780511667275.002

DeKeyser, R., \& Robinson, P. (2001). Automaticity and automatization. In P. Robinson (Ed.), Cognition and second language instruction (pp. 125-151). Cambridge University Press. https://doi.org/10.1017/CBO9781139524780.007

Dewey, J. (1933). How we think. Free Press.

Dupuy, B. (1999). Narrow listening: An alternative way to develop listening comprehension in the foreign language classroom. System, 24(1), 97-100. https://doi.org/10.1016/S0346-251X(99)00030-5

East, M. (2012). Task-based language teaching from the teachers' perspective. John Benjamins. https://doi.org/10.1075/tblt.3

East, M. (2014a). Encouraging innovation in a modern foreign language initial teacher education programme: What do beginning teachers make of task-based language teaching? The Language Learning Journal, 42(3), 261-274. https://doi.org/10.1080/09571736.2013.856455

East, M. (2014b). Mediating pedagogical innovation via reflective practice: A comparison of preservice and in-service teachers' experiences. Reflective Practice: International and Multidisciplinary Perspectives, 15(5), 686-699. https://doi.org/10.1080/14623943.2014.944128

East, M. (2018). How do beginning teachers conceptualise and enact tasks in school foreign language classrooms? In V. Samuda, K. Van den Branden, \& M. Bygate (Eds.), TBLT as a researched pedagogy (pp. 23-50). John Benjamins. https://doi.org/10.1075/tblt.12.02eas

East, M. (2019). Embedding innovation into school modern foreign languages programmes: Outcomes of two teachers' inquiries into their own practices. The European Journal of Applied Linguistics and TEFL, 8(2), 141-157.

Ellis, N. C., \& Larsen-Freeman, D. (2009). Constructing a second language: Analyses and computational simulations of the emergence of linguistic constructions from usage. Language Learning, 59, 90-125. https://doi.org/10.1111/j.1467-9922.2009.00537.x

Ellis, N. C., \& Wulff, S. (2015). Usage-based approaches in second language acquisition. In B. VanPatten \& J. Williams (Eds.), Theories in second language acquisition (pp. 75-93). Routledge.

Ellis, R. (1994). A theory of instructed second language acquisition. In N. Ellis (Ed.), Implicit and explicit learning of languages (pp. 79-114). Academic Press.

Ellis, R. (1997). SLA research and language teaching. Oxford University Press.

Ellis, R. (2001). Investigating Form-Focused Instruction. In R. Ellis (Ed.) Form-Focused Instruction and second language learning. Blackwell.

Ellis, R. (2003). Task-based language teaching and learning. Cambridge University Press.

Ellis, R. (2005). Instructed second language acquisition: A literature review. Learning Media. 
Ellis, R. (2009). Task-based language teaching: Sorting out the misunderstandings. International Journal of Applied Linguistics, 19(3), 221-246. https://doi.org/10.1111/j.1473-4192.2009.00231.x

Ellis, R. (2010). Second language acquisition, teacher education and language pedagogy. Language Teaching, 43(2), 182-201. https://doi.org/10.1017/So261444809990139

Ellis, R. (2011). Macro- and micro-evaluations of task-based teaching. In B. Tomlinson (Ed.), Materials development in language teaching (2nd ed., pp. 212-235). Cambridge University Press.

Ellis, R. (2012). Language teaching research and language pedagogy. Wiley Blackwell. https://doi.org/10.1002/9781118271643

Ellis, R. (2019). Towards a modular language curriculum for using tasks. Language Teaching Research, 23(4), 454-475. https://doi.org/10.1177/1362168818765315

Ellis, R., \& Barkhuizen, G. (2005). Analysing learner language. Oxford University Press.

Ellis, R., Basturkmen, H., \& Loewen, S. (2001). Learner uptake in communicative ESL lessons. Language Learning, 51(2), 281-318. https://doi.org/10.1111/1467-9922.00156

Ellis, R., Loewen, S., Elder, C., Erlam, R., Philp, J., \& Reinders, H. (2009). Implicit and explicit language knowledge in second language learning, testing and teaching. Multilingual Matters.

Ellis, R., Loewen, S., \& Erlam, R. (2006). Implicit and explicit feedback and the acquisition of L2 grammar. Studies in Second Language Acquisition, 28, 339-368.

https://doi.org/10.1017/S0272263106060141

Ellis, R., \& Shintani, N. (2014). Exploring language pedagogy through second language acquisition research. Routledge.

Ellis, R., Skehan, P., Li, S., Shintani, N., \& Lambert, C. (2020). Task-based language teaching: Theory and practice. Cambridge University Press. https://doi.org/10.1017/9781108643689

Erlam, R. (2008). What do you researchers know about language teaching? Bridging the gap between SLA research and language pedagogy. Innovation in Language Learning and Teaching, 2(3), 253-267. https://doi.org/10.1080/17501220802158958

Erlam, R. (2013). Listing and comparing tasks in the language classroom: Examples of Willis and Willis's (2007) taxonomy in practice. The New Zealand Language Teacher, 39, 7-14.

Erlam, R. (2015a). "New tricks": Teachers talk about task-based language teaching. Babel, 50(1), 4-11.

Erlam, R. (2015b). Why the Interact standard is good for your classroom. The New Zealand Language Teacher, 41, 22-33.

Erlam, R. (2016a). "I'm still not sure what a task is": Teachers designing language tasks. Language Teaching Research. 20(3), 279-299. https://doi.org/10.1177/1362168814566087

Erlam, R. (2016b). Using evaluation to promote change in language teacher practice. Papers in Language Testing and Assessment, 5(1), 41-65.

Erlam, R., \& Ellis, R. (2018). Task-based language teaching for beginner-level learners of L2 French: An exploratory study. Canadian Modern Language Review, 71(1), 1-26. https://doi.org/10.3138/cmlr.3831

Erlam, R., \& Ellis, R. (2019). Input-based tasks for beginner-level learners: An approximate replication and extension of Erlam and Ellis (2018). Language Teaching, 52(4), 490-511. https://doi.org/10.1017/So261444818000216

Erlam, R., \& Pimentel-Hellier, M. (2017). Opportunities to attend to language form in the adolescent near-beginner foreign language classroom. Language Awareness, 26(2), 59-77. https://doi.org/10.1080/09658416.2017.1314487

Erlam, R., \& Sakui, K. (2006). Instructed second language acquisition case studies. Ministry of Education. 
Farrell, T. S. C. (2016). The practices of encouraging TESOL teachers to engage in reflective practice: An appraisal of recent research contributions. Language Teaching Research, 20(2), 223-247. https://doi.org/10.1177/1362168815617335

Farrell, T. S. C., \& Ives, J. (2015). Exploring teacher beliefs and classroom practices through reflective practice. Language Teaching Research, 19(5), 594-610. https://doi.org/10.1177/1362168814541722

Feiman-Nemser, S. (2008). Teacher learning: How do teachers learn to teach? In M. CochranSmith, S. Feiman-Nemser, J. McIntyre, \& K. Demers (Eds.), Handbook of research on teacher education: Enduring questions in changing contexts (3rd ed., pp. 697-705). Routledge.

Freese, A. R. (2006). Reframing one's teaching: Discovering our teacher selves through reflection and inquiry reflective practice. Teaching and Teacher Education, 22, 100-119.

https://doi.org/10.1016/j.tate.2005.07.003

Gatbonton, E. (2015, September 16-18). Task repetition to utterance repetition and accuracy. [Colloquium presentation] 6th Biennial Task Based Language Teaching conference, Leuven, Belgium.

Gibbs, C. J., \& Holt, R. F. (2003). The teaching of international languages in New Zealand schools in Years 7 and 8: An evaluation study. Ministry of Education.

Gower, R., \& Walters, S. (1983). Teaching practice handbook. Oxford University Press.

Hammerness, K. M., Darling-Hammond, L., \& Bransford, J. (2005). How teachers learn and develop. In L. Darling-Hammond, \& J. Bransford (Eds.), Preparing teachers for a changing world: What teachers should learn and be able to do (pp. 358-389). Jossey-Bass.

$\mathrm{Hu}, \mathrm{G}$. (2002). Recent important developments in secondary English language teaching in the P.

R. China. Language Culture and Curriculum, 15(1), 30-49. https://doi.org/10.1080/07908310208666631

Hu, G., \& McKay, S. L. (2012). English language education in East Asia: Some recent developments. Journal of Multilingual and Multicultural Development, 33(4), 345-362. https://doi.org/10.1080/01434632.2012.661434

$\mathrm{Hu}, \mathrm{R}$. (2013). Task-based language teaching: Responses from Chinese teachers of English. TESL-EJ, 16(4), 1-21.

Insley, S., \& Thomson, W. (2008). Supporting teachers to increase the quality and quantity of student target language use: Description and analysis of the "Teacher Professional Development in Languages" (TPDL) programme. The New Zealand Language Teacher, 34, 21-30.

Jeon, I. J., \& Hahn, J. W. (2006). Exploring EFL teachers' perceptions of task-based language teaching: A case study of Korean secondary school classroom practice. Asian EFL Journal, 8(1), 123-143.

Johnson, K. E., \& Golombeck, P. R. (2018). Informing and transforming language teacher education pedagogy. Language Teaching Research, 24(1), 116-127.

https://doi.org/10.1177/1362168818777539

Keck, C., Iberri-Shea, G., Tracy-Venturea, N., \& Wa-Mbaleka, S. (2006). Investigating the empirical link between task-based interaction and acquisition: A quantitative meta-analysis. In J. M. Norris \& L. Ortega (Eds.), Synthesizing research on language learning and teaching (pp. 91-131). John Benjamins. https://doi.org/10.1075/lltt.13.08kec

Keck, C., \& Kim, Y. (2014). Pedagogical grammar. John Benjamins. https://doi.org/10.1075/z.190

Keenan, J. M., \& MacWhinney, B. (1987). Understanding the relationship between comprehension and production. In H. W. Dechert \& M. Raupach (Eds.), Psycholinguistic models of production (pp. 150-155). Ablex. 
Kennedy, M. M. (1999). The role of preservice teacher education. In L. Darling-Hammond \& G. Sykes (Eds.), Teaching as the learning profession: Handbook of policy and practice (pp. 54-85). Jossey Bass.

Killion, J., \& Todnem, G. (1991). A process of personal theory building. Educational Leadership, 48(6), 14-17.

Klapper, J. (2003). Taking communication to task? A critical review of recent trends in language teaching. The Language Learning Journal, 27, 33-42. https://doi.org/10.1080/09571730385200061

Korthagen, F. (2011). Making teacher education relevant for practice: The pedagogy of realistic teacher education. Orbis Scholae, 5(2), 31-50. https://doi.org/10.14712/23363177.2018.99

Korthagen, F. (2017). Inconvenient truths about teacher learning: Towards professional development 3.0. Teachers and Teaching, 23(4), 387-405.

https://doi.org/10.1080/13540602.2016.1211523

Kubanyiova, M. (2012). Teacher development in action: Understanding language teachers' conceptual change. Palgrave Macmillan. https://doi.org/10.1057/9780230348424

Kubanyiova, M., \& Feryok, A. (2015). Language teacher cognition in applied linguistics research: Revisiting the territory, redrawing the boundaries, reclaiming the relevance. The Modern Language Journal, 99(3), 435-449. https://doi.org/10.1111/modl.12239

Kumaravadivelu, B. (2001). Towards a post-method pedagogy. TESOL Quarterly, 35, 537-560. https://doi.org/10.2307/3588427

Lantolf, J. (2000). (Ed.). Sociocultural theory and second language learning. Oxford University Press.

Lantolf, J., \& Beckett, T. (2009). Sociocultural theory and second language acquisition. Language Teaching, 42, 459-475. https://doi.org/10.1017/So261444809990048

Legutke, M. (2012). Teaching teenagers. In A. Burns \& J. Richards (Eds.), The Cambridge guide to pedagogy and practice in second language teaching (pp. 112-119). Cambridge University Press.

Lightbown, P. M. (2014). Making the minutes count in L2 teaching. Language Awareness, 23, 3-23. https://doi.org/10.1080/09658416.2013.863903

Linsen, B. (1994). A trial-and-error process: The introduction of task-based language teaching. A practical description from primary education in Flanders. In S. Kroon \& T. Vallen (Eds.), Nederlands als tweede taal in het onderwijs. Praktijkbeschrijvingen uit Nederland en Vlaanderen [Dutch as a second language in education: Practical descriptions from the Netherlands and Flanders] (pp. 131-159). SDU Uitgeverij.

Littlewood, W. (2007). Communicative and task-based language teaching in East Asian classrooms. Language Teaching, 40(3), 243-249. https://doi.org/10.1017/S0261444807004363

Littlewood, W. (2014). Communication-oriented teaching: Where are we now? Where do we go from here? Language Teaching, 47, 249-362. https://doi.org/10.1017/So261444812000134

Liu, Y., Mishan, F., \& Chambers, A. (2018). Investigating EFL teachers' perceptions of task-based language teaching in higher education in China. The Language Learning Journal, 49(2), 131-146. https://doi.org/10.1080/09571736.2018.1465110

Loewen, S. (2004). Uptake in incidental focus on form in meaning-focused ESL lessons. Language Learning, 54, 153-187. https://doi.org/10.1111/j.1467-9922.2004.00251.x

Loewen, S. (2005). Incidental focus on form and second language learning. Studies in Second Language Acquisition, 27, 361-386. https://doi.org/10.1017/So272263105050163 
Loewen, S., \& Reinders, H. (2011). Key concepts in second language acquisition. Palgrave Macmillan. https://doi.org/10.1007/978-0-230-34627-7

Long, M. H. (1983). Does second language instruction make a difference? A review of research. TESOL Quarterly, 17(3), 359-382. https://doi.org/10.2307/3586253

Long, M. H. (1985). A role for instruction in second language acquisition: Task-based language teaching. In K. Hyltenstam \& M. Pienemann (Eds.), Modelling and assessing second language development (pp. 77-99). Multilingual Matters.

Long, M. H. (1988). Instructed interlanguage development. In L. Beebe (Ed.), Issues in second language acquisition: Multiple perspectives (pp. 115-141). Newbury House.

Long, M. H. (1991). Focus on form: A design feature in language teaching methodology. In K. de

Bot, R. Ginsberg, \& C. Kramsch (Eds.), Foreign language research in cross-cultural perspective (pp. 39-52). John Benjamins. https://doi.org/10.1075/sibil.2.07lon

Long, M. H. (1996). The role of the linguistic environment in second language acquisition. In

W. C. Ritchie \& T. K. Bhatia (Eds.), Handbook of second language acquisition (pp. 413-468). Academic Press.

Long, M. H. (2015). Second language acquisition and task-based language teaching. Wiley Blackwell. Long, M. H., \& Crookes, G. (1992). Three approaches to task-based language teaching. TESOL

Quarterly, 26(1), 27-56. https://doi.org/10.2307/3587368

Long, M., Lee, J., \& Hillman, K. K. (2019). Task-based language learning. In J. Schwieter \& A. Benati (Eds.), Cambridge handbook of language and learning (pp. 500-526). Cambridge University Press. https://doi.org/10.1017/9781108333603.022

Loughran, J. J. (2002). Effective reflective practice: In search of meaning in learning about teaching. Journal of Teacher Education, 53, 33-43. https://doi.org/10.1177/0022487102053001004 Loughran, J. J. (2010). What expert teachers do: Teachers' professional knowledge of classroom practice. Routledge.

Mackey, A., \& Goo, J. (2007). Interaction research in SLA: A meta-analysis and research synthesis. In A. Mackey (Ed.), Conversational interaction in second language acquisition: A series of empirical studies (pp. 407-453). Oxford University Press.

McDonough, K. (2015). Perceived benefits and challenges with the use of collaborative tasks in EFL contexts. In M. Bygate (Ed.), Domains and directions in the development of TBLT (pp. 225-245). John Benjamins. https://doi.org/10.1075/tblt.8.08mcd

McDonough, K., \& Chaikitmongkol, W. (2007). Teachers' and learners' reactions to a task-based EFL course in Thailand. TESOL Quarterly, 41(1), 107-132.

https://doi.org/10.1002/j.1545-7249.2007.tbooo42.x

McNiff, J. (2016). You and your action research project (4th ed.). Routledge. https://doi.org/10.4324/9781315693620

Miles, M. B., \& Huberman, A. H. (1994). Qualitative data analysis: A sourcebook of new methods. Sage.

Ministry of Education. (2007a). The generic framework for teaching and learning languages in English-medium schools. Learning Media.

Ministry of Education. (2007b). The New Zealand curriculum. Learning Media.

Ministry of Education. (2012). Pedagogy for learning languages. Retrieved on 4 August 2021 from https://seniorsecondary.tki.org.nz/Learning-languages/Pedagogy

Ministry of Education. (2017). What's new or different. Retrieved on 4 August 2021 from http:// seniorsecondary.tki.org.nz/Learning-languages/What-s-new-or-different 
Ministry of Education. (2020). Teaching as inquiry. Retrieved on 4 August 2021 https://nzcurriculum. tki.org.nz/Teaching-as-inquiry

Muijs, D., Kyriakides, L., van der Werf, G., Creemers, B., Timperley, H., \& Earl, L. (2014). State of the art - teacher effectiveness and professional learning. School Effectiveness and School Improvement: An International Journal of Research, Policy and Practice, 25(2), 231-256. https://doi.org/10.1080/09243453.2014.885451

Müller-Hartmann, A., \& Schocker-von Ditfurth, M. (2011). Teaching English: Task-supported language learning. Ferdinand Schöningh.

Müller-Hartmann, A., \& Schocker-von Ditfurth, M. (2018). The challenges of integrating focus on form within tasks: Findings from a classroom research project in secondary EFL classrooms. In V. Samuda, K. Van den Branden, \& M. Bygate (Eds.), TBLT as a researched pedagogy (pp. 97-129). John Benjamins. https://doi.org/10.1075/tblt.12.05har

Nation, I. S. P., \& Macalister, J. (2010). Language curriculum design. Routledge.

Newman, F., \& Holzman, L. (1997). The end of knowing: A new developmental way of learning. Routledge.

Newton, J., Yates, E., Shearn, S., \& Nowitzki, W. (2010). Intercultural communicative language teaching: Implications for effective teaching and learning - A literature review and an evidencebased framework for effective teaching. Ministry of Education.

Norris, J. (2009). Task-based language teaching and testing. In M. Long \& C. Doughty (Eds.), The handbook of language teaching (pp. 578-594). Wiley Blackwell.

https://doi.org/10.1002/9781444315783.ch30

Nunan, D. (1989). Designing tasks for the communicative classroom. Cambridge University Press.

Nunan, D. (2004). Task-based language teaching. Cambridge University Press. https://doi.org/10.1017/CBO9780511667336

Ogilvie, G., \& Dunn, W. (2010). Taking teacher education to task: Exploring the role of teacher education in promoting the utilization of task-based language teaching. Language Teaching Research, 14(2), 161-181. https://doi.org/10.1177/1362168809353875

Oh, S. (2001). Two types of input modification and EFL reading comprehension: Simplification versus elaboration. TESOL Quarterly, 35, 69-96. https://doi.org/10.2307/3587860

Oliver, R., \& Bogachenko, T. (2018). Teacher perceptions and use of tasks in school ESL classrooms. In V. Samuda, K. Van den Branden, \& M. Bygate (Eds.), TBLT as a researched pedagogy (pp. 71-95). John Benjamins. https://doi.org/10.1075/tblt.12.04oli

Ortega, L. (2007). Meaningful L2 practice in foreign language classrooms: A cognitive-interactionist SLA perspective. In R. DeKeyser (Ed.), Practice in a second language: Perspectives from applied linguistics and cognitive psychology (pp. 180-207). Cambridge University Press. https://doi.org/10.1017/CBO9780511667275.011

Ortega, L. (2015). Researching CLIL and TBLT interfaces. System, 54, 103-109. https://doi.org/10.1016/j.system.2015.09.002

Pham, N. T., \& Nguyen, H. B. (2018). Teachers' perceptions about task-based language teaching and its implementation. European Journal of Foreign Language Teaching, 3(2). Retrieved on 4 August 2021 from https://oapub.org/edu/index.php/ejfl/article/view/1619

Philp, J., Adams, R., \& Iwashita, N. (2014). Peer interaction and second language learning. Routledge. Pica, T., Kanagy, R., \& Falodun, J. (1993). Choosing and using communication tasks for second language research and instruction. In G. Crookes \& S. Gass (Eds.), Tasks and language learning. Integrating theory and practice. (pp. 9-34). Multilingual Matters.

Prabhu, N. S. (1987). Second language pedagogy. Oxford University Press. 
Richards, K. (2003). Qualitative inquiry in TESOL. Palgrave Macmillan. https://doi.org/10.1057/9780230505056

Richards, J. C., \& Rodgers, T. (2014). Approaches and methods in language teaching (3rd ed.). Cambridge University Press.

Robinson, P. (Ed.) (2001). Cognition and second language instruction. Cambridge University Press. https://doi.org/10.1017/CBO9781139524780

Robinson, P. (2011). Task-based language learning: A review of issues. Language Learning, 61, Supp. 1, 1-36.

Samuda, V. (2001). Guiding relationships between form and meaning during task performance: The role of the teacher. In M. Bygate, P. Skehan, \& M. Swain (Eds.), Researching pedagogic tasks: Second language learning, teaching and testing. Pearson Education.

Samuda, V., \& Bygate, M. (2008). Tasks in second language learning. Palgrave Macmillan. https://doi.org/10.1057/9780230596429

Samuda, V., Van den Branden, K., \& Bygate, M. (Eds.). (2018). TBLT as a researched pedagogy. John Benjamins. https://doi.org/10.1075/tblt.12

Scarino, A. (2014). Learning as reciprocal, interpretive meaning-making: A view from collaborative research into the professional learning of teachers of languages. The Modern Language Journal, 98(1), 386-401. https://doi.org/10.1111/j.1540-4781.2014.12068.x

Schmidt, R. (1995). Attention and awareness in foreign language learning. University of Hawai' $i$.

Schön, D. (1983). The reflective practitioner: How professionals think in action. Basic Books.

Schön, D. (1987). Educating the reflective practitioner: Towards a new design of teaching and learning in the professions. Jossey-Bass.

Shintani, N. (2016). Input-based tasks in foreign language instruction for young learners. John Benjamins. https://doi.org/10.1075/tblt.9

Shulman, L. S. (1986). Those who understand: Knowledge growth in teaching. Educational Researcher, 15(2), 4-14. https://doi.org/10.3102/0013189X015002004

Skehan, P. (1996). Second language acquisition research and task-based language instruction. In J. Willis \& D. Willis (Eds.), Challenge and change in language teaching (pp. 17-30). Heinemann.

Skehan, P. (1998). Task-based instruction. Annual Review of Applied Linguistics, 18, 268-286. https://doi.org/10.1017/S0267190500003585

Skehan, P., Xiaoyue, B., Qian, L., \& Wang, Z. (2012). The task is not enough: Processing approaches to task-based performance. Language Teaching Research, 16(2), 170-187. https://doi.org/10.1177/1362168811428414

Stenhouse, L. (1975). An introduction to curriculum research and development. Heinemann.

Swain, M. (2005). The output hypothesis: Theory and research. In E. Hinkel (Ed.), Handbook of research in second language teaching and learning (pp. 471-483). Lawrence Erlbaum Associates.

Swain, M., \& Lapkin, S. (1998). Interaction and second language learning: Two adolescent French immersion students working together. The Modern Language Journal, 82(3), 320-337. https://doi.org/10.1111/j.1540-4781.1998.tbo1209.x

Swan, M. (2005). Legislation by hypothesis: The case of task-based instruction. Applied Linguistics, 26(3), 376-401. https://doi.org/10.1093/applin/amio13

Timperley, H. (2011). Realizing the power of professional learning. Open University Press.

Tolosa, C. (2007). Beliefs and the teaching of Spanish: Native and non-native teachers' views. New Zealand Language Teacher, 33, 33-37. 
Van den Branden, K. (2006). Training teachers: Task-based as well? In K. Van den Branden (Ed.), Task-based language education: From theory to practice (pp. 217-248). Cambridge University Press. https://doi.org/10.1017/CBO9780511667282.011

Van den Branden, K. (2009). Mediating between predetermined order and chaos: The role of the teacher in task-based language education. International Journal of Applied Linguistics, 19(3), 264-285. https://doi.org/10.1111/j.1473-4192.2009.00241.x

Van den Branden, K. (2016). The role of teachers in task-based language education. Annual Review of Applied Linguistics, 36, 164-181. https://doi.org/10.1017/S0267190515000070

Van den Branden, K., Bygate, M., \& Norris, J. M. (2009). Task-based language teaching: A reader. In K. Van den Branden, M. Bygate, \& J. M. Norris (Eds.). Task-based language teaching: A reader (pp. 1-13). John Benjamins. https://doi.org/10.1075/tblt.1.02van

Vandommele, G., Van den Branden, K., \& Van Gorp, K. (2018). Task-based language teaching: How task-based is it really? In V. Samuda, K. Van den Branden, \& M. Bygate (Eds.), TBLT as a researched pedagogy (pp. 165-197). John Benjamins. https://doi.org/10.1075/tblt.12.07van

Vygotsky, L. (1978). Mind in society: The development of higher psychological processes. Harvard University Press.

Waite, J. (1992). Aoteareo: Speaking for ourselves, a discussion on the development of a New Zealand languages policy. Learning Media.

Wedell, M. (2009). Planning for educational change: Putting people and their contexts first. Continuum.

White, L. (1991). Adverb placement in second language acquisition: Some effects of positive and negative evidence in the classroom. Second Language Research, 7 (2), 133-161.

Widdowson, H. G. (1998). The theory and practice of critical discourse analysis. Applied Linguistics, 19, 136-151. https://doi.org/10.1093/applin/19.1.136

Willis, D., \& Willis, J. (2007). Doing task-based teaching. Oxford University Press.

Willis, J. (1996). A framework for task-based learning. Longman.

Willis, J. (2004). Perspectives on task-based instruction. In B. L. Leaver \& J. Willis, Task- based instruction in foreign language education: Practices and programs (pp. 3-44). Georgetown University Press.

Wyatt, M., \& Borg, S. (2011). Development in the practical knowledge of language teachers: A comparative study of three teachers designing and using communicative tasks on an in-service BA TESOL programme in the Middle East. Innovation in Language Learning and Teaching, 5, 233-252. https://doi.org/10.1080/17501229.2010.537340

Yim, S. (2009). South Korean teachers' perceptions of TBLT. TESOL Review, 1(1), 29-50.

Yoon, K. S., Duncan, T., Lee, S. W. Y., Scarloss, B., \& Shapley, K. (2007). Reviewing the evidence on how teacher professional development affects student achievement (Issues and Answers Report, REL 2007 No. 033). US. Department of Education, Regional Educational Laboratory Southwest.

Zheng, X., \& Borg, S. (2014). Task-based language teaching in China: Secondary school teachers' beliefs and practices. Language Teaching Research, 18(2), 205-221. https://doi.org/10.1177/1362168813505941 


\section{Description of in-school support component of TPDL}

\section{Introduction}

All the teacher participants in this study had completed the TPDL (Teacher Professional Development Languages) programme, and it was through this programme that many of them learnt about TBLT for the first time. Chapter 1 outlines the rationale for the programme, its main aims, and the theoretical basis and core principles that underpinned it. It also gives an overview of the three main components of the year-long programme which are depicted in Figure 1A.

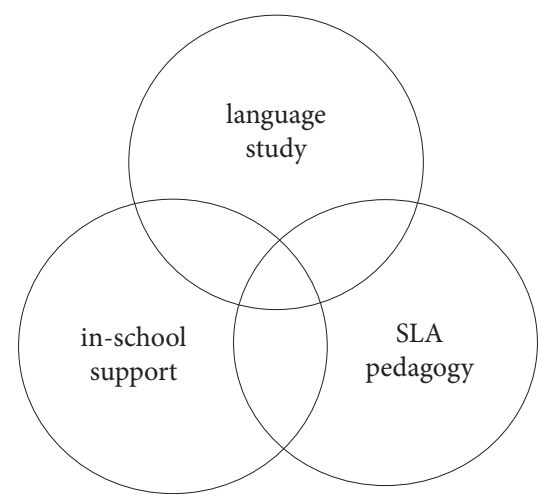

Figure 1A. Main components of TPDL programme

This appendix gives more detailed information about the in-school support component of TPDL. It includes data from one teacher participant (not a teacher who also participated in this study) as a guide as to how the TPDL facilitators worked with participants. A description of this component of the programme may provide information about how teachers were enabled to enact TBLT principles in their classroom practice.

\section{In-school support component}

The in-school support component provided for each programme participant to be visited four times over the course of the year by a TPDL facilitator, an employee of the TPDL team. The TPDL facilitator observed each participant as s/he taught a lesson with her/his language class and then took part in a learning discussion with the participant at the end of the lesson. Two key documents were used during this discussion as a reference to guide the discussion and to assist the participant in evaluating his/her practice. These were: 
a. The "Evidence of Principles and Strategies" or EPS (Figure 1B) and

b. The "Progress Standards" (Figure 1C)

The EPS (see Figure 1B for an extract of this document) drew heavily on Erlam and Sakui (2006) to establish criteria against which the classroom practice of the participants could be evaluated.

Figure 1B. Extract (p. 1) from Evidence of Principles and Strategies document

Evidence of teachers demonstrating principles, strategies and resources that are effective in improving student achievement in the target language.

1. Formulaic chunks in the TL that students were heard using:

Visit 2:

Visit 3:

Visit 4:

2. In the following ways you provide TL input for your students:

Using TL for classroom management

Visit 2

Visit 3

Visit 4

Visit 2

Visit 3

Visit 4

Visit 2

Visit 3

Visit 4

$\begin{array}{lllll}5 & 4 & 3 & 2 & 1 \\ 5 & 4 & 3 & 2 & 1 \\ 5 & 4 & 3 & 2 & 1\end{array}$

Using TL for social goals

3. Other sources of TL input during the lesson

Visit 2:

Visit 3:

Visit 4:

(Erlam, 2016b)

The second document, the Progress Standards (see Figure 1C for an extract of this document), evaluated teacher practice against three key criteria and set goals for the next TPDL facilitator visit. The three criteria were determined by Insley and Thomson (2008), based on their knowledge of aspects of teacher practice not commonly in evidence in the classroom, yet crucial for beginner language learners. They are:

1. Teacher use of the target language (TL)

2. Student use of the target language

3. Opportunities for learners to interact in the target language in the classroom

The design of both of these documents allowed for documentation of changes in practice during TPDL facilitator visits over the course of the year and, at the same time, the setting of targets for subsequent visits. However, neither document was used during Visit 1. During Visit 1, "baseline" data, used to evaluate future practice, were collected. A shorter, one-page version of the EPS was used for this purpose. 
Figure 1C. Extract from Process Standards Document showing standards for Visit 2

\section{Visit 2}

Expected progress:

1. Teachers are using TL for social goals, classroom management and instruction.

2. Students show evidence of using the TL in meaningful classroom contexts.

3. Students work in pairs or groups to complete language tasks.

Accelerated progress:

1. Teachers are making significant use of the TL for social goals, classroom management and instruction.

2. Students show evidence of using the TL in meaningful classroom contexts and their TL utterances are more than just words and short phrases.

3. There is evidence of students using strategies to cope in the TL.

During classroom observations, the TPDL facilitator collected data that were used to contribute to the learning discussion, and which constituted evidence for the Progress Standards document. It was important for all visits that the TPDL facilitator had the opportunity to observe the same class so that ongoing student learning could be documented as potential evidence of successful practice. See Table 1A for an outline of how visits proceeded and of the data that were collected and then analysed jointly by the teacher and facilitator.

Table 1A. Visit schedule and data collection/analysis

\begin{tabular}{lll}
\hline Visit no & Facilitator during the lesson & Facilitator and teacher after the lesson \\
\hline Visit & $\begin{array}{l}\text { Observes lesson and writes down } \\
\text { teacher discourse, along with as many } \\
\text { students' utterances as possible. }\end{array}$ & $\begin{array}{l}\text { Together discuss lesson, review transcript } \\
\text { of teacher discourse, complete EPS and } \\
\text { set Progress Standards for next visit. }\end{array}$ \\
Visit & $\begin{array}{l}\text { Observes lesson, choosing 2 students } \\
\text { (if possible same students over the 2 } \\
\text { lessons) and writing down as many of }\end{array}$ & $\begin{array}{l}\text { Together discuss lesson, review transcript } \\
\text { of students' discourse, complete EPS and } \\
\text { set Progress Standards for next visit (or, at } \\
\text { their utterances as possible. }\end{array}$ \\
\hline
\end{tabular}

During Visits 1 and 2, the data collected were mainly in the form of a written record of as much as the TPDL facilitator could write down of what the teacher said during the lesson. S/he also noted down, where possible, what s/he heard students say. At the conclusion of each of these two visits, the teacher and the facilitator examined this transcript of teacher and student talk during the learning conversation. The facilitator highlighted, on this document, all instances of target language used by the teacher. S/he then established and identified with the teacher participant all other utterances which could have been said in the target language, rather than in English. Table 1B shows a short extract of a copy of the transcript of Jane from Visit 1, a participant discussed in Erlam (2016b). Note that the target language (i.e., French, indicated here in italics) used by Jane and her students was highlighted and that those utterances that Jane and the facilitator agreed COULD have been said using the target language were asterisked. These tended to be formulaic expressions where the use of French would have been appropriate because the context would have facilitated comprehension on the part of the students. 
Table 1B. Example of transcript and coding from facilitator Visit 1

\begin{tabular}{|c|c|}
\hline Teacher's utterances & Students' utterances \\
\hline \multicolumn{2}{|l|}{${ }^{\star}$ Ok girls } \\
\hline \multicolumn{2}{|l|}{${ }^{*}$ back a little bit } \\
\hline \multicolumn{2}{|l|}{${ }^{*}$ catch it and } \\
\hline \multicolumn{2}{|l|}{${ }^{*}$ say salutation } \\
\hline${ }^{*}$ it doesn't matter just want to & Bonsoir \\
\hline${ }^{\star}$ hear the French & Bonjour \\
\hline \multirow[t]{4}{*}{ *quick } & Salut \\
\hline & Bonsoir \\
\hline & Bonjour \\
\hline & bonne nuit \\
\hline C'est bon & Salut \\
\hline \multicolumn{2}{|l|}{${ }^{*}$ sit down if you } \\
\hline \multirow[t]{2}{*}{${ }^{*}$ say it girls } & au revoir \\
\hline & Salut \\
\hline \multicolumn{2}{|l|}{${ }^{*}$ girls asseyez-vous correctement } \\
\hline \multirow[t]{3}{*}{${ }^{*}$ so no accidents } & A tout a l'heure \\
\hline & Au revoir \\
\hline & Bonjour \\
\hline allez & ${ }^{\star}$ I don’t know \\
\hline \multicolumn{2}{|l|}{${ }^{*}$ girls don't search for something } \\
\hline \multicolumn{2}{|l|}{${ }^{*}$ next one is question and answer } \\
\hline \multicolumn{2}{|l|}{${ }^{\star}$ how do you ask } \\
\hline \multicolumn{2}{|l|}{${ }^{*}$ what's your name? } \\
\hline & ${ }^{*}$ Wait \\
\hline \multicolumn{2}{|l|}{${ }^{*}$ that's ok } \\
\hline *3 ways & ${ }^{\star}$ Is it? \\
\hline
\end{tabular}

Table 1C shows an extract of the transcript that the TPDL facilitator recorded for this same participant, Jane, during Visit 2. It is clear that Jane was using significantly more target language with her students during this second observation.

Figure 1D shows the TPDL facilitator's ratings for Jane's use of the target language in the classroom over the course of the four facilitator visits. These ratings were recorded on the EPS document, of which Figure 1D is an extract.

During Visits 3 and 4, the use of the target language by the teacher was evaluated against key criteria (as demonstrated in Figure 1D) but the main focus of the TPDL facilitator changed from attention to the language used by the teacher to a focus on the language used by the students. Accordingly, the TPDL facilitator chose two students at random and positioned her/himself near these students to be able to record, again on paper, the language that s/he heard them use. This attention to the second objective of the Progress Standards recognised that effective teacher practice will result in gains in student use of the target language. Table 1D provides an extract from the facilitator transcript of Jane's third observed lesson. The asterisked utterances are those which both Jane and the facilitator agreed could have been said in the target language by the students who had been observed. 
Table 1C. Example of transcript and coding from facilitator Visit 2

\section{Teacher's utterances}

Regardez

Regardez le tableau blanc

Quelle est...?

Il y a des lettres qui manquent

Viens écrivez à

Quelle est la date de

Oui très bien

Et ici qu'est-ce que je mets

point d'interrogation

alors

merci

Je voudrais une volontaire

regardez

For adults you say

comment allez-vous

Quelle est la date de ton anniversaire?

If you need help you could say

Je ne sais pas

Je ne comprends pas

Aide-moi

means help

Aide-moi

Quelle est la date de ton anniversaire?

\section{Students' utterances}

Regardez

When is your birthday?

You need an " $i$ "

Ton

A question mark

Bonjour

Je mappelle

Comment tu t'appelles?

Cava bien

Je ne sais pas

Je ne comprends pas

Aide-moi s'il te plaît

${ }^{\star}$ Miss

Le 23 mai

2. In the following ways you provide TL input for your students:

Visit 2

Visit 3

Visit 4

\section{Using TL for Classroom Management}

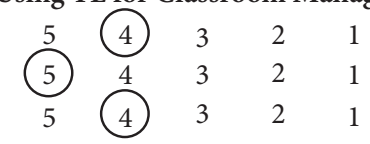

Using TL for Social Goals

Visit 2

Visit 3

Visit 4

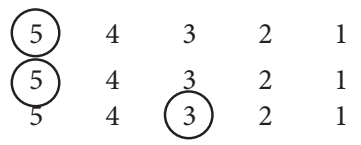

Using TL for Language Goals

Visit 2

Visit 3

Visit 4

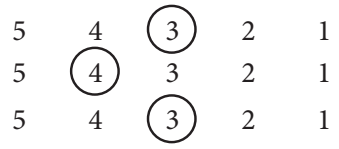

( 5 being entirely in TL and 1 being entirely in English)

Figure 1D. Facilitator data collected for Jane on the EPS document, p. 1 (Erlam, 2016b) 
Table 1D. Example of transcript and coding from facilitator Visit 3 (Erlam, 2016)

\begin{tabular}{ll}
\hline Student 1 & Student 2 \\
\hline${ }^{*}$ Yeah I think that it should be English & \\
${ }^{*}$ Okay come on & \\
as-tu? & \\
*you go & Merci \\
yeah & un crayon? \\
un crayon? & \\
${ }^{*}$ Is it my turn? & un crayon? \\
un baton de colle? & une règle? \\
oui & des ciseaux? \\
merci &
\end{tabular}

During the learning discussion at the conclusion of each lesson, the TPDL facilitator and the teacher completed together the EPS after they had considered together the transcript of teacher/ student talk. This document recorded evidence of effective practice over the course of three facilitator visits, thus allowing for a record of progress. At the same time, the Progress Standards document was completed and targets were set for the following visit. It is important to note that, over the course of the four visits, the TPDL facilitator aimed to progressively facilitate rather than lead the discussion, relying on the teacher to reflect on and evaluate their own practice (Dangel et al., 2004; Scarino, 2014).

\section{Conclusion}

There are a number of features of this aspect of the programme which are important with respect to teachers learning about TBLT.

1. The main theoretical basis for the programme was not TBLT, but Ellis's (2005) Principles of Effective Instructed Language Learning. However, tasks and task-supported or task-based language teaching were presented throughout the programme as an effective way of operationalising these principles in classroom practice.

2. An important initial focus of the programme, including this component, was the use of formulaic language in the classroom, the aim being to give learners the tools that they needed to communicate in the target language.

3. Another important focus during Visits 1 and 2 was teacher use of the target language in the classroom with the ultimate aim that the teacher would be using the target language for most of their talk with students in a way which was comprehensible and motivating.

4. The Progress Standards also measured progress in terms of student use of the target language and in terms of opportunities for students to interact in the target language. The accelerated aims for Visit 4 stated that:

Student use of the TL is predominant and displays a rich repertoire of formulaic expressions and multi-clause conversation in the TL.

Students are taking ownership of their interactions in the TL 


\section{APPENDIX 2}

\section{Template for the inquiry report and marking criteria}

EDPROFST 360 Teaching Languages in Schools

$40 \%$ - Word limit: 3,000 words (Note: the template is provided as a guide for your report).

Name:

Title of the inquiry:

Introduction (4 marks; approx. 300-400 words)

Context (your class, your students)

Rationale for your inquiry (justification; why you wanted to do the inquiry)

Relevant Literature (8 marks; approx. 1,000-1,200 words) [How does your inquiry relate to what we know about language teaching/learning? Refer to research and academic literature]

Task (16 marks; approx. 1,200-1,500 words) (Remember to attach the evidence as an Appendix)

Description of the task (Use the criteria for task)

Experience teaching the task (How the task was implemented)

Evaluation of the task effectiveness (Evaluate how effective was the task using two different approaches. Use the evidence you collected. Attach the evidence)

Conclusion (8 marks; approx. 400-500 words)

Task revision (how you might improve the task based on your evaluation)

Constraints (discuss any limitations or factors that may have affected the task)

Conclusions (final comments and overall conclusion)

References (part of the 4 marks for Academic writing; use APA referencing style; approx. 150 words) 


\section{Pedagogical Realities of Implementing Task-based Language Teaching}

Assignment 3: Inquiry Learning Report

Marking Schedule

(40 marks for the written report; 10 marks for oral presentation)

\begin{tabular}{|c|c|c|c|c|c|c|c|c|}
\hline Not evident & & Evident & & Explanation & & $\begin{array}{l}\text { Clear explanation / } \\
\text { discussion }\end{array}$ & & $\begin{array}{l}\text { Clear explanation, } \\
\text { discussion justification }\end{array}$ \\
\hline Introduction & 0 & & 1 & & 2 & & 3 & \\
\hline Context not stated & & Some context stated & & Context stated & & $\begin{array}{l}\text { Context clearly stated } \\
\text { with some explanation }\end{array}$ & & $\begin{array}{l}\text { Context clearly stated } \\
\text { and explained }\end{array}$ \\
\hline Rationale not stated & & $\begin{array}{l}\text { Rationale stated but } \\
\text { incomplete (e.g., } \\
\text { language rationale not } \\
\text { discussed) }\end{array}$ & & Rationale provided & & $\begin{array}{l}\text { Rationale provided } \\
\text { and justified }\end{array}$ & & $\begin{array}{l}\text { Rationale provided and } \\
\text { justified according to } \\
\text { literature }\end{array}$ \\
\hline Relevant literature & 0 & & 2 & & 4 & & 6 & \\
\hline $\begin{array}{l}\text { No research referred } \\
\text { to }\end{array}$ & & Research referred to & & $\begin{array}{l}\text { Relevant research } \\
\text { appropriately referred } \\
\text { to }\end{array}$ & & $\begin{array}{l}\text { A range of research } \\
\text { referred to and } \\
\text { appropriately woven } \\
\text { into discussion }\end{array}$ & & $\begin{array}{l}\text { A wide range of } \\
\text { research referred to and } \\
\text { appropriately woven into } \\
\text { discussion }\end{array}$ \\
\hline Task & 0 & & 4 & & 8 & & 12 & 1 \\
\hline Task not described & & $\begin{array}{l}\text { Task described using } \\
\text { the criteria for tasks }\end{array}$ & & $\begin{array}{l}\text { Task clearly described } \\
\text { using the criteria for } \\
\text { tasks }\end{array}$ & & $\begin{array}{l}\text { Task clearly defined } \\
\text { and described using } \\
\text { the criteria for tasks }\end{array}$ & & $\begin{array}{l}\text { Task clearly defined, } \\
\text { described and justified } \\
\text { using the criteria for } \\
\text { tasks }\end{array}$ \\
\hline $\begin{array}{l}\text { Task evaluation not } \\
\text { included }\end{array}$ & & $\begin{array}{l}\text { Some evaluation of } \\
\text { the task }\end{array}$ & & $\begin{array}{l}\text { Clear evaluation of the } \\
\text { task }\end{array}$ & & $\begin{array}{l}\text { Clear and convincing } \\
\text { evaluation of the task }\end{array}$ & & $\begin{array}{l}\text { Clear and highly } \\
\text { convincing evaluation of } \\
\text { the task }\end{array}$ \\
\hline $\begin{array}{l}\text { Examples of evidence } \\
\text { not included }\end{array}$ & & $\begin{array}{l}\text { Examples of evidence } \\
\text { included }\end{array}$ & & $\begin{array}{l}\text { Range of examples of } \\
\text { evidence included }\end{array}$ & & $\begin{array}{l}\text { Range of examples of } \\
\text { evidence included and } \\
\text { explained }\end{array}$ & & $\begin{array}{l}\text { Range of examples of } \\
\text { evidence included, } \\
\text { explained and used to } \\
\text { inform task evaluation }\end{array}$ \\
\hline
\end{tabular}




\section{Template for the inquiry report and marking criteria $\mathbf{2 7 1}$}

\begin{tabular}{|c|c|c|c|c|c|c|c|c|}
\hline Not evident & & Evident & & Explanation & & $\begin{array}{l}\text { Clear explanation / } \\
\text { discussion }\end{array}$ & & $\begin{array}{l}\text { Clear explanation, } \\
\text { discussion justification }\end{array}$ \\
\hline Conclusion & 0 & & 2 & & 4 & & 6 & \\
\hline Task not revised & & Some task revision & & Task revised & & $\begin{array}{l}\text { Task appropriately } \\
\text { revised/ next steps } \\
\text { identified }\end{array}$ & & $\begin{array}{l}\text { Task revision } \\
\text { appropriate and justified } \\
\text { / next steps identified } \\
\text { and justified }\end{array}$ \\
\hline Constraints not stated & & $\begin{array}{l}\text { Constraints } \\
\text { mentioned }\end{array}$ & & Constraints discussed & & $\begin{array}{l}\text { Relevant and } \\
\text { appropriate } \\
\text { constraints discussed }\end{array}$ & & $\begin{array}{l}\text { Relevant and } \\
\text { appropriate constraints } \\
\text { discussed and accurately } \\
\text { explained }\end{array}$ \\
\hline Conclusions not stated & & Conclusions stated & & $\begin{array}{l}\text { Mostly valid } \\
\text { conclusions stated } \\
\text { clearly }\end{array}$ & & $\begin{array}{l}\text { Valid conclusions } \\
\text { discussed }\end{array}$ & & $\begin{array}{l}\text { Valid conclusions clearly } \\
\text { discussed with reference } \\
\text { to literature }\end{array}$ \\
\hline Academic standards & 0 & & 1 & & 2 & & 3 & \\
\hline $\begin{array}{l}\text { Poor standard of } \\
\text { academic writing of } \\
\text { the report; the report } \\
\text { is poorly structured; } \\
\text { no references provided }\end{array}$ & & $\begin{array}{l}\text { Acceptable standard } \\
\text { of academic writing of } \\
\text { the report; the report } \\
\text { is poorly structured; } \\
\text { faulty referencing }\end{array}$ & & $\begin{array}{l}\text { Adequate standard of } \\
\text { academic writing of } \\
\text { the report; acceptable } \\
\text { structuring of } \\
\text { the report; minor } \\
\text { referencing errors }\end{array}$ & & $\begin{array}{l}\text { Good standard of } \\
\text { academic writing } \\
\text { of the report; clear } \\
\text { structure of the report; } \\
\text { proper referencing }\end{array}$ & & $\begin{array}{l}\text { High standard of } \\
\text { academic writing of the } \\
\text { report; clear structure } \\
\text { of report; proper } \\
\text { referencing. }\end{array}$ \\
\hline
\end{tabular}




\section{APPENDIX 3}

\section{Interview questions (telephone or email)}

\section{Section 1}

- What learning was most significant for you during TPDL?

- Has this learning changed your classroom practice? How?

- Was there any learning/ideas that you gained from completing TPDL that you have not been able to implement in your classroom practice? What was this and why have you not been able to implement it?

\section{Section 2}

- What do you think of TBLT as a language teaching methodology [educational innovation]?

- What are its benefits for the language classroom?

- Any disadvantages?

- Do you think TBLT fits well with the NZ curriculum? Why/why not?

- In your Inquiry Learning assignment you described a lesson you taught. I want to ask you more about this lesson...

- Do you implement TBLT in your classroom? Can you explain how? If not, why not?

If answer is no, the interview stops here.

- How often do you implement TBLT/ use tasks in the classroom?

- Is there any thing that makes implementing Task-based (TB) language teaching difficult for you in your classroom?

- Would it be possible for me/us to come and observe you teaching a TB lesson? If this could be a possibility you do not need to let us know now, but we can leave some information about how this could work and you can let us know when you are ready. To help us know how feasible this would be for us we would like to know how often you see your class(es).

\section{Section 3}

If the answer is a definite "no" to the request for us to observe a lesson, proceed as follows with the interview:

- Can you please describe a task/TB lesson you have taught recently?

- In designing this task/TB lesson, where did you start?

- What was the rationale for the task/TB lesson?

- What were the goals for your task/TB lesson?

- Tell us about the classroom - the year level, type of student.

- What happened in the classroom when you taught this task?

- Was the task implemented as you had planned? Why/why not?

- From your point of view was it successful or not? Why/why not?

- How did you evaluate its effectiveness?

- How do your students respond to tasks?

- How do you see a task as being different from an activity? 


\section{APPENDIX 4}

\section{Student questionnaire}

\section{Student questionnaire}

1. What did you learn today in your [target language] lesson? Please write as many things as you want.

2. Please indicate how much you enjoyed today's [target language] lesson. Place an X over the right box for you.

\begin{tabular}{|l|l|l|l|l|}
\hline really not enjoyable & not very enjoyable & neutral & enjoyable & very enjoyable \\
\hline
\end{tabular}

3. Please explain why you did or did not enjoy the [target language] lesson.

4. Is speaking in [target language] hard for you? Please place an $\mathrm{X}$ over the right box for you.

\begin{tabular}{|l|l|l|l|l|}
\hline very hard for me & H hard for me & neutral & ok for me & easy for me \\
\hline
\end{tabular}

5. Please explain why speaking [target language] is hard or not hard for you.

6. Please write one thing that you really liked about today's [target language] lesson. If there was nothing, that is ok.

7. Please write one thing that you did not like about today's [target language] lesson. If there was nothing, that is ok.

Thank you 


\section{APPENDIX 5 \\ Interview questions for teachers whose practice we observed}

\section{Background information}

Tell me when/how you decided to become a teacher of languages. How long have you taught in $\mathrm{NZ}$ ? /in this school?

\section{General}

How do you describe yourself as a teacher of languages? What are your priorities as a teacher? And as a teacher of languages?

When you think about the ideal language teacher, what sort of images/ideas come to mind?

\section{General TPDL}

What learning was most significant for you during the TPDL programme?

How has this learning impacted on your classroom practice?

Was there any learning/ideas that you gained from completing TPDL that you have not been able to implement in your classroom practice? What was this and why have you not been able to implement it?

\section{Prior knowledge about TBLT}

Before TPDL what did you know about TBLT?

What relevance, if any, did it have for you in your teaching context?

\section{Reaction to TBLT during TPDL}

What did you learn about TBLT through TPDL?

To what extent did it fit with your approach to teaching when you first heard about it?

Did it fit with your beliefs about effective language learning?

How did you personally feel about it?

Do you think that it can promote successful language acquisition? Why/how? Why not?

Do you think that it has something to offer that more traditional approaches don't? If so, what? 


\section{Experience with TBLT after TPDL}

Were you motivated to try TBLT after you completed TPDL? Why/why not?

If you tried it what happened?

Is it easy in your current teaching context to implement TBLT? Why/why not?

Do you implement TBLT in your classroom now? Can you explain how? If not, why not?

How often do you use a task in your language classroom? Tell us about the classroom - the year level, type of student.

How do your students respond to tasks?

So what do you think of TBLT as a language teaching methodology/educational innovation now? What are its benefits for the language classroom?

Any disadvantages?

Is there any thing that makes implementing Task-based language teaching difficult for you in your classroom?

What aspects of TBLT do you think fit well with the NZ curriculum?

\section{Comments re lesson just observed}

[Note: Ask questions in parentheses if lesson observed was not TB]

[Can you please describe a task/TB lesson you have taught recently?]

In this section, I'm going to ask you to walk me through your planning process with tasks

In designing this task/TB lesson, where did you start?

What was the rationale for the task/TB lesson?

What were the goals for your task/TB lesson?

Tell me about the classroom - the year level, type of student.

[What happened in the classroom when you taught this task?]

Was the task implemented as you had planned? Why/why not?

From your point of view was it successful or not? Why/why not?

How did you evaluate its effectiveness?

How do you see a task as being different from an activity? 



\section{Name index}

A

Andon, N. $13,33,48,57,182$, 226-228, 231, 234, 252

\section{B}

Borg, S. 11-12, 33-34, 44-45, 49, 56-57, 73, 231-232, 244

Breen, M. P. 119, 177, 182, 242 Brumfit, C. J. 7, 184

Bygate, M. 1-3, 8-10, 29-30, 59, 89, 92, 177, 199, 201-202, $213,216,221-222,237-238$, 241,244

C

Carless, D. 3, 11-13, 33, 88-89, $93,95,208,219,221$

\section{D}

DeKeyser, R. 10, 132, 163, 237

\section{E}

East, M. 1, 8, 11, 13, 15-16, 23, $28,33,40,49,56,60-61,86$, $118,231,234,243$

Ellis, N. C. 163,236

Ellis, R. 1-2, 5-12, 15, 17-19, 21-25, 29, 40-41, 44, 47, 49, $53-56,62,64-65,68-69,72$, $74,77,79,81,87-88,97,115,117$, $119,125-126,132-133,136,152$, $154,177,180,185-186,189-191$, 193-194, 198, 200, 203, 205, 211, 220-221, 223, 227-228, 230, 232, 234, 236, 238, 240, $242,245,248,250,252,268$

Erlam, R. 8, 12-13, 16-23, 25-26, 29-30, 33, 40, 65, 69-70, 72-73, 86, 95, 114, 149, 180-183, 190-191, 194, $198,200,210,221,227,235$, 247-248, 250-251, 264-265, 267-268
$\mathrm{H}$

Hu, G. 11, 244

K

Keck, C. 6

Korthagen, F. 39-40, 51-52, 54, 57

Kubanyiova, M. $34,40,45,48$, 54, 87, 223-225, 227

Kumaravadivelu, B. 29

\section{L}

Lantolf, J. 6, 132

Lightbown, P. M. 163, 237

Littlewood, W. 54, 180, 221, 227-228

Loewen, S. $\quad 70,132,134,181$

Long, M. H. 3-6, 8-9, 92, 129, $133-134,175,179-180,183,186$, 192-198, 200-201, 209, 211, $213,222,226,239,241$

Loughran, J. J. $\quad 39-40,48$, $55-57,60,231$

M

Mackey, A. 6

McDonough, K. $\quad$ 12-13, 150

N

Norris, J. M. 7

Nunan, D. 23, 41, 65, 69, 200, 247

O

Ortega, L. $163,176,237$

P

Philp, J. 144, 177, 236

Prabhu, N. S. 182

R

Robinson, P. 5, 132
S

Samuda, V. 1-2, 8-10, 29-30, $33,56,59,89,92,118,186,199$, 202, 213, 216, 221, 234, 237

Schön, D. $34,39,56,60$

Shintani, N. 7-10, 12, 21-22, $24-25,55,65,68-69,72,86$, 97, 125-126, 136, 180, 185, 190, 197-198, 203, 228, 230, 242, 245, 248

Shulman, L. S. $\quad 34,40,45-46$

Skehan, P. 7, 69-70, 191, 237

Swain, M. 5, 132

V

Van den Branden, K. 1, 10, $13,29,33,35,49,54,82,95$, $115-116,144,176-177,185,221$, 227, 233-234, 252

Vygotsky, L. 6

W

White, L. 154

Widdowson, H. G. $\quad$ 176, 238

Willis, J. 23-24, 41, 65, 68-69, $183,189,191-192,200$, 206-207, 214 



\section{Subject index}

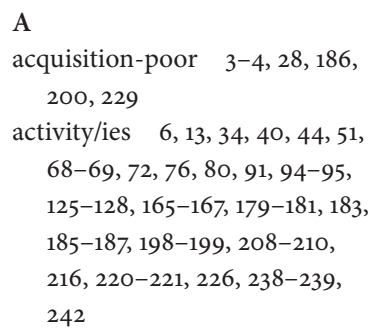

beginner language learner see beginner

best method $29,80,201$

\section{C}

CEFR 15

clarification of meaning 144 clarification request 134, 150, 195

CLIL 176 see also content and language integrated learning cognitions 33-35, 57 cognitive challenge

$144,167-168,176,239$

cognitive processes $\quad 6,191-192$

collaborative learning

196-197, 201

communicative competence

$11,14,23,230$

communicative gap

$128,167,198,207-208$

communicative goals

$68,185,187$

communicative outcomes

$144,176-177,226,242$

communicative purposes

$94,177,187,233$

conceptual change $35,40,54$,

$88,223-224$

constraints $85,90,92,94-95$,

116, 221-222, 229

construct see task construct

content and language

integrated learning $\quad 155$

see also CLIL

content knowledge $40,46,48$,

56,59

corrective feedback see feedback creative language use

$163,175-176,235,237$

creativity 107-108, 191, 200

cultural knowledge 14

curriculum 8-11, 14-16, 18-19, 22-24, 27-29, 48-49, 89,

93, 184, 193, 208, 212-213,

217-220, 223, 227, 230-231,

240, 243

\section{D}

designing tasks $\quad 95,117,192,211$, 222, 247-248, 260 see also task design dissonance 224-225
$\mathrm{E}$

engagement $64,66,76,79$,

81-82, 93, 101-102, 108,

$114-115,132,144,152,167,232$

enjoyment $8,75,81,96,115$,

$136,144,152,167,174,217,226$

experiential learning $\quad 21-22$,

$35,48,57$

explicit information 10,216

explicit knowledge $\quad 8,10,17$,

241-242

explicit metalinguistic

information see

metalinguistic information

F

feedback $5-7,34,52,62,74$, 104-106, 117, 149, 152, 224-225, 235, 246

corrective $5,133,144,151$, 195,235

negative $147,195,197,201$

see also recasts

flipped mastery $125,164-166$, 213-214, 216, 222, 224-225, 250

fluency $7,51,91,93-94,113,132$, $163,176,184,186,199,245$

focused tasks $9,11,115,117,138$, $146,149,157,161,165,169,172$, 175-176, 185-187, 189, 199-200, 211, 227, 235, 238, 241-242, 247 focus on form $9,17,23,46-47$, 51, 132-134, 152, 195-197, 201, 214-215, 227

focus on formS $9,51,66,143$, $152,167,176,180,186-7,195$, $214,237-239,241,249$

focus on meaning $23,51,54$, $65-66,71,73,99,101,104$, 109-110, 112, 126, 133-135, 138, $141,144,146,149,154,157,161$, $165,169,172,180-182,186-187$, 198, 207-208, 215, 234, 245

formulaic language $66,111,162$, $194-195,268$ 


\section{G}

gap $5,18,22,65,68-69,70$,

71-73, 99, 101, 104, 109-110, $112,117,126-128,132-134,138$, 141-142, 146, 149, 152, 154, 157, $161,165,167,169,172,181-182$, 185, 194, 198, 207-208, 234, 256 see also communicative gap see also information gap

grammar 5, 11, 15, 23, 51, 66, 73, $76,79,152,165,167-168$, $176,180,195,205-206,208$, 212-216, 223, 238-239, 241, 249 exercises $165,167-168,176$, 238-239, 241

\section{I}

implementing TBLT 2, 4, 12, 33, $54-55,85,91-96,114-116,188$, 191, 196, 203, 205, 215-216, 218, 220, 226, 229, 231, 233

implicit knowledge $\quad 6-8,17,45$, 241-242

incidental 6, 9-10, 133, 156, $166-7,242$

incidental learning 175,177 , 237, 241-242

individual differences see individual learner needs individual learner needs $17,222-223,227,250$ inductive approach 194,197 , 201, 203, 214, 227, 249

information gap $55,66-67,76$, 108, 115

Information processing 5 innovation $2,34,49,57,65,75$, 86-90, 93-95, 116, 220-221, $223,227,229-231,246,250$ input $5-7,12,17,45,53-54$, 68, 70, 73, 87, 99-100, 105, $107,115,117,132,134-135,152$, 162-163, 174-176, 190, 194, 199, 208, 237, 245, 247 elaborated 100, 132, 135, 144, $175,194,198,235$ extensive 102, 237 see also repeated exposure to language input extended 144, 175, 235 rich 194 input-based tasks 12,55 , $64,68,79,83,95,117,165$, 190-191, 194, 197, 200-201, 238-239, 245-248

inquiry $34,48,57,60-61$ see also learning inquiry inquiries $59-61,63,65-66$, $74-78,80-83,222,231-233$, 246,250

intentional $10,40,60,175,177$, 239, 241

intentional learning $\quad 6,10,177$, 241-243

interacted $98,103,112,138,143$, $149,163,173,175,194,237$

interaction $6,15-16,24,26$, 46-47, 66, 91, 97-106, 109, $111-115,123,132,138,142,144$, $152,170,175,177,196,220$, 235-236

Interaction hypothesis 5-6 interactional authenticity $15,115,117,232,236$ internal syllabus see syllabus interviews $27,36-37,62,85-86$, $88-89,96,114,116,124$, 203-204, 233, 236, 250 item-based learning 70, 181, 245,247

\section{$\mathrm{K}$}

Key Competencies $\quad 89,219$

\section{L}

lack of time $12,91,94-95$, $116-117,126,182,216,220,227$, $233,246,249-250$

lack of resources see resources language activating 186 language as an object 144, 195, $167-168,228,238$

language as a tool 144, 168, 175-176, 238

language related episodes see LREs

language support 69-70,106, 109, 138, 141-142, 146, 149, $154,157-158,162,181,247$

language users $7,16,69,71,74$, $81,138,141,146,149,154,157$ $161,165,167-168,174,176,182$, 194-195, 217 learner-centred $14,48,88$, 101, 196

learner's internal syllabus see syllabus

learning inquiry $23-25,27$, $36-37,59,61-66,70,72-73$, $76-81,231-233,269-271$

limitations $75,78,94-95,116$, 186, 221-222, 251

limitations of TBLT 55, 91, 108, 222

linguistic syllabus see syllabus listening 101, 104, 208 comprehension 146,190

literacy 222, 244

LREs $132-136,138,142$, 146-147, 149-150, 152, 154-155, $157,162-163,166-167,170$, 173-174, 235

M

memorisation 144, 201 metalinguistic information 134-135, 144, 149-150, 152, 173, 175,235

methodological principles 193, 197, 201, 222 motivation $8,43,50,52,62$, $64,66,75,79,81-82,92-93$, 101-102, 108, 115, 131, 144, 177, 182, 208, 217, 219, 222, 226, $232,236,239-240$

\section{$\mathrm{N}$}

NCEA $14-16,29,48,184,188$, 193, 210, 212, 220

negative evidence 5, 154, 195 negotiation of meaning 134 , $144,152,175,196,235$ noticing 5-6, 45 Noticing hypothesis 5

\section{O}

openness to TBLT 43, 223, 225 outcomes inquiry $60,80-81$ language learning 18,40 , $61,76,212-213,229,233$, 242-244 see also task outcomes teacher learning $\quad 82,196,233$ TPDL programme 53,88 
output $\quad 5-7,17,45,67,73,105$, $107,147,162,170,172,174,176$, 235, 238-239, 247 see also pushed output output-tasks $95,172-173,183$, 190, 194, 197, 200, 237, 245, 247-248

Output hypothesis 5

\section{P}

pedagogic tasks 92, 115, 167-168, 183-185, 189, 209-210, 217, 226, 241

pedagogical spaces $177,234-235$, 237, 244, 252

pedagogical tools $1,4,21,92$, 117-119, 216

pedagogy $16,18-24,33,35,48$, 59-61, 231, 234, 242, 250 post-task $44,47,55,105,146$, 189-190, 200, 210-211, 249 see also task cycle preselected language 135 , $143-144,163,174-176,182-183$, 185-186, 199-200, 237, 240 pre-task $47,53,70,77,90,132$, 151, 159, 169, 189-190, 200, 210

Principles of Effective Instructed SLA $16-17,19$, 21-24, 29, 40-41, 87, 193, 205, 230, 250, 252, 268

Principles of TBLT 2, 26, 46, 129, 177, 179, 192-193, 197-201, 208-209, 218, 221-222, 226-228, 231, 234, 263 professional development $2,30,33-35,49,56-57,61,63$, $81-83,85-86,88,96,116-117$, 191, 197, 199, 201, 205-207, 220, 226-227, 230-234, 246, 248-249

pushed output $7,144,148,152$, $170,173,175$

\section{R}

reading 210,216 reading comprehension 190 reading log $24-25,36-37$, 39-42, 44-46, 50, 54-55, 57, 231 recasts $112,144,147,152$, 154-155, 173, 175, 195

recycling language $107,117,132$, $159,163,174,176,237-238,240$ reflection $18,22,35,39-42$, $49-52,54-57,60-62,80-82$, 90, 93, 95, 101-102, 115, 117-118, 231

repeated exposure to language input 157, 182, 199, 237 resources

lack of 12, 94-95, 216, 220-221, 227, 250

learner $8,22,47,65,68-72$, $77,89,95,99,104,110,112$, 126-128, 138, 141, 146, 149, $154,157,161,165,169,172$, $181,183,186,198-199,207$, $245,247-248$

retention see student retention revision see task revision role of teacher $33,52,57,60$, $115,144,158,163,174,177$ rule-based learning 70,181 , 245,248

S

scaffolding $6,70,90,108,132$, $135,144,147,150,152,157,159$, $163,167,173-175,182,196,199$, 201, 235, 238, 240, 245, 247 situational grammar exercises see grammar exercises

SLA pedagogy $\quad 19-23,59$ Sociocultural theory 5-6,34 spoken production 15,162 , 190-191, 200, 237 structural syllabus see syllabus student engagement see engagement student retention 217,226 surveys $66-68,71,107,111$, 210, 221

syllabus $7-8,10,193,200,211$, 227, 243-244

built-in see internal internal 17, 46-47, 195-196 linguistic 196 structural 9,11, 177 task-based 9,11, 193, 197, 199-201, 211, 213, 226, 239-240, 243

\section{$\mathrm{T}$}

target tasks $166-168,176$, 183-185, 193, 199, 209-210, 215-216, 238-239, 241

tasks as pedagogical tools see pedagogical tools

task-as-workplan 59, 65, 69, 123, 182, 189

task completion $182,201,247$ task construct $13,22,29,68,74$, 208, 221, 232, 245, 249

task criteria $65,68-72,74$, 8o-83, 98-99, 104, 108-110, $112,125-128,138,141,146$, $149,154,157,161,165,169,172$, 180-183, 198, 207-208, 223, 227, 232, 234, 245

task cycle $5,55,183,187$, 189-190, 200, 210-211, 249

task dependency 247 task design $\quad 25,54,65-66,68$, $70,72-74,77,83,114,117$, $126-128,180-183,185-187,199$, 211-213, 221-223, 226-227, 232 , 234-235, 238, 243, 247, 249

task evaluation $25,62,68$, $72-74,77,82,99,104,110,112$, $125,138,141,146,149,154,157$, $161,165,169,172$

task goals $\quad 66-68,185-188$ task input $\quad 53,68,70,99,117$ see also input

task-in-theory $33,48,56,85$, $118,230-231,234$

task planning see task design task outcomes 22, 24, 44-45, $52,55,62,65,69,71-73,77$, 99, 101, 104, 110, 112, 117, 126, $128,138,141,143-144,146,149$, $154,157,161,165,167,169,172$, 176-177, 181-182, 184, 198, 207, $212-213,226,234,242-243$

task revision $73,77-78$, 222, 232

task sequence 189-190, 237 see also task cycle

task-supported 10, 23, 79, 196, 216, 268 see also TSLT

taxonomy of tasks see Willis and Willis's taxonomy

TBLT materials $\quad 221,223,227$ see also resources 
teacher education $\quad 39-40$, $47,55,183,252$ see also professional development teacher educators $33,40,47$, $82-83,223,229,232,246$ teacher learning $33-35,39,49$, $56,59,80,82,118,229$ see also professional development teacher reflection see reflection teacher's role see role of teacher teaching grammar see grammar time $3,7,12-13,34,40,77-78$, $117,125-126,198,207,209$, 220-221, 232, 241, 246 see also lack of time time constraints see lack of time tool for communication 26,39 , $53,168,177,228,235-236,238$, 241, 268

TPDL 1-2, 18-22, 24-27,

29-30, 33-35, 40, 61, 69-70, 73, 85-91, 97, 108, 113-114, 116, $119,122,181,188,191,195-196$, 201, 205-211, 214, 216, 220, 223-226, 233, 245-249, 263-268

TSLT 10, 21, 23-24, 201
$\mathrm{U}$

unfocused tasks $142,154-155$, $185-187,211,235$

unpredicted language see creative language use uptake of TBLT $1,27,57$, 220-221, 223, 227, 231, 240

W

Willis and Willis's taxonomy $68,183,191-192,200$ written production $\quad 172-174$, 190, 200, 237 
This book documents how teachers, working in school foreign language learning contexts and teaching beginner learners of languages other than English, learn about and use tasks. It first presents a pedagogically researched account of how teachers learn about, design and evaluate tasks, after being introduced to TBLT during an in-service programme. The authors then go into classrooms to explore ways in which teachers continue to use tasks, as part of their regular ongoing classroom language programmes, following their in-service education. The book documents how the teachers use tasks to open up opportunities for language learning for students and investigates how teachers understand and position tasks and TBLT as relevant and of value to their teaching contexts. The challenges that teachers face in incorporating TBLT into their practice are also explored. The book suggests how the use of the task as a pedagogic tool may contribute to ongoing understanding about TBLT.

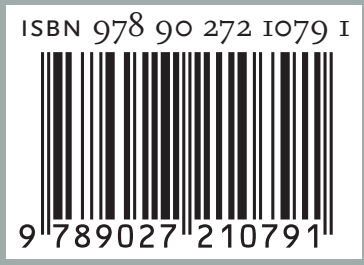

\section{John Benjamins Publishing Company}

